\title{
A Survey of Steel Moment-Resisting Frame Buildings Affected by the 1994 Northridge Earthquake
}

Nabih F.G Youssef

David Bonowitz

John L. Gross

April 1995

Building and Fire Research Laboratory

National Institute of Standards and Technology

Gaithersburg, MD 20899

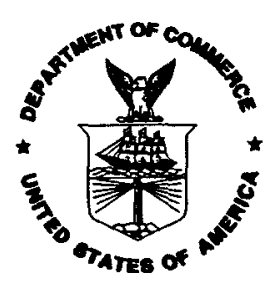

U.S. Department of Commerce

Ronald H. Brown, Secretary

Technology Administration

Mary L. Good, Under Secretary for Technology

National Institute of Standards and Technology

Arati Prabhakar, Director 


\section{Acknowledgements}

The survey forms used in this study were produced by Prof. Sami Masri, Rawn Nelson, David Bonowitz, Prof. Steve Mahin, Dr. Charles Thiel, Tom Sabol and Richard Holguin.

The engineering firms contributing survey responses as of October 20, 1994 are The Allen Company, Brandow \& Johnston, Dames \& Moore, EQE/San Francisco, Englekirk \& Sabol,Forell/Elsesser Engineers, John A. Martin Associates, Kariotis \& Associates, KPFF, Law/Crandall, Myers Nelson Houghton, Nabih Youssef \& Associates, Skidmore, Owings \& Merrill and Wiss Janney Elstner. The hard work and dedication of those who completed the survey forms under considerable time pressure are appreciated.

The technical review and assistance in preparing the report by Ann Bieniawski and careful review by Diana Todd are gratefully acknowledged. 


\begin{abstract}
The January 1994 Northridge earthquake damaged a variety of building types throughout greater Los Angeles. Perhaps the most alarming pattern of structural damage involved brittle failures at beam-to-column connections in steel moment-resisting frames (MRF's). This damage has called into question the predictability of the behavior of steel MRF's and the reliability of conventional connections used in California buildings over the last two decades. In response to this damage, emergency changes to the Uniform Building Code now require specific test results in lieu of reliance on a prescribed detail.
\end{abstract}

This report presents results of a survey of MRF's inspected for connection damage since the earthquake. As a catalogue of inspected MRF's, both damaged and undamaged, the survey is intended to provide an overall view of the greater Los Angeles steel frame population, as well as a single-source building-specific record of observed conditions. Tabulated survey responses can help form a quantitative context for future research, hazard assessment, and policy making. A computerized database was developed to track submittals, compile basic survey data, and generate the summary tables shown in the report.

Principal conclusions from the survey data support the observation that MRF connection damage is not well correlated to any single structural characteristic. On the contrary, the survey data show that connection performance may be best understood in probabilistic, not deterministic, terms, with emphasis on construction and inspection quality. In other words, when the connection works, it works extremely well. But it might not work, if any link in the chain of design assumptions and construction procedures is weak.

It is essential to note, however, that current survey data does not include analysis results or estimates of actual seismic demands from the Northridge earthquake. Without these, any reading of survey results must remain open to the possibility that conventional MRF connections are flawed by their basic configuration and are simply incapable of ductile behavior at high strain rates [Skiles and Campbell, 1994]. This alternate theory, which would fundamentally change the way engineers think about steel MRF behavior, can only be discarded if analysis with recorded ground motions can show that damage did not correlate with demand. Survey results reported here show only that damage did not correlate well with design. 


\section{Preface}

The survey of steel moment resisting frame buildings reported herein was undertaken by NIST in an effort to provide the engineering profession with an accurate characterization of the nature and extent of damage resulting from the Northridge earthquake. The motivation was to guide engineers and policy makers in hazard assessment and to provide a quantitative context for future research. The issues facing engineers and ploicy makers are indeed pressing and timely collection and reporting of survey data is deemed essential.

The data collected were available from a variety of sources including design drawings, specifications, engineer's reports and field measurements. Invariably the data collected were in English units. Conversion was required to the International System of Units (SI). Data are presented in SI units in all tables and both SI and English units in the text. Recorded data were often approximate (for example floor areas were recorded to the nearest $1000 \mathrm{ft}^{2}$ ) and conversions were made to preserve essentially the same level of accuracy.

The conversions shown below may prove useful is using this document and its appendices.

\section{SI Unit Conversions}

\begin{tabular}{|c|c|c|}
\hline To convert from & to & multiply by \\
\hline inch (in) & milimeter $(\mathrm{mm}) \quad \ldots$ & 25.4 \\
\hline foot $(\mathrm{ft})$ & meter $(\mathrm{m}) \quad \ldots .$. & 0.3048 \\
\hline & $\mathrm{m}^{2} \quad \ldots \ldots$ & 0.0929 \\
\hline 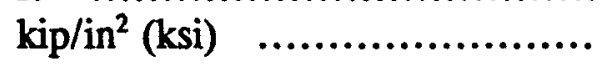 & 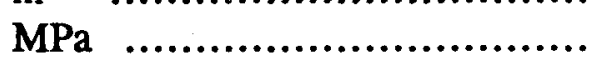 & 6.895 \\
\hline milimeter $(\mathrm{mm}) \quad \ldots$ & inch (in) & 0.0394 \\
\hline meter $(m) \quad \ldots \ldots$ & foot $(\mathrm{ft})$ & 3.2808 \\
\hline $\mathrm{m}^{2} \quad \ldots \ldots \ldots \ldots . . . .$. & & 10.764 \\
\hline MPa $\ldots . . .$. & kip/in ${ }^{2}(\mathrm{ksi})$ & 0.1450 \\
\hline
\end{tabular}




\section{Contents}

Acknowledgements $\ldots \ldots \ldots \ldots \ldots \ldots \ldots \ldots \ldots \ldots \ldots \ldots \ldots \ldots$

Abstract ............................... ii

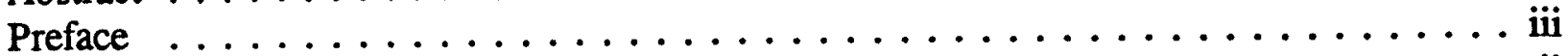

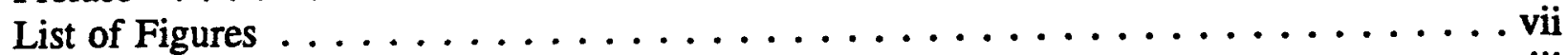

List of Tables $\ldots \ldots \ldots \ldots \ldots \ldots \ldots \ldots \ldots \ldots \ldots \ldots \ldots \ldots$

Abbreviations and Definitions ...................... ix

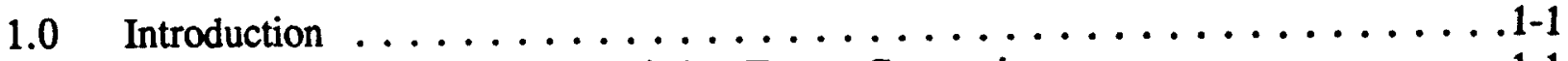

1.1 Damage to Moment-Resisting Frame Connections ............1-1

1.1.1 Historical Performance ................... 1-1

1.1.2 Response to Observed Damage ................. 1-3

1.2 Survey of Available Data $\ldots \ldots \ldots \ldots \ldots \ldots \ldots \ldots$

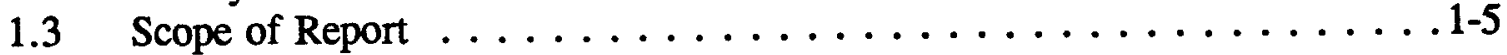

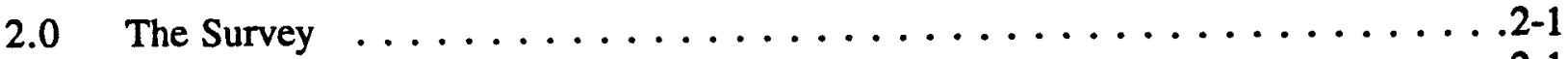

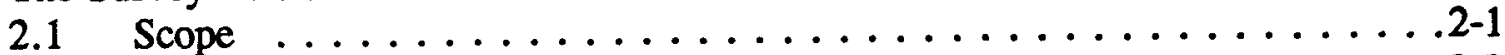

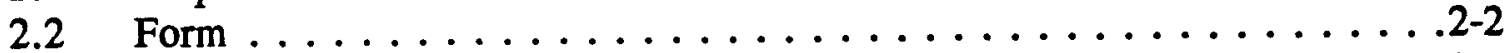

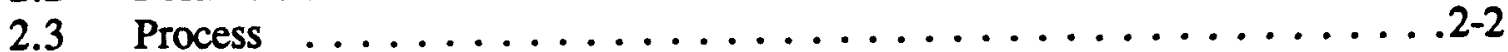

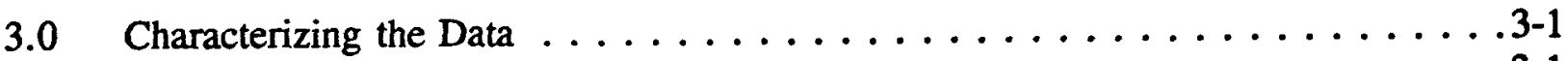

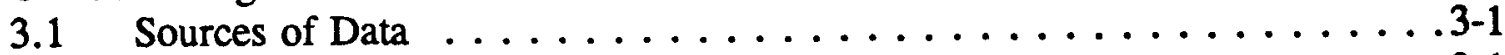

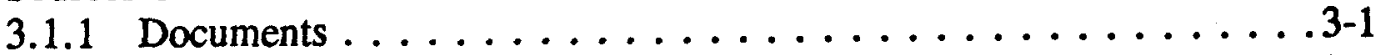

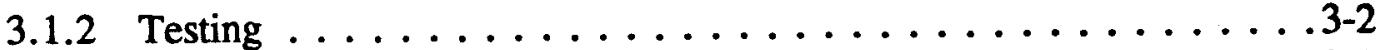

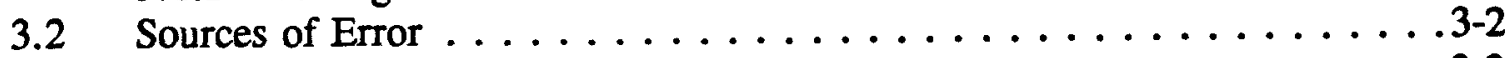

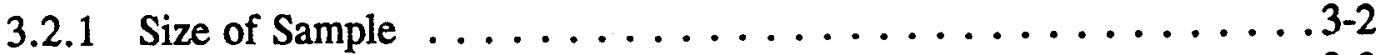

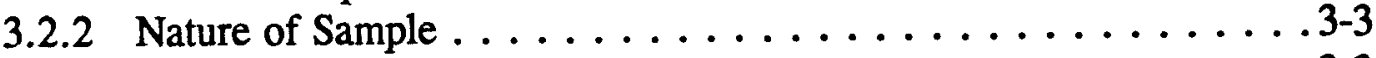

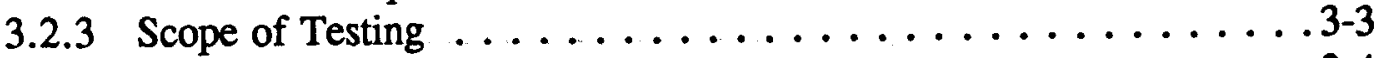

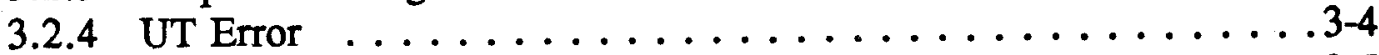

3.2 .5 Completeness of Survey Responses ... . . . . . . . . . 3-5

3.2 .6 Quality of Survey Responses ... . . . . . . . . . . . 3-5

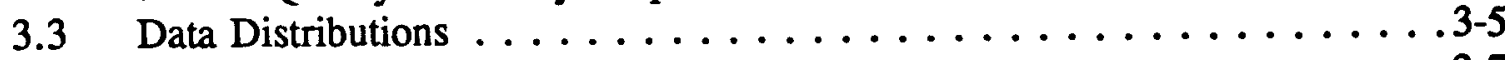

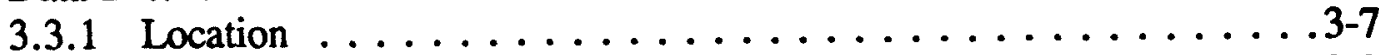

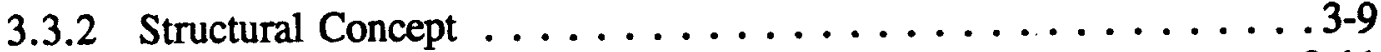

3.3.3 Structural Detailing ................... 3-11

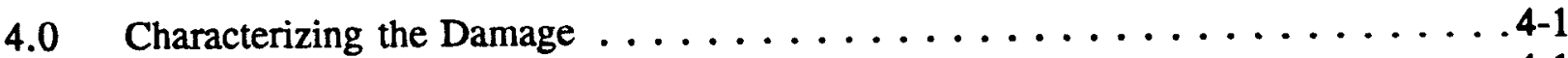

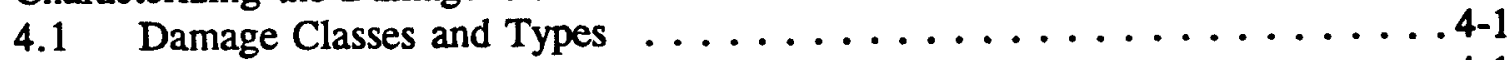

4.1.1 Incipient Root Cracks (Type W1) . . . . . . . . . . . . . 4-1

4.1.2 Fusion Zone Damage (Types W4 and C5) .......... 4-5

4.1.3 Damage Class Combinations ................. 4-5

4.2 Damage Distributions ........................ . . . . . . . . . . . . . . .

4.2 .1 Damage Score ... . . . . . . . . . . . . . . 4-8

4.2 .2 Damage Ratios ....................... . . . . . 
4.2 .3 No Damage . . . . . . . . . . . . . . . . . . 4-11

4.2.4 Weld Damage Only . . . . . . . . . . . . . 4-11

4.2.5 Column Web Damage . . . . . . . . . . . . 4-11

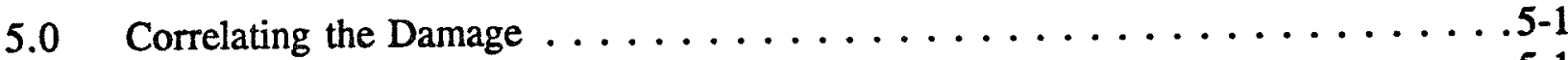

5.1 Method .........................

5.2 Non-MRF Damage $\ldots \ldots \ldots \ldots \ldots \ldots \ldots \ldots \ldots . \ldots \ldots . \ldots \ldots \ldots$

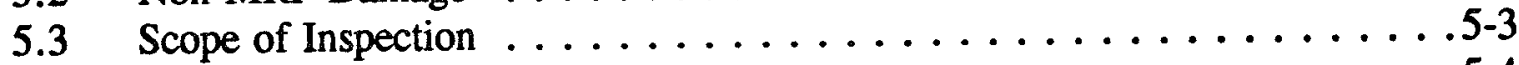

5.4 Location . . . . . . . . . . . . . . . . . . .5-4

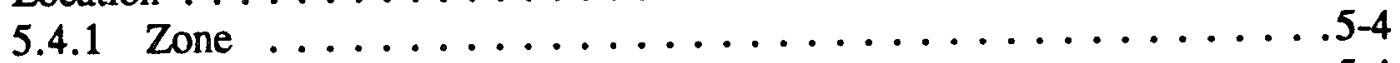

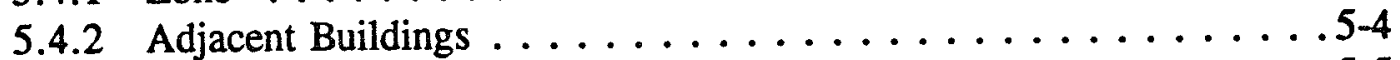

5.4 .3 Directionality .................... . . . .

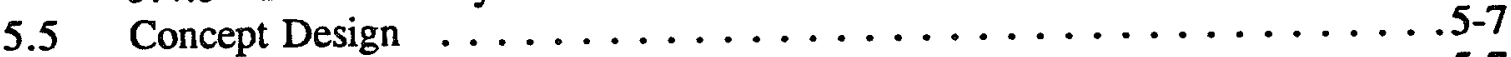

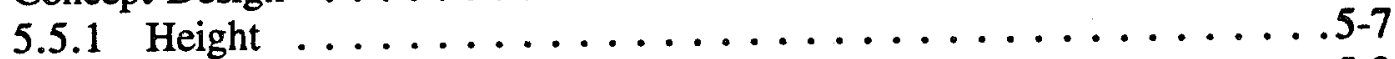

5.5.2 Frame Configuration . . . . . . . . . . . . 5-9

5.5 .3 Redundancy . . . . . . . . . . . . . . . 5-10

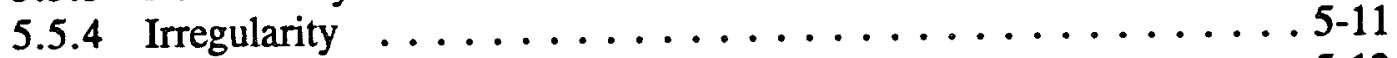

5.6 Detail Design . . . . . . . . . . . . . . . . 5-12

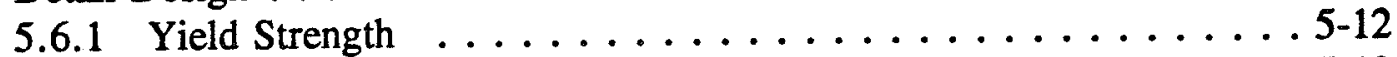

5.6 .2 Member Size . . . . . . . . . . . . . 5-12

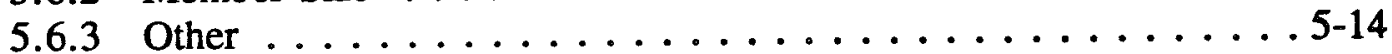

5.7 Material \& Construction Quality . . . . . . . . . . . . 5-14

6.0 Conclusions and Recommendations $\ldots \ldots \ldots \ldots \ldots \ldots \ldots \ldots \ldots \ldots$

6.1 Conclusions ......................6-1

6.2 Considerations .....................6-2

6.3 Implications . . . . . . . . . . . . . . . . . .

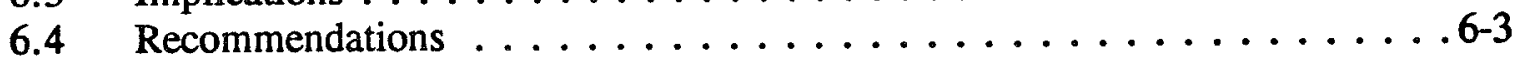

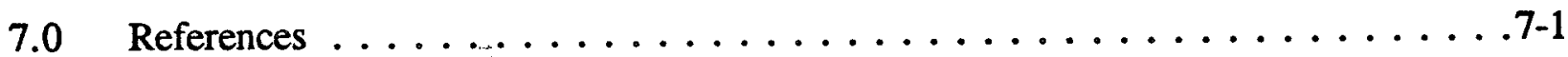

Appendix A: Survey Summaries $\ldots \ldots \ldots \ldots \ldots \ldots \ldots \ldots \ldots \ldots \ldots \ldots \ldots \ldots \ldots$

Appendix B: Survey Forms . . . . . . . . . . . . . . . . B-1 Appendix C: Inspection \& Testing Criteria and Report Formats . . . . . . . C-1 


\section{List of Figures}

Figure 1-1. Conventional Steel MRF Beam-to-Column Joint $\ldots \ldots \ldots \ldots \ldots \ldots$ 1-2

Figure 3-1. Location of Geographic Zones and Recorded Ground Accelerations . . . . . 3-8

Figure 4-1. Survey Form Damage Types $\ldots \ldots \ldots \ldots \ldots \ldots \ldots \ldots \ldots . \ldots \ldots . . \ldots \ldots$

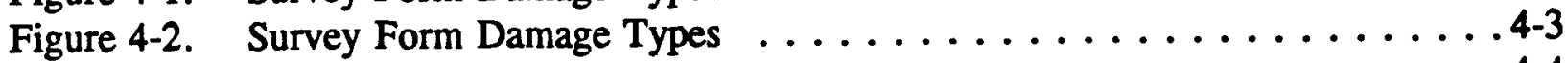

Figure 4-3. Survey Form Damage Types $\ldots \ldots \ldots \ldots \ldots \ldots \ldots \ldots .4$ 


\section{List of Tables}

Table 3-1.

Table 3-2.

Table 3-3.

Table 3-4.

Table 3-5.

Table 3-6.

Table 3-7.

Table 3-8.

Table 3-9.

Table 3-10.

Table 3-11.

Table 3-12.

Table 3-13.

Table 3-14.

Table 3-15.

Table 4-1.

Table 4-2.

Table 4-3.

Table 4-4.

Table 4-5.

Table 4-6.

Table 5-1.

Table 5-2.

Table 5-3.

Table 5-4.

Table 5-5.

Table 5-6.

Table 5-7.

Table 5-8.

Table 5-9.

Table 5-10.

Table 5-11.

Table 5-12.

Table 5-13.

Table 5-14.

Table 5-15.

Table 5-16.
Characteristics of Surveyed Buildings . . . . . . . . . . . . 3-6

Summary of Survey Data by Geographic Zone . . . . . . . . . . . 3-9

Summary of Survey Data by Building Height $\ldots \ldots \ldots \ldots \ldots \ldots$ 3-10

Summary of Survey Data by Upper Floor Area . . . . . . . . . . 3-11

Number and Orientation of Frames in Surveyed Buildings $\ldots \ldots \ldots$ 3-12

Summary of Survey Data by Number of Bays per Frame . . . . . . 3-14

List of Least Redundant Surveyed Buildings . . . . . . . . . . . . . 3-14

Structural Irregularities in Surveyed Buildings . . . . . . . . . . 3-15

Summary of Survey Data by Diaphragm Type . . . . . . . . . 3-16

Summary of Survey Data by Nominal Steel Strength . . . . . . . . 3-16

Summary of Survey Data by Exterior Column Type . . . . . . . . 3-17

Summary of Survey Data by Girder Size . . . . . . . . . . . . 3-17

Surveyed Girder Types with Group 4 W14 Columns . . . . . . . . . . 3-18

Summary of Survey Data by Beam Web Connection Type . . . . . . . 3-19

Summary of Survey Data by Girder Flange Weld Process . . . . . . . . . 3-19

Summary of Surveyed Damage By Building $\ldots \ldots \ldots \ldots \ldots \ldots$ 4-6

Summary of Surveyed Damage by Class . . . . . . . . . . . . 4-9

Surveyed Buildings with No Damage . . . . . . . . . . . . 4-11

Surveyed Buildings with Weld Damage Only $\ldots \ldots \ldots \ldots \ldots . . .4$ 4-12

Surveyed Buildings with Column Web Damage . . . . . . . . . 4-12

Surveyed Floor-Frames With Column Web Damage . . . . . . . . . 4-13

Surveyed Buildings with Reported Lateral Set . . . . . . . . . . . . 5-2

Aggregate Damage Ratios and Score for Surveyed Buildings

with Reported Lateral Set . . . . . . . . . . . . . . . . . . 5-3

Damage Ratios and Scores by Zone . . . . . . . . . . . 5-5

Damage Ratios and Scores by Frame Direction . . . . . . . . . . 5-5

Damage Ratios and Scores by Zone and Frame Direction . . . . . . . 5-6

Damage Ratios and Scores for 3-Bay Frames by Bay Width . . . . . 5-7

Damage Ratios and Scores for 3-Bay Frames by Bay Width . . . . . . 5-7

Damage Ratios and Scores in 3 to 5-Story Buildings by Floor Level . . . 5-8

Damage Ratios and Scores in 11 to 14-Story Buildings by Floor Level . . 5-9

Damage Ratios and Scores by Number of Bays per Frame . . . . . . . 5-9

Damage Ratios and Scores by Number of Bays per Frame . . . . . . 5-10

Aggregate Damage Ratios and Scores for Least Redundant Buildings . . 5 5-11

Damage Ratios and Scores by Building Irregularity . . . . . . . . . 5-11

Damage Ratios and Scores by Nominal Column Strength . . . . . . . 5-12

Damage Ratios and Scores by WF Girder Depth . . . . . . . . 5-13

Damage Ratios and Scores for W36 Girders by Bay Width . . . . . . 5-13 


\section{Abbreviations and Definitions}

See also the Abbreviations and Definitions on the survey forms in Appendix B.

Building

Connection

Damage Class

TG

BG

TC

BC

TW

BW

$S$

PZ

$\mathrm{CW}$

Damage Ratio

Damage Score

Damage Type

Floor-Frame
Set of diaphragms laterally supported by the same set of frames or structurally separated from other diaphragms by seismic joints.

Intersection of one frame beam with one frame column, generally comprising a top flange connection, a bottom flange connection, and a web connection. A typical interior joint with a continuous column and beams on both sides constitutes two connections.

A set of damage types found in the same part of a connection. Damage to the beam flange at the top of the connection Damage to the beam flange at the bottom of the connection Damage to the column flange at the top of the connection Damage to the column flange at the bottom of the connection Damage to the beam flange weld at the top of the connection Damage to the beam flange weld at the bottom of the connection Damage to the shear connection, including bolts, welds, and plates Damage to panel zone continuity plates or welds, or ductile damage to column web or web doubler plate

Cracking in column web or web doubler plate

For a given set of floor-frames and a given damage class, the number of floor-frames with the given damage class observed divided by the total number of floor-frames in the set, expressed as a decimal or percentage. See Section 4.2.2.

For a given set of floor-frames, a weighted sum of the number of floorframes with each of the most common damage classes, divided by the total number of floor-frames in the set, expressed as a decimal. See Section 4.2.1.

A specific pattern of yielding, buckling, or cracking. See Figures 4-1, 4-2, and 4-3.

The set of connections in one frame at one level.

Floor Construction Types

LC Lightweight concrete with no metal deck

MC Metal deck with normal weight concrete fill

MCL Metal deck with lightweight concrete fill

W Wood diaphragm with wood or metal floor joists 
Frame

Geographic Zone

HAZ

Incipient Root Crack A minor buried crack in the weld metal or HAZ, detectable by UT only. Possibly a pre-earthquake planar weld discontinuity. Interpreted by some survey engineers to include all rejectable weld discontinuities of any kind, or even all discontinuities whether rejectable by American Welding Society (AWS) criteria or not. See Section 4.1.1.

MRF

WDR

Stories

UT

VI

Web Connection Types

B

W

WB

Weld Processes

FCAW

SMAW

System of moment-connected beams and columns generally in a single vertical plane.

Geographic area selected for locating buildings in this survey such that buildings within each area would be expected to experience similar ground motions.

\section{Heat affected zone of a weld}

Moment-resisting frame. Also used to refer to an entire building whose lateral load resisting system includes MRF's.

Weld Damage Ratio. For a given building, the approximate portion of all reported weld damage that is thought or confirmed by the survey engineer to be incipient root cracking, expressed as a decimal. For a set of floor-frames, the average over all the defined floor-frames of WDR for the buildings from which those floor-frames come. In other words, while WDR is given for a building as a whole, for statistical purposes each floor-frame is assumed to have the same WDR. See Section 4.1.1.

The number of stories above ground for which the lateral load-resisting system in at least one direction is composed of steel MRF's (i.e., does not include stories below ground or stories above ground framed with concrete frames or walls, steel diagonal braces, etc.).

Ultrasonic testing

Visual inspection

Bolted connection

Welded connection

A connection which is both welded and bolted

Flux-cored arc weld

Shielded metal-arc weld 


\subsection{Introduction}

The January 1994 Northridge earthquake damaged a variety of building types throughout greater Los Angeles. Perhaps the most alarming pattern of structural damage involved brittle failures at beam-to-column connections in steel moment-resisting frames (MRF's). This damage has called into question the predictability of steel MRF behavior and the reliability of conventional connections used in California buildings over the last two decades. In response to this damage, emergency changes to the Uniform Building Code (UBC) now require specific test results in lieu of reliance on a prescribed detail.

This report presents results of a survey of MRF's inspected for connection damage since the earthquake. As a catalogue of inspected MRF's, both damaged and undamaged, the survey is intended to provide an overall view of the greater Los Angeles steel frame population, as well as a single-source building-specific record of observed conditions. Tabulated survey responses can help form a quantitative context for future research, hazard assessment, and policy making.

\subsection{Damage to Moment-Resisting Frame Connections}

Although the Northridge earthquake damaged other steel assemblies such as base plates and diagonal braces, the most common damage to steel structures was in the connections of moment-resisting frames. The seismic design philosophy for MRF's assumes that in large earthquakes frame elements will be stressed beyond their elastic range; inelastic behavior, which is useful for dissipating the energy of earthquake shaking, is allowed, but only in ductile elements. Since welds and bolts are not sufficiently ductile, the design philosophy does not allow connection failure. Instead, the role of the beam-to-column connection in a ductile MRF is to maintain its strength while adjacent beams and/or panel zones yield and deform inelastically [SEAOC, 1990].

The UBC, which is adopted with modifications by nearly all California jurisdictions as the standard for seismic design, codified this philosophy by requiring connection strength greater than beam strength. (While the UBC specified connection strength, it did not quantify a plastic rotation demand.) Since the 1988 Edition, the UBC also included a prescribed detail which could be used without supporting calculations or condition-specific testing. The prescribed detail required beam flanges welded to the column with complete penetration groove welds and beam webs connected with welds and/or high strength bolts [ICBO, 1988 \& 1991]. In fact, this conventional detail was in wide use throughout California for years before the 1988 UBC. A generic version is shown in Figure 1-1. Recent Code changes have deleted the prescribed detail calling instead for test results or calculations to demonstrate specific connection capacity ["ICBO Board...," 1994].

\subsubsection{Historical Performance}

The prescribed or conventional detail was justified by tests from the early 1970's [SEAOC, 


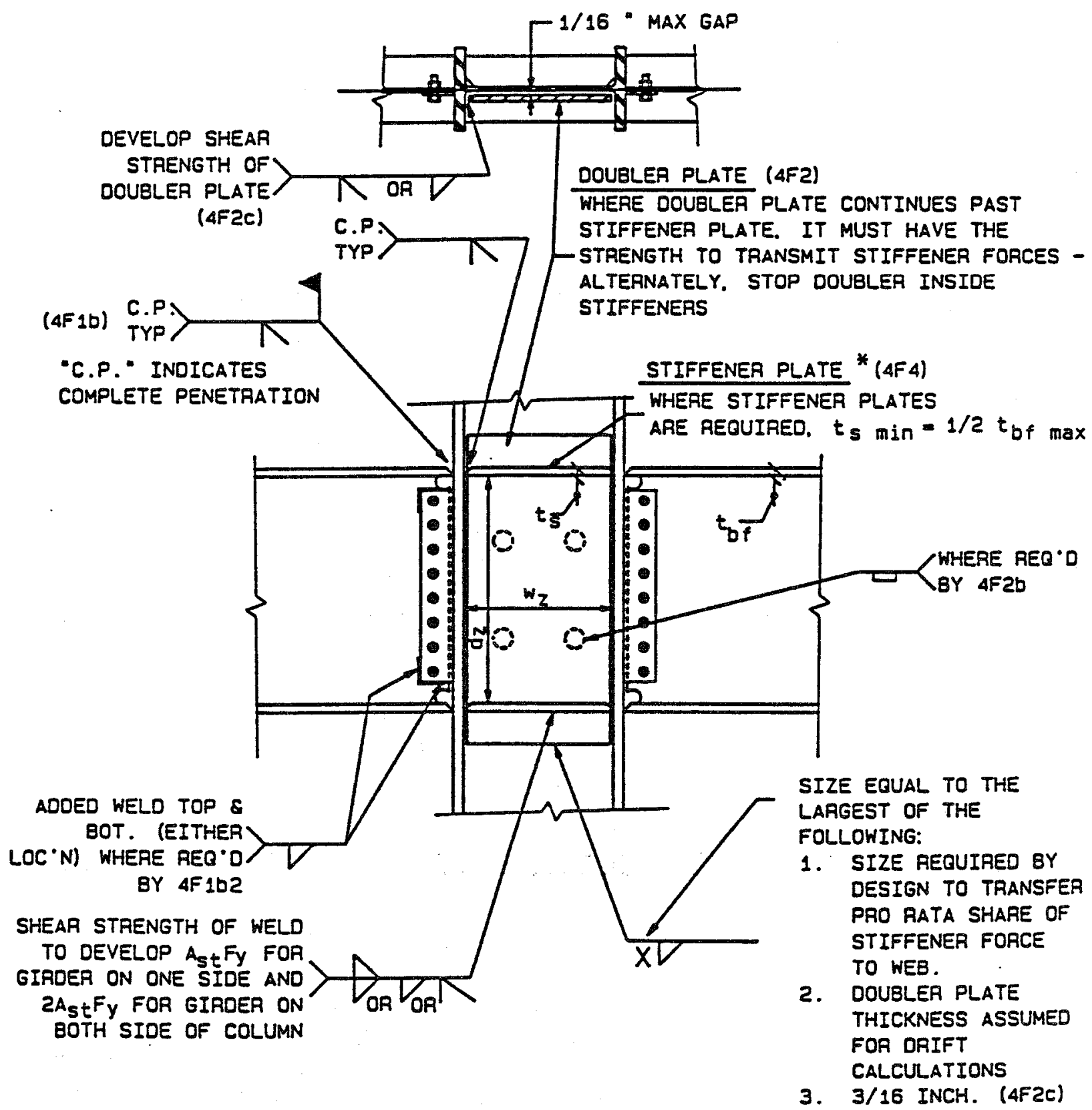

STIFFENER AND DOUBLER PLATES FIGURE LF-1

Figure 1-1. Conventional Steel MRF Beam-to-Column Joint Source: SEAOC, 1990 
1990]. These tests confirmed adequate strength and plastic rotation capacity for specific beam . sizes and loading patterns. However, while most test programs on conventional connections were able to show impressive results with some specimens, all experienced some unacceptable behavior limited by non-ductile connection failures [Popov \& Pinkney, 1969; Popov \& Bertero, 1973; Popov et al, 1985; Popov \& Tsai, 1987, Engelhardt \& Husain, 1993]. A careful reading of joumal articles from 1969 through 1993, benefitting from hindsight and the Northridge experience, reveals that weld defects, bolt slippage, or other diverse factors have in some cases made the connection the most critical part of the frame, directly violating the main precept of the ductile MRF design philosophy. Since the Northridge earthquake, some leading researchers have said that none of the observed MRF connection failures can really be called unexpected [Bertero et al, 1994].

While connection reliability can be questioned on the basis of historical test results, the performance of steel frames in earthquakes prior to Northridge has been thought to be excellent, and in practice, the steel MRF has long been considered perhaps the most reliable structural system for resisting seismic loads [Yanev et al, 1991]. Confidence in the prescribed connection detail has led to its use with a variety of member sizes, frame dimensions, shear connectors, flange weld processes, and lateral force resisting system configurations.

Many initial inspections of steel frame buildings following the Northridge earthquake found only minor non-structural damage. Based on prior earthquake experience, engineers had no reason to suspect cracked welds or fractured columns hidden behind soffits, ceilings, and fireproofing. Only after a few reports of steel damage began to circulate did engineers and owners revisit buildings to perform more complete inspections. In time, these inspections revealed several distinct damage types, a number of which (e.g. weld cracks, column flange tearing, and bolt failure) had been observed in past testing programs [Popov \& Stephen, 1972; Popov \& Bertero, 1973; Popov et al, 1985; Popov \& Tsai, 1987; Engelhardt \& Husain, 1993]. Within three months, fifty steel frames had been confirmed as damaged to some degree. By September 1994, eight months after the earthquake, the estimate had grown to over 100 damaged MRF buildings. (See Section 3.2.1 for a more detailed discussion of these estimates.)

\subsubsection{Response to Observed Damage}

As more damage was found, some building owners initiated systematic inspection and testing programs, and in many cases proceeded with engineered repairs, even in the absence of consensus standards and procedures. Other owners, whose buildings sustained little apparent damage and no substantial loss of function, have waited for government mandates to inspect their buildings. Given the number of damaged buildings reported and estimates of the total MRF population (see Section 3.2.1), it is likely that about $100 \mathrm{MRF}$ buildings in heavily affected areas have not yet been inspected for connection damage.

Meanwhile, organizations and ad hoc committees in industry, academia, and government have begun studying the damage and developing new approaches to analysis, repair, strengthening, and design of steel MRF's [AISC, 1994; SAC, Advisory No. 3]. A number of 
researchers and practitioners have speculated on the causes of observed damage, but there is no conclusive evidence that any one factor, whether related to design, construction, or unique ground motion, is consistently responsible [Sabol, 1994; Shipp et al, 1994; SEAOC

Seismology Committee, 1994; Bertero et al, 1994]. Joint ventures of interested organizations have initiated testing programs to establish the causes of specific failures and the feasibility of proposed repairs. Local government responses have included emergency regulations and suspension of the Code-prescribed connection for new construction. Most significantly, the International Conference of Building Officials (ICBO) Board of Directors in September passed an emergency revision to the 1994 UBC deleting the prescribed detail and calling for test results or calculations to demonstrate both strength and inelastic rotation capacity ["ICBO Board...," 1994].

\subsection{Survey of Available Data}

Ten months after the Northridge earthquake, inspection, testing, preliminary research, and building-specific repair were ongoing. For the steel MRF population as a whole, the following issues were among those still unresolved:

- the quantitative extent of different damage types,

- the correlation between damage and site factors such as ground motion,

- the correlation between damage and design factors such as frame configuration,

- the correlation between damage and construction factors such as weld quality control.

To address these issues, the National Institute of Standards and Technology (NIST) contracted Nabih Youssef \& Associates (NYA) to compile and analyze available data on steel MRF's inspected since the January 17 earthquake. A survey was developed for distribution to engineers who were already involved with the collection of data on the MRF connections. The goal was to make the results of this survey available to people working in all earthquake-related fields.

In the short term, the goal of this survey was to identify the nature and extent of observed damage, providing an accurate assessment of the situation as of November, 1994. In the long term, it is hoped that survey responses will provide insight or direction to researchers, practicing engineers, and policy makers studying the following issues, among others:

- $\quad$ the extent to which factors that correlated with damage also caused damage,

- the suitability of proposed repair and retrofit schemes,

- the nature of potential hazards remaining in unrepaired or undamaged frames,

- the relative merits of proposed code revisions and policy responses.

The survey was designed to address both the short term goal of quickly collecting damage data and the long term goal of supporting potential users with a comprehensive centralized database. The inherent conflicts between these two goals led to some revisions in survey 
scope midway through data collection. Eighteen buildings were submitted on the original survey form in the first three weeks of data collection; these responses formed the basis for the preliminary report presented at an industry workshop in September, 1994 [NYA, 1994]. A revised and shortened survey form was distributed to twenty-one survey engineers in midSeptember. (Appendix B includes copies of both survey forms.) This report presents data from a total of 51 surveyed buildings submitted by October 21, 1994. Survey engineers have agreed to submit data on approximately $\mathbf{4 0}$ more buildings as test results become available.

A computerized database was developed to track submittals, compile basic survey data, and generate the summary tables discussed in this report. Not all survey items have been entered into the computerized database.

\subsection{Scope of Report}

The data reported here represents 51 inspected MRF buildings comprising 330 inspected frames, 1290 inspected floor-frames, and 5120 inspected beam-to-column connections. Survey forms were completed by 14 different engineering offices. A damage score is calculated for each building based on the types of damage found. These damage scores are used to examine various structural characteristics of the building to establish any correlations between these characteristics and the amount of damage to the building.

Section 2.0 of this report describes the survey effort in detail. Section 3.0 discusses the sources of available data and the distribution of reported buildings by location and type. Section 4.0 describes and quantifies observed connection damage. Section 5.0 discusses correlations between observed damage and factors such as building location and frame configuration. Section 6.0 presents conclusions drawn from the survey responses. 


\subsection{The Survey}

\subsection{Scope}

The survey described in this report attempts, within the limits of available resources, to address both the short term goal of collecting damage data and the long term goal of supporting potential users with a comprehensive centralized database. It is beyond the current scope to collect all data of potential interest on every steel MRF affected by the Northridge earthquake. The short term survey goal requires data on building identification, basic description of construction and configuration, and a list of observed damage, perhaps keyed to frame elevations. The long term goal, however, requires specific structural descriptions.

When the survey effort began, five original contributing engineering firms had approximately 40 buildings with testing complete and approximately 10 more with testing in-progress. By October, 51 completed surveys had been submitted, and another 40 or so had been promised by 20 survey engineers, pending completion of testing and approval of building owners.

From the beginning, the survey scope was limited in order to facilitate response. Steps taken toward this end included:

- $\quad$ limiting the subject buildings to steel MRF's only, i.e. excluding braced frames, dual systems, and other steel assemblies damaged by the Northridge earthquake

- limiting the subject buildings to those with beam column joints visually inspected or tested, i.e. not collecting data on potentially damaged buildings

- $\quad$ requiring no inspection or testing beyond that which had already been completed

- $\quad$ requiring no analysis, calculation, or numerical design check

- accepting responses of "Unknown" to avoid additional research or interviews

- requesting information for each floor-frame instead of each connection

- eliminating survey sections not directly related to building description and earthquake response, e.g. sections on ground motion, costs, repair, or potential upgrade

In practice, the scope of survey responses was limited by the project schedule and a lack of available documents. In particular, because the survey engineers were generally not the original design engineers, most had no immediate access to original documents (e.g., steel mill certifications, weld specifications, structural calculations, etc.). As discussed below, the survey form was revised midway through data collection in response to these practical limitations. 


\subsection{Form}

Due to limited time and availability of documents, initial responses were substantially incomplete on issues of building design history, non-structural detailing, steel and weld properties, and building performance in previous earthquakes. Reported damage was sometimes poorly labeled because the format for reporting it was time consuming and confusing. Additionally, the completeness of inspection, testing, and UT documentation used as the basis of survey responses seemed to vary widely.

For these reasons, and with the hope of improving response, the original survey form was modified. The substantive changes put less emphasis on building history and more emphasis on the nature of post-earthquake evaluations. The procedure for reporting damage (Survey Section V) was simplified into a tabular form. While information was still requested for each inspected floor-frame, the number of affected connections in each floor-frame was no longer reported. The potential effects of this loss of robustness are discussed briefly in Section 3.2.5.

Copies of the two survey forms are given in Appendix B. Eighteen buildings were surveyed with the original form, the rest with the revised form or a combination of the two.

\subsection{Process}

The survey process for each building involved distribution of survey forms, completion and submittal of forms, database entry, quality control by telephone, and revisions as needed. Each building survey progressed on its own schedule due to ongoing inspection in various stages and a constantly expanding list of participating engineers.

In most cases, survey engineers completed the forms themselves. In order to expedite submittal, however, NYA staff completed some survey forms based on interviews with and documents provided by the survey engineer.

Provisions were made to protect the confidentiality of building owners and survey engineer clients. A building ID Code was selected for each building and, in this report, buildings are identified by this code only. Building, owner, and tenant names were not reported on survey forms. Street addresses were generally given on the written survey form with instructions to keep confidential. If so noted, street addresses were not entered into the computerized database. Instead, each building was assigned to a geographic zone, and specific building location is given only in terms of zip codes, neighborhoods, or cross streets, if at all. Despite these measures, some owners of known damaged buildings declined to release information for this survey. 


\subsection{Characterizing the Data}

\subsection{Sources of Data}

As of October 20,1994, fourteen engineering firms had contributed survey data, and a total of twenty had agreed to participate. Firms were invited to participate based on their access to current building information, specifically reports of connection inspection and testing. In general, the survey engineer for a particular building had been retained by its owner to perform post-earthquake assessments and to design repairs or strengthening. In the typical case, the survey engineer was not the original engineer of record and was familiar with the building only from post-earthquake inspections. In all but a few cases, specialty contractors exposed the connections and performed the visual inspections and testing; typically, the engineer performed only a building walkthrough and visual inspection of some connections.

\subsubsection{Documents}

Though not listed in Appendix A or tracked in the current computer database, each completed survey form lists the sources of data used as the basis of response. Surveys completed on the revised form (see Appendix B) also list the documents available for future reference.

In general, the following documents were used as the basis of survey responses:

- Original structural design drawings

- Post-Northridge connection visual inspection reports

- Post-Northridge connection test reports

- Undocumented first-hand knowledge of the original building and observed damage

Occasionally, the following documents were also available and cited as the basis of response:

- Original architectural design drawings

- Post-Northridge building walkthrough notes or rapid assessment report

- Post-Northridge repair drawings based on connection test reports

Where the survey engineer was also the original engineer of record, some of the following documents may have been available as reference. In general, however, the following documents were not available to the survey engineer:

- Original structural calculations and design criteria

- Original soil/geotechnical reports

- Steel/Welding specifications

- Fabrication/Erection drawings

- Structural as-built drawings

- Weld or steel samples removed for testing 


\subsubsection{Testing}

Inspection and test reports were typically prepared by the laboratory performing the tests, not by the survey engineers. Sample inspection criteria and report forms are included in Appendix C. Specific test locations were typically selected by the engineer on the basis of visible damage, recent experience, judgement, and access.

Connection inspection and testing generally involved the following basic steps: removal of finishes; removal of fireproofing to expose beam flange connections, beam web connections, column panel zone, and column flanges below the beam; cleaning of the connection, generally by wire brush only; visual inspection of members and connectors; and ultrasonic testing of beam flange welds and column flanges. Seven of the 51 survey responses were based on visual inspection only. Not counting these seven buildings, $94 \%$ of visually inspected connections were also tested.

The revised survey form requested specific responses regarding the type and extent of testing; the original form did not (see Appendix B). For the 33 buildings surveyed with the revised form, typical testing involved UT only. In a few cases, magnetic particle testing and/or liquid dye penetrant testing were used to supplement the UT. Weld or base metal samples were generally not taken, and may not have been tested when they were. Despite some indications that effective UT requires removal of the backing bar and careful preparation of the weld [SAC, Session Summaries, Session 1], survey responses indicate that backing bars were seldom removed for inspection or testing.

Lack of access to the outside of perimeter connections and to the top surface of beam top flanges was a common constraint on full inspection and UT. The few buildings with exterior walls or slabs removed were either under construction, vacated due to heavy damage, or temporarily vacated to perform the work. By contrast, the typical surveyed building was occupied at the time of the earthquake, reoccupied shortly after the earthquake, and continuously occupied (with limited, temporary disruptions) during inspection and testing.

\subsection{Sources of Error}

\subsubsection{Size of Sample}

The number of surveyed buildings required for valid correlations is directly related to the number of buildings in the steel MRF population affected by the Northridge earthquake. Following the earthquake, the Los Angeles Department of Building \& Safety conducted a search of Los Angeles building permit records since 1961 for Type I and II steel framed buildings. The search found about 1200 buildings in all of Los Angeles, including about 300 in heavily damaged San Fernando Valley and West Los Angeles. This does not include buildings in separate jurisdictions such as Beverly Hills or Santa Monica. As of October, 1994, the survey included data from 51 buildings, 46 of which are in the San Fernando Valley, West L.A., or nearby Santa Monica. Assuming a current total population of 
approximately $500 \mathrm{MRF}$ buildings in the areas of strongest shaking, the survey represents about a $10 \%$ sample.

As for confirmed damaged buildings, the Los Angeles Department of Building \& Safety ad hoc Steel Subcommittee identified about 50 buildings with damaged connections by April, 1994. By June, the Subcommittee had compiled a list of 77 buildings drawn mostly from the records of local testing firms [SAC, Program...]. In early August, five engineering firms participating in this survey indicated that they were involved with 62 buildings, most of which were not on the City's list of 77. The combination of these two numbers corroborates oft-cited estimates of "over 100" damaged steel MRF's [SEAOC Seismology Committee, 1994]. (This otherwise unconfirmed estimate was originally based on job records from the city's two largest testing firms.)

\subsubsection{Nature of Sample}

Local jurisdictions including the City of Los Angeles are developing inspection ordinances for steel MRF buildings [Holguin, Ordinance...]. As of October, 1994, however, all inspection and testing programs had been voluntary, usually motivated by visible frame damage, other structural damage, heavy non-structural damage, or observed MRF damage in similar nearby buildings. Since the present survey includes only inspected buildings, it is therefore likely that the sample represents the most-damaged subset of the MRF population. Mandatory inspections, however, will yield data on a broader range of MRF's, both damaged and undamaged.

\subsubsection{Scope of Testing}

Survey instructions specified no minimum scope of testing. Survey engineers were requested to report on any building with any level of connection inspection or testing, whether damaged or not. As noted above, many owners were not compelled to undertake substantial voluntary inspections in the absence of severe non-structural damage. Consequently, many buildings remain uninspected or only minimally inspected.

Among the surveyed buildings, the scope of inspection and testing varied. Thirteen of the 51 surveyed buildings had complete testing at every connection in every frame. As noted above, seven buildings had no testing, but six of these had thorough visual inspection. At building ESI2, preliminary visual inspection of only one floor-frame revealed cracking into the column web; results of further inspection were unavailable. Overall, of the 44 tested buildings, 25 had more than half of their floor-frames inspected and tested to some degree, and 32 buildings had at least a quarter inspected. Within each tested floor-frame, the number of tested connections also varied, but was generally high. Three quarters of all floor-frames had more than half of their connections tested.

The SEAOC Seismology Committee has recommended inspection and testing of at least $15 \%$ of all MRF connections in low-rise buildings [SEAOC Seismology Committee, 1994]. The scope of testing in nearly all of the surveyed buildings would meet this standard. Correlation 
of observed damage to scope of inspection is discussed in Section 5.3.

In addition to the number of connections tested, the scope of testing within a given connection may affect survey results slightly. In most cases, backing bars, slabs and finishes above the beam top flange, and exterior window wall obstructing the outside of perimeter frame connections were not removed. This limited the inspection and testing, especially at the beam top flange.

\subsubsection{UT Error}

Because weld damage was recorded much more frequently than any other damage class, and because most of that damage was detected only by UT, it is important to consider the reliability and consistency of ultrasonic testing. F. Robert Preece, in a monograph for the Steel Committee of California [Preece], has written that "the ultrasonic method is highly dependent on the skill and integrity of the operator. " Preece and others have noted that this dependence, coupled with the pressure of a tight construction schedule, sometimes leads a technician to accept welds based on uncertain UT readings. A common situation involves readings near the mid-length of the beam flange weld where interference from the beam web makes both welding and UT difficult. A UT indication in this area is likely to be read unconservatively, ignored, or assumed to be just the edge of the backing bar [Benson]. After an earthquake, when real damage has already been observed, the opposite situation may prevail: technicians may feel pressure to find "damage" or indications, erring on the conservative side.

Reliability of UT and other testing is not merely a function of technician psychology, however. A root cause, say experts, is inadequate training and meaningless, inconsistent certification [SAC, Advisory No. 3]. Compounding the problem is a lack of training for engineers, who are largely unfamiliar with testing procedures or welding in general. In particular, engineers regularly reference AWS D1.1 [AWS] in project specifications, but many are not taught to distinguish quality workmanship from. "fitness for purpose" or discontinuities from defects or earthquake damage.

Survey responses highlighted some of these uncertainties. In some cases, weld cracks went undetected by UT until backing bars were removed for a closer look. In other cases, UT suggested weld cracks, but none could be found when the backing bar was removed for repair.

The effect on survey results is largely limited to damage type W1: incipient root cracks detected by UT. As discussed in Section 4.1.1, different survey engineers reported different conditions as W1, sometimes reporting all indications found, other times reporting only what could clearly be identified as earthquake damage. For a given building, this variability is quantified by isolating the percentage of all weld damage that is type W1. 


\subsubsection{Completeness of Survey Responses}

As previously noted, many of the responses on the original survey form were incomplete when original architectural drawings and construction phase documents were unavailable. Except for the many buildings with unknown flange weld processes, this did not affect the general structure or damage descriptions. Two of the 51 buildings surveyed to date reported damage by frame type, not by individual floor-frame. Consequently, that data is inconsistent and could not be used in characterizing and correlating the damage.

Another completeness issue involves the survey scope. As previously noted, damage data was collected for each floor-frame, not each connection. This was done to improve response, as a connection-by-connection survey would take too much time and effort to complete, but data for a whole building or frame would not be detailed enough. As a result, if a 3-bay (6connection) floor-frame is indicated as having bottom weld damage, for example, the new survey form does not record whether one connection or all six are damaged. Further, if a floor-frame has both shear connection damage (class $S$ ) and damage to the bottom flange weld (class BW), for example, it's not clear from the survey if the two damage classes occurred in the same or different connections within the floor-frame. Finally, a 6-connection frame with three different damage types all in different connections will be represented three times in a list of damaged floor-frames even though only half its connections are affected, while a similar floor-frame with the same damage type in all its connections will be represented only once. (This last example is most significant in its effect on damage scores, defined later in the report.)

\subsubsection{Quality of Survey Responses}

Survey responses were checked for completeness and consistency. When questions arose, responses were checked by telephone interview with the survey engineer. In general, the responses were of high quality and consistency.

\subsection{Data Distributions}

Table 3-1 lists the 51 buildings surveyed, sorted by geographic zone. Heights and floor areas are listed to indicate building size, and the number of inspected or tested floor-frames is given to indicate the amount of data in the survey. Appendix A includes more detail on each building. The distribution of survey data by location, structural concept, and structural detailing is discussed below. Location data is directly related to the level of shaking experienced by each building; a given earthquake can be expected to impose similar demands on buildings in the same zone. Structural concept refers to building massing, redundancy, regularity, and other aspects of structural design usually addressed during a project's conceptual design phase. Structural detailing encompasses the balance of structural design decisions, including materials, member sizes, and connection types. 


\begin{tabular}{|c|c|c|c|c|c|c|}
\hline Building ID & Zone & $\begin{array}{c}\text { Year } \\
\text { Designed }\end{array}$ & $\begin{array}{c}\text { MRF } \\
\text { Stories }\end{array}$ & $\begin{array}{c}\text { Lower Floor } \\
\text { Area }\left[\mathrm{m}^{2}\right]\end{array}$ & $\begin{array}{c}\text { Upper Floor } \\
\text { Area }\left[\mathbf{m}^{2}\right]\end{array}$ & $\begin{array}{l}\text { No of Inspected } \\
\text { Floor-Frames }\end{array}$ \\
\hline DM1 & LAX & 1970 & 15 & 5,600 & 2,000 & 5 \\
\hline SOM1 & MW & 1986 & 4 & 1,700 & 1,700 & 9 \\
\hline BJ05 & NR & 1990 & 11 & 2,700 & 2,300 & 55 \\
\hline BJ06 & NR & 1989 & 2 & 4,700 & 4,700 & 12 \\
\hline LCIB & NR & 1990 & 4 & & 2,900 & 3 \\
\hline LCIE & NR & 1990 & 3 & 2,500 & 1,400 & 9 \\
\hline EQE1 & $\overline{S C}$ & 1991 & 4 & 2,000 & 2,000 & 16 \\
\hline EQE2 & $\overline{S C}$ & 1991 & 1 & 2,500 & 2,500 & 6 \\
\hline KPFF1A & $\mathrm{SC}$ & 1981 & 2 & 900 & 900 & 4 \\
\hline BJ01 & SM & 1989 & 4 & 1,300 & 1,300 & 23 \\
\hline ESI2 & SM & 1990 & 5 & 2,000 & 2,000 & 1 \\
\hline ESI5 & SM & 1989 & 6 & 1,700 & 1,400 & 46 \\
\hline$\overline{B A K}$ & SO & 1982 & 6 & 2,400 & 1,900 & 12 \\
\hline BJ04 & so & 1981 & 4 & 1,000 & 1,000 & 16 \\
\hline ESI7 & so & 1989 & 3 & 1,400 & 1,400 & 13 \\
\hline JAM 7482 & SO & 1983 & $\overline{4}$ & 1,600 & 1,300 & 28 \\
\hline JAM7484 & so & 1985 & 4 & 1,500 & 1,500 & 20 \\
\hline JAM7487 & so & 1979 & 12 & 1,200 & 1,400 & 41 \\
\hline JAM7489 & So & 1979 & 6 & 2,000 & 2,000 & 7 \\
\hline KAR3 & SO & & 17 & & & 3 \\
\hline MNH04 & so & 1981 & $\overline{6}$ & 3,000 & 3,000 & 12 \\
\hline NYA550 & SO & 1985 & 6 & 5,000 & 2,000 & 15 \\
\hline SOA & SO & 1984 & 4 & 2,800 & 2,300 & 22 \\
\hline BJ02E & $\overline{\mathrm{UC}}$ & 1992 & 3 & 2,700 & 2,700 & 27 \\
\hline ESI3 & UC & 1984 & 8 & & 700 & 1 \\
\hline
\end{tabular}

Table 3-1. Characteristics of Surveyed Buildings ${ }^{1}$

1 The following guidelines apply to all tables:

blank = not applicable or no response was recorded on the survey sheet

? = response was recorded on survey sheet as shown but the reporter was uncertain about the answer 


\begin{tabular}{|c|c|c|c|c|c|c|}
\hline Building ID & Zone & $\begin{array}{c}\text { Year } \\
\text { Designed }\end{array}$ & $\begin{array}{l}\text { MRF } \\
\text { Stories }\end{array}$ & $\begin{array}{c}\text { Lower Floor } \\
\text { Area }\left[\mathrm{m}^{2}\right]\end{array}$ & $\begin{array}{c}\text { Upper Floor } \\
\text { Area }\left[m^{2}\right]\end{array}$ & $\begin{array}{l}\text { No of Inspected } \\
\text { Floor-Frames }\end{array}$ \\
\hline WEA & UC & 1979 & 4 & 700 & 1,700 & 24 \\
\hline BJ09 & WH & 1982 & 5 & 8,400 & 4,600 & 50 \\
\hline BJ10 & WH & 1990 & 5 & 4,600 & 4,600 & 13 \\
\hline BJ11 & WH & 1991 & 5 & 2,400 & 2,400 & 26 \\
\hline BJ18 & WH & 1987 & 3 & 2,000 & 2,000 & 24 \\
\hline ESI8 & WH & 1987 & 25 & 2,600 & 2,500 & 216 \\
\hline KAR2 & WH & 1978 & 4 & & 2,600 & 12 \\
\hline MNH02 & $\overline{\mathrm{WH}}$ & 1984 & 3 & & 2,900 & 16 \\
\hline NYA539 & WH & 1984 & 3 & & 2,600 & 14 \\
\hline NYA544 & WH & 1975 & 13 & 2,400 & 2,400 & 56 \\
\hline WJE1 & WH & & 18 & 1,800 & 1,800 & 68 \\
\hline$\overline{\mathrm{ACl}}$ & WLA & 1984 & 3 & 1,700 & 1,700 & 19 \\
\hline ESI1 & WLA & 1993 & 5 & & 1,100 & 50 \\
\hline ESI4 & WLA & 1988 & 27 & & 1,300 & 10 \\
\hline FE1 & WLA & 1965 & 17 & 2,800 & 2,100 & 4 \\
\hline JAM7480 & WLA & 1983 & 11 & 3,000 & 2,100 & 14 \\
\hline JAM7485 & WLA & 1984 & 4 & 1,100 & 1,100 & 25 \\
\hline JAM7486 & WLA & 1983 & 13 & 1,900 & 1,500 & 44 \\
\hline $\mathrm{MNH} 03 \mathrm{AB}$ & WLA & 1978 & 3 & 1,000 & 1,000 & 38 \\
\hline MNH03CDE & WLA & 1978 & 3 & 1,600 & 1,600 & 77 \\
\hline MNH03F & WLA & 1978 & 3 & 500 & 500 & 17 \\
\hline MNH03G & WLA & 1978 & 3 & 400 & 400 & 12 \\
\hline MNH03H & WLA & 1978 & 3 & 700 & 700 & 9 \\
\hline NYA577 & WLA & 1980 & 14 & 3,000 & 1,600 & 20 \\
\hline NYA591 & WLA & 1970 & 28 & 2,200 & 2,200 & 16 \\
\hline NYA592 & WLA & 1969 & 20 & 2,300 & 2,300 & 10 \\
\hline
\end{tabular}

Table 3-1. Characteristics of Surveyed Buildings

(Continued)

\subsubsection{Location}

Each building is located in one of nine geographic zones, as listed in Table 3-1 and shown in Figure 3-1. The zones suggest themselves according to patterns of development and the clustered nature of the 51 buildings. Table 3-2 summarizes the data of Table 3-1 for each 


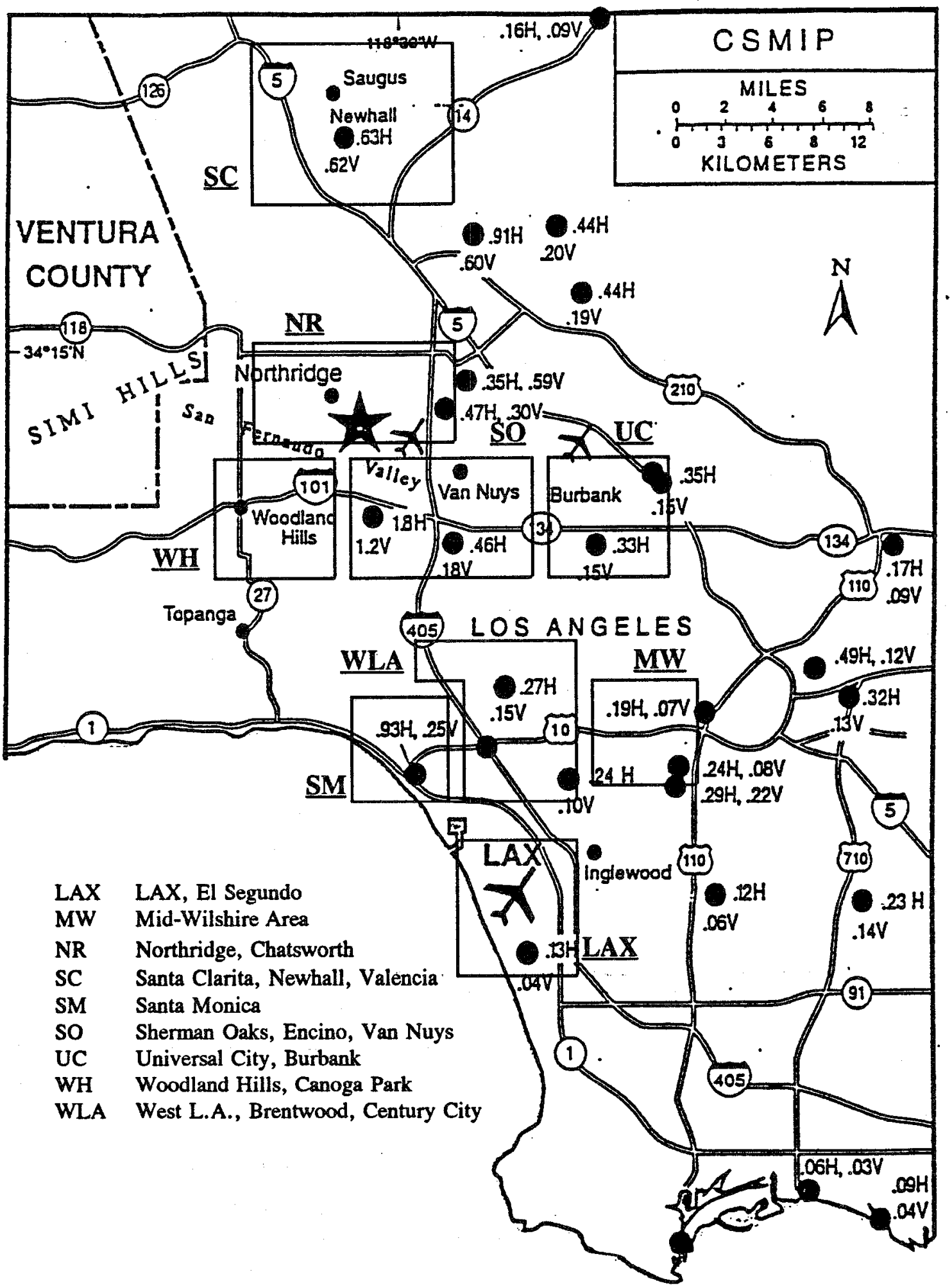

Figure 3-1. Location of Surveyed Buildings and Recorded Ground Accelerations Source: CSMIP 
zone. The 15 buildings in zone WLA are the most dispersed and can therefore be expected to represent the most diverse soil conditions and ground motions. The buildings in zones WLA and SM could be considered together based on their relative proximity, but are listed separately to indicate separate political jurisdictions. Three zones, SO, WH, and WLA, account for 36 of the 51 surveyed buildings, but five of the zone WLA buildings are separate superstructures on a shared site, and three of the zone WH buildings are structurally independent wings of a single complex.

\begin{tabular}{|c|c|c|c|c|c|c|c|c|}
\hline \multirow{2}{*}{ Zone } & \multirow{2}{*}{$\begin{array}{l}\text { No of } \\
\text { Bldgs }\end{array}$} & \multirow{2}{*}{ Fr-Frms } & \multicolumn{2}{|c|}{ Year Designed } & \multicolumn{2}{|c|}{ Bldg Ht [stories] } & $\begin{array}{c}\text { Min Frr } \\
\text { Area [m²] }\end{array}$ & $\begin{array}{c}\text { Max Fr } \\
\text { Area [m²] }\end{array}$ \\
\cline { 4 - 8 } & & Oldest & Newest & Shortest & Tallest & & \\
\hline \hline LAX & 1 & 5 & 1970 & 1970 & 15 & 15 & 2,000 & 2,000 \\
\hline MW & 1 & 9 & 1986 & 1986 & 4 & 4 & 1,700 & 1,700 \\
\hline NR & 4 & 79 & 1989 & 1990 & 2 & 11 & 1,400 & 4,700 \\
\hline SC & 3 & 26 & 1981 & 1991 & 1 & 4 & 900 & 2,500 \\
\hline SM & 3 & 70 & 1989 & 1990 & 4 & 6 & 1,300 & 2,000 \\
\hline SO & 11 & 189 & 1979 & 1989 & 3 & 17 & 1,000 & 3,000 \\
\hline UC & 3 & 52 & 1979 & 1992 & 3 & 8 & 700 & 2,700 \\
\hline WH & 10 & 495 & 1975 & 1991 & 3 & 25 & 1,800 & 4,600 \\
\hline WLA & 15 & 365 & 1965 & 1993 & 3 & 28 & 400 & 2,300 \\
\hline
\end{tabular}

Table 3-2. Summary of Survey Data by Geographic Zone

Figure 3-1 also shows recorded peak accelerations, as published by CSMIP [CSMIP]. The nearest recorded horizontal acceleration is less than $0.33 \mathrm{~g}$ for only two zones, MW and LAX, which are represented in the survey by one building each. However, four buildings in the eastern portion of zone WLA are nearer to the station recording $0.27 \mathrm{~g}$ peak horizontal acceleration than to the Santa Monica station recording 0.93g. Downtown Los Angeles, near recorded peak horizontal accelerations of $0.32 \mathrm{~g}$ and $0.49 \mathrm{~g}$, currently has no buildings in the survey.

\subsubsection{Structural Concept}

Table 3-3 shows the distribution of survey data by building height. Three- to six-story buildings account for 33 of the 51 buildings surveyed, but they differ in size, with floor areas as small as 400 square meters (4500 square feet) and as large as 4600 square meters $(50,000$ square feet). Floor diaphragm size is more consistent among the taller buildings but any study of the tall buildings as a class will be dominated by building ESI8 whose 216 inspected and tested floor-frames represent the most of any surveyed building. The average floor 
diaphragm size for all buildings and floor-frames in the survey is about 2000 square meters $(21,000$ square feet), a figure which was practically law among office developers in the early 1980's [Garreau]. Thus, the surveyed buildings can be considered representative of the larger MRF population at least in terms of floorplate. Tables 3-1 and 3-3 show that this floor area can be found in buildings of almost any height. Table 3-4 shows the distribution of surveyed buildings and floor-frames by typical upper floor area.

\begin{tabular}{|c|c|c|c|c|}
\hline $\begin{array}{l}\text { MRF } \\
\text { Stories }\end{array}$ & No of Bldgs & Fr-Frms & $\begin{array}{c}\text { Min Fir } \\
\text { Area }\left[\mathbf{m}^{2}\right]\end{array}$ & $\begin{array}{c}\text { Max } \mathbf{F r} \\
\text { Area }\left[\mathbf{m}^{2}\right]\end{array}$ \\
\hline 1 & 1 & 6 & 2,500 & 2,500 \\
\hline 2 & 2 & 16 & 900 & 4,700 \\
\hline 3 & 12 & 275 & 400 & 2,900 \\
\hline 4 & 11 & 198 & 1,000 & 2,900 \\
\hline 5 & 5 & 140 & 1,100 & 4,600 \\
\hline 6 & 5 & 92 & 1,400 & 3,000 \\
\hline 8 & 1 & 1 & 700 & 700 \\
\hline 11 & 2 & 69 & 2,100 & 2,300 \\
\hline 12 & 1 & 41 & 1,400 & 1,400 \\
\hline 13 & 2 & 100 & 1,500 & 2,400 \\
\hline 14 & 1 & 20 & 1,600 & 1,600 \\
\hline 15 & 1 & 5 & 2,000 & 2,000 \\
\hline 17 & 2 & 7 & 2,100 & 2,100 \\
\hline 18 & 1 & 68 & 1,800 & 1,800 \\
\hline 20 & 1 & 10 & 2,300 & 2,300 \\
\hline 25 & 1 & 216 & 2,500 & 2,500 \\
\hline 27 & 1 & 10 & 1,300 & 1,300 \\
\hline 28 & 1 & 16 & 2,200 & 2,200 \\
\hline
\end{tabular}

Table 3-3. Summary of Survey Data by Building Height

Structural redundancy is considered essential to reliable seismic behavior [Freeman, 1987; Naiem, 1989; SEAOC, 1990] and in the wake of observed Northridge damage, increased redundancy has been suggested as a method to improve connection performance [Malley and Saunders, 1994; SAC, Session Summaries, Session 4]. Redundancy can be achieved by using multi-bay frames, providing several frames in each principal direction, distributing the frames in plan to minimize the effects of irregularity and torsion, or by combining these and other measures. 


\begin{tabular}{|c|c|c|c|c|}
\hline \multirow{2}{*}{$\begin{array}{c}\text { Floor Area } \\
{\left[\mathbf{m}^{2}\right]}\end{array}$} & \multirow{2}{*}{ No of Bldgs } & \multirow{2}{*}{ Flr-Frms } & \multicolumn{2}{|c|}{ Bldg Ht [stories] } \\
\cline { 4 - 5 } & & & Shortest & Tallest \\
\hline$<700$ & 3 & 38 & 3 & 3 \\
\hline $700-1,500$ & 14 & 324 & 2 & 27 \\
\hline $1,500-2,200$ & 16 & 359 & 3 & 18 \\
\hline $2,200-3,000$ & 13 & 479 & 1 & 28 \\
\hline$\geq 3,000$ & 4 & 87 & 2 & 6 \\
\hline
\end{tabular}

Table 3-4. Summary of Survey Data by Upper Floor Area

For each building, the number of frames in each direction is given in Table 3-5. As shown, nearly all the surveyed buildings were reported as oriented with N-S and E-W principal directions. The number and average width of bays in each building was not compiled for this survey, but the overall distribution of inspected frames by number of bays and average bay width is given in Table 3-6. The 3-bay frame is most common, showing up in 31 of the 51 surveyed buildings, but bay widths range widely, from one to three times a typical story height of 3.7 meters (12 feet) .

Floor area tributary to a given frame or bay can be considered a quantitative measure of redundancy, but such detail was not compiled in this survey. For purposes of correlating observed damage to redundancy, the least redundant buildings can be identified as those with fewer than three frames in a given direction and only one or two bays in those frames. The buildings and floor-frames that meet these conditions are identified in Table 3-7.

Structural irregularities require special attention in design because they are at odds with the assumptions inherent in basic code procedures. Whether the irregularities in surveyed buildings were properly considered during design is unknown. For purposes of correlating observed damage to regularity, the irregular conditions in surveyed buildings are identified in Table 3-8. Twenty-nine of 51 buildings had irregularities of some kind; eight had both vertical and plan irregularities. The most common irregularities, reentrant comers and significant changes in mass from floor to floor, were due to setbacks in the building envelope, a common architectural design feature of 1980's office buildings [Garreau].

\subsubsection{Structural Detailing}

Table 3-9 shows the number of surveyed buildings and inspected floor-frames for different floor diaphragm types. Wood and concrete diaphragms are fundamentally different in terms of seismic behavior because wood floors are generally much lighter, do not act together with frame beams as composite members, and are less rigid and therefore much less prone to 


\begin{tabular}{|c|c|c|c|c|c|}
\hline Building ID & N-S & E.W & NE-SW & NW-SE & Remarks \\
\hline DM1 & 2 & 2 & & & \\
\hline SOM1 & 3 & 3 & & & \\
\hline BJ05 & 4 & 2 & & & \\
\hline BJ06 & 2 & 3 & & & \\
\hline LCIB & & & 6 & 8 & \\
\hline LCIE & 8 & 11 & & & \\
\hline EQE1 & 2 & 2 & & & \\
\hline EQE2 & 3 & 3 & & & \\
\hline KPFF1A & 2 & 2 & & & \\
\hline BJ01 & & & 2 & 5 & \\
\hline ESI2 & 3 & 4 & & & \\
\hline ESI5 & & & 4 & 2 & $\begin{array}{l}\text { At floors 1-4, } 2 \text { 2-bay NWSE frames. At flrs 5-7, } 4 \\
\text { 1-bay NWSE frames. }\end{array}$ \\
\hline BAK & 2 & 3 & & & \\
\hline BJ04 & 2 & 2 & & & \\
\hline ES17 & 3 & 3 & & & \\
\hline JAM7482 & 3 & 4 & & & \\
\hline JAM7484 & 2 & 2 & & & \\
\hline JAM7487 & 2 & 2 & & & \\
\hline JAM7489 & 4 & 5 & & & \\
\hline KAR3 & 2 & 2 & & & Actual compass directions need to be confirmed. \\
\hline MNH04 & 4 & 4 & & & \\
\hline NYA550 & 5 & 5 & & & At floors 5-7(rf), 2 NS, 2 EW. \\
\hline SOA & 4 & 6 & & & \\
\hline BJO2E & 6 & 4 & & & \\
\hline ESI3 & 1 & & 1 & 1 & \\
\hline WEA & 2 & 4 & & & \\
\hline BJ09 & 8 & 8 & & & \\
\hline
\end{tabular}

Table 3-5. Number and Orientation of Frames in Surveyed Buildings 


\begin{tabular}{|c|c|c|c|c|c|}
\hline Building ID & N-S & E-W & NE-SW & NW-SE & Remarks \\
\hline BJ10 & 4 & 4 & & & \\
\hline BJ11 & 4 & 4 & & & \\
\hline BJ18 & 3 & 3 & & & \\
\hline ES18 & 3 & 3 & 1 & 2 & \\
\hline \multicolumn{6}{|l|}{ KAR2 } \\
\hline MNH02 & 4 & 2 & & & \\
\hline NYA539 & 6 & 6 & & & \\
\hline NYA544 & 2 & 2 & & & \\
\hline WJE1 & 2 & 2 & & & \\
\hline $\mathrm{ACl}$ & 4 & 4 & & & \\
\hline ESI1 & 5 & 5 & & & \\
\hline ESI4 & 2 & 2 & & & $\begin{array}{l}\text { NOTE: NS frames "bend" in plan, are not in single } \\
\text { vertical plane. EW frames differ in orientation by } \\
\text { about } 40 \text { degrees, but resultant is normal to resultant } \\
\text { of NS frames. }\end{array}$ \\
\hline FE1 & 0 & 2 & & & NS direction is Shear Wall System. \\
\hline JAM7480 & 4 & 4 & & & \\
\hline JAM7485 & 2 & 3 & & & \\
\hline JAM7486 & & & 2 & 2 & \\
\hline MNH03AB & & & 6 & 8 & \\
\hline MNH03CDE & & & 14 & 13 & \\
\hline MNH03F & & & 3 & 4 & \\
\hline MNH03G & & & 2 & 2 & \\
\hline MNH03H & & & 2 & 3 & \\
\hline NYA577 & 6 & 2 & & & $\begin{array}{l}\text { At ground, including small frames under low roofs; } \\
8 \mathrm{NS}, 4 \mathrm{EW}, 2 \mathrm{NWSE} \text {. }\end{array}$ \\
\hline NYA591 & 0 & 2 & & & \\
\hline NYA592 & 2 & 2 & & & \\
\hline
\end{tabular}

Table 3-5. Number and Orientation of Frames in Surveyed Buildings (Continued) 


\begin{tabular}{|c|c|c|r|r|c|}
\hline No of Bays & $\begin{array}{c}\text { No of Bldgs } \\
\text { Represented }\end{array}$ & Flr-Frms & $\begin{array}{c}\text { Min Typ Bay } \\
\text { Width [m] }\end{array}$ & $\begin{array}{c}\text { Avg Typ Bay } \\
\text { Width [m] }\end{array}$ & $\begin{array}{c}\text { Max Typ Bay } \\
\text { Width [m] }\end{array}$ \\
\hline \hline 1 & 15 & 207 & 5.5 & 9.5 & 14.0 \\
\hline 2 & 19 & 450 & 3.4 & 7.0 & 10.4 \\
\hline 3 & 31 & 309 & 4.6 & 7.6 & 12.2 \\
\hline 4 & 20 & 135 & 4.0 & 7.3 & 9.8 \\
\hline 5 & 12 & 124 & 4.0 & 8.5 & 9.8 \\
\hline 6 & 4 & 19 & 4.9 & 5.2 & 8.8 \\
\hline 7 & 3 & 25 & 4.6 & 4.9 & 5.2 \\
\hline 8 & 1 & 1 & 8.8 & 8.8 & 8.8 \\
\hline 9 & 1 & 4 & 7.6 & 7.6 & 7.6 \\
\hline 11 & 3 & 16 & 6.1 & 7.0 & 7.6 \\
\hline
\end{tabular}

Table 3-6. Summary of Survey Data by Number of Bays per Frame

\begin{tabular}{|c|c|c|c|c|c|}
\hline Building ID & Zone & Direction & Fr-Frms & No of Frms & No of Bays \\
\hline \hline KPFF1A & SC & NS & 2 & 2 & 2 \\
\hline ESI5 & SM & NWSE & 10 & 2 & 2 \\
\hline BJ04 & SO & EW & 6 & 2 & 2 \\
\hline BJ04 & SO & NS & 6 & 2 & 2 \\
\hline JAM7484 & SO & EW & 10 & 2 & 1 \\
\hline JAM7484 & SO & NS & 10 & 2 & 1 \\
\hline WEA & UC & NS & 8 & 2 & 1 \\
\hline WJE1 & WH & EW & 34 & 2 & 2 \\
\hline WJE1 & WH & NS & 34 & 2 & 2 \\
\hline JAM7485 & WLA & NS & 8 & 2 & 2 \\
\hline
\end{tabular}

Table 3-7. List of Least Redundant Surveyed Buildings 


\begin{tabular}{|c|c|c|}
\hline Building ID & Vertical Irregularities & Plan Irregularities \\
\hline DM1 & Y possible soft story \& geom irreg at setback above podium base. & $\mathbf{N}$ \\
\hline BJ05 & Y possible mass irreg at floor 9 setback. & Y out-of-plane offsets at floors 2 and 9. \\
\hline BJ06 & $\mathbf{N}$ & $\mathrm{Y}$ diaph discont at $15 \times 30 \mathrm{~m}$ atrium opng. \\
\hline LCIB & Unknown & $\begin{array}{l}\text { Y apparent diaph discont at atrium, but } \\
\text { reported as Unknown }\end{array}$ \\
\hline LCIE & Unknown & $\begin{array}{l}\text { Y apparent reent comers, but reported as } \\
\text { Unknown }\end{array}$ \\
\hline EQE2 & $\mathbf{N}$ & Y reent comer: L-shaped floors. \\
\hline ES12 & $\mathbf{N}$ & $Y$ reent corners \\
\hline ESI5 & $Y$ in plane discontinuity at floor 5 . & Y out-of-plane offsets at floor 5. \\
\hline BJ04 & Y possible geom irreg at floor 3 frame 2 setback. & $\mathbf{N}$ \\
\hline ESI7 & $\mathbf{N}$ & Y reent comers: L-shaped floors. \\
\hline JAM7482 & $\mathbf{N}$ & $Y$ possible reent corners \\
\hline JAM7487 & $\begin{array}{l}\text { Y possible soft story at tall columns, floor } 2 \& 3 \\
\text { mezzanine/partial floor }\end{array}$ & $\begin{array}{l}\text { Y reent comers \& diaph discont } @ \text { partial } \\
\text { floors } 2 \text { and } 3 .\end{array}$ \\
\hline JAM7489 & $\mathbf{N}$ & Y reent corners: $T$-shape floors \\
\hline NYA550 & $Y$ mass \& geom irreg at floor 4 setback. & $Y$ reentrant comer \\
\hline SOA & $\mathbf{N}$ & $Y$ reent corners \\
\hline WEA & $Y$ mass irreg & $\mathbf{N}$ \\
\hline BJ09 & Y possible mass irreg at floor 3 setback. & $Y$ reent comers at floor 3 and above. \\
\hline BJ18 & $\begin{array}{l}\mathrm{N} \text { but note discontinuous top story columns landing midspan on } \\
\text { floor } 3 \text { girders. }\end{array}$ & Y reent corner, L-shaped floors. \\
\hline ESI8 & $\mathbf{N}$ & $Y$ reent corners. \\
\hline MNH02 & $\mathbf{N}$ & $Y$ reent comers \\
\hline NYA539 & $\mathbf{N}$ & Y reentrant comer (L-shaped diaphragm) \\
\hline $\mathrm{ACl}$ & Y possible geom irreg at setbacks. & $Y$ possible reent corners \\
\hline ESI1 & $Y$ mass irreg at floor setbacks. & $\begin{array}{l}\text { Y torsional irreg, reent corners, diaph } \\
\text { discontinuity reported. }\end{array}$ \\
\hline ESI4 & $\mathbf{N}$ & Y reent comers \\
\hline FE1 & $\mathbf{N}$ & Y out-of-plane offset at base \\
\hline JAM7480 & $Y$ mass geom irregs due to many setbacks & Y possible reent corners \\
\hline JAM7486 & Y possible mass irreg at floor 6 setback/deck type change & $\mathbf{N}$ \\
\hline MNH03CDE & $\mathbf{N}$ & Y reent comers \\
\hline NYAS77 & $Y$ mass \& geom irreg at floor $2 \& 3$ low roof setbacks. & $\mathbf{N}$ \\
\hline
\end{tabular}

\section{Table 3-8. Structural Irregularities in Surveyed Buildings}




\begin{tabular}{|c|c|c|c|c|}
\hline Floor Construction & No of Bldgs & Flr-Frms & Min Flr Area [m $\left.{ }^{2}\right]$ & Max Flr Area [m²] \\
\hline \hline LC & 1 & 10 & 2,300 & 2,300 \\
\hline MC & 19 & 673 & 1,300 & 4,700 \\
\hline MC or MCL? & 3 & 48 & 1,700 & 2,400 \\
\hline MCL & 19 & 299 & 700 & 4,600 \\
\hline MCL/MC & 1 & 46 & 1,400 & 1,400 \\
\hline W & 8 & 214 & 400 & 1,700 \\
\hline
\end{tabular}

\section{Table 3-9. Summary of Survey Data by Diaphragm Type}

torsional response. Most of the buildings with metal deck and concrete fill also have steel studs at nominal spacings, probably intended for shear transfer only. Because of the variety of beam depths and deck orientations all using the same typical stud spacing, it is difficult without analysis to characterize beams as composite with any reliability.

Table 3-10 shows the distribution of survey data by specified column and beam yield strengths. Some engineers specify Grade 50 columns in combination with A36 beams to help ensure a "strong-column-weak-beam" design. However, the actual relative strengths of A36 and A572-Gr50 may vary widely, and the two steel grades have markedly different yield/tensile strength ratios [Hamburger and Frank, 1994]. These uncertainties can affect the states of stress and strain in frame members and welds. As shown in Table 3-10, the combination of A36 steel in both the columns and the beams is represented by more surveyed buildings, but the combination of A572-Gr50 steel in the columns and A36 steel in the beams is represented by more of the reported floor-frames. Both combinations appear in buildings of varying ages and heights, although the average building height of all floor-frames with the combination of A572-Gr50 steel in columns and A36 steel in beams is significantly higher than that of the floor-frames with the combination of A36 steel in both columns and beams.

\begin{tabular}{|c|c|c|c|c|c|c|c|c|}
\hline \multirow{2}{*}{$\begin{array}{c}\text { Column } \\
\text { Steel }\end{array}$} & \multirow{2}{*}{$\begin{array}{c}\text { Beam } \\
\text { Steel }\end{array}$} & \multirow{2}{*}{$\begin{array}{c}\text { No of } \\
\text { Bldgs }\end{array}$} & \multirow{2}{*}{ Fr-Frms } & \multicolumn{2}{|c|}{ Year Designed } & \multicolumn{3}{|c|}{ Bldg Height [stories] } \\
\cline { 5 - 9 } & & & & Oldest & Newest & Shortest & Avg & Tallest \\
\hline & & 2 & 5 & 1981 & 1984 & 2 & 3 & 8 \\
\hline & A36 & 1 & 14 & 1983 & 1983 & 11 & 11 & 11 \\
\hline A36 & A36 & 28 & 540 & 1965 & 1991 & 1 & 6 & 28 \\
\hline A572-Gr50 & A36 & 19 & 705 & 1970 & 1993 & 2 & 14 & 27 \\
\hline A572-Gr50? & A36? & 1 & 26 & 1991 & 1991 & 5 & 5 & 5 \\
\hline
\end{tabular}

Table 3-10. Summary of Survey Data by Nominal Steel Strength 
Table 3-11 gives an approximate (member size data was not complete for some buildings) count of surveyed buildings and floor-frames with different types of exterior columns. The distribution of interior column types is similar, but with fewer box columns. The AISC [AISC,1989] Group 3 and 4 W14 sections dominate the survey. Table 3-12 gives approximate counts for each nominal beam depth (built-up beams are not included).

\begin{tabular}{|c|c|c|c|c|c|c|}
\hline $\begin{array}{c}\text { Typical Exterior } \\
\text { Column }\end{array}$ & No of Bldgs & \multirow{2}{*}{ Fr-Frms } & \multicolumn{2}{|c|}{ Year Designed } & \multicolumn{2}{|c|}{ Bldg Height [stories] } \\
\cline { 4 - 7 } & & & Oldest & Newest & Shortest & Tallest \\
\hline \hline Box or Built-Up & 4 & 118 & 1975 & 1984 & 3 & 13 \\
\hline W8 & 4 & 22 & 1978 & 1978 & 3 & 3 \\
\hline W12/14 Group 3 & 22 & 171 & 1970 & 1991 & 1 & 17 \\
\hline W12/14 Group 4 & 25 & 446 & 1970 & 1993 & 3 & 27 \\
\hline W14 Group 5 & 4 & 67 & 1981 & 1988 & 2 & 27 \\
\hline W21/24/27 & 5 & 91 & 1979 & 1992 & 2 & 11 \\
\hline
\end{tabular}

Table 3-11. Summary of Survey Data by Exterior Column Type

\begin{tabular}{|c|c|c|c|c|c|c|c|}
\hline \multirow{2}{*}{$\begin{array}{l}\text { Typical } \\
\text { Girder }\end{array}$} & \multirow{2}{*}{$\begin{array}{l}\text { No of } \\
\text { Bldgs }\end{array}$} & \multirow[t]{2}{*}{ Flr-Frms } & \multicolumn{2}{|c|}{ Year Designed } & \multirow{2}{*}{$\begin{array}{c}\text { Min Bay } \\
\text { [m] }\end{array}$} & \multirow{2}{*}{$\begin{array}{c}\text { Avg Bay } \\
{[\mathrm{m}]}\end{array}$} & \multirow{2}{*}{$\begin{array}{c}\text { Max Bay } \\
\text { [m] }\end{array}$} \\
\hline & & & Oldest & Newest & & & \\
\hline W14/16 & 6 & 48 & 1978 & 1983 & 4.6 & 5.8 & 8.5 \\
\hline W18 & 9 & 46 & 1970 & 1990 & 3.7 & 6.1 & 12.2 \\
\hline W21 & 12 & 112 & 1970 & 1990 & 3.4 & 5.5 & 12.2 \\
\hline W24 & 23 & 135 & 1970 & 1992 & 4.0 & 7.0 & 10.4 \\
\hline W27 & 19 & 56 & 1970 & 1993 & 4.9 & 7.9 & 12.2 \\
\hline w30 & 20 & 106 & 1970 & 1992 & 4.0 & 7.6 & 12.8 \\
\hline W33 & 20 & 174 & 1970 & 1993 & 4.9 & 8.5 & 12.8 \\
\hline W36 & 30 & 533 & 1970 & 1993 & 4.6 & 7.9 & 14.0 \\
\hline
\end{tabular}

Table 3-12. Summary of Survey Data by Girder Size (WF girders only)

Clearly, sections from 610 to 914 millimeters ( 24 to 36 inches) deep are used in a variety of conditions. As for combinations of column and beam sizes, Table 3-13 shows the different typical beams found in combination with Group 4 W14 columns. The W36x150-230 beams are most common. 


\begin{tabular}{|c|c|c|}
\hline Typical Girder & $\begin{array}{l}\text { No of } \\
\text { Bldgs }\end{array}$ & $\begin{array}{l}\text { Fir- } \\
\text { Frms }\end{array}$ \\
\hline$W 14 \times 26$ & 3 & 13 \\
\hline W18 186 & 1 & 2 \\
\hline $\begin{array}{c}\text { W21x?, W24x?, } \\
\text { W27x? }\end{array}$ & 1 & 2 \\
\hline W21 250 & 2 & 17 \\
\hline$W 21 \times 83-W 24 \times 131$ & 1 & 1 \\
\hline $\begin{array}{l}\text { W24x146, } \\
W 33 \times 130\end{array}$ & 1 & 1 \\
\hline $\begin{array}{l}\text { W24x162, } \\
W 36 \times 135\end{array}$ & 1 & 1 \\
\hline W24x62 & 1 & 1 \\
\hline W24x68 & 1 & 1 \\
\hline W24x76 & 1 & 2 \\
\hline$W 27 \times 146$ & 2 & 6 \\
\hline W27x84 & 2 & 3 \\
\hline$W 27 \times 94$ & 2 & 2 \\
\hline W30x 108 & 3 & 3 \\
\hline $\begin{array}{l}\text { W30x108, } \\
W 30 \times 116\end{array}$ & 1 & 2 \\
\hline W30x116 & 1 & 2 \\
\hline W30x124 & 1 & 2 \\
\hline $\begin{array}{l}\text { W30x124, } \\
W 30 \times 132\end{array}$ & 1 & 4 \\
\hline W30x132 & 1 & 1 \\
\hline $\begin{array}{l}\text { W30x191, } \\
\text { W36 } 150\end{array}$ & 1 & 1 \\
\hline W30x99 & 3 & 11 \\
\hline W33 3118 & 4 & 11 \\
\hline
\end{tabular}

\begin{tabular}{|c|c|c|}
\hline Typical Girder & $\begin{array}{l}\text { No of } \\
\text { Bldgs }\end{array}$ & $\begin{array}{c}\text { Frr- } \\
\text { Frms }\end{array}$ \\
\hline W33x130 & 1 & 4 \\
\hline W33x141 & 2 & 2 \\
\hline W33x152 & 3 & 11 \\
\hline W33x201 & 2 & 5 \\
\hline W33-221 & 1 & 2 \\
\hline W33×241 & 2 & 12 \\
\hline W33x280 & 1 & 3 \\
\hline W36 135 & 3 & 5 \\
\hline $\mathrm{W} 36 \times 150$ & 6 & 45 \\
\hline W36 160 & 4 & 24 \\
\hline W36 170 & 8 & 37 \\
\hline W36x182 & 6 & 35 \\
\hline W36x194 & 8 & 46 \\
\hline $\begin{array}{c}\text { W36x194, } \\
\text { BU36 }\end{array}$ & 1 & 1 \\
\hline $\begin{array}{c}\text { W36x194, } \\
\text { BU48 }\end{array}$ & 1 & 1 \\
\hline $\mathrm{W} 36 \times 210$ & 5 & 48 \\
\hline W36 $\times 230$ & 8 & 51 \\
\hline$W 36 \times 245$ & 4 & 24 \\
\hline W36x260 & 4 & 12 \\
\hline W36×280 & 3 & 8 \\
\hline W36 300 & 1 & 6 \\
\hline & & \\
\hline
\end{tabular}

Table 3-13. Surveyed Girder Types with Group 4 W14 Columns

Table 3-14 shows the data distribution for different web connection types. The correlation with age is clear: the oldest buildings have all-welded beam webs, the newest have bolted webs with supplemental welds as required by the UBC since 1988, and most of the surveyed

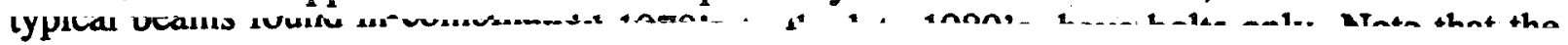
are most common. 
recent buildings with WB type connections generally have supplemental welds only where required by Code, that is at the lightest sections within each beam depth group.

\begin{tabular}{|c|c|c|c|c|}
\hline \multirow{2}{*}{$\begin{array}{c}\text { Web Conn } \\
\text { Type }\end{array}$} & \multirow{2}{*}{ No of Bldgs } & \multirow{2}{*}{ Fir-Frms } & \multicolumn{2}{|c|}{ Year Designed } \\
\cline { 4 - 5 } & & & Oldest & Newest \\
\hline B & 37 & 1027 & 1975 & 1990 \\
\hline Unknown & 2 & 26 & 1989 & 1989 \\
\hline W & 4 & 35 & 1965 & 1970 \\
\hline WB & 8 & 202 & 1988 & 1993 \\
\hline
\end{tabular}

Table 3-14. Summary of Survey Data by Beam Web Connection Type

\begin{tabular}{|c|c|c|c|c|}
\hline \multirow{2}{*}{$\begin{array}{c}\text { Flange Weld } \\
\text { Process }\end{array}$} & \multirow{2}{*}{ No of Bldgs } & \multicolumn{2}{|c|}{ Year Designed } & \multirow{2}{*}{$\begin{array}{c}\text { Fr- } \\
\text { Frms }\end{array}$} \\
\cline { 3 - 4 } & & Oldest & Newest & \\
\hline \hline FCAW & 8 & 1965 & 1993 & 389 \\
\hline SMAW & 6 & 1978 & 1990 & 83 \\
\hline SMAW? & 3 & 1984 & 1990 & 86 \\
\hline Unknown & 34 & 1969 & 1992 & 732 \\
\hline
\end{tabular}

Table 3-15. Summary of Survey Data by Girder Flange Weld Process

Table 3-15 shows the data distribution for different beam flange weld processes. Because weld processes are frequently not shown on structural drawings, 34 of the 51 survey responses either did not report a weld process or reported it as unknown. 


\subsection{Characterizing the Damage}

\subsection{Damage Classes and Types}

The survey form described MRF connection damage with 24 different types, as shown in Figures 4-1 through 4-3. For reporting purposes, beam flange, column flange, and weld damage were further identified as occurring at either the top or bottom of the connection. (See Abbreviations and Definitions for damage class abbreviations.) In addition, narrative descriptions of non-structural damage and non-MRF structural damage were provided, and overall structural damage in each building was categorized by the survey engineers as None, Isolated, or Widespread. These descriptions are given for each building in Appendix A.

\subsubsection{Incipient Root Cracks (Type W1)}

The most commonly observed damage was in bottom flange welds (class BW), and a large portion of these conditions are small or incipient root cracks detected by UT (type W1). No descriptions or definitions beyond those in Figure 4-3 were provided to the survey engineers. Instead, many survey engineers relied on definitions provided by their testing lab, examples of which are given in Appendix C. Although procedures and acceptance criteria became more detailed and standardized as more buildings were inspected, UT results for many buildings were submitted without complete descriptions of the testing scope and findings.

If low rejection rates are achieved initially, a large project can have up to $75 \%$ of its flange welds not UT'd during construction; if rejectable welds exist, they may not be found. And, as discussed previously, UT procedures call for significant judgement, which may err on the unconservative side during construction but on the conservative side during post-earthquake inspections. Consequently, there is some question as to how many root discontinuities and rejectable welds were actually caused by the earthquake. For the survey, some engineers reported all discontinuity signals as W1 damage, even if they would normally be acceptable for new construction, on the theory that they could be "small root tears" worth investigating further (see Appendix C). Others reported only rejectable conditions. Still others reported only conditions clearly identified as earthquake damage. (Note that the typical standard for ultrasonic testing of welds, AWS D1.1 Chapter 8, is primarily intended to check workmanship, not "fitness for purpose.")

Because this damage type was so prevalent and variously defined, and because damage statistics are reported here by class not type, it was necessary to distinguish W1 conditions from other weld damage. To do this, the survey form asked survey engineers to estimate the percentage of all weld damage considered to be type W1. Although definitions of W1 "damage" varied among the many survey engineers, the amount of definite weld damage caused by the earthquake can be approximated by multiplying the number of floor frames in damage classes for top weld (TW) damage or bottom weld (BW) damage by the factor (1-WDR), where WDR is the weld damage ratio. This approach was used for computing damage scores. 


\section{SURVEY OF}

\section{STEEL MRF BUILDINGS}

AFFECTED BY THE JANUARY 1994 NORTHRIDGE EARTHQUAKE

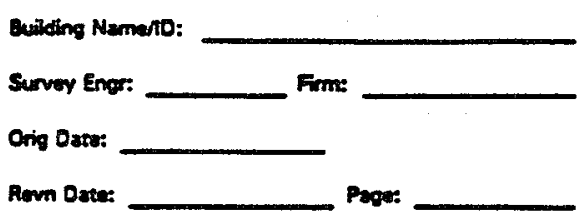

SECTION $V$ continued

REFERENCE SCHEDULE OF DAMAGE TYPES (See Reference Details below for piczorial deseription.)

$\mathbf{6}$

GIRDER DAMAGE
G1 buckled flange
G2 yielded flange
G3 flange tearout near weld
G4 flange crack outside HAZ

CF

COLUMN FLANGE DAMAGE

C1 incipient flange crack (dotected by UT)

C2 complete flange tearout or divot

C3 full or portial cross-fiange crack in HAZ

C4 tull or parial cross-flange crack outsida HAZ

C5 lamellar fiange tearing

W Flange Weld DAMAGE

W1 incipient crack, especially at weld root ldetected by UM

W2 crack through weld metal, full or partial width of flange

W3 tracture at girder interface

W4 fracture at column intertace

S SHEAR CONNECTION DAMAGE

S1 column to web of column to shear tab weld erack

S2 wab to shear tab supplemental weld erack

S3 web or shear tab crack, especially through bolt holes

S4 wob or shear tab deformation, especially at holes.

S5 loose, damaged, of missing bolzs; faying surfaces out of contact

PZ PANE ZONE DAMAGE

P1 fracture, buekJe, or yield of eontinuity plate

P2 erack in continuity plate welds

P3 buckle, yield, or ductile deformation of doubler plate or column web

P4 crack in doubler plate welds

CW COLUMN WEB DAMAGE

P5 partial depth crack in eolumn web or doubler plate lextension of C3 or C4)

P6 full or near full depth crack in column web or doubler plate

Figure 4-1. Survey Form Damage Types

(See Appendix B) 


\section{SURVEY OF}

STEEL MRF BUILDINGS

AFFECTED BY THE JANUARY 1994 NORTHRIDGE EARTHQUAKE
Euiting Namano:

Survey Enor: Fim:

Oris Daxe:

Am Dere: Pape:

SECTION $V$ continued

REFERENCE DETAIL (See Referenca Schedule above for damage type descriptions.)

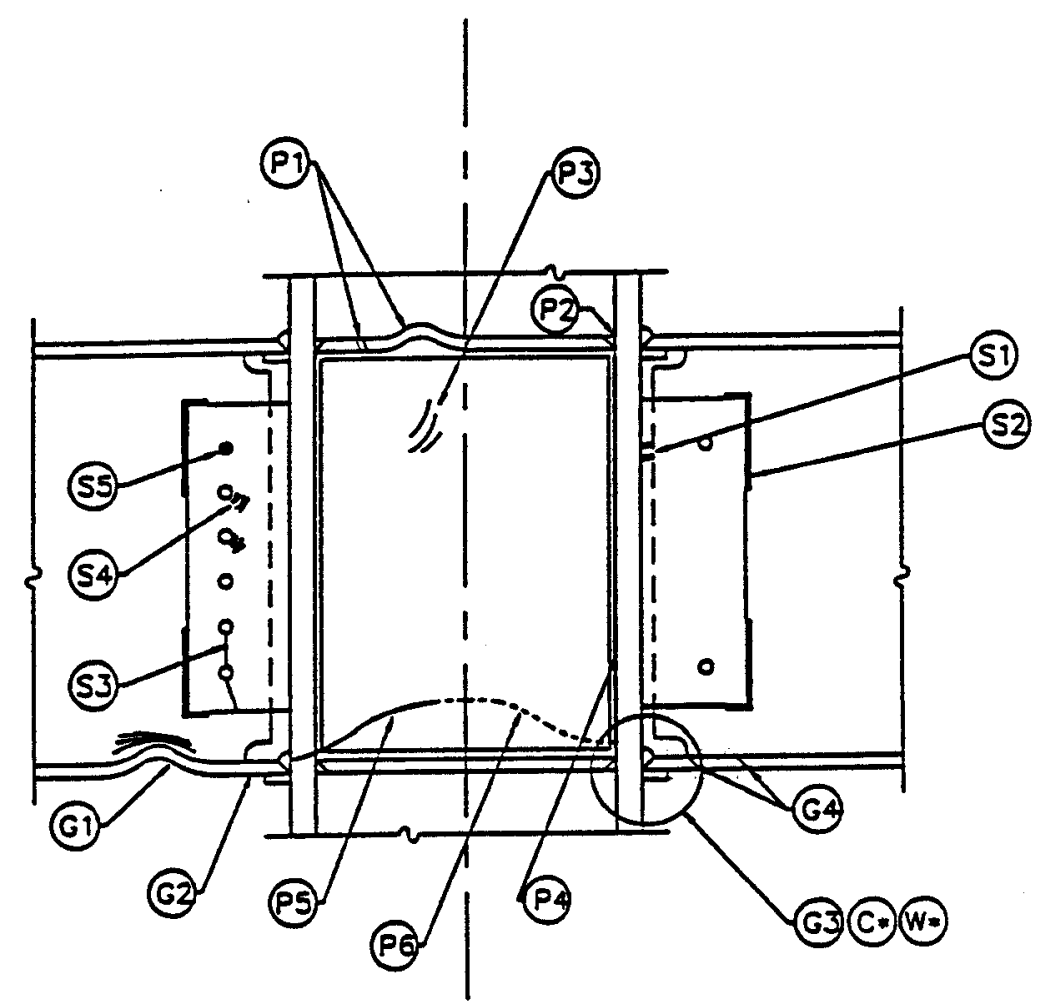

REFERENCE DETAIL: MRF JOINT DAMAGE TYPES

NOTE: SEE REFERENCE SCHEDULE FOR DESCRIPTION

Figure 4-2. Survey Form Damage Types

(See Appendix B) 
SURVEY OF

STEEL MRF BUILDINGS

AFFECTED BY THE JANUARY 1994 NORTHRIDGE EARTHQUAKE

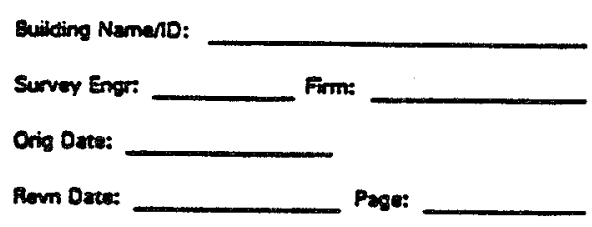

Building Nameno.

Surver Engr:

Orig Date:

Rom Dore: Page:

SECTION $V$ continued

REFERENCE DETAlL (See Reference Schedule above for damage type descriptions.)

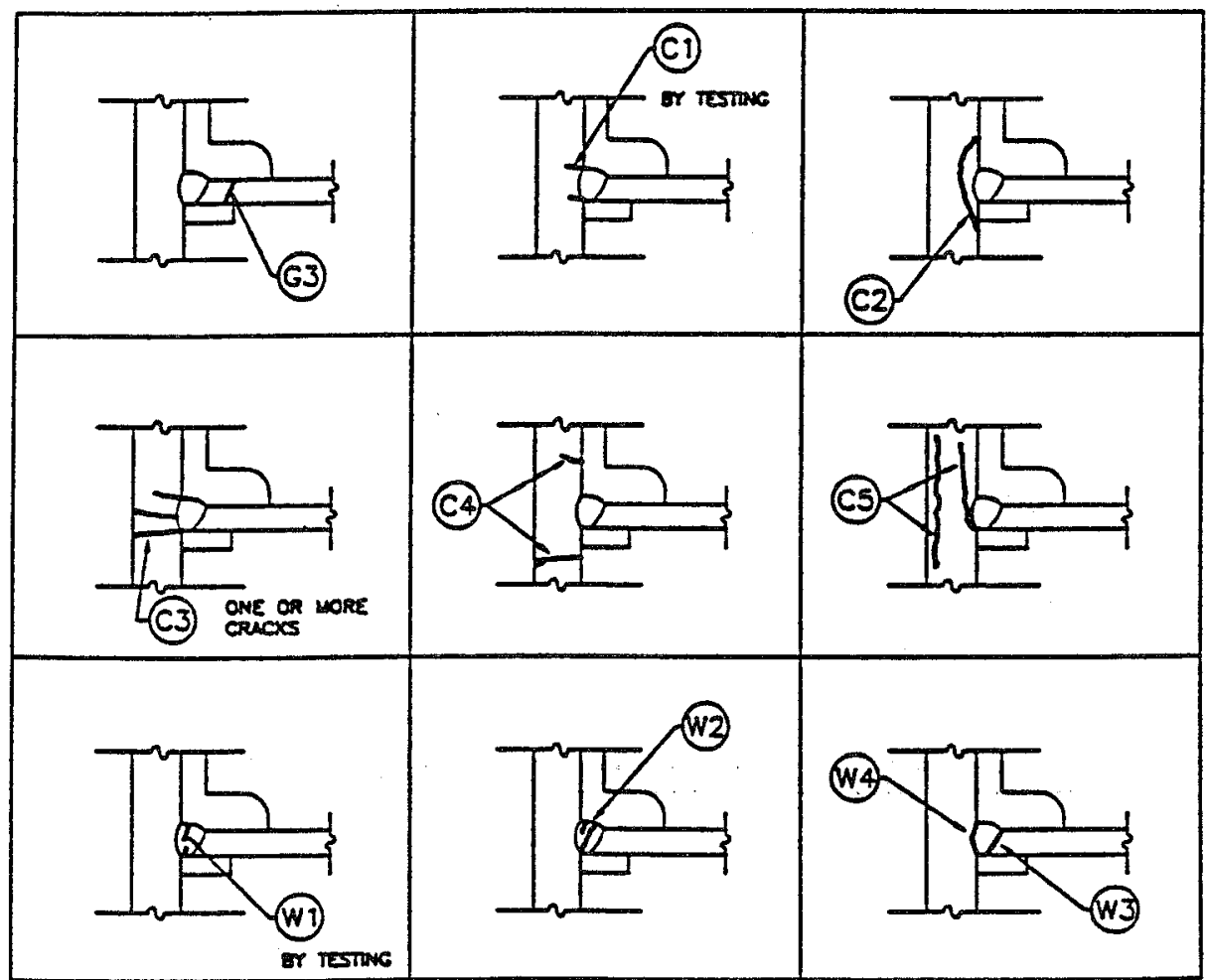

REFERENCE DETAIL: MRF DAMAGE TYPES

NOTE: SEE REFERENCE SCHEDULE FOR DESCRIPTION

Figure 4-3. Survey Form Damage Types

(See Appendix B) 


\subsubsection{Fusion Zone Damage (Types W4 and C5)}

The survey damage types shown in Figures 4-1 through 4-3 were grouped into classes according to the part of the connection most affected. Damage types W3 and W4 occur at the interface of weld and parent metal. These types were grouped with class $\mathrm{W}$ because damage at the weld interface is generally considered a function of inadequate welds, specifically poor fusion resulting from insufficient preheat or poor workmanship.

If damage near the interface is not visible, it is difficult to distinguish clearly by UT whether a crack occurs in the weld or parent metal. Consequently, damage types W4 and C5 can be confused with each other. In some cases, damage type C2, a tear in the parent material, can also be confused or combined with type W4 or C5. Different survey engineers may have reported this kind of damage differently; some reported uncertain or combined types as damage to both weld and column. For survey purposes, this may affect damage statistics compiled by class, as W4 and C5 damage are in different classes. However, the net effect on conclusions drawn is not expected to be significant.

\subsubsection{Damage Class Combinations}

Some damage classes always appear to occur together in the same connection. However, because the survey reports damage in each floor-frame, not each connection, these combinations cannot be quantitatively confirmed. The related damage classes include:

- Top weld (TW) damage occurs in 213 floor-frames in 25 buildings. About $75 \%$ of those floor-frames also have bottom weld (BW) damage. TW occurs by itself in only 48 floor-frames in six buildings.

- Shear (S) damage occurs in 44 floor-frames, always in combination with either bottom weld (BW) damage or bottom column flange (BC) damage, and about half the time with both.

- Column web (CW) damage, as expected, always occurs in combination with column flange cracking. In 46 of 47 cases, the crack is at the bottom of the connection. In 33 floor-frames, column web (CW) damage was observed without damage to the shear connection.

\subsection{Damage Distributions}

Table 4-1 summarizes the number of inspected floor-frames with each class of damage in each building. The buildings are listed by zone for comparison with Table 3-1. Table 4-2 summarizes the incidences of damage, showing the number of buildings and floor-frames in which each class was found at least once, as well as the range of conditions in which each class is represented. Clearly, each damage class is represented in buildings of various ages and heights and in frames with various numbers of bays and bay widths. 


\begin{tabular}{|c|c|c|c|c|c|c|c|c|c|c|c|c|c|}
\hline \multirow{2}{*}{$\begin{array}{l}\text { Building } \\
\text { ID }\end{array}$} & \multirow[t]{2}{*}{ Zone } & \multirow[t]{2}{*}{ WDR } & \multirow[t]{2}{*}{ Flr-Frms } & \multicolumn{9}{|c|}{ Damage Class } & \multirow{2}{*}{$\begin{array}{c}\text { Damage } \\
\text { Score }\end{array}$} \\
\hline & & & & TG & BG & $\mathbf{T C}$ & $\mathrm{BC}$ & TW & BW & $\mathbf{s}$ & $\mathbf{P Z}$ & $\mathrm{CW}$ & \\
\hline DM1 & LAX & & 5 & 0 & 0 & 0 & 0 & 0 & 0 & 0 & 0 & 0 & 0.00 \\
\hline SOM1 & MW & 1.00 & 9 & & 0 & & 0 & & 6 & 0 & 0 & 0 & 0.33 \\
\hline BJ05 & NR & 0.70 & 55 & 0 & 0 & 1 & 15 & 3 & 35 & 0 & 0 & 0 & 1.10 \\
\hline BJ06 & NR & 0.75 & 12 & 0 & 0 & 0 & 3 & 1 & 9 & 2 & 0 & 3 & 2.21 \\
\hline LCIB & NR & 0.05 & 3 & 0 & 4 & 0 & 12 & 9 & 13 & 2 & 1 & 4 & \\
\hline LCIE & NR & 0.00 & 9 & 0 & 0 & 0 & 6 & 2 & 13 & 0 & 1 & 3 & \\
\hline EQE1 & SC & 0.00 & 16 & 0 & 4 & 0 & 16 & 0 & 0 & 8 & 0 & 7 & 4.31 \\
\hline EQE2 & SC & 0.00 & 6 & 0 & 0 & 0 & 5 & 0 & 0 & 0 & 0 & 5 & 4.17 \\
\hline KPFF1A & SC & 0.60 & 4 & 0 & 1 & 0 & 0 & 0 & 3 & 0 & 0 & 0 & 0.68 \\
\hline BJ01 & SM & 0.90 & 23 & 0 & 3 & 1 & 4 & 11 & 21 & 2 & 0 & 0 & 1.36 \\
\hline ESI2 & SM & 0.00 & 1 & 0 & 0 & & 1 & & 0 & 0 & 0 & 1 & 5.00 \\
\hline ESI5 & SM & 0.30 & 46 & 0 & 0 & 0 & 11 & 34 & 44 & 0 & 0 & 0 & 2.51 \\
\hline BAK & so & 0.00 & 12 & 0 & 0 & 0 & 0 & & 10 & 0 & 0 & 0 & 1.25 \\
\hline BJ04 & So & 0.30 & 16 & 0 & 0 & 0 & 1 & 1 & 14 & 0 & 0 & 0 & 1.25 \\
\hline ESI7 & so & 0.00 & 13 & 0 & 0 & 0 & 0 & 0 & 3 & 2 & 0 & 0 & 0.65 \\
\hline JAM7482 & so & 0.50 & 28 & 0 & 0 & 2 & 6 & 8 & 16 & 0 & 0 & 1 & 1.39 \\
\hline JAM7484 & so & 0.50 & 20 & 0 & 0 & 1 & 3 & 15 & 16 & 4 & 0 & 1 & 2.40 \\
\hline JAM7487 & So & 1.00 & 41 & 0 & 0 & 0 & 1 & 0 & 11 & 0 & 0 & 0 & 0.18 \\
\hline JAM7489 & so & & 7 & 0 & 0 & 0 & 0 & 0 & 0 & 0 & 0 & 0 & 0.00 \\
\hline KAR3 & so & 0.00 & 3 & 0 & 0 & 0 & 3 & 0 & 0 & 0 & 0 & 0 & 2.00 \\
\hline MNHO4 & so & & 12 & 0 & 0 & 0 & 0 & 0 & 0 & 0 & 0 & 0 & 0.00 \\
\hline NYA550 & So & 1.00 & 15 & 0 & 0 & 0 & 0 & 0 & 4 & 0 & 0 & 0 & 0.13 \\
\hline SOA & so & 0.00 & 22 & 0 & 3 & 0 & 8 & 1 & 9 & 6 & 0 & 0 & 1.95 \\
\hline BJ02E & UC & 0.50 & 27 & 0 & 0 & 1 & 16 & 11 & 23 & 4 & 7 & 5 & 3.30 \\
\hline ESI3 & UC & 1.00 & 1 & 0 & 0 & 0 & 1 & 0 & 1 & 1 & 0 & $\mathbf{0}$ & 4.50 \\
\hline WEA & UC & 0.00 & 24 & 0 & 0 & 0 & 5 & 2 & 6 & 0 & 0 & 5 & 1.54 \\
\hline BJ09 & WH & 0.90 & 50 & 0 & 0 & 0 & 1 & 1 & 18 & 0 & 0 & 0 & 0.27 \\
\hline
\end{tabular}

Table 4-1. Summary of Surveyed Damage By Building: Aggregate Damage Score \& Number of Floor-Frames in Each Damage Class 


\begin{tabular}{|c|c|c|c|c|c|c|c|c|c|c|c|c|c|}
\hline \multirow[t]{2}{*}{ Building ID } & \multirow[t]{2}{*}{ Zone } & \multirow[t]{2}{*}{ WDR } & \multirow[t]{2}{*}{ Flr-Frms } & \multicolumn{9}{|c|}{ Damage Class } & \multirow{2}{*}{$\begin{array}{l}\text { Damage } \\
\text { Score }\end{array}$} \\
\hline & & & & TG & BG & $\mathbf{T C}$ & BC & TW & BW & $\mathbf{S}$ & $\mathbf{P Z}$ & $\mathbf{C W}$ & \\
\hline $\mathrm{BJ} 10$ & WH & & 13 & 0 & 0 & 0 & 0 & 0 & 0 & 0 & 0 & 0 & 0.00 \\
\hline BJ 11 & WH & 1.00 & 26 & 0 & 0 & 2 & 7 & 8 & 15 & 0 & 0 & $\mathbf{0}$ & 0.98 \\
\hline BJ18 & WH & 0.75 & 24 & 0 & 0 & 0 & 2 & 1 & 14 & 0 & 0 & 0 & 0.64 \\
\hline ES18 & WH & 0.80 & 216 & 0 & 0 & 0 & 0 & 74 & 77 & 0 & 0 & $\mathbf{0}$ & 0.49 \\
\hline KAR2 & WH & 0.20 & 12 & 0 & 1 & 0 & 7 & 0 & 6 & 0 & 2 & 6 & 3.32 \\
\hline MNH02 & WH & 0.75 & 16 & 0 & 0 & 0 & 4 & 0 & 9 & 0 & 4 & 4 & 1.67 \\
\hline NYA539 & WH & 1.00 & 14 & 0 & 0 & 0 & 0 & 6 & 13 & 0 & 0 & 0 & 0.68 \\
\hline NYA544 & WH & 0.50 & 56 & 5 & 9 & 0 & 9 & 0 & 25 & 9 & 0 & 0 & 1.09 \\
\hline WJE1 & WH & 0.00 & 68 & 0 & 0 & 0 & 6 & 0 & 13 & 0 & 0 & 0 & 0.46 \\
\hline $\mathrm{ACl}$ & WLA & 0.00 & 19 & 0 & 1 & 0 & 2 & 0 & 16 & 0 & 0 & 0 & 1.47 \\
\hline ESI1 & WLA & 0.00 & 50 & 0 & 0 & 0 & 3 & 1 & 7 & 2 & 0 & 0 & 0.44 \\
\hline ESI4 & WLA & 0.10 & 10 & 0 & 0 & 0 & 0 & 5 & 6 & 0 & 0 & 0 & 1.54 \\
\hline FE1 & WLA & & 4 & 0 & 0 & 0 & 0 & 0 & 0 & 0 & 0 & 0 & 0.00 \\
\hline JAM7480 & WLA & 0.33 & 14 & 0 & 0 & 1 & 9 & 2 & 12 & 1 & 0 & 1 & 2.81 \\
\hline JAM7485 & WLA & 0.40 & 25 & 0 & 0 & 0 & 9 & 11 & 17 & 1 & 0 & $\mathbf{0}$ & 2.03 \\
\hline JAM7486 & WLA & 1.00 & 44 & 0 & 0 & 0 & 0 & 1 & 9 & 0 & 0 & 0 & 0.11 \\
\hline $\mathrm{MNH} 03 \mathrm{AB}$ & WLA & 0.00 & 38 & 0 & 0 & 0 & 0 & 2 & 5 & 0 & 0 & 0 & 0.28 \\
\hline MNH03CDE & WLA & 0.00 & 77 & 0 & 0 & 0 & 1 & 0 & 8 & 0 & 0 & 1 & 0.22 \\
\hline MNH03F & WLA & 0.00 & 17 & 0 & 0 & 0 & 0 & 0 & 3 & 0 & 0 & $\mathbf{0}$ & 0.26 \\
\hline MNH03G & WLA & 0.00 & 12 & 0 & 0 & 0 & 0 & 0 & 1 & 0 & 0 & 0 & 0.13 \\
\hline MNH03H & WLA & 0.00 & 9 & 0 & 0 & 0 & 0 & 0 & 0 & 0 & 0 & 0 & 0.00 \\
\hline NYA577 & WLA & 1.00 & 20 & 0 & 0 & 0 & 0 & 2 & 19 & 0 & 0 & 0 & 0.53 \\
\hline NYA591 & WLA & 1.00 & 16 & 0 & 0 & 0 & 0 & 1 & 2 & 0 & 0 & $\mathbf{0}$ & 0.09 \\
\hline NYA592 & WLA & & 10 & 0 & 0 & 0 & $\mathbf{0}$ & 0 & 0 & 0 & 0 & 0 & 0.00 \\
\hline
\end{tabular}

Table 4-1. Summary of Surveyed Damage By Building: Aggregate Damage Score \& Number of Floor-Frames in Each Damage Class (Continued) 


\subsubsection{Damage Score}

The final column of Table 4-1 gives a rough damage "score" for each building. The ratios of damaged floor-frames to inspected floor-frames for the most common damage classes are weighted and summed as follows ( $F F=$ total inspected/tested floor-frames):

$\begin{array}{rlr}\text { Damage Score }= & (\mathrm{TW}+\mathrm{BW}) / \mathrm{FF} & \times 0.5 \\ & +(\mathrm{TW}+\mathrm{BW})(1-\mathrm{WDR}) / \mathrm{FF} & \times 1.0 \\ & +\mathrm{S} / \mathrm{FF} & \times 2.0 \\ & +\mathrm{BC} / \mathrm{FF} & \times 2.0 \\ & +\mathrm{CW} / \mathrm{FF} & \times 3.0\end{array}$

Thus, a single floor-frame with no damage would score 0 ; with only incipient root cracking in bottom welds, 0.5 ; with complete bottom weld fracture only, 1.5 ; with incidences of all five of the most common damage classes, 10. For groups of floor-frames, the score reflects the ratios of damaged to inspected floor-frames, so that a building with widespread weld damage can score higher than one with isolated flange tears. Note that this scoring system takes no account of the number of inspected, tested, or damaged connections within a single floor-frame, nor the number of inspected floor-frames within a single frame. In particular, because data is available only for individual floor-frames, not individual connections, comparison of scores for different groups of floor-frames is only valid for sufficiently large groups. (See Section 3.2.5 regarding completeness of responses.) Also, note that the effective weights for shear $(S)$ and column web (CW) damage are actually higher than they appear because shear $(S)$ and column web $(\mathrm{CW})$ damage always occur in combination with other classes, as noted above.

This scoring of observed damage is tentative, experimental, and intended only as a check on conclusions drawn from raw numbers of damaged floor-frames. The weights are based on engineering judgement as to the relative severity, structural and financial, of each damage class. Different weights may be equally valid. No study of statistical sensitivity has been made.

Damage scores for each building are given in Table 4-1. The scores for buildings LCIB and LCIE must be ignored, as their surveys reported damage for each frame type, not for each floor-frame. As shown in Table 4-1, the minimum score is 0 , while the maximum is 5.0, reflecting the small number of inspected floor-frames in building ESI2. Among buildings with six or more inspected floor-frames (for example a 3-story building with one frame inspected in each direction), the minimum score is 0 , while the maximum is 4.31 .

Excluding LCIB and LCIE, the aggregate score for buildings with six or more inspected floor-frames is 0.98 , or approximately 1.0 , using a survey-wide average WDR of 0.50 . The mean score for this subset of 43 buildings is 1.15 , or rounded to 1.2 , and the standard deviation is 1.14 . Thus, any sufficiently large group of floor-frames with an aggregate damage score greater than $1.15+1.14=2.29$, or roughly 2.3 , has significantly more than average damage. Seven of the 43 "well-inspected" buildings meet this criterion. 


\subsubsection{Damage Ratios}

Damage ratio, expressed in decimal or percentage form, is used here to mean the simple ratio of damaged floor-frames (or buildings) to total floor-frames (or buildings). From either a building or floor-frame perspective, the most common damage is seen from Table 4-2 to be in beam flange welds (classes TW and BW). Compared to the next most common damage class, column flange tearing, weld damage was observed in three times as many floor-

\begin{tabular}{|c|c|c|c|c|c|c|c|c|c|c|}
\hline \multirow{2}{*}{$\begin{array}{c}\text { Damage } \\
\text { Class }\end{array}$} & \multirow{2}{*}{$\begin{array}{l}\text { No of } \\
\text { Bldgs }\end{array}$} & \multirow{2}{*}{$\begin{array}{l}\text { Frr- } \\
\text { Frms }\end{array}$} & \multicolumn{2}{|c|}{ Year Designed } & \multicolumn{2}{|c|}{ Bldg Ht [stories] } & \multirow{2}{*}{$\begin{array}{c}\text { Min \# } \\
\text { Bays }\end{array}$} & \multirow{2}{*}{$\begin{array}{c}\text { Max \# } \\
\text { Bays }\end{array}$} & \multirow{2}{*}{$\begin{array}{c}\text { Min Bay } \\
\text { Width[m] }\end{array}$} & \multirow{2}{*}{$\begin{array}{l}\text { Max Bay } \\
\text { Width[m] }\end{array}$} \\
\hline & & & Oldest & Newest & Shortest & Tallest & & & & \\
\hline Full Survey & 51 & 1290 & 1966 & 1994 & 1 & 28 & 1 & 11 & 3.4 & 14.0 \\
\hline TG & 1 & 5 & 1976 & 1976 & 13 & 13 & 5 & 5 & 9.8 & 9.8 \\
\hline BG & 8 & 26 & 1976 & 1994 & 2 & 13 & 2 & 5 & 4.0 & 9.8 \\
\hline TC & 7 & 9 & 1984 & 1994 & 3 & 11 & 1 & 4 & 5.2 & 11.9 \\
\hline $\mathrm{BC}$ & 30 & 177 & 1976 & 1994 & 1 & 18 & 1 & 7 & 3.4 & 14.0 \\
\hline TW & 25 & 213 & 1970 & 1994 & 2 & 28 & 1 & 11 & 3.4 & 14.0 \\
\hline BW & 40 & 552 & 1970 & 1994 & 2 & 28 & 1 & 11 & 3.4 & 14.0 \\
\hline $\mathbf{S}$ & 13 & 44 & 1976 & 1994 & 2 & 13 & 1 & 6 & 4.0 & 12.2 \\
\hline PZ & 5 & 15 & 1985 & 1994 & 3 & 4 & 2 & 4 & 5.5 & 10.4 \\
\hline CW & 14 & 47 & 1979 & 1994 & 1 & 11 & 1 & 6 & 3.4 & 11.9 \\
\hline Any Damage & 44 & 629 & 1970 & 1994 & 1 & 28 & 1 & 11 & 3.4 & 14.0 \\
\hline No Damage & 45 & 661 & 1966 & 1994 & 1 & 28 & 1 & 11 & 3.4 & 14.0 \\
\hline Weld Only & 36 & 426 & 1970 & 1994 & 2 & 28 & 1 & 11 & 3.4 & 14.0 \\
\hline$>$ Weld Only & 32 & 186 & 1976 & 1994 & 1 & 18 & 1 & 7 & 3.4 & 14.0 \\
\hline
\end{tabular}

Table 4-2. Summary of Surveyed Damage by Class

frames. About $41 \%$ of all inspected floor-frames had some bottom weld (BW) damage, and about $17 \%$ reported top weld (TW) damage, although Table 4-1 suggests that perhaps half or more of this is incipient root cracking only. Cracking or tearing in the column flange at the bottom of the connection (class BC) also occurs in about $12 \%$ of inspected floor frames. Column flange cracks extended into the column web (class $\mathrm{CW}$ ) in 47 floor-frames in 14 different surveyed buildings. The other damage types appear in far fewer floor-frames and buildings. Top beam and top column flange damage is reported most rarely; this may be due in part to limited access to the top surface of the beam top flange. 
The damage classes labeled "No Damage" and "Weld Only" in Table 4-2 require some explanation. First, note that the "No Damage" statistics include floor-frames which may have been only minimally inspected - perhaps only one or two connections cleaned. With more complete inspection, some damage may be found. (Of the 661 undamaged floor-frames, 471 had at least half of their connections visually inspected or at least a quarter of them UT'd.) Second, the number of buildings in these two categories indicates the number in which at least one floor-frame had no damage or only weld damage. However, the number of buildings with no damage or only weld damage in the entire building can be derived from the table:
No. of buildings surveyed:
51
No. with any damage:
$44(86 \%)$
No. with no damage at all: $\quad 51-44=7(14 \%)$
No. with more than weld damage:
$32(63 \%)$
No. with weld damage only:
$44-32=$
$12(24 \%)$

On a floor-frame basis, the corresponding totals are taken directly from Table 4-2:
No. of floor-frames surveyed:
1290
No. with any damage:
$629(49 \%)$
No. with no damage:
$661(51 \%)$
No. with more than weld damage:
$186(14 \%)$
No. with weld damage only:
$426(33 \%)$

Discounting minor weld damage, the percentage of buildings with serious damage can be estimated as $63 \%$ with more than weld damage plus half (1-WDR using survey-wide average WDR of 0.50 ) of the $24 \%$ with weld damage only, or a total of $75 \%$. Similarly, the percentage of floor frames with no serious damage can be estimated by taking $51 \%$ with no damage plus half of the $33 \%$ with weld damage only, or $67 \%$. Thus, while most buildings (75\%) had serious damage to welds or parent metal, most individual floor-frames $(67 \%)$ did not. Another way of stating this is that only 33\% (100\%-67\%) of floor frames had serious damage. And, because a damaged floor-frame can have several undamaged connections, it stands to reason that fewer that $33 \%$ of individual connections would have serious damage. (A database of individual connections, as opposed to floor-frames, would establish this percentage more reliably.)

This limited data suggests that damage estimates and reliability analyses can assume a worst case loss of about $33 \%$ of all MRF connections. In other words, an owner or engineer assessing a typical but as yet uninspected MRF in West L.A. (for example) can reasonably assume that no more than $30 \%$ of the building's connections are damaged and can plan inspections or changes in building use accordingly. Of course, this percentage must be tempered by the influences of various site and design factors discussed below. Furthermore, a reliability analysis must consider the likelihood that within a single floor-frame the loss of one connection may trigger damage in its neighbors, leading to the functional loss of the entire floor-frame. Such a study is beyond the scope of this survey. 


\subsubsection{No Damage}

Table 4-3 isolates the seven buildings with no damage at all. Only four zones are represented, but they are the zones furthest from the epicenter and with the largest number of surveyed buildings. It is noteworthy that every zone with more than four surveyed buildings has at least one building with no damage. Recalling that the overall survey sample (as of October, 1994) probably represents the worst conditions within the MRF population, this suggests that broader inspection will reveal more and more buildings with limited or no damage. On the other hand, some of the buildings in Table 4-3 were only minimally inspected; although the survey data is not conclusive (see Section 5.3), it is reasonable to expect that more complete inspection could reveal more damage.

\begin{tabular}{|c|l|c|c|c|c|c|c|c|}
\hline Building ID & Zone & $\begin{array}{c}\text { Year } \\
\text { Designed }\end{array}$ & $\begin{array}{c}\text { MRF } \\
\text { Stories }\end{array}$ & $\begin{array}{c}\text { Upper Floor } \\
\text { Area [m²] }\end{array}$ & $\begin{array}{c}\text { Floor } \\
\text { Const }\end{array}$ & Fir-Frms & $\begin{array}{c}\text { Insp'd } \\
\text { Conns }\end{array}$ & $\begin{array}{c}\text { Tested } \\
\text { Conns }\end{array}$ \\
\hline DM1 & LAX & 1970 & 15 & 2,000 & MC & 5 & 13 & 13 \\
\hline JAM7489 & SO & 1979 & 6 & 2,000 & MCL & 7 & 8 & 8 \\
\hline MNH04 & SO & 1981 & 6 & 3,000 & MCL & 12 & 31 & 31 \\
\hline BJ10 & WH & 1990 & 5 & 4,600 & MCL & 13 & 35 & 35 \\
\hline FE1 & WLA & 1965 & 17 & 2,100 & MC & 4 & 12 & 12 \\
\hline MNH03H & WLA & 1978 & 3 & 700 & W & 9 & 32 & 0 \\
\hline NYA592 & WLA & 1969 & 20 & 2,300 & LC & 10 & 10 & 10 \\
\hline
\end{tabular}

Table 4-3. Surveyed Buildings with No Damage

\subsubsection{Weld Damage Only}

Table 4-4 isolates the twelve buildings with weld damage only. As with the undamaged buildings, this subset represents a range of locations, ages, sizes, and materials. Again, note that each of the most-represented zones has buildings with weld damage only. Two of these buildings, BAK and ESI4, have weld damage so widespread that their damage scores approach those of buildings with more serious fractures.

\subsubsection{Column Web Damage}

Table 4-5 isolates the 12 buildings with the most serious damage: fracture through the column flange into the column web. (Buildings LCIB and LCIE also have column web (CW) damage but are not included here because of incompatible survey data.) Only the two zones furthest from Northridge, each of which has only one surveyed building, are not represented. The range of building ages and heights appears more narrow for these buildings, all of which are post-1978, and all but one of which is less than six stories. (However, note that BJO2E is 


\begin{tabular}{|c|c|c|c|c|c|c|c|c|c|c|c|c|}
\hline Building ID & Zone & $\begin{array}{c}\text { Year } \\
\text { Des'd }\end{array}$ & $\begin{array}{c}\text { MRF } \\
\text { Stories }\end{array}$ & $\begin{array}{c}\text { Upper Frr } \\
\text { Area [m }\end{array}$ & $\begin{array}{c}\text { Flr } \\
\text { Cnst }\end{array}$ & $\begin{array}{c}\text { Column } \\
\text { Steel }\end{array}$ & $\begin{array}{c}\text { Beam } \\
\text { Steel }\end{array}$ & WDR & $\begin{array}{c}\text { Fir- } \\
\text { Frms }\end{array}$ & TW & BW & $\begin{array}{c}\text { Damage } \\
\text { Score }\end{array}$ \\
\hline SOM1 & MW & 1986 & 4 & 1,700 & W & A36 & A36 & 1.00 & 9 & & 6 & 0.33 \\
\hline BAK & SO & 1982 & 6 & 1,900 & MCL & A572-Gr50 & A36 & 0.00 & 12 & & 10 & 1.25 \\
\hline NYA550 & SO & 1985 & 6 & 2,000 & MCL & A572-A36 & A36 & 1.00 & 15 & 0 & 4 & 0.13 \\
\hline ESI8 & WH & 1987 & 25 & 2,500 & MC & A572-Gr50 & A36 & 0.80 & 216 & 74 & 77 & 0.49 \\
\hline NYA539 & WH & 1984 & 3 & 2,600 & MC & A36 & A36 & 1.00 & 14 & 6 & 13 & 0.68 \\
\hline ESI4 & WLA & 1988 & 27 & 1,300 & MCL & A572-Gr50 & A36 & 0.10 & 10 & 5 & 6 & 1.54 \\
\hline JAM7486 & WLA & 1983 & 13 & 1,500 & MC & A572-Gr50 & A36 & 1.00 & 44 & 1 & 9 & 0.11 \\
\hline MNH03AB & WLA & 1978 & 3 & 1,000 & W & A36 & A36 & 0.00 & 38 & 2 & 5 & 0.28 \\
\hline MNH03F & WLA & 1978 & 3 & 500 & W & A36 & A36 & 0.00 & 17 & 0 & 3 & 0.26 \\
\hline MNH03G & WLA & 1978 & 3 & 400 & W & A36 & A36 & 0.00 & 12 & 0 & 1 & 0.13 \\
\hline NYA577 & WLA & 1980 & 14 & 1,600 & MCL & A572-Gr50 & A36 & 1.00 & 20 & 2 & 19 & 0.53 \\
\hline NYA591 & WLA & 1970 & 28 & 2,200 & MCL & A36 & A36 & 1.00 & 16 & 1 & 2 & 0.09 \\
\hline
\end{tabular}

Table 4-4. Surveyed Buildings with Weld Damage Only

\begin{tabular}{|c|c|c|c|c|c|c|c|c|c|c|c|}
\hline Building ID & Zone & $\begin{array}{c}\text { Year } \\
\text { Des'd }\end{array}$ & $\begin{array}{c}\text { MRF } \\
\text { Stories }\end{array}$ & $\begin{array}{c}\text { Upper Fr } \\
\text { Area [m }]\end{array}$ & $\begin{array}{c}\text { Flr } \\
\text { Cnst }\end{array}$ & $\begin{array}{c}\text { Column } \\
\text { Steel }\end{array}$ & $\begin{array}{c}\text { Beam } \\
\text { Steel }\end{array}$ & WDR & $\begin{array}{c}\text { Fr- } \\
\text { Frms }\end{array}$ & CW & $\begin{array}{c}\text { Damage } \\
\text { Score }\end{array}$ \\
\hline \hline BJ06 & NR & 1989 & 2 & 4,700 & MC & A572-Gr50 & A36 & 0.75 & 12 & 3 & 2.21 \\
\hline EQE1 & SC & 1991 & 4 & 2,000 & MC & A572-Gr50 & A36 & 0.00 & 16 & 7 & 4.31 \\
\hline EQE2 & SC & 1991 & 1 & 2,500 & MC & A36 & A36 & 0.00 & 6 & 5 & 4.17 \\
\hline ESI2 & SM & 1990 & 5 & 2,000 & MCL & A572-Gr50 & A36 & 0.00 & 1 & 1 & 5.00 \\
\hline JAM7482 & SO & 1983 & 4 & 1,300 & W & A36 & A36 & 0.50 & 28 & 1 & 1.39 \\
\hline JAM7484 & SO & 1985 & 4 & 1,500 & MCL & A36 & A36 & 0.50 & 20 & 1 & 2.40 \\
\hline BJ02E & UC & 1992 & 3 & 2,700 & MC & A572-Gr50 & A36 & 0.50 & 27 & 5 & 3.30 \\
\hline WEA & UC & 1979 & 4 & 1,700 & W & A36 & A36 & 0.00 & 24 & 5 & 1.54 \\
\hline KAR2 & WH & 1978 & 4 & 2,600 & MC & A36 & A36 & 0.20 & 12 & 6 & 3.32 \\
\hline MNH02 & WH & 1984 & 3 & 2,900 & MC & A36 & A36 & 0.75 & 16 & 4 & 1.67 \\
\hline JAM7480 & WLA & 1983 & 11 & 2,100 & MC & & A36 & 0.33 & 14 & 1 & 2.81 \\
\hline MNH03CDE & WLA & 1978 & 3 & 1,600 & W & A36 & A36 & 0.00 & 77 & 1 & 0.22 \\
\hline
\end{tabular}

Table 4-5. Surveyed Buildings with Column Web Damage 


\begin{tabular}{|c|c|c|c|c|c|c|c|c|}
\hline $\begin{array}{c}\text { Building } \\
\text { ID }\end{array}$ & Zone & Dir'n & $\mathbf{F l r}$ & $\begin{array}{l}\text { No of } \\
\text { Bays }\end{array}$ & $\begin{array}{c}\text { Typ Bay } \\
\text { Width } \\
\text { [m] }\end{array}$ & $\begin{array}{c}\text { Typ Ext } \\
\text { Col }\end{array}$ & $\underset{\text { Typ Int }}{\text { Col }}$ & Typ Beam \\
\hline BJ06 & NR & NS & 2 & 5 & 9.8 & W21x364 & W21x364 & W $36 \times 230,260$ \\
\hline BJ06 & NR & NS & 2 & 5 & 9.8 & W21 2333 & W21x333 & W36 230,260 \\
\hline BJ06 & NR & NS & 3 & 5 & 9.8 & W21×364 & W21x364 & $W 36 \times 135,150$ \\
\hline LCIB & NR & NESW & & 3 & 9.5 & $\begin{array}{c}\text { W14x233- } \\
342\end{array}$ & W14x233-342 & $\begin{array}{c}\text { W21,W24, } \\
\text { W27 }\end{array}$ \\
\hline LCIB & NR & NWSE & & 3 & 6.1 & $\mathbf{n a}$ & W14x176-233 & $\begin{array}{l}\text { W21x62- } \\
\text { W24x117 }\end{array}$ \\
\hline LCIE & NR & NS & & 2 & 9.5 & W14 233 & W14×233 & $\begin{array}{l}\text { W21x83- } \\
\text { W24x131 }\end{array}$ \\
\hline EQE1 & SC & NS & 2 & 4 & 6.1 & & $W 14 \times 159$ & W30x116 \\
\hline EQE1 & SC & NS & 2 & 4 & 6.1 & & W14x159 & W30x116 \\
\hline EQE1 & SC & NS & 3 & 4 & 6.1 & & W14x145 & W30x108 \\
\hline EQE1 & SC & NS & 3 & 4 & 6.1 & & W14x145 & W30x108 \\
\hline EQE1 & SC & EW & 3 & 3 & 6.1 & & W14x211 & W33x130 \\
\hline EQE1 & SC & NS & 4 & 4 & 6.1 & & $W 14 \times 145$ & W27×94 \\
\hline EQE1 & SC & NS & 4 & 4 & 6.1 & & W $14 \times 145$ & W27x94 \\
\hline EQE2 & SC & NS & 1 & 2 & 7.3 & W12x136 & & $W 24 \times 76$ \\
\hline EQE2 & SC & NS & 1 & 1 & 8.2 & W12x190 & na & $w 36 \times 160$ \\
\hline$\overline{\mathrm{EQE} 2}$ & SC & EW & 1 & 2 & 7.3 & W12x136 & & $W 24 \times 76$ \\
\hline $\mathrm{EQE} 2$ & SC & EW & 1 & 2 & 7.3 & W12x136 & & W $24 \times 76$ \\
\hline EQE2 & SC & NS & 1 & 2 & 6.1 & W12x136 & & W30x99 \\
\hline ESI2 & SM & EW & 2 & 1 & 6.1 & W14x193 & $\mathbf{n a}$ & W36x135 \\
\hline JAM7482 & so & NS & 2 & 2 & 10.2 & W14x398 & W14×398 & W36 210 \\
\hline
\end{tabular}

Table 4-6. Surveyed Floor-Frames With Column Web Damage 


\begin{tabular}{|c|c|c|c|c|c|c|c|c|}
\hline $\begin{array}{c}\text { Building } \\
\text { DD }\end{array}$ & Zone & Dir'n & Frr & $\begin{array}{l}\text { No of } \\
\text { Bays }\end{array}$ & $\begin{array}{c}\text { Typ } \\
\text { Bay } \\
\text { Width } \\
\text { [m] }\end{array}$ & $\begin{array}{c}\text { Typ Ext } \\
\text { Col }\end{array}$ & $\begin{array}{c}\text { Typ Int } \\
\text { Col }\end{array}$ & Typ Beam \\
\hline JAM7484 & so & NS & 1 & 1 & 11.9 & $W 14 \times 311$ & na & W36 $\times 230$ \\
\hline BJ02E & UC & NS & 2 & 3 & 10.4 & $\mathbf{n a}$ & $W 24 \times 162$ & $\begin{array}{l}\text { W24x84, } \\
\text { W36 } 210\end{array}$ \\
\hline BJ02E & UC & NS & 2 & 3 & 10.4 & na & $W 24 \times 192$ & W36x135 \\
\hline BJ02E & UC & NS & 2 & 3 & 10.4 & na & $W 24 \times 192$ & W36x135 \\
\hline BJ02E & UC & NS & 3 & 3 & 10.4 & na & W24x279 & $w 36 \times 210$ \\
\hline BJ02E & UC & NS & 3 & 3 & 10.4 & na & W24×279 & $W 36 \times 210$ \\
\hline WEA & UC & EW & 2 & 1 & 7.3 & W $24 \times 68$ & na & W24x76 \\
\hline WEA & UC & EW & 2 & 1 & 7.3 & $W 24 \times 110$ & na & W33x118 \\
\hline WEA & UC & EW & 2 & 1 & 7.3 & $W 24 \times 110$ & na & W33 3118 \\
\hline WEA & UC & EW & 2 & 1 & 9.1 & $W 27 \times 145$ & na & W36x 160 \\
\hline WEA & UC & EW & 3 & 1 & 7.3 & W24×94 & $\mathbf{n a}$ & W30 $\times 108$ \\
\hline KAR2 & WH & NS & 2 & 4 & 9.1 & W14x136 & W14x342 & BU42 \\
\hline KAR2 & WH & NS & 2 & 4 & 9.1 & W14x136 & W14x370 & BU42 \\
\hline KAR2 & WH & NS & 3 & 4 & 9.1 & W14x95 & W $14 \times 211$ & BU42 \\
\hline KAR2 & WH & NS & 3 & 4 & 9.1 & W14x95 & $\mathrm{W} 14 \times 211$ & BU42 \\
\hline KAR2 & WH & NS & 4 & 4 & 9.1 & W14x84 & W14x 158 & BU42 \\
\hline KAR2 & WH & NS & 4 & 4 & 9.1 & W14x84 & W14x 158 & $\mathrm{BU} 42$ \\
\hline MNH02 & WH & NS & 1 & 2 & 8.5 & BU24 & BU24 & BU40 \\
\hline MNH02 & WH & NS & 1 & 2 & 8.5 & BU24 & BU24 & BU40 \\
\hline MNH02 & WH & NS & 1 & 2 & 8.5 & BU24 & BU24 & BU40 \\
\hline MNH02 & WH & NS & 1 & 2 & 8.5 & BU24 & BU24 & BU40 \\
\hline JAM7480 & WLA & EW & 11 & 6 & 8.8 & & & W36 150 \\
\hline $\begin{array}{c}\text { MNH03C } \\
\text { DE }\end{array}$ & WLA & NESW & 2 & 2 & 3.4 & W14x90 & & $W 21 \times 50$ \\
\hline
\end{tabular}

Table 4-6. Surveyed Floor-Frames with Column Web Damage (Continued) 
actually a 3-story MRF on top of a 6-story concrete structure.) Note that while buildings WEA and MNH02 have relatively many floor-frames with at least one cracked column web, their damage scores are close to the average building score of 1.15 (see Section 4.2.1). This suggests a deficiency in the scoring formula, since these buildings should be considered heavily damaged.

Column web cracking is serious and rare enough to warrant more full description. Table 4-6 lists characteristics of each floor-frame with column web (CW) damage. Additional information for each listed building can be found in Table 4-5 and in Appendix A. From Tables 4-5 and 4-6, it is clear that column web fractures have occurred in a variety of building locations, sizes, frame configurations, diaphragm types, and framing details. 


\subsection{Correlating the Damage}

\subsection{Method}

Valid correlations between damage and building characteristics require data samples of reliable quality and comparability. The sources of survey error given in Section 3.2 must be considered in all of the discussions that follow.

For this report, correlations are studied by comparing damage scores or damage ratios of a specific subset of buildings or floor-frames to the aggregate scores and ratios of a larger subset, usually the complete set of surveyed conditions. It should be emphasized that the correlations cited are not based on statistics. For the survey as a whole, aggregate scores and ratios include the following rounded values, as discussed in Sections 4.2.1 and 4.2.2:

Damage Score: average for buildings with 6 or more floor-frames

building average plus one standard deviation

floor-frame aggregate

0.98

$\begin{array}{lll}\text { Damage Ratios: } & \text { bottom weld } & .41 \\ & \text { top weld } & .16 \\ & \text { bottom column flange } & .12\end{array}$

(Note that none of the correlations include data from buildings LCIB and LCIE, whose survey responses were not comparable to those of other buildings.)

\subsection{Non-MRF Damage}

Except in the most severe cases, MRF connection damage is impossible to identify without disruptive and costly inspection. It would be useful to know if the extent of MRF damage could be predicted on the basis of visible non-MRF damage. The survey forms recorded nonMRF damage only in qualitative, narrative form, as shown in the Appendix A summaries.

Most of the surveyed buildings reported some non-MRF structural damage, ranging from minor spalling around base plates to permanent lateral set and, in one case, near partial collapse. Eight buildings were found to have significant permanent lateral set, as summarized in Table 5-1. (Note that most surveyed buildings were not checked for plumbness. Also, note that buildings can experience substantial inelasticity without measurable lateral set.) The average damage score for these eight buildings is 2.2 , significantly higher than the survey average. 


\begin{tabular}{|c|c|c|c|c|}
\hline Building ID & Zone & Stories & $\begin{array}{c}\text { Damage } \\
\text { Score }\end{array}$ & \multicolumn{1}{|c|}{ Non-MRF Structural Damage } \\
\hline BAK & SO & 6 & 1.25 & $\begin{array}{l}\text { YES - Out of plumb 64 to 76 mm (2.5 to 3 in) in the N-S } \\
\text { direction. }\end{array}$ \\
\hline BJ05 & NR & 11 & 1.10 & $\begin{array}{l}\text { YES - Northerly } 51 \mathrm{~mm} \text { (2 in) permanent displacement } 10 \\
\text { roof (11th floor). }\end{array}$ \\
\hline EQE1 & SC & 4 & 4.31 & $\begin{array}{l}\text { YES - 51 mm (2 in) perm. deflection to S at roof, 3.49 cm } \\
\text { (1.375 in) at ground floor. 35 mm (1.375 in) perm. } \\
\text { deflection to W at roof, 25 mm (1 in) at ground floor. }\end{array}$ \\
\hline EQE2 & SC & 1 & 4.17 & $\begin{array}{l}\text { YES - 102 mm (4 in) perm. deflection to NW at roof. Crack } \\
\text { across diaphragm with 51 mm (2 in) separation. Pullout } \\
\text { failure of pre-cast attachments. Failure of non-moment beam } \\
\text { connection at drop of roof about 102 mm (4 in). Pullout of } \\
\text { roof from block walls. Pounding damage of block walls with } \\
\text { roof diaphragm and with adjacent parking structure. }\end{array}$ \\
\hline JAM7484 & SO & 4 & 2.40 & $\begin{array}{l}\text { YES - Distortion to beam web \& shear tab in a few nonframe } \\
\text { connections. 51-89 mm (2-3.5 in) out-of plumb, northerly, at } \\
\text { 4th floor. }\end{array}$ \\
\hline KAR3 & SO & 17 & 2.00 & $\begin{array}{l}\text { YES - Measured deflection of 89 mm (3.5 in) of the top } \\
\text { relative to the base of 18-story N-S frame. All the } \\
\text { deformation is within the top six stories. }\end{array}$ \\
\hline SOA & SO & 4 & 1.95 & $\begin{array}{l}\text { YES - Base plate anchors broke free from base plates. Large } \\
\text { areas of spalled concrete around many column bases. One } \\
\text { base shifted 19 mm (.75 in) north, another 10 mm (.375 in). }\end{array}$ \\
\hline WH & 18 & 0.46 & $\begin{array}{l}\text { YES - 152 mm (6 in) perm. lateral displacement in height of } \\
\text { 18 story building. Steel stair connections broken. Mechanical } \\
\text { room block walls broken at connections to steel floor framing. } \\
\text { Marble panel anchorages in lobby damaged. }\end{array}$ \\
\hline
\end{tabular}

Table 5-1. Surveyed Buildings with Reported Lateral Set

Table 5-2 shows the aggregate damage for the 202 inspected floor-frames in these eight buildings. Only the number of floor-frames with bottom column flange (BC) damage is significantly higher than average. The column web $(\mathrm{CW})$ damage ratio of 0.06 represents 13 floor-frames, but twelve of these are in only two buildings. In summary, permanent lateral set appears to be only weakly related to significant MRF connection damage. In fact, building BAK sustained a permanent lateral set with weld damage only.

Current survey responses do not justify a correlation study between MRF connection damage and non-structural damage. First, non-structural damage is expected in large earthquakes. Second, although most surveyed buildings had some non-structural damage, the reported damage is highly varied, and much damage had already been repaired by the time MRF connection inspection began. Finally, there is strong anecdotal evidence that MRF damage can be present either with or without heavy non-structural damage [SEAOC Seismology Committee, 1994]. 


\begin{tabular}{|c|c|c|c|c|c|c|c|c|}
\hline No of Bldgs & WDR & Flr-Frms & \multicolumn{5}{|c|}{ Damage Class } & \multirow{2}{*}{ Damage Score } \\
\cline { 4 - 7 } & & & BC & TW & BW & S & CW & \\
\hline 8 & 0.24 & 202 & 0.28 & 0.09 & 0.41 & 0.09 & 0.06 & 1.56 \\
\hline
\end{tabular}

Table 5-2. Aggregate Damage Ratios and Score for Surveyed Buildings with Reported Lateral Set

\subsection{Scope of Inspection}

Even assuming reliable and consistent UT, a limited inspection program may fail to find widely scattered damage. A sufficient inspection scope is essential if damaged MRF's cannot be identified by outwardly visible damage (see above) or by geographic location (discussed below). With current survey data, a study of observed damage vs. scope of inspection can consider the number of inspected floor-frames within a building and the number of inspected connections within a floor-frame.

Since complete testing may have been motivated by visible connection damage, this correlation study should only include buildings in which damage could not be observed easily through fireproofing. The subset considered here consists of the 19 buildings with no damage or weld damage only. Of these 19, only one was fully inspected; that is, only building ESI8 had close to $100 \%$ of its floor-frames and connections tested. Only six of these buildings had at least $25 \%$ of their total floor-frames reported and $25 \%$ of the connections in those floorframes tested. The average damage score for the 13 least-inspected buildings with no damage or weld damage only is 0.31 ; the average score for the other six more thoroughly tested buildings is 0.29 . As this data is sparse, these averages are not especially meaningful, except to show that the survey data for this subset of buildings cannot conclusively show a link between damage and level of inspection.

A different subset of somewhat more damaged buildings is the set with column flange damage but without visible shear connection or column web damage. Ten buildings, with damage scores ranging from 0.2 to 2.5 and averaging 1.1, meet this criterion. Of these, five had testing of at least half of the connections in at least half of all floor-frames. (Note that this is a noticeably higher level of inspection than in buildings with no damage or weld damage only.) These five have an average score of 1.3, while the less inspected five averaged 0.9 . Again, without robust data, the survey results are suggestive but not conclusive of a link between scope of inspection and observed damage.

In some buildings, structural analysis was used to locate connections for testing. If damage locations can be determined rationally, then there could be a negative correlation between damage and testing, as marginal testing will consider fewer and fewer critically stressed locations. Survey data is insufficient to test this hypothesis on a floor-frame level.

As noted in Section 3.1.2, access to the beam top flange and the outside of connections in perimeter frames was frequently limited. It is possible that the incidences of top column 
flange (TC) damage are so few because the inspection and testing there was limited, but the survey data is not complete enough to test such a hypothesis. Some engineers suspect that serious damage at the top of the connection would manifest as damage to the diaphragm above; if no evidence of diaphragm damage was seen, then limited inspection of the top flange is justified.

In addition, there are reasons to believe that damage at the top of the connection should be more rare than at the bottom: at the top, the extreme flange fiber is at the toe of the weld, not at the root/backing bar notch; for a beam acting compositely with a concrete slab, the imposed bending is resisted in part by the slab; and in composite members, the neutral axis is shifted from the steel mid-depth up toward the top flange, leading to higher strains at the bottom weld and lower strains at the top. Given these explanations, it is reasonable to look for top column flange (TC) damage and top flange weld (TW) damage at non-composite beams. However, the eight buildings and 214 floor-frames with wood diaphragms showed no higher incidence of these damage classes than did those with metal deck and concrete fill.

\subsection{Location}

\subsubsection{Zone}

Table 4-1 gives damage data for the surveyed buildings sorted by geographic zone. Each zone represents a range of damage levels, showing that buildings subjected to similar ground motions exhibited markedly different performance, even though their steel MRF structures were probably designed to similar criteria. There is not a direct correlation between geographic location and extent of MRF damage.

Tables 4-3, 4-4, and 4-5 give the zones represented by three different damage levels. Table 5-3 summarizes the damage for each zone, giving the ratio of damaged floor-frames in each class and the aggregate damage score for the entire zone. By damage score, Santa Clarita (SC), Universal City (UC), and Santa Monica (SM) are significantly above the survey average of 1.0, although these zones all have small samples of only three buildings each. This supports the suggestion from Section 4.2.3 that the survey's limited sample has captured the worst damage in each zone and that further inspection and testing within a given zone will reveal some buildings with minor or no damage.

\subsubsection{Adjacent Buildings}

A study of neighboring but otherwise very different buildings requires greater detail than the current survey provides. Three sets of buildings, however, are on adjacent sites and are constructed from similar details as distinct but related parts of larger projects: BJ10 \& 11, BJ05 \& 06, and MNH03AB, CDE, F, G, \& H. Table 4-1 is sufficient to show that the extent of damage can vary greatly, even in these similar adjacent buildings. In particular, BJ10 is undamaged while BJ11 has column flange tears in one fourth of its floor-frames. The 
MNH03 buildings have similar low damage scores, but note that the only non-weld damage in all five buildings is in the irregular (U-shaped) MNH03CDE.

\begin{tabular}{|c|c|c|c|c|c|c|c|c|c|}
\hline \multirow[t]{2}{*}{ Zone } & \multirow[t]{2}{*}{ No of Bldgs } & \multirow[t]{2}{*}{ Flr-Frms } & \multirow[t]{2}{*}{ WDR } & \multicolumn{5}{|c|}{ Damage Class } & \multirow{2}{*}{$\begin{array}{l}\text { Damage } \\
\text { Score }\end{array}$} \\
\hline & & & & $\mathrm{BC}$ & TW & BW & $\mathbf{S}$ & $\mathbf{C W}$ & \\
\hline LAX & 1 & 5 & & 0.00 & 0.00 & 0.00 & 0.00 & 0.00 & 0.00 \\
\hline MW & 1 & 9 & 1.00 & 0.00 & 0.00 & 0.67 & 0.00 & 0.00 & 0.33 \\
\hline NR & 2 & 67 & 0.71 & 0.27 & 0.06 & 0.66 & 0.03 & 0.04 & 1.30 \\
\hline SC & 3 & 26 & 0.09 & 0.81 & 0.00 & 0.12 & 0.31 & 0.46 & 3.78 \\
\hline SM & 3 & 70 & 0.49 & 0.23 & 0.64 & 0.93 & 0.03 & 0.01 & 2.14 \\
\hline so & 11 & 189 & 0.50 & 0.12 & 0.13 & 0.44 & 0.06 & 0.01 & 0.96 \\
\hline UC & 3 & 52 & 0.28 & 0.42 & 0.25 & 0.58 & 0.10 & 0.19 & 2.63 \\
\hline WH & 10 & 495 & 0.66 & 0.07 & 0.18 & 0.38 & 0.02 & 0.02 & 0.72 \\
\hline WLA & 15 & 365 & 0.27 & 0.07 & 0.07 & 0.29 & 0.01 & 0.01 & 0.61 \\
\hline
\end{tabular}

Table 5-3. Damage Ratios and Scores by Zone

\begin{tabular}{|c|c|c|c|c|c|c|c|c|c|}
\hline \multirow[t]{2}{*}{ Direction } & \multirow[t]{2}{*}{ No of Bldgs } & \multirow[t]{2}{*}{ Flr-Frms } & \multirow[t]{2}{*}{ WDR } & \multicolumn{5}{|c|}{ Damage Class } & \multirow{2}{*}{$\begin{array}{l}\text { Damage } \\
\text { Score }\end{array}$} \\
\hline & & & & BC & TW & BW & $S$ & CW & \\
\hline EW & 37 & 449 & 0.54 & 0.11 & 0.14 & 0.36 & 0.02 & 0.02 & 0.80 \\
\hline NESW & 10 & 156 & 0.34 & 0.08 & 0.19 & 0.37 & 0.01 & 0.01 & 0.87 \\
\hline NS & 38 & 481 & 0.53 & 0.20 & 0.15 & 0.52 & 0.06 & 0.06 & 1.35 \\
\hline NWSE & 10 & 192 & 0.44 & 0.02 & 0.19 & 0.30 & 0.00 & 0.00 & 0.55 \\
\hline
\end{tabular}

Table 5-4. Damage Ratios and Scores by Frame Direction

\subsubsection{Directionality}

Table 5-4 separates the reported floor-frames by compass direction, clearly showing greater damage in North-South frames. Table 5-5 breaks the data down further by geographic zone, ignoring zones LAX and MW which have only one building each. (Note that at this level, a number of zone-direction combinations are represented by only one or two buildings and relatively few floor-frames.) Data from zones SO, WH, and WLA show that the N-S 
directionality is strongest north of the Santa Monica Mountains and weakest in Santa Monica and West L.A. It should be noted that strong motion records in the Santa Monica area showed a stronger E-W component than N-S component.

\begin{tabular}{|c|c|c|c|c|c|c|c|c|c|c|}
\hline Zone & \multirow{2}{*}{ Direction } & \multirow{2}{*}{$\begin{array}{l}\text { No of } \\
\text { Bldgs }\end{array}$} & & & WDR & Flr-Frms & \multicolumn{6}{|c|}{ Damage Class } & $\begin{array}{c}\text { Damage } \\
\text { Score }\end{array}$ \\
\hline NR & EW & 2 & 0.71 & 30 & 0.20 & 0.07 & 0.70 & 0.00 & 0.00 & 1.00 \\
\hline NR & NS & 2 & 0.71 & 37 & 0.32 & 0.05 & 0.62 & 0.05 & 0.08 & 1.54 \\
\hline SC & EW & 3 & 0.09 & 13 & 0.77 & 0.00 & 0.08 & 0.31 & 0.23 & 2.95 \\
\hline SC & NS & 3 & 0.09 & 13 & 0.85 & 0.00 & 0.15 & 0.31 & 0.69 & 4.60 \\
\hline SM & EW & 1 & 0.00 & 1 & 1.00 & 0.00 & 0.00 & 0.00 & 1.00 & 5.00 \\
\hline SM & NESW & 2 & 0.42 & 30 & 0.40 & 0.77 & 1.00 & 0.07 & 0.00 & 2.84 \\
\hline SM & NWSE & 2 & 0.56 & 39 & 0.08 & 0.56 & 0.90 & 0.00 & 0.00 & 1.53 \\
\hline SO & EW & 9 & 0.61 & 84 & 0.05 & 0.13 & 0.36 & 0.00 & 0.00 & 0.53 \\
\hline SO & NS & 11 & 0.41 & 105 & 0.17 & 0.13 & 0.50 & 0.11 & 0.02 & 1.33 \\
\hline UC & EW & 2 & 0.21 & 28 & 0.25 & 0.14 & 0.50 & 0.04 & 0.14 & 1.83 \\
\hline UC & NS & 3 & 0.35 & 24 & 0.63 & 0.38 & 0.67 & 0.17 & 0.25 & 3.53 \\
\hline WH & EW & 10 & 0.63 & 204 & 0.05 & 0.19 & 0.29 & 0.01 & 0.00 & 0.54 \\
\hline WH & NESW & 1 & 0.80 & 24 & 0.00 & 0.17 & 0.25 & 0.00 & 0.00 & 0.29 \\
\hline WH & NS & 10 & 0.64 & 219 & 0.12 & 0.17 & 0.52 & 0.03 & 0.05 & 1.02 \\
\hline WH & NWSE & 1 & 0.80 & 48 & 0.00 & 0.21 & 0.25 & 0.00 & 0.00 & 0.32 \\
\hline WLA & EW & 8 & 0.33 & 82 & 0.13 & 0.12 & 0.44 & 0.01 & 0.01 & 0.98 \\
\hline WLA & NESW & 7 & 0.21 & 102 & 0.01 & 0.03 & 0.22 & 0.00 & 0.01 & 0.37 \\
\hline WLA & NS & 7 & 0.37 & 76 & 0.16 & 0.09 & 0.49 & 0.04 & 0.00 & 1.05 \\
\hline WLA & NWSE & 7 & 0.22 & 105 & 0.00 & 0.05 & 0.10 & 0.00 & 0.00 & 0.18 \\
\hline \hline
\end{tabular}

Table 5-5. Damage Ratios and Scores by Zone and Frame Direction

$\mathrm{N}-\mathrm{S}$ directionality in the five northernmost zones is corroborated by reports of permanent lateral set, given in Table 5-1, and by the damage data in Tables 5-6 and 5-7. In 3-bay frames with bay widths of 9.1 to 12.2 meters ( 30 to 40 feet), there are 100 surveyed floorframes overall. As can be determined from Tables 5-6 and 5-7, all of the shear (S) and column web (CW) damage and 14 of 16 bottom column flange (BC) damage cases are in the N-S direction. 


\begin{tabular}{|c|c|c|c|c|c|c|c|c|c|}
\hline \multirow{2}{*}{$\begin{array}{c}\text { Typ Bay } \\
\text { Width [m] }\end{array}$} & \multirow{2}{*}{ No of Bldgs } & \multirow{2}{*}{ Frr-Frms } & \multirow{2}{*}{ WDR } & \multicolumn{5}{|c|}{ Damage Class } & Damage \\
\cline { 5 - 9 } & & & & BC & TW & BW & S & CW & \\
\hline \hline $4.6-5.8$ & 9 & 114 & 0.29 & 0.09 & 0.11 & 0.18 & 0.01 & 0.00 & 0.54 \\
\hline $6.1-8.8$ & 15 & 87 & 0.45 & 0.14 & 0.13 & 0.43 & 0.05 & 0.01 & 0.98 \\
\hline $9.1-12.2$ & 15 & 100 & 0.82 & 0.16 & 0.09 & 0.38 & 0.03 & 0.05 & 0.85 \\
\hline
\end{tabular}

Table 5-6. Damage Ratios and Scores for 3-Bay Frames by Bay Width

\begin{tabular}{|c|c|c|c|c|c|c|c|c|c|}
\hline \multirow{2}{*}{$\begin{array}{l}\text { Typ Bay } \\
\text { Width [m] }\end{array}$} & \multirow[t]{2}{*}{ No of Bldgs } & \multirow[t]{2}{*}{ Flr-Frms } & \multirow[t]{2}{*}{ WDR } & \multicolumn{5}{|c|}{ Damage Class } & \multirow{2}{*}{$\begin{array}{c}\text { Damage } \\
\text { Score }\end{array}$} \\
\hline & & & & BC & TW & BW & $\mathbf{S}$ & $\mathbf{C W}$ & \\
\hline $4.6-5.8$ & 2 & 16 & 0.70 & 0.00 & 0.00 & 0.06 & 0.00 & 0.00 & 0.05 \\
\hline $6.1-8.8$ & 5 & 33 & 0.59 & 0.06 & 0.15 & 0.61 & 0.00 & 0.00 & 0.81 \\
\hline $9.1-12.2$ & 5 & 49 & 0.81 & 0.29 & 0.14 & 0.43 & 0.06 & 0.10 & 1.39 \\
\hline
\end{tabular}

Table 5-7. Damage Ratios and Scores for 3-Bay Frames by Bay Width: North-South Frames, 1 to 14-Story, Zones NR, SC, SO, UC, WH

\subsection{Concept Design}

\subsubsection{Height}

As shown in Table 4-5, column web (CW) damage is mostly limited to buildings shorter than six stories. Overall, the average damage score for 34 surveyed buildings less than seven stories tall is 1.2 , about the same as the average for the entire survey. Damage ratios for these buildings are also close to overall survey averages: bottom weld (BW) damage, 0.44; top weld (TW) damage, 0.16 ; bottom column flange (BC) damage, 0.16 . Damage in the 14 taller buildings (excluding ESI8, whose 216 floor-frames skew the sample) is somewhat lower than average, but not significantly so. Thus, short buildings do not appear significantly more prone to MRF damage than tall buildings.

The location of damage within a building's height may indicate that damage is associated with certain modes of vibration. Table 5-8 shows damage characteristics for frames at each level of 3 to 5 story buildings. (Floor \#1 data may be anomalous, since ground floor conditions vary greatly depending on column fixity and basement structure. Roof data may also reflect various loading and penthouse framing conditions.) In 3- and 4-story buildings, Table 5-8 shows a clear trend: more damage at lower stories, notably bottom column flange (BC) damage, bottom weld (BW) damage and column web (CW) damage. This reflects the 
story drift and shear distribution of a flexible frame in its first vibration mode. The trend does not show in the 5-story buildings, although the data there is relatively sparse.

\begin{tabular}{|c|c|c|c|c|c|c|c|c|c|c|}
\hline \multirow[t]{2}{*}{ Stories } & \multirow{2}{*}{$\begin{array}{l}\text { Floor \# } \\
\text { or Roof }\end{array}$} & \multirow{2}{*}{$\begin{array}{l}\text { No of } \\
\text { Bldgs }\end{array}$} & \multirow{2}{*}{$\begin{array}{c}\text { Flr- } \\
\text { Frms }\end{array}$} & \multirow[t]{2}{*}{ WDR } & \multicolumn{5}{|c|}{ Damage Class } & \multirow{2}{*}{$\begin{array}{c}\text { Damage } \\
\text { Score }\end{array}$} \\
\hline & & & & & $\mathbf{B C}$ & TW & BW & $\mathbf{S}$ & $\mathrm{CW}$ & \\
\hline 3 & 1 & 3 & 24 & 0.88 & 0.17 & 0.25 & 0.71 & 0.00 & 0.17 & 1.43 \\
\hline 3 & 2 & 11 & 95 & 0.17 & 0.13 & 0.09 & 0.47 & 0.04 & 0.04 & 1.22 \\
\hline 3 & 3 & 10 & 78 & 0.15 & 0.08 & 0.05 & 0.31 & 0.01 & 0.03 & 0.74 \\
\hline 3 & Roof & 9 & 69 & 0.12 & 0.04 & 0.01 & 0.13 & 0.01 & 0.00 & 0.32 \\
\hline 4 & 1 & 3 & 19 & 0.21 & 0.21 & 0.42 & 0.58 & 0.21 & 0.05 & 2.29 \\
\hline 4 & 2 & 10 & 47 & 0.38 & 0.53 & 0.28 & 0.68 & 0.17 & 0.19 & 3.05 \\
\hline 4 & 3 & 10 & 49 & 0.40 & 0.31 & 0.22 & 0.55 & 0.14 & 0.12 & 2.12 \\
\hline 4 & 4 & 10 & 48 & 0.39 & 0.23 & 0.19 & 0.54 & 0.02 & 0.08 & 1.56 \\
\hline 4 & Roof & 7 & 32 & 0.33 & 0.13 & 0.25 & 0.47 & 0.03 & 0.00 & 1.15 \\
\hline 5 & 1 & 3 & 16 & 0.98 & 0.19 & 0.06 & 0.31 & 0.00 & 0.00 & 0.57 \\
\hline 5 & 2 & 5 & 37 & 0.62 & 0.05 & 0.05 & 0.43 & 0.00 & 0.03 & 0.62 \\
\hline 5 & 3 & 4 & 27 & 0.57 & 0.11 & 0.15 & 0.30 & 0.00 & 0.00 & 0.63 \\
\hline 5 & 4 & 4 & 22 & 0.48 & 0.14 & 0.09 & 0.27 & 0.05 & 0.00 & 0.73 \\
\hline 5 & 5 & 2 & 20 & 0.45 & 0.05 & 0.05 & 0.20 & 0.05 & 0.00 & 0.46 \\
\hline 5 & Roof & 2 & 18 & 0.40 & 0.00 & 0.00 & 0.06 & 0.00 & 0.00 & 0.06 \\
\hline
\end{tabular}

Table 5-8. Damage Ratios and Scores in 3 to 5-Story Buildings by Floor Level

Table 5-9 gives data characteristics for different portions of six 11- to 14-story mid-rise buildings. Bottom weld (BW) damage is observed at about the same rate at lower and upper levels. Greater bottom column flange (BC) damage leads to higher ratios and scores around mid-height and at top floors, but this may be an artifact of limited sample sizes. For the six surveyed mid-rise buildings, there is no clear correlation between damage and floor number.

Limited data (see Table 3-3) prohibits useful studies of damage vs. floor number for highrise buildings. 


\begin{tabular}{|c|c|c|c|c|c|c|c|c|c|c|}
\hline Stories & \multirow{2}{*}{ Floor \# } & \multirow{2}{*}{$\begin{array}{l}\text { No of } \\
\text { Bldgs }\end{array}$} & \multirow{2}{*}{ Frr- } & WDS & & \multicolumn{6}{|c|}{ Damage Class } & Damage \\
\cline { 6 - 10 } & & & & & BC & TW & BW & S & CW & \\
\hline $11-14$ & $2-4$ & 5 & 50 & 0.79 & 0.12 & 0.00 & 0.46 & 0.1 & 0.00 & 0.73 \\
\hline $11-14$ & $5-7$ & 6 & 63 & 0.75 & 0.22 & 0.06 & 0.51 & 0.1 & 0.00 & 1.00 \\
\hline $11-14$ & $8-10$ & 5 & 57 & 0.80 & 0.07 & 0.04 & 0.53 & 0.0 & 0.00 & 0.57 \\
\hline $11-14$ & $11-15$ & 6 & 40 & 0.70 & 0.20 & 0.05 & 0.48 & 0.0 & 0.03 & 0.95 \\
\hline
\end{tabular}

Table 5-9. Damage Ratios and Scores in 11 to 14-Story Buildings by Floor Level

\subsubsection{Frame Configuration}

With reference to Table 3-6, Tables 5-10 and 5-11 give damage characteristics according to the number of bays per frame. Both tables exclude frames of more than five bays, which are not as well represented.

Table 5-10 considers all surveyed buildings (except LCIB and LCIE). Note that the 2-bay frame data is dominated by 216 floor-frames from building ESI8. As a group, 1-bay frames have the highest damage score and bottom weld (BW) and top weld (TW) damage ratios, but they do not stand out from the other groups as significantly more prone to damage. Survey wide, there does not appear to be a correlation between observed damage and the number of bays per frame.

\begin{tabular}{|c|c|c|c|c|c|c|c|c|c|}
\hline \multirow[t]{2}{*}{ Bays } & \multirow[t]{2}{*}{ No of Bldgs } & \multirow[t]{2}{*}{ Flr-Frms } & \multirow[t]{2}{*}{ WDR } & \multicolumn{5}{|c|}{ Damage Class } & \multirow{2}{*}{$\begin{array}{c}\text { Damage } \\
\text { Score }\end{array}$} \\
\hline & & & & $\mathbf{B C}$ & TW & $\mathbf{B W}$ & $\mathbf{S}$ & $\mathrm{CW}$ & \\
\hline 1 & 13 & 205 & 0.33 & 0.11 & 0.24 & 0.53 & 0.04 & 0.04 & 1.32 \\
\hline 2 & 18 & 448 & 0.50 & 0.08 & 0.23 & 0.38 & 0.00 & 0.02 & 0.84 \\
\hline 3 & 29 & 301 & 0.50 & 0.13 & 0.11 & 0.32 & 0.03 & 0.02 & 0.79 \\
\hline 4 & 20 & 135 & 0.56 & 0.19 & 0.08 & 0.47 & 0.05 & 0.09 & 1.27 \\
\hline 5 & 12 & 124 & 0.53 & 0.18 & 0.02 & 0.39 & 0.14 & 0.02 & 1.10 \\
\hline
\end{tabular}

Table 5-10. Damage Ratios and Scores by Number of Bays per Frame

Table 5-11 considers the same data for a subset of floor-frames: North-South (NS) oriented frames in low- and mid-rise buildings (1 to 14 stories), located north of West L.A. in zones that showed predominant NS directionality (see Table 5-3). As NS frames have already been shown to have more damage in these zones, the high scores and ratios in Table 5-11 are not surprising. One- and 2-bay frames have the highest weld damage ratios, but 4- and 5-bay 
frames have very high ratios of column flange cracking and the highest damage scores overall.

In light of observed Northridge damage, the use of 1-bay frames has been questioned because each connection represents half of a frame's energy dissipation capacity, and with only two connections per floor, the loss of one could greatly increase demand on the other. Although the data is limited for this narrow subset of floor-frames, Table 5-11 shows that 1-bay frames experienced only average damage. Despite this finding, one bay frames continue to present a concern for Engineers due to their lack of redundancy. Because 4- and 5-bay frames are highly redundant, the severity of high scores shown in Table 5-11 depends on the number of damaged connections within each frame, but those numbers were not tracked by the survey.

\begin{tabular}{|c|c|c|c|c|c|c|c|c|c|}
\hline \multirow[t]{2}{*}{ Bays } & \multirow[t]{2}{*}{ No of Bldgs } & \multirow[t]{2}{*}{ Flr-Frms } & \multirow[t]{2}{*}{ WDR } & \multicolumn{5}{|c|}{ Damage Class } & \multirow{2}{*}{$\begin{array}{l}\text { Damage } \\
\text { Score }\end{array}$} \\
\hline & & & & $\mathbf{B C}$ & TW & BW & $\mathbf{S}$ & $\mathrm{CW}$ & \\
\hline 1 & 7 & 44 & 0.41 & 0.07 & 0.25 & 0.55 & 0.14 & 0.07 & 1.48 \\
\hline 2 & 7 & 37 & 0.56 & 0.30 & 0.14 & 0.70 & 0.00 & 0.19 & 1.95 \\
\hline 3 & 11 & 98 & 0.71 & 0.16 & 0.12 & 0.43 & 0.03 & 0.05 & 0.97 \\
\hline 4 & 7 & 40 & 0.55 & 0.43 & 0.03 & 0.43 & 0.10 & 0.30 & 2.38 \\
\hline 5 & 4 & 50 & 0.37 & 0.36 & 0.04 & 0.56 & 0.28 & 0.06 & 2.14 \\
\hline
\end{tabular}

Table 5-11. Damage Ratios and Scores by Number of Bays per Frame: North-South Frames, 1 to 14-Story, Zones NR, SC, SO, UC, WH

Tables 5-6 and 5-7 show the damage in the most common frame configuration, 3 bays, broken down by typical bay width. Table 5-6 considers all surveyed floor-frames; Table 5-7 considers only NS floor-frames in 1-14 story buildings north of West L.A. Surprisingly, the subset of North-South data shows less overall damage than the survey as a whole. Both tables show somewhat less damage in frames with shorter bays, though the Table 5-7 data is sparse. At best, there is a weak correlation between damage and long bays.

\subsubsection{Redundancy}

As described in Section 3.3.2, Table 3-7 lists the least redundant frames in the survey: those with only one or two bays in directions with only two frames. For the seven buildings represented, damage scores range from 0.46 to 2.51 , averaging 1.55 , somewhat greater than the overall survey average.

Table 5-12 gives the aggregate damage for these least redundant floor-frames. All the damage ratios and scores are close to the survey-wide averages. By this measure, at least, there is no correlation between observed damage and lack of structural redundancy. Surveyed buildings that are least redundant and irregular are discussed in the next section. 


\begin{tabular}{|c|c|c|c|c|c|c|c|c|}
\hline \multirow{2}{*}{ No of Bldgs } & \multirow{2}{*}{ Flr-Frms } & WDR & \multicolumn{5}{|c|}{ Damage Class } & Damage \\
\cline { 4 - 7 } & & & BC & TW & BW & S & CW & \\
\hline \hline 7 & 128 & 0.16 & 0.13 & 0.22 & 0.44 & 0.03 & 0.02 & 1.25 \\
\hline
\end{tabular}

Table 5-12. Aggregate Damage Ratios and Scores for Least Redundant Buildings (Ref. Table 3-7)

\subsubsection{Irregularity}

Table 3-8 lists potential irregularities in surveyed buildings. The 27 buildings listed represent both the lowest and highest damage scores in the survey. Their average score is 1.2 , the same as the survey average. The average damage score for the eight buildings with both plan and vertical irregularities is 1.1. Note that the scope and severity of listed irregularities varies from building to building and that some or all of a building's irregularities may have been adequately addressed during design.

Table 5-13 gives aggregate damage characteristics by type of irregularity. While buildings with both vertical and plan irregularities have slightly higher bottom weld $(\mathrm{BW})$ damage ratios, the 22 surveyed buildings with no irregularities have the highest column web (CW) damage ratio and the highest damage score. Clearly, there is no correlation between damage and structural irregularity.

\begin{tabular}{|c|c|c|c|c|c|c|c|c|c|}
\hline \multirow[t]{2}{*}{ Irregularity } & \multirow[t]{2}{*}{ No of Bldgs } & \multirow[t]{2}{*}{ Fr-Frms } & \multirow[t]{2}{*}{ WDR } & \multicolumn{5}{|c|}{ Damage Class } & \multirow{2}{*}{$\begin{array}{c}\text { Damage } \\
\text { Score }\end{array}$} \\
\hline & & & & BC & TW & BW & $\mathbf{S}$ & $C W$ & \\
\hline Both & 8 & 290 & 0.54 & 0.14 & 0.14 & 0.51 & 0.01 & 0.00 & 0.94 \\
\hline Neither & 22 & 429 & 0.35 & 0.19 & 0.14 & 0.39 & 0.07 & 0.04 & 1.25 \\
\hline Plan & 22 & 740 & 0.55 & 0.10 & 0.19 & 0.42 & 0.02 & 0.02 & 0.87 \\
\hline Vertical & 13 & 399 & 0.58 & 0.12 & 0.12 & 0.49 & 0.01 & 0.02 & 0.86 \\
\hline
\end{tabular}

Table 5-13. Damage Ratios and Scores by Building Irregularity (Ref. Table 3-8)

Of the seven least redundant structures discussed above, three also have some irregularity: ESI5, BJ04, and WEA. Although hardly a robust sample, these three buildings have an aggregate bottom weld (BW) damage ratio of 0.74 , a top weld (TW) damage ratio of 0.43 , a bottom column flange (BC) damage ratio of 0.20 , and an average damage score of 1.8 , all well above survey-wide averages.

An interesting comparison is provided by the five MNH03 buildings, all fairly redundant and all built from identical details on a shared foundation. Though only visually inspected, four 
of the five experienced no damage or just weld damage. With a C-shaped plan, Building MNH03CDE is the only irregular building of the five and also the only one with observed bottom column flange $(\mathrm{BC})$ damage and column web $(\mathrm{CW})$ damage.

\subsection{Detail Design}

\subsubsection{Yield Strength}

With reference to Table 3-10, Table 5-14 presents damage characteristics for the two main column steel grades. Based on nominal strengths, there is no clear correlation between observed damage and column material strength. With survey data on nominal strengths only, however, it is difficult to draw any conclusions regarding observed damage and material properties, since the variation of actual yield strength in A36 and multi-certified steel is well documented [Hamburger and Frank, 1994].

\begin{tabular}{|c|c|c|c|c|c|c|c|c|c||}
\hline \multirow{2}{*}{$\begin{array}{c}\text { Column } \\
\text { Steel }\end{array}$} & No of Bldgs & Flr-Frms & WDR & \multicolumn{5}{|c|}{ Damage Class } & \multirow{2}{*}{$\begin{array}{c}\text { Damage } \\
\text { Score }\end{array}$} \\
\cline { 5 - 9 } & & & & BC & TW & BW & S & CW & \\
\hline A36 & 26 & 528 & 0.36 & 0.12 & 0.09 & 0.35 & 0.0 & 0.04 & 0.96 \\
\hline A572-Gr50 & 19 & 705 & 0.58 & 0.11 & 0.21 & 0.44 & 0.0 & 0.02 & 0.94 \\
\hline
\end{tabular}

Table 5-14. Damage Ratios and Scores by Nominal Column Strength

\subsubsection{Member Size}

Without original criteria and calculations, it is difficult to tell which issues controlled the member design for surveyed buildings. However, with bay widths of 7.6 meters ( 25 feet) or greater (Table 3-6) and only a handful of bays in each direction (Tables 3-5 and 3-6), it is possible that many of the surveyed buildings, even those only three or four stories tall, were controlled by stiffness concerns, their members selected mainly to meet maximum code drift limits. For a given story drift, frame geometry, and constant relative member stiffness, beam curvatures at the column face are known, and for a given curvature, deeper wide flange beams experience greater strains in their flanges and flange welds. These large strains may be related to observed MRF connection damage.

To test this hypothesis, the following subset of floor-frames is considered: buildings 3 stories or taller with concrete diaphragms, floor-frames with typical bay widths between 7.3 and 11.0 meters (24 and 36 feet), Group 4 W14 columns (see Table 3-11), and wide flange beams of different nominal depths (see Tables 3-12 and 3-13). Table 5-16 shows the damage in these floor-frames. No consistent pattern is apparent, although the data is sparse for W30 and smaller beams. 
In Table 5-15, the bay widths (beam spans) are limited because for similar story drifts, longer spans yield lower beam flange stresses. This fact can also be used to test the relation between damage and beam flange strain. Tables 5-6 and 5-7 show overall damage parterns by bay width. Confining the study to floor-frames with W36 beams meeting the conditions of Table 5-15 yields the damage data in Table 5-16. Again, there is no recognizable pattem relating damage to beam span in this subset of floor-frames.

Without at least a simplified analysis, survey data are not sufficient to relate damage to design details. And without much more robust data, it may require time-history analysis with recorded ground motions to reveal any valid correlations.

\begin{tabular}{|c|c|c|c|c|c|c|c|c|c|}
\hline \multirow[t]{2}{*}{ Typ Girder } & \multirow[t]{2}{*}{ No of Bldgs } & \multirow[t]{2}{*}{ Fr-Frms } & \multirow[t]{2}{*}{ WDR } & \multicolumn{5}{|c|}{ Damage Class } & \multirow{2}{*}{$\begin{array}{c}\text { Damage } \\
\text { Score }\end{array}$} \\
\hline & & & & $\overline{B C}$ & TW & BW & $\mathbf{S}$ & $\mathbf{C W}$ & \\
\hline W24 & 1 & 2 & & 0.00 & 0.00 & 0.00 & 0.00 & 0.00 & 0.00 \\
\hline W27 & 3 & 3 & 0.65 & 0.00 & 0.00 & 0.33 & 0.00 & 0.00 & 0.28 \\
\hline W30 & 4 & 18 & 0.50 & 0.00 & 0.00 & 0.67 & 0.00 & 0.00 & 0.67 \\
\hline W33 & 6 & 47 & 0.63 & 0.02 & 0.00 & 0.17 & 0.00 & 0.00 & 0.19 \\
\hline W36 & 14 & 176 & 0.72 & 0.06 & 0.10 & 0.44 & 0.01 & 0.01 & 0.56 \\
\hline
\end{tabular}

Table 5-15. Damage Ratios and Scores by WF Girder Depth: Buildings $>3$ Stories, Concrete Diaphragms, Group 4 W14 Columns, and 7.3- to 11.0-m Bay Widths

\begin{tabular}{|c|c|c|c|c|c|c|c|c|c|}
\hline \multirow[t]{2}{*}{ Typ Bay [m] } & \multirow[t]{2}{*}{ No of Bldgs } & \multirow[t]{2}{*}{ Flr-Frms } & \multirow[t]{2}{*}{ WDR } & \multicolumn{5}{|c|}{ Damage Class } & \multirow{2}{*}{$\begin{array}{l}\text { Damage } \\
\text { Score }\end{array}$} \\
\hline & & & & $\mathbf{B C}$ & TW & BW & $\mathbf{S}$ & $\mathrm{CW}$ & \\
\hline $4.6-6.1$ & 7 & 103 & 0.75 & 0.07 & 0.34 & 0.34 & 0.02 & 0.00 & 0.68 \\
\hline $6.1-7.6$ & 6 & 116 & 0.75 & 0.03 & 0.27 & 0.41 & 0.03 & 0.00 & 0.63 \\
\hline $7.6-9.1$ & 10 & 78 & 0.76 & 0.00 & 0.00 & 0.01 & 0.00 & 0.00 & 0.01 \\
\hline $9.1-10.7$ & 12 & 88 & 0.65 & 0.00 & 0.00 & 0.01 & 0.00 & 0.00 & 0.01 \\
\hline $10.7-12.2$ & 2 & 19 & 0.26 & 0.11 & 0.37 & 0.58 & 0.26 & 0.05 & 2.07 \\
\hline $12.2-15.2$ & 3 & 20 & 0.29 & 0.20 & 0.40 & 0.50 & 0.05 & 0.00 & 1.59 \\
\hline
\end{tabular}

Table 5-16. Damage Ratios and Scores for W36 Girders by Bay Width: Buildings > 3 Stories, Concrete Diaphragms, Group 4 W14 Columns 


\subsubsection{Other}

The current survey data cannot support meaningful studies of damage correlations by shear connection type, weld process, or composite beam behavior. Data shown in Section 3.3.3 indicates that damage to floor-frames in buildings with wood diaphragms was not significantly different from damage patterns overall; the aggregate damage score for the 214 floor-frames is 0.58 , slightly lower than average.

As noted above, buildings with similar details can have various levels of damage, even when situated on adjacent sites.

\subsection{Material \& Construction Quality}

The lack of measurable correlation in this set of data between observed damage and basic design characteristics suggests that correlations be sought in either demand-based or reliability-based parameters. Predictability of damage may be a function of either local rotations and strains or a function of material and construction quality. These cases are not related to the set of concerns typically addressed by practicing engineers and the design criteria of building codes.

This alone is a valuable conclusion. Still, it requires confirmation with studies beyond the scope of the current survey. Among the possible demand-based damage indicators are:

- plastic rotation demand at the connection

- weld stress due to beam overstrength

- weld strain

- strain rate

- panel zone deformation causing local kinks at the flange welds

- through-thickness stresses in the column flange

Among the possible reliability-based damage indicators are:

- base metal quality

- weld metal quality

- weld quality and workmanship, including preheat, deposition rate, interpass temperature, wind shielding, etc.

- inspection and testing quality, including rejection of end dams, UT reliability, etc.

- fabrication and fit-up, including size and shape of weld access holes, flange preparation, and root opening 


\subsection{Conclusions and Recommendations}

\subsection{Conclusions}

Current survey data comprises 1290 inspected floor-frames from 51 steel MRF buildings. The floor-frames represent a variety of locations, building sizes, frame configurations, and construction types. The principal conclusions drawn from this data are:

- Observed damage ranges from none to complete column web fracture. The most common damage found is partial or complete fracture of beam flange groove welds. About $40 \%$ of all reported floor-frames have some cracking in the bottom weld; about $15 \%$ have some cracking in the top weld. Three quarters of the floor-frames with top weld damage also have bottom weld damage. Overall, about half of all the reported weld damage is limited to UT-rejectable discontinuities or incipient root cracking, some of which certainly predates the Northridge earthquake.

- Damage to base metal occurs most frequently as fracture of the column flange adjacent to the beam bottom flange weld: about $15 \%$ of floor-frames have one or more incidences of this type of fracture. Similar damage at the top of the connection was reported in only 9 floor-frames, but the low number may be partly due to obstruction of inspection by floor diaphragms above.

- The most serious damage types, column web cracking and shear connection damage, each occurred in about $4 \%$ of reported floor frames, and always in combination with weld or column flange fracture. Column web fracture was observed in a variety of building locations, sizes, frame configurations, diaphragm types, and framing details.

- On a floor-frame basis, about half of all floor-frames reported no damage, and another third reported weld damage only. Considering that about half of all reported weld damage was "incipient root cracking" only, it can be concluded that about two thirds of all reported floor-frames had nothing more than root cracks. However, while root cracks and weld discontinuities may be relatively easy to repair or even acceptable, observed column flange and weld fracture patterns suggest strongly that serious damage is related to the condition at the weld root.

Survey data was studied for correlations between observed damage and basic structural characteristics. Only two clear patterns were found. Specifically, studies of correlations between observed damage and surveyed building characteristics found that:

- North of the Santa Monica Mountains, North-South oriented frames were more damaged than others. No strong directionality was found in Santa Monica, West Los Angeles, or Universal City.

- In low-rise buildings (3 to 5 stories), lower floor levels were more damaged than upper floor levels. No similar patterns were apparent for mid-rise or high-rise buildings. 
- Structural or non-structural non-MRF damage did not correlate with damage ratios and/or damage scores.

- Building height and floor diaphragm area did not correlate with damage ratios and/or damage scores.

- Frame configuration (bay length and number of bays per frame) did not correlate with damage ratios and/or damage scores.

- Structural redundancy (number of frames and bays in a given direction) did not correlate with damage ratios and/or damage scores.

- Structural regularity (principally building line setbacks and reentrant corners) did not correlate with damage ratios and/or damage scores.

- Member size and nominal yield strength did not correlate with damage ratios and/or damage scores.

\subsection{Considerations}

In drawing these conclusions, it is essential to remember that:

- The database sample is limited and perhaps unrepresentative (though probably conservatively so). The most serious damage types were reported in each of the geographic zones represented by more than one building. In the three zones with more than four surveyed buildings, buildings with no damage at all or weld damage only were also reported. This suggests that the survey may have captured the worst damage in each zone and that inspection of more buildings will find a greater percentage with little or no damage.

- The scope of inspection within each building varied, and in some cases was extremely limited. More inspection will obviously give a more accurate picture, but there is no strong evidence that more inspection within a building will find more or less damage.

- No estimates of true structural demands from the Northridge earthquake were available for correlation with observed damage.

- No estimates of the impact of observed damage on building performance were available, and none are implied by this report.

\subsection{Implications}

The conclusions listed previously - especially the lack of correlation between damage and structural characteristics - yield some lessons for engineers, researchers, and others studying 
the effects of major earthquakes on steel frame buildings:

- Design standards for new construction should consider the likelihood and potential impact of brittle connection failure in the conventional welded-flange MRF connection. In response to observed Northridge earthquake damage the ICBO, in an emergency Code change, has deleted the prescribed connection from the 1994 UBC ["ICBO Board...," 1994].

- Studies of the limited survey data suggest that damage is not related to building and frame configuration, or structural detailing. Engineers and researchers studying the cause of damage and potential repair or upgrade schemes should therefore consider that MRF performance may be a function of issues not typically considered by practicing designers. That is, performance may be related to peculiar ground motions (including vertical accelerations), unique localized demands, or the reliability of material and construction quality.

- Pre-earthquake evaluation of existing steel MRF buildings should consider the likelihood and potential impact of brittle connection failure. Survey data show that approaches limited to document review and simplified analysis (e.g. FEMA 178 [FEMA, 1992]) will not account for observed behavior.

- Post-earthquake evaluation should include visual inspection and testing of some portion of MRF connections. Survey data show that assessments based on building walkthroughs (e.g. ATC-20 Rapid Evaluation Method [ATC]) may not find significant MRF damage, and that follow-up evaluations limited to visual inspection and drawing review (e.g. ATC-20 Detailed Evaluation Method [ATC]) may not uncover partially fractured welds and frame members.

\subsection{Recommendations}

The value of current survey data can be enhanced by correlating observed damage with specific estimates of local ground motion and resulting frame forces, and by experimental studies to determine the effects of weld discontinuities, root cracks, and other damage patterns on connection and frame performance. Recommended future efforts directly related to this survey include:

- Continued collection of data with the current scope and format.

- Continued use and improvement of the survey form developed in this effort both as a tool for data collection and as an indicator of useful information types and formats.

- Collection of recorded ground motion parameters for each zone or neighborhood.

- Analysis of specific or generic buildings to generate demands for damage correlation studies. Both elastic and inelastic analysis, using code lateral forces and recorded 
ground motions, should be used to assess the efficacy of simplified methods.

- Maintenance of the existing database and coordination with potential users, including designers, researchers, and building officials.

- Collection of more detailed data, especially regarding actual steel strength and weld properties.

- Development of a separate database for individual connections, as opposed to floorframes. 


\subsection{References}

American Institute of Steel Construction (AISC). Manual of Steel Construction, Allowable Stress Design. Ninth Edition, AISC, Inc., Chicago, IL, October, 1989.

American Institute of Steel Construction (AISC). Northridge Steel Update I. AISC, Inc., Chicago, IL, October, 1994.

American Welding Society (AWS) (1986). Structural Welding Code - Steel, Tenth Edition (ANSI/AWS D1.1-86). American Welding Society, Inc., 1986 (reprinted May 1987).

Applied Technology Council (ATC). Procedures for Postearthquake Safety Evaluation of Buildings (ATC-20). Applied Technology Council, Redwood City, CA. (Prepared for ATC by R. P. Gallagher Associates, Inc., San Francisco.)

Benson, Bill. Personal communication to David Bonowitz / NYA, September, 1994.

Bertero, Vitelmo V., Anderson, James C., and Krawinkler, Helmut (1994). Performance of Steel Building Structures During the Northridge Earthquake (UCB/EERC-94/09).

Earthquake Engineering Research Center, Richmond, CA, August 1994.

Bertero, V. V., Popov, E. P., and Krawinkler, H. (1972). "Beam-Column Subassemblages Under Repeated Loading." J. of the Structural Division, ASCE, v98 nST5, May, 1972.

California Strong Motion Instrumentation Program (CSMIP). 5th CSMIP Quick Report of January 25, 1994. Figure 1, cited in Shipp et al (1994).

Engelhardt, M. D. (1994). "Testing of Full Scale Steel Moment Connections, Progress Report, August 2, 1994." Unpublished.

Engelhardt, M. D. and Husain, A. S. (1993). "Cyclic-Loading Performance of Welded Flange - Bolted Web Connections." J. of Structural Engineering, v119, n12, December 1993.

Federal Emergency Management Agency (FEMA) (1992). NEHRP Handbook for the Seismic Evaluation of Existing Buildings (FEMA-178). BSSC, Washington, D.C., 1992.

Freeman, Sigmund A. (1987). "Code Designed Steel Frame Performance Characteristics." Dynamics of Structures (Proceedings of the Sessions at Structures Congress '87 related to Dynamics of Structures, Orlando, Florida, August 17-20, 1987). American Society of Civil Engineers, 1987.

Garreau, Joel. Edge City: Life on the New Frontier. Doubleday, New York, 1988. 
Hamburger, Ronald O. and Frank, Karl. "Performance of Welded Steel Moment Connections: Issues Related to Materials and Mechanical Properties, " in Invitational Workshop on Steel Seismic Issues, September 8 and 9, 1994: Strawman Papers.

Holguin, Richard. Ordinance No. by facsimile, November 14, 1994. - Personal correspondence with David Bonowitz / NYA

ICBO (1988). Uniform Building Code. International Conference of Building Officials (ICBO), Whittier, CA, 1988.

ICBO (1991). Uniform Building Code. International Conference of Building Officials (ICBO), Whittier, CA, 1991.

"ICBO Board Approves Emergency Structural Design Provision." Building Standards, September-October 1994, p26.

Malley, Jim and Saunders, Mark (1994). "Steel Moment Frame Update." Structural Engineers Association of Northern California News, vXLIX n8, August 1994.

Naeim, Farzad, ed. The Seismic Design Handbook (Chapter 5: Architectural Considerations, by Christopher Arnold). Van Nostrand Reinhold, New York, 1989.

Nabih Youssef \& Associates (NYA) (1994). "A Survey of Steel Moment-Resisting Frame Buildings Damaged by the 1994 Northridge Earthquake (Preliminary Report). " NIST GCR 94-660. Unpublished.

Popov, E. P., Amin N. R., Louie, J. C., and Stephen, R. M. (1985). "Cyclic Behavior of Large Beam-Column Assemblies." Earthquake Spectra, v1 n2, February 1985.

Popov, E. P. and Bertero, V. V. (1973). "Cyclic Loading of Steel Beams and Connections." J. of the Structural Division, ASCE, v99 nST6, June, 1973.

Popov, E. P. and Pinkney, R. B. (1969). "Cyclic Yield Reversal in Steel Building Connections." J. of the Structural Division, ASCE, v95 nST3, March 1969.

Popov, E. P. and Stephen, R. M. (1972). "Cyclic Loading of Full Size Steel Connections." Bulletin No. 21, American Iron and Steel Institute (AISI), Washington, D.C., cited in Chen (1985) and in Popov and Tsai (1987), similar to Popov and Bertero (1973).

Popov, E. P. and Tsai, K. C. (1987). "Performance of Large Steel Moment Connections Under Cyclic Loads." SEAOC Proceedings, 56th Annual Convention, October 1987, San Diego. 
Preece, Robert F. Structural Steel in the 80's - Materials, Fastening and Testing. The Steel Committee of California. Reproduced in Steel Moment Frame Connection Advisory No. 2 (Internal Working Document). SAC Joint Venture Partnership, Sacramento, October 19, 1994

Sabol, Thomas A. (1994). "Damage to Ductile Steel Frames in the Northridge Earthquake." Distributed by the Structural Engineers Association of Southern California in conjunction with the Northridge Earthquake Seminar, March 26, 1994.

SAC Joint Venture Partnership. Steel Moment Frame Connection Advisory No. 1. SAC, September 26, 1994.

SAC Joint Venture Partnership. Steel Moment Frame Connection Advisory No. 2. SAC, October 19, 1994.

SAC Joint Venture Partnership. Steel Moment Frame Connection Advisory No. 3. SAC, In Progress.

SAC Joint Venture Partnership. Program to Reduce Earthquake Hazards in Steel Moment Frame Structures (Attachment A). Submitted to the California Office of Emergency Services, July 7, 1994.

SAC Joint Venture Partnership. Session Summaries. Reports from Working Groups from the Invitational Workshop on Steel Seismic Issues, September 8 \& 9, 1994.

SEAOC (1990). Recommended Lateral Force Requirements and Commentary. Structural Engineers Association of California (SEAOC), Sacramento, 1990.

SEAOC Seismology Committee (1994). "Ductile Steel Frame Beam-Column Joints: A Discussion of Preliminary Observations, Conclusions and Recommendations." Unpublished. DRAFT copy, August 26, 1994.

Shipp, John G., Sabol, Thomas A., and Lew, Marshall (1994). "Northridge Earthquake, 17 January, 1994: Seismic Performance of Steel." Presented at the American Iron and Steel Institute 1994 General Meeting, May 18-19, 1994. Unpublished.

Skiles, J. L. and Campbell, H. H. (1994). "Why Steel Fractured in the Northridge Earthquake." Steel Moment Frame Connection Advisory No. 1. SAC Joint Venture Partnership, Sacramento, September 26, 1994.

Yanev, Peter I., Gillengerten, John D., and Hamburger, Ronald O. (1991) The Performance of Steel Buildings in Past Earthquakes. American Iron and Steel Institute, 1991. 
Appendix A: Survey Summaries 
Survey Form : new

Pre Nridge Status : OC
Survey Date : 10/12/94

Status as of 10/12/94 Inspection/Testing:

Repair/Retrofit:

$\begin{array}{ll}\text { OC } & \text { Building ID: } \quad \text { AC1 } \\ \text { IP } & \\ \text { NS } & \text { Geographic Zone: WA }\end{array}$

\section{Northridge Tag: $N$}

Non-MRF Structural Damage?

NO "None so far. Pin-based columns not yet inspected."

\section{Non-Structural Damage?}

Life Safety related:

Other. $\quad$ YES "Brick veneer deformed out-of-plane relative to original position."

Design Code : LABC

Year Designed : 1984

Year Built: 1984

Plan Irregularities?

$Y$ possible reent corners
MRF Stories Above Ground: 3

MRF Stories Below Ground: 0
Ground Floor Area [sf]: 18,000

Upper Floor Area [sf]: $\quad \mathbf{8 , 0 0 0}$
Vertical Irregularities?

Y possible geom irreg at setbacks.
Column Fy [ksi]: 36

Girder Fy [ksi]: 36

Floor Construction Type: MC/L?

Web Connection Type: B

Flange Weld Process: SMAW?
Number of Frames in Each Direction:

$\begin{array}{lll}\text { N-S } 4 & \text { NE-SW } \\ \text { E-W } 4 & \text { NW-SE }\end{array}$

Notes:

\section{MRF Connection Inspection/Testing Scope and Damage Summary}

Total No of Conns in Inspected FF's: 128

No of Connections Inspected: $\quad 31$

No of Connections Tested: $\quad 31$
No of Inspected Floor-Frames: 19

$\%$ W1 : $0.0 \%$

Damage Score :1.47

Number of Floor-Frames in each Damage Class for each inspected/tested Frame.

\begin{tabular}{|c|c|c|c|c|c|c|c|c|c|c|c|c|c|c|c|}
\hline Frame & Direction & Bays & Avg Width & Flr-Frms & TG & $B G$ & TC & $B C$ & TW & BV & & $\mathrm{s}$ & & $\mathrm{PZ}$ & $\mathrm{CW}$ \\
\hline $\begin{array}{l}10 \\
14 \\
2 \\
6 \\
\text { AN } \\
\text { AS } \\
\text { GN } \\
\text { GS }\end{array}$ & $\begin{array}{l}\text { EW } \\
\text { EW } \\
\text { EW } \\
\text { EW } \\
\text { NS } \\
\text { NS } \\
\text { NS } \\
\text { NS }\end{array}$ & \begin{tabular}{l|}
4 \\
3 \\
3 \\
3 \\
4 \\
4 \\
3 \\
4
\end{tabular} & $\begin{array}{l}30 \\
30 \\
30 \\
30 \\
30 \\
30 \\
30 \\
30\end{array}$ & \begin{tabular}{l|l} 
& \\
3 \\
3 \\
3 \\
3 \\
3 \\
2 \\
1
\end{tabular} & $\begin{array}{l}0 \\
0 \\
0 \\
0 \\
0 \\
0 \\
0 \\
0\end{array}$ & $\begin{array}{l}1 \\
0 \\
0 \\
0 \\
0 \\
0 \\
0 \\
0\end{array}$ & $\begin{array}{l}0 \\
0 \\
0 \\
0 \\
0 \\
0 \\
0 \\
0\end{array}$ & $\begin{array}{l}0 \\
2 \\
0 \\
0 \\
0 \\
0 \\
0 \\
0\end{array}$ & $\begin{array}{l}0 \\
0 \\
0 \\
0 \\
0 \\
0 \\
0 \\
0\end{array}$ & & $\begin{array}{l}7 \\
3 \\
2 \\
2 \\
3 \\
3\end{array}$ & & & $\begin{array}{l}0 \\
0 \\
0 \\
0 \\
0 \\
0 \\
0 \\
0\end{array}$ & \\
\hline
\end{tabular}




$\begin{array}{lclll}\text { Survey Form : new } & \text { Survey Date : 10/11/94 } & & \\ \text { Pre Nridge Status : OC } & \begin{array}{c}\text { Status as of 10/11/94 } \\ \text { Inspection/Testing: }\end{array} & \text { OC } & \text { Building ID: } & \text { BAK } \\ & \text { Repair/Retrofit: } & \text { C } & \text { Geographic Zone: SO }\end{array}$

Northridge Tag: $Y$

Non-MRF Structural Damage?

YES "Out of plumb 2.5 to 3 inches in the north-south direction."

Non-Structural Damage?

Life Safety related: YES "Anchors for exterior precast panels 'badly deformed.' Cracking of 1st story masonry walls."

Other:

$\begin{array}{llll}\text { Design Code : UBC } & 1979 ? & \text { MRF Stories Above Ground: } 6 & \text { Ground Floor Area [sf]: 26,000 } \\ \text { Year Designed : } 1982 & & \text { MRF Stories Below Ground: } 1 & \text { Upper Floor Area [sf]: 20,000 }\end{array}$

Year Built :

Plan Irregularities?

N

Vertical Irregularities?

$\mathbf{N}$

Column Fy [ksi]: 50

Number of Frames in Each Direction:

Girder Fy [ksi]: 36

N-S 2 NE-SW

E-W $3 \quad$ NW-SE

Floor Construction Type: MCL

Web Connection Type: B

Notes:

Flange Weld Process: $U$

\section{MRF Connection Inspection/Testing Scope and Damage Summary}

Total No of Conns in Inspected FF's: 72

No of Connections Inspected: $\quad 72$

No of Inspected Floor-Frames: 12

No of Connections Tested:

0

$\% \mathrm{~W} 1: 0.0 \%$

Damage Score :1.25

Number of Floor-Frames in each Damage Class for each inspected/tested Frame.

\begin{tabular}{|l|l|r|r|r|r|r|r|r|r|r|r|r|r|}
\hline Frame & Direction & Bays & Avg Width & Flr-Frms & TG & BG & TC & BC & TW & BW & S & PZ & CW \\
\hline 13 & NS & 3 & 28 & 6 & 0 & 0 & 0 & 0 & & 5 & 0 & 0 & 0 \\
3 & NS & 3 & 28 & 6 & 0 & 0 & 0 & 0 & & 5 & 0 & 0 & 0 \\
\hline
\end{tabular}




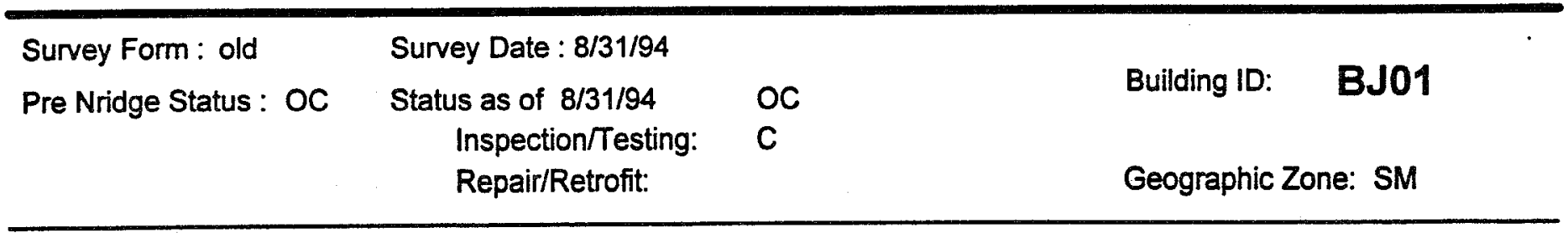

Northridge Tag: N

Non-MRF Structural Damage?

Non-Structural Damage?

Life Safety related:

Other: $\quad$ YES "Glass block feature wall damage. Ceilings \& Partitions \& Shelving."

$\begin{array}{llll}\text { Design Code : UBC } & 1988 & \text { MRF Stories Above Ground:4 } & \text { Ground Floor Area [sf]: 13,550 } \\ \text { Year Designed : } 1989 & & \text { MRF Stories Below Ground: } & \text { Upper Floor Area [sf]: 13,550 } \\ \text { Year Built: } 1990 & & \text { Vertical Irregularities? } \\ \begin{array}{l}\text { Plan Irregularities? } \\ N\end{array} & \end{array}$

Column Fy [ksi]: 50

Girder Fy [ksi]: 36

Floor Construction Type: MC

Web Connection Type:

Flange Weld Process:
Number of Frames in Each Direction:

$\begin{array}{ll}\text { N-S } & \text { NE-SW } 2 \\ \text { E-W } & \text { NW-SE } 5\end{array}$

Notes:

\section{MRF Connection Inspection/Testing Scope and Damage Summary \\ Total No of Conns in Inspected FF's: 110 \\ No of Connections Inspected: $\quad 110$ \\ No of Connections Tested: $\quad 110$ \\ No of Inspected Floor-Frames: 23 \\ $\% \mathrm{~W} 1$ : $90.0 \%$ \\ Damage Score :1.36}

Number of Floor-Frames in each Damage Class for each inspected/tested Frame.

\begin{tabular}{|l|l|r|r|r|r|r|r|r|r|r|r|r|r|}
\hline Frame & Direction & Bays & Avg Width & Flr-Frms & TG & BG & TC & BC & TW & BW & S & PZ & CW \\
\hline 3 & NESW & 4 & & 3 & 0 & 1 & 1 & 2 & 3 & 3 & 2 & 0 & 0 \\
6 & NESW & 4 & & 3 & 0 & 2 & 0 & 2 & 1 & 3 & 0 & 0 & 0 \\
B & NWSE & 3 & & 4 & 0 & 0 & 0 & 0 & 4 & 2 & 0 & 0 & 0 \\
CWS & NWSE & 1 & & 3 & 0 & 0 & 0 & 0 & 0 & 3 & 0 & 0 & 0 \\
D & NWSE & 1 & & 3 & 0 & 0 & 0 & 0 & 0 & 3 & 0 & 0 & 0 \\
E & NWSE & 1 & & 3 & 0 & 0 & 0 & 0 & 0 & 3 & 0 & 0 & 0 \\
$G$ & NWSE & 3 & & 4 & 0 & 0 & 0 & 0 & 3 & 4 & 0 & 0 & 0 \\
\hline
\end{tabular}




\begin{tabular}{lllll}
\hline Survey Form : comb & Survey Date : 10/13/94 & & \\
Pre Nridge Status : UC & $\begin{array}{c}\text { Status as of } 8 / 31 / 94 \\
\text { Inspection/Testing: }\end{array}$ & UC & B \\
& Repair/Retrofit: & C & Building ID: & BJO2E \\
& & Geographic Zone: UC \\
\hline
\end{tabular}

Northridge Tag: $\mathbf{N}$

Non-MRF Structural Damage?

YES "Minor cracks in stair and elevator enclosure. CMU walls in concrete parking structure below. Minor fillet weld cracks in misc. connections to MRF columns (non-MRF members)."

Non-Structural Damage?

Life Safety related: na: building under construction

Other:

na: building under construction

\begin{tabular}{|c|c|c|c|}
\hline $\begin{array}{l}\text { Design Code : UBC } \\
\text { Year Designed : } 1992\end{array}$ & 1991 & $\begin{array}{l}\text { MRF Stories Above Ground: } 3 \\
\text { MRF Stories Below Ground: } 0\end{array}$ & $\begin{array}{l}\text { Ground Floor Area [sf]: } 29,000 \\
\text { Upper Floor Area [sf]: } 29,000\end{array}$ \\
\hline Year Built: & & & \\
\hline $\begin{array}{l}\text { Plan Irregularities? } \\
\mathbf{N}\end{array}$ & & $\underset{N}{\text { Vertic }}$ & ies? \\
\hline
\end{tabular}

Column Fy [ksi]: 50

Girder Fy [ksi]: 36

Floor Construction Type: MC

Web Connection Type: WB

Flange Weld Process: $U$
Number of Frames in Each Direction:

$\begin{array}{ll}\text { N-S } 6 & \text { NE-SW } \\ \text { E-W } 4 & \text { NW-SE } \\ \text { Notes: } & \end{array}$

\section{MRF Connection Inspection/Testing Scope and Damage Summary}

Total No of Conns in Inspected FF's: 135

No of Connections Inspected:

121

No of Connections Tested:
No of Inspected Floor-Frames: 27

$\%$ W1: $50.0 \%$

Damage Score :3.30

Number of Floor-Frames in each Damage Class for each inspected/tested Frame.

\begin{tabular}{|l|l|r|r|r|r|r|r|r|r|r|r|r|r|}
\hline Frame & Direction & Bays & Avg Width & Flr-Frms & TG & BG & TC & BC & TW & BW & S & PZ & CW \\
\hline $22 C$ & NS & 3 & 34 & 1 & 0 & 0 & 0 & 1 & 1 & 1 & 0 & 1 & 1 \\
$22 N$ & NS & 3 & 34 & 3 & 0 & 0 & 1 & 3 & 1 & 3 & 1 & 2 & 1 \\
$22 S$ & NS & 3 & 34 & 3 & 0 & 0 & 0 & 2 & 1 & 3 & 2 & 2 & 1 \\
$29 C$ & NS & 3 & 34 & 3 & 0 & 0 & 0 & 2 & 2 & 2 & 0 & 0 & 1 \\
$29 N$ & NS & 3 & 34 & 2 & 0 & 0 & 0 & 2 & 0 & 2 & 0 & 1 & 0 \\
$29 S$ & NS & 3 & 34 & 3 & 0 & 0 & 0 & 3 & 2 & 2 & 0 & 0 & 1 \\
A & EW & 3 & 18 & 3 & 0 & 0 & 0 & 1 & 1 & 3 & 0 & 0 & 0 \\
D & EW & 3 & 18 & 3 & 0 & 0 & 0 & 1 & 1 & 3 & 1 & 0 & 0 \\
G & EW & 4 & 18 & 3 & 0 & 0 & 0 & 0 & 1 & 3 & 0 & 1 & 0 \\
K & EW & 3 & 18 & 3 & 0 & 0 & 0 & 1 & 1 & 1 & 0 & 0 & 0 \\
\hline
\end{tabular}


Survey Form : new

Pre Nridge Status : OC
Survey Date : 9/29/94

Status as of $9 / 29 / 94$

OC

Building ID:

BJ04

Inspection/Testing:

Repair/Retrofit:
C

IP
Geographic Zone: SO

Northridge Tag: $Y$

Non-MRF Structural Damage?

YES "At 2nd floor, bolts in non-frame beams spanning N-S were sheared, 5 locations total: Note that A307 bolts were used in error. Cracks/spalls in first floor concrete near most frame column base plates." NOTE: Yellow tag was based on this and LS-related non-struc damage, not on MRF damage, which was unseen. Tag was removed after preliminary repairs. Building was not retagged after discovery of MRF damage.

Non-Structural Damage?

Life Safety related: YES "Stud wall (exterior building enclosure) separated from floor @ 2nd and 3rd floors. NE corner stair post (steel TS) had lost anchorage to supporting block wall."

Other:

Design Code : LABC 1980 MRF Stories Above Ground:4

Year Designed : 1981

Year Built :

1981

Plan Irregularities?

N

\section{Column Fy [ksi]: 36}

Girder Fy [ksi]: 36

Floor Construction Type: MCL

Web Connection Type: B

Flange Weld Process:

\section{MRF Stories Below Ground: 0}

Ground Floor Area [sf]: 10,600

Upper Floor Area [sf]: $\quad 10,600$

Vertical Irregularities?

$Y$ possible geom irreg at floor 3 frame 2 setback.
Number of Frames in Each Direction:

$\begin{array}{ll}\text { N-S } 2 & \text { NE-SW } \\ \text { E-W } 2 & \text { NW-SE }\end{array}$

Notes:

\section{MRF Connection Inspection/Testing Scope and Damage Summary}

Total No of Conns in Inspected FF's: 74

No of Connections inspected: $\quad 73$

No of Inspected Floor-Frames: 16

No of Connections Tested:

73

$\%$ W1 : $30.0 \%$

Damage Score :1.25

Number of Floor-Frames in each Damage Class for each inspected/tested Frame.

\begin{tabular}{|l|l|r|r|r|r|r|r|r|r|r|r|r|r|}
\hline Frame & Direction & Bays & Avg Width & Fir-Frms & TG & BG & TC & BC & TW & BW & S & PZ & CW \\
\hline 2 & NS & 3 & 21 & 4 & 0 & 0 & 0 & 1 & 1 & 4 & 0 & 0 & 0 \\
6 & NS & 2 & 27 & 4 & 0 & 0 & 0 & 0 & 0 & 3 & 0 & 0 & 0 \\
E & EW & 2 & 29 & 4 & 0 & 0 & 0 & 0 & 0 & 4 & 0 & 0 & 0 \\
EW & 2 & 29 & 4 & 0 & 0 & 0 & 0 & 0 & 3 & 0 & 0 & 0 \\
\hline
\end{tabular}




\begin{tabular}{lllll}
\hline Survey Form : new & $\begin{array}{c}\text { Survey Date : 10/6/94 } \\
\text { Pre Nridge Status : OC } \\
\text { Status as of 10/6/94 } \\
\text { Inspection/Testing: } \\
\text { Repair/Retrofit: }\end{array}$ & $\begin{array}{l}\text { OC } \\
\text { NS }\end{array}$ & Building ID: & BJ05 \\
& Repraphic Zone: NR \\
\hline
\end{tabular}

Northridge Tag : N

Non-MRF Structural Damage?

YES "Northerly 2" permanent displacement @ roof (11th floor)."

Non-Structural Damage?

Life Safety related: NO

Other:

YES "Ceilings, furnishings, floor tiles, lobby stonework damaged."

\begin{tabular}{|c|c|c|c|}
\hline $\begin{array}{l}\text { Design Code : LABC } \\
\text { Year Designed : } 1990\end{array}$ & 1088 & $\begin{array}{l}\text { MRF Stories Above Ground: } 11 \\
\text { MRF Stories Below Ground: } 1\end{array}$ & $\begin{array}{l}\text { Ground Floor Area [sf]: } 29,000 \\
\text { Upper Floor Area [sf]: } 25,000\end{array}$ \\
\hline
\end{tabular}

Year Built : 1991

Plan Irregularities?

Y out-of-plane offsets at floors 2 and 9.

Vertical Irregularities?

$Y$ possible mass irreg at floor 9 setback.

Column Fy [ksi]: 50

Girder Fy [ksi]: 36

Floor Construction Type: MC

Web Connection Type: WB

Flange Weld Process: SMAW?
Number of Frames in Each Direction:

$\begin{array}{ll}\text { N-S } 4 & \text { NE-SW } \\ \text { E-W } 2 & \text { NW-SE }\end{array}$

Notes:

\section{MRF Connection Inspection/Testing Scope and Damage Summary}

Total No of Conns in Inspected FF's: 548

No of Connections Inspected: $\quad 361$

No of Connections Tested: $\quad 361$
No of Inspected Floor-Frames: 55

$\% W_{1}: 70.0 \%$

Damage Score :1.10

Number of Floor-Frames in each Damage Class for each inspected/tested Frame.

\begin{tabular}{|l|l|r|r|r|r|r|r|r|r|r|r|r|r|}
\hline Frame & Direction & Bays & Avg Width & Flr-Frms & TG & BG & TC & BC & TW & BW & S & PZ & CW \\
\hline 16 & NS & 6 & 18 & 10 & 0 & 0 & 0 & 5 & 0 & 9 & 0 & 0 & 0 \\
18 & NS & 3 & 16 & 6 & 0 & 0 & 0 & 0 & 0 & 0 & 0 & 0 & 0 \\
5 & NS & 3 & 16 & 7 & 0 & 0 & 0 & 0 & 0 & 1 & 0 & 0 & 0 \\
7 & NS & 6 & 18 & 10 & 0 & 0 & 1 & 4 & 1 & 9 & 0 & 0 & 0 \\
D & EW & 7 & 16 & 8 & 0 & 0 & 0 & 2 & 0 & 8 & 0 & 0 & 0 \\
F.5 & EW & 3 & 32 & 3 & 0 & 0 & 0 & 0 & 0 & 2 & 0 & 0 & 0 \\
1.5 & EW & 3 & 32 & 4 & 0 & 0 & 0 & 0 & 0 & 0 & 0 & 0 & 0 \\
L & EW & 7 & 16 & 7 & 0 & 0 & 0 & 4 & 2 & 6 & 0 & 0 & 0 \\
\hline
\end{tabular}




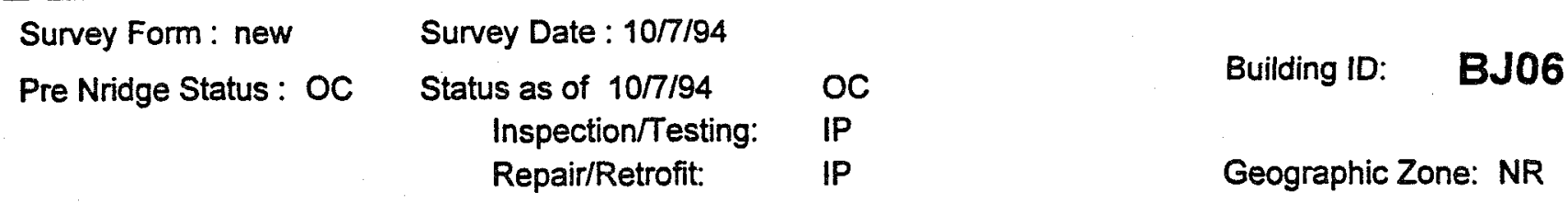

Northridge Tag: $\mathrm{N}$

Non-MRF Structural Damage?

YES "Insignificant (1/4") lateral set determined by survey."

Non-Structural Damage?

Life Safety related:

Other: $\quad$ YES "spalling at precast connections;" damage/breakage to "floor tiles, partitions, windows, ceilings;" "furnishings fell over."

Design Code : LABC

1988

Year Designed : 1989

Year Built :

1991

Plan Irregularities?

$Y$ diaph discont at $50 \times 100 \mathrm{ft}$ atrium opng.

Column Fy [ksi]:50

Girder Fy [ksi]: 36

Floor Construction Type: MC

Web Connection Type: WB

Flange Weld Process: SMAW?
MRF Stories Above Ground:2

MRF Stories Below Ground: 0
Ground Floor Area [sf]: 51,000

Upper Floor Area [sf]: 51,000
Vertical Irregularities?

N

Number of Frames in Each Direction:

$\begin{array}{lll}N-S & 2 & \text { NE-SW } \\ \text { E-W } 3 & \text { NW-SE }\end{array}$

Notes:

\section{MRF Connection Inspection/Testing Scope and Damage Summary \\ Total No of Conns in Inspected FF's: 84 \\ No of Connections Inspected: \\ No of Inspected Floor-Frames: 12 \\ No of Connections Tested: \\ $\%$ W1 : $75.0 \%$ \\ Damage Score :2.21}

Number of Floor-Frames in each Damage Class for each inspected/tested Frame.

\begin{tabular}{|l|l|r|r|r|r|r|r|r|r|r|r|r|r|}
\hline Frame & Direction & Bays & Avg Width & Flr-Frms & TG & BG & TC & BC & TW & BW & S & PZ & CW \\
\hline 1 & NS & 5 & 32 & 2 & 0 & 0 & 0 & 2 & 1 & 2 & 1 & 0 & 2 \\
14 & NS & 5 & 32 & 2 & 0 & 0 & 0 & 1 & 0 & 2 & 1 & 0 & 1 \\
A & EW & 1 & 32 & 1 & 0 & 0 & 0 & 0 & 0 & 0 & 0 & 0 & 0 \\
$C$ & EW & 1 & 32 & 1 & 0 & 0 & 0 & 0 & 0 & 0 & 0 & 0 & 0 \\
E & EW & 3 & 32 & 2 & 0 & 0 & 0 & 0 & 0 & 2 & 0 & 0 & 0 \\
L & EW & 4 & 32 & 2 & 0 & 0 & 0 & 0 & 0 & 2 & 0 & 0 & 0 \\
$S$ & EW & 3 & 32 & 2 & 0 & 0 & 0 & 0 & 0 & 1 & 0 & 0 & 0 \\
\hline
\end{tabular}




\begin{tabular}{|c|c|c|c|}
\hline Survey Form : new & Survey Date : 10/21/94 & & \\
\hline Pre Nridge Status : OC & $\begin{array}{l}\text { Status as of } 10 / 21 / 94 \\
\text { InspectionTesting: } \\
\text { Repair/Retrofit: }\end{array}$ & $\begin{array}{l}\text { OC } \\
\text { IP } \\
\text { NS }\end{array}$ & $\begin{array}{l}\text { Building ID: } \quad \text { BJ09 } \\
\text { Geographic Zone: WH }\end{array}$ \\
\hline
\end{tabular}

Northridge Tag: N

Non-MRF Structural Damage?

NO "none"

Non-Structural Damage?

Life Safety related: YES "Piping, conduit, mechanical system damage - for Hospital, this was Lifo-Safety related."

Other. YES "partitions, ceilings, expansion joint materialilashing at adjacent buildings damaged."

$\begin{array}{lll}\text { Design Code : T24 CBC } 1979 & \text { MRF Stories Above Ground: } 5 & \text { Ground Floor Area [sf]: } 90,000 \\ \text { Year Designed : } 1982 & \text { MRF Stories Below Ground: } 0 & \text { Upper Floor Area [sf]: } 50,000\end{array}$

Year Built : 1983

Plan Irregularities?

$Y$ reent comers at floor 3 and above.

Vertical Irregularities?

Y possible mass irreg at fioor 3 setback.

Column Fy [ksi]: 50

Girder Fy [ksi]: 36

Floor Construction Type: MC

Web Connection Type: B

Flange Weld Process: U
Number of Frames in Each Direction:
N-S 8
NE-SW
E-W 8
NW-SE

Notes:

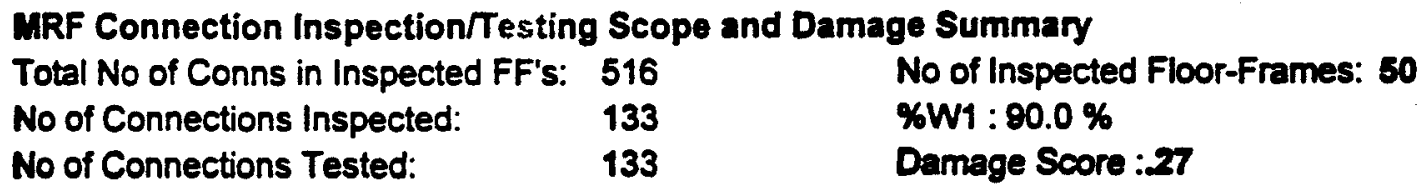

MRF Connection Inspection/Testing Scope and Damage Summary

Total No of Conns in Inspected FF's: $\mathbf{5 1 6}$

No of Connections Tested:

133

No of Inspected Floor-Frames: 50

Damage Score: 27 
Number of Floor-Frames in each Damage Class for each inspected/tested Frame.

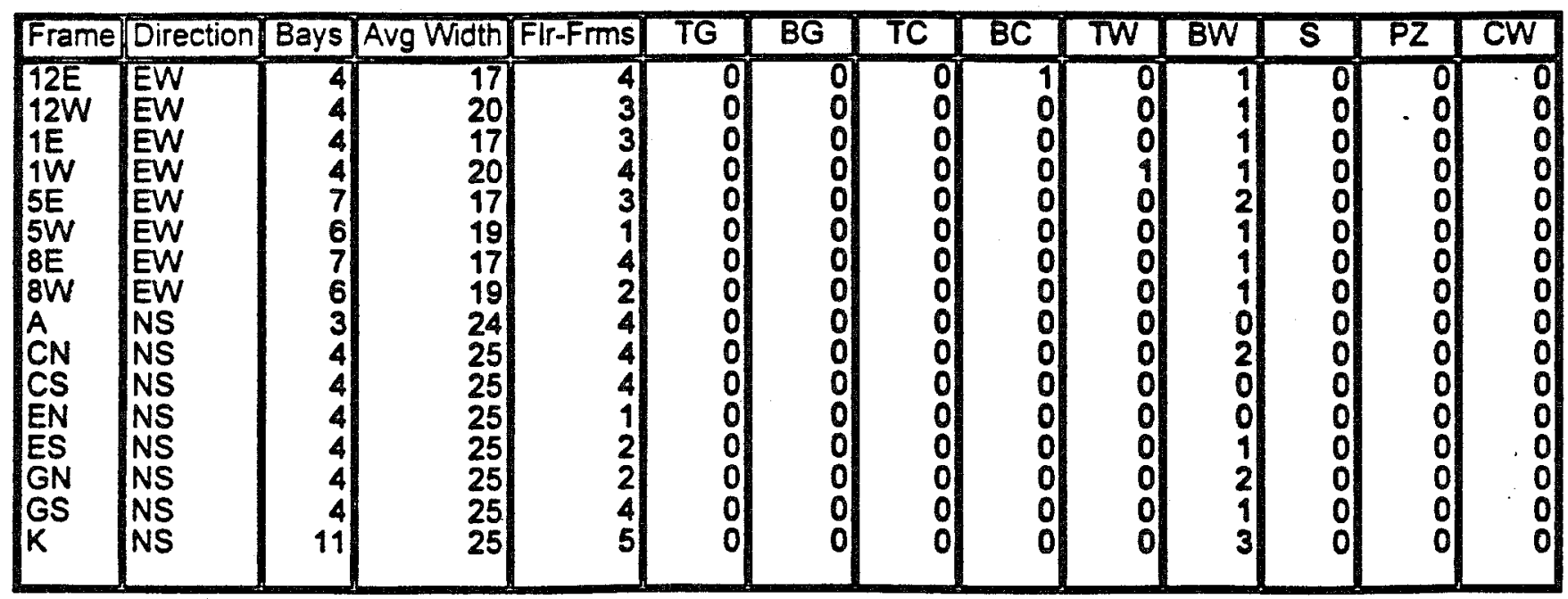


Friday, January 13, 1995

\begin{tabular}{lrlll}
\hline Survey Form: new & Survey Date : 10/4/94 & & Building ID: & BJ10 \\
Pre Nridge Status : OC & $\begin{array}{c}\text { Status as of 10/4/94 } \\
\text { Inspection/Testing: } \\
\text { Repair/Retrofit: }\end{array}$ & $\begin{array}{l}\text { OC } \\
\text { na }\end{array}$ & Geographic Zone: WH
\end{tabular}

Northridge Tag: $\mathbf{N}$

Non-MRF Structural Damage?

NO "None."

Non-Structural Damage?

Life Safety related:

Other. YES "partitions, plumbing, piping, no life safety impact"

Design Code : Unknown

Year Designed : 1990

Year Built : 1991

Plan Irregularities?

$\mathbf{N}$

Column Fy [ksi]: 50

Girder Fy [ksi]: 36

Floor Construction Type: $\mathrm{MCL}$

Web Connection Type: B

Flange Weld Process: U
MRF Stories Above Ground: 5

MRF Stories Below Ground: 1
Ground Floor Area [sf]: 50,000

Upper Floor Area [sf]: 50,000

Vertical Irregularities?

N

Number of Frames in Each Direction:

$\begin{array}{ll}\text { N-S } 4 & \text { NE-SW } \\ \text { E-W } 4 & \text { NW-SE }\end{array}$

Notes:

\section{MRF Connection Inspection/Testing Scope and Damage. Summary}

Total No of Conns in Inspected FF's: 86

No of Connections Inspected:

35

No of Connections Tested:

35

No of Inspected Floor-Frames: 13

\%W1 :

Damage Score :0.00

Number of Floor-Frames in each Damage Class for each inspectedtested Frame.

\begin{tabular}{|l|l|r|r|r|r|r|r|r|r|r|r|r|r|}
\hline Frame & Direction & Bays & Avg Width & Flr-Frms & TG & BG & TC & BC & TW & BW & S & PZ & CW \\
\hline 1 & EW & 4 & 20 & 1 & 0 & 0 & 0 & 0 & 0 & 0 & 0 & 0 & 0 \\
12 & EW & 4 & 20 & 2 & 0 & 0 & 0 & 0 & 0 & 0 & 0 & .0 & 0 \\
9 & EW & 4 & 20 & 1 & 0 & 0 & 0 & 0 & 0 & 0 & 0 & 0 & 0 \\
AN & NS & 3 & 30 & 3 & 0 & 0 & 0 & 0 & 0 & 0 & 0 & 0 & 0 \\
GN & NS & 3 & 30 & 1 & 0 & 0 & 0 & 0 & 0 & 0 & 0 & 0 & 0 \\
GS & NS & 3 & 30 & 2 & 0 & 0 & 0 & 0 & 0 & 0 & 0 & 0 & 0 \\
J & NS & 3 & 24 & 3 & 0 & 0 & 0 & 0 & 0 & 0 & 0 & 0 & 0 \\
\hline
\end{tabular}


Survey Form : new

Survey Date : 9/30/94

Pre Nridge Status : UC

Status as of $9 / 30 / 94$

UC

Building ID: $\quad$ BJ11

Inspection/Testing: IP

Repair/Retrofit:

IP

Geographic Zone: WH

Northridge Tag: $\mathbf{N}$

Non-MRF Structural Damage?

NO "None"

Non-Structural Damage?

Life Safety related:

Other.

YES "Required miscellaneous repairs to paint, plumbing, etc."

Design Code :T24 CBC

Year Designed : 1991

Year Built :

1992

Plan IrTegularities? N

Column Fy [ksi]:50?

Girder Fy [ksi]: 36 ?

Floor Construction Type: MC/L?

Web Connection Type: WB

Flange Weld Process: U
MRF Stories Above Ground: 5

MRF Stories Below Ground: 1
Ground Floor Area [st]: 26,000

Upper Floor Area [sf]: 26,000

Vertical Irregularities?

N

Number of Frames in Each Direction:

$\begin{array}{ll}\text { N-S } 4 & \text { NE-SW } \\ \text { E-W } 4 & \text { NW-SE }\end{array}$

Notes:

\section{MRF Connection Inspection/Testing Scope and Damage Summary \\ Total No of Conns in Inspected FF's: 156 \\ No of Connections Inspected: $\quad 138$ \\ No of Inspected Floor-Frames: 26 \\ No of Connections Tested: \\ $\% W 1: 100.0 \%$ \\ Damage Score :.98}

Number of Floor-Frames in each Damage Class for each inspected/tested Frame.

\begin{tabular}{|l|l|r|r|r|r|r|r|r|r|r|r|r|r|}
\hline Frame & Direction & Bays & Avg Width & FIr-Frms & TG & BG & TC & BC & TW & BW & S & PZ & CW \\
\hline 1 & EW & 3 & 17 & 3 & 0 & 0 & 0 & 2 & 1 & 1 & 0 & 0 & 0 \\
12 & EW & 3 & 17 & 4 & 0 & 0 & 1 & 1 & 1 & 3 & 0 & 0 & 0 \\
5 & EW & 3 & 17 & 3 & 0 & 0 & 1 & 2 & 1 & 1 & 0 & 0 & 0 \\
8 & EW & 3 & 17 & 3 & 0 & 0 & 0 & 0 & 1 & 1 & 0 & 0 & 0 \\
$\mathrm{CCN}$ & NS & 3 & 25 & 3 & 0 & 0 & 0 & 1 & 0 & 2 & 0 & 0 & 0 \\
$\mathrm{CCS}$ & NS & 3 & 25 & 3 & 0 & 0 & 0 & 0 & 0 & 0 & 0 & 0 & 0 \\
YN & NS & 3 & 25 & 3 & 0 & 0 & 0 & 1 & 1 & 3 & 0 & 0 & 0 \\
YS & NS & 3 & 25 & 4 & 0 & 0 & 0 & 0 & 3 & 4 & 0 & 0 & 0 \\
\hline
\end{tabular}




\begin{tabular}{|c|c|c|c|}
\hline $\begin{array}{l}\text { Survey Form : new } \\
\text { Pre Nridge Status : OC }\end{array}$ & $\begin{array}{l}\text { Survey Date : } 10 / 13 / 94 \\
\text { Status as of } 10 / 13 / 94 \\
\text { Inspection/Testing: } \\
\text { Repair/Retrofit: }\end{array}$ & $\begin{array}{l}\text { OC } \\
\text { C } \\
\text { NS }\end{array}$ & $\begin{array}{l}\text { Building ID: } \quad \text { BJ18 } \\
\text { Geographic Zone: WH }\end{array}$ \\
\hline
\end{tabular}

Northridge Tag : $\mathrm{N}$

Non-MRF Structural Damage?

YES "Possible settlement of soil adjacent to basement wall. Block wall minor cracking."

Non-Structural Damage?

Life Safety related:

Other.

YES "Exterior cladding cracked. Ceiling damage. Mechanical units shifted off isolators."

$\begin{array}{llll}\text { Design Code : LABC? } & 1985 ? & \text { MRF Stories Above Ground:3 } & \text { Ground Floor Area [sf]: 21,000 } \\ \text { Year Designed : } 1987 & & \text { MRF Stories Below Ground: } 0 & \text { Upper Floor Area [sf]: 21,000 }\end{array}$

Year Built : 1989

Plan Irregularities?

Y reent comer, L-shaped floors.

Vertical Irregularities?

$\mathrm{N}$ but note discontinuous top story columns landing midspan on floor 3 girders.

Column Fy [ksi]: 50

Number of Frames in Each Direction:

Girder Fy [ksi]: 36

$\begin{array}{ll}\text { N-S } 3 & \text { NE-SW } \\ \text { E-W } 3 & \text { NW-SE } \\ \text { Notes: } & \end{array}$

Floor Construction Type: $M C$

Web Connection Type: B

Notes:

Flange Weld Process: U

MRF Connection Inspection/Testing Scope and Damage Summary

Total No of Conns in Inspected FF's: 68

No of Connections Inspected: $\quad 68$

No of Inspected Floor-Frames: 24

No of Connections Tested:

68

$\% W_{1}: 75.0 \%$

Damage Score :.64

Number of Floor-Frames in each Damage Class for each inspected/tested Frame.

\begin{tabular}{|l|l|r|r|r|r|r|r|r|r|r|r|r|r|}
\hline Frame & Direction & Bays & Avg Width & FIr-Frms & TG & BG & TC & BC & TW & BW & S & PZ & CW \\
\hline 1 & NS & 1 & 30 & 4 & 0 & 0 & 0 & 0 & 0 & 3 & 0 & 0 & 0 \\
3 & NS & 2 & 30 & 4 & 0 & 0 & 0 & 1 & 0 & 2 & 0 & 0 & 0 \\
6 & NS & 1 & 36 & 4 & 0 & 0 & 0 & 0 & 0 & 3 & 0 & 0 & 0 \\
A & EW & 1 & 30 & 4 & 0 & 0 & 0 & 0 & 0 & 1 & 0 & 0 & 0 \\
C & EW & 3 & 30 & 4 & 0 & 0 & 0 & 0 & 1 & 1 & 0 & 0 & 0 \\
G & EW & 1 & 36 & 4 & 0 & 0 & 0 & 1 & 0 & 4 & 0 & 0 & 0 \\
\hline
\end{tabular}


Survey Form : new

Pre Nridge Status : OC
Survey Date : 10/10/94

Status as of $10 / 10 / 94$

Inspection/Testing:

Repair/Retrofit:
OC

Building ID: DM1

C

C

Geographic Zone: LAX

Northridge Tag: $N$

Non-MRF Structural Damage?

NO "None"

Non-Structural Damage?

Life Safety related: YES "Stair system worked as non-structural building braces and showed damage."

Other: YES "Drywall and plaster in stainwells cracked at each floor."

\begin{tabular}{lllll}
\hline Design Code : UBC & 1969 & MRF Stories Above Ground: 15 & Ground Floor Area [sf]: 60,000 \\
Year Designed : 1970 & & MRF Stories Below Ground: 2 & Upper Floor Area [sf]: 21,000
\end{tabular}

Year Built: 1971

Plan Irregularities?

N

Vertical Irregularities?

$Y$ possible soft story \& geom irreg at setback above podium base.

Column Fy [ksi]: 50

Number of Frames in Each Direction:

Girder Fy [ksi]: 36

$\begin{array}{lll}\text { N-S } 2 & \text { NE-SW } \\ \text { E-W } 2 & \text { NW-SE }\end{array}$

Floor Construction Type: MC

Notes:

Web Connection Type: W

Flange Weld Process: U

\section{MRF Connection Inspection/Testing Scope and Damage Summary}

Total No of Conns in Inspected FF's: 62

No of Connections Inspected: $\quad 13$

No of Inspected Floor-Frames: 5

No of Connections Tested:

13

$\%$ W1 :

Damage Score :0.00

Number of Floor-Frames in each Damage Class for each inspected/tested Frame.

\begin{tabular}{|l|l|r|r|r|r|r|r|r|r|r|r|r|r|}
\hline Frame & Direction & Bays & Avg Width & Fir-Frms & TG & BG & TC & BC & TW & BW & S & PZ & CW \\
\hline 4 & EW & 5 & 30 & 2 & 0 & 0 & 0 & 0 & 0 & 0 & 0 & 0 & 0 \\
A & NS & 7 & 15 & 1 & 0 & 0 & 0 & 0 & 0 & 0 & 0 & 0 & 0 \\
\hline
\end{tabular}


Survey Form : new

Pre Nridge Status : OC
Survey Date : 9/29/94

$\begin{array}{cc}\text { Status as of 9/29/94 } & \text { OC } \\ \text { Inspection/Testing: } & \text { C } \\ \text { Repair/Retrofit: } & \text { C }\end{array}$

Building ID: EQE1

Geographic Zone: SC

\section{Northridge Tag : YG}

Non-MRF Structural Damage?

YES "2" permanent deflection to south at roof, 1-3/8" at ground floor. 1-3/8" permanent deflection to west at roof, 1 " at ground floor."

Non-Structural Damage?

Life Safety related:

Other: $\quad$ YES "Buckled single angle out-of-plane braces for precast panels. Chipped corners and minor cracking of some precast panels. Some broken glass, dropped ceiling tiles, and partition wall damage."

Design Code: UBC

Year Designed : 1991

Year Built : 1992

Plan Irregularities?

N

1988

MRF Stories Above Ground: 4 MRF Stories Below Ground: 0

Ground Floor Area [sf]: 21,200

Upper Floor Area [sf]: 21,500
Vertical Irregularities?

$\mathrm{N}$

Number of Frames in Each Direction:

$\begin{array}{lll}\text { N-S } & 2 & \text { NE-SW } \\ \text { E-W } 2 & \text { NW-SE }\end{array}$

Notes:

Web Connection Type: WB

Flange Weld Process: FCAW

\section{MRF Connection Inspection/Testing Scope and Damage Summary}

Total No of Conns in Inspected FF's: 112

No of Connections Inspected: $\quad 112$

No of Inspected Floor-Frames: 16

No of Connections Tested:

$\% \mathrm{~W} 1: 0.0 \%$

Damage Score :4.31

Number of Floor-Frames in each Damage Class for each inspected/tested Frame.

\begin{tabular}{|l|l|r|r|r|r|r|r|r|r|r|r|r|r|}
\hline Frame & Direction & Bays & Avg Width & Frr-Frms & TG & BG & TC & BC & TW & BW & S & PZ & CW \\
\hline 1 & NS & 4 & 20 & 4 & 0 & 0 & 0 & 4 & 0 & 0 & 2 & 0 & 3 \\
10 & NS & 4 & 20 & 4 & 0 & 2 & 0 & 4 & 0 & 0 & 2 & 0 & 3 \\
$B$ & EW & 3 & 23 & 4 & 0 & 1 & 0 & 4 & 0 & 0 & 2 & 0 & 0 \\
$M$ & EW & 3 & 20 & 4 & 0 & 1 & 0 & 4 & 0 & 0 & 2 & 0 & 1 \\
\hline
\end{tabular}




\section{Survey Form : new}

Pre Nridge Status : OC

\section{Survey Date : 9/29/94}

Status as of $9 / 29 / 94$ Inspection/Testing: Repair/Retrofit:

OC
C

\section{Building ID: EQE2}

Geographic Zone: SC

Northridge Tag : YG

Non-MRF Structural Damage?

YES "4" permanent deflection to Northwest at roof. Crack across diaphragm with 2" separation. Pullout failure of pre-cast attachments. Failure of non-moment beam connection at drop of roof about 4". Pullout of roof from block walls. Pounding damage of block walls with roof diaphragm and with adjacent parking structure."

Non-Structural Damage?

Life Safety related:

Other:

YES "Extensive partition wall, ceiling, and glass damage. Cracked precast panels."

\begin{tabular}{llll}
\hline Design Code : UBC 1988 & MRF Stories Above Ground: 1 & Ground Floor Area [sf]: 27,000 \\
Year Designed : 1991 & & MRF Stories Below Ground: 0 & Upper Floor Area [sf]: 27,000
\end{tabular}

Year Built : 1992

Plan Irregularities?

$Y$ reent corner: L-shaped floors.

Vertical Irregularities?

N

Column Fy [ksi]: 36

Girder Fy [ksi]: 36

Floor Construction Type: MC

Web Connection Type: WB

Flange Weld Process: FCAW
Number of Frames in Each Direction:

$\begin{array}{ll}\text { N-S } 3 & \text { NE-SW } \\ \text { E-W } 3 & \text { NW-SE } \\ \text { Notes: } & \end{array}$

\section{MRF Connection Inspection/Testing Scope and Damage Summary}

Total No of Conns in Inspected FF's: 20

No of Connections Inspected: $\quad 20$

No of Inspected Floor-Frames: 6

No of Connections Tested:

20

$\% W_{1}: 0.0 \%$

Damage Score :4.17

Number of Floor-Frames in each Damage Class for each inspected/tested Frame.

\begin{tabular}{|l|l|l|r|r|r|r|r|r|r|r|r|r|r|}
\hline Frame & Direction & Bays & Avg Width & Fir-Frms & TG & BG & TC & BC & TW & BW & S & PZ & CW \\
\hline $2 L$ & NS & 2 & 24 & 1 & 0 & 0 & 0 & 1 & 0 & 0 & 0 & 0 & 1 \\
$6 L$ & NS & 1 & 27 & 1 & 0 & 0 & 0 & 1 & 0 & 0 & 0 & 0 & 1 \\
KL & EW & 1 & 30 & 1 & 0 & 0 & 0 & 0 & 0 & 0 & 0 & 0 & 0 \\
RL & EW & 2 & 24 & 1 & 0 & 0 & 0 & 1 & 0 & 0 & 0 & 0 & 1 \\
RL & NS & 2 & 24 & 1 & 0 & 0 & 0 & 1 & 0 & 0 & 0 & 0 & 1 \\
\hline
\end{tabular}


Survey Form : old

Pre Nridge Status : UC

\section{Survey Date : 8/23/94}

Status as of $8 / 23 / 94$

Inspection/Testing:

Repair/Retrofit:
UC

C

IP
Building ID: $\quad$ ESI1

Geographic Zone: WLA

Northridge Tag: N

Non-MRF Structural Damage?

YES "Slip connections reached end of travel at lowest level of bldg. \& angles bolted to web were slightly bent."

Non-Structural Damage?

Life Safety related: NO "Building not occupied."

Other:

NO "None. Cladding not on."

$\begin{array}{llll}\text { Design Code : UBC } & 1991 & \text { MRF Stories Above Ground: } 5 & \text { Ground Floor Area [sf]: } \\ \text { Year Designed : } 1993 & & \text { MRF Stories Below Ground: } 0 & \text { Upper Floor Area [sf]: } 11,800\end{array}$

Year Built : 1994

Plan Irregularities?

$Y$ torsoinal irreg, reent corners, diaph discontinuity

Vertical Irregularities? reported.

$Y$ mass irreg at floor setbacks.

Column Fy [ksi]: 50

Girder Fy [ksi]: 36

Floor Construction Type: MCL

Web Connection Type: WB

Flange Weld Process: FCAW
Number of Frames in Each Direction:

$\begin{array}{lll}\text { N-S } & 5 & \text { NE-SW } \\ \text { E-W } 5 & \text { NW-SE }\end{array}$

Notes:

\section{MRF Connection Inspection/Testing Scope and Damage Summary}

Total No of Conns in Inspected FF's: 100

No of Connections Inspected: $\quad 100$

No of Connections Tested: $\quad 100$
No of Inspected Floor-Frames: $\mathbf{5 0}$

$\%$ W1: $0.0 \%$

Damage Score :.44

Number of Floor-Frames in each Damage Class for each inspected/tested Frame.

\begin{tabular}{|l|l|r|r|r|r|r|r|r|r|r|r|r|r|}
\hline Frame & Direction & Bays & Avg Width & Flr-Frms & TG & BG & TC & BC & TW & BW & S & PZ & CW \\
\hline A & NS & 1 & 20 & 5 & 0 & 0 & 0 & 0 & 0 & 1 & 1 & 0 & 0 \\
B & NS & 1 & 40 & 5 & 0 & 0 & 0 & 0 & 0 & 2 & 0 & 0 & 0 \\
C & NS & 1 & 40 & 5 & 0 & 0 & 0 & 0 & 0 & 1 & 0 & 0 & 0 \\
D & NS & 1 & 40 & 5 & 0 & 0 & 0 & 2 & 1 & 2 & 1 & 0 & 0 \\
E & EW & 1 & 20 & 5 & 0 & 0 & 0 & 1 & 0 & 1 & 0 & 0 & 0 \\
F & EW & 1 & 20 & 5 & 0 & 0 & 0 & 0 & 0 & 0 & 0 & 0 & 0 \\
G & NS & 1 & 20 & 5 & 0 & 0 & 0 & 0 & 0 & 0 & 0 & 0 & 0 \\
H & EW & 1 & 40 & 5 & 0 & 0 & 0 & 0 & 0 & 0 & 0 & 0 & 0 \\
1 & EW & 1 & 40 & 5 & 0 & 0 & 0 & 0 & 0 & 0 & 0 & 0 & 0 \\
$\mathrm{~J}$ & EW & 1 & 40 & 5 & 0 & 0 & 0 & 0 & 0 & 0 & 0 & 0 & 0 \\
\hline
\end{tabular}




\begin{tabular}{lcll}
\hline Survey Form: old & $\begin{array}{c}\text { Survey Date : } 8 / 19 / 94 \\
\text { Pre Nridge Status : UC } \\
\text { Status as of 8/19/94 } \\
\text { Inspection/Testing: } \\
\text { Repair/Retrofit: }\end{array}$ & $V$ & Building ID: $\quad$ ESI2 \\
\hline
\end{tabular}

Northridge Tag : N

Non-MRF Structural Damage?

YES "Buckled rod braces in penthouse. Cracks in non-structural masonry walls."

Non-Structural Damage?

Life Safety related: NO "None."

Other: $\quad$ YES "Cracks in non-structural masonry walls."

\begin{tabular}{|c|c|c|c|}
\hline $\begin{array}{l}\text { Design Code: UBC } \\
\text { Year Designed : } 1990\end{array}$ & $1989 ?$ & $\begin{array}{l}\text { MRF Stories Above Ground: } 5 \\
\text { MRF Stories Below Ground: } 0\end{array}$ & $\begin{array}{l}\text { Ground Floor Area [sf]: } 21,000 \\
\text { Upper Floor Area [sf]: } 21,000\end{array}$ \\
\hline
\end{tabular}

Year Built : 1993

Plan Irregularities? $Y$ reent corners

Vertical Irregularities?

N

Column Fy [ksi]: 50

Number of Frames in Each Direction:

Girder Fy [ksi]: 36

$\begin{array}{lll}\text { N-S } & 3 & \text { NE-SW } \\ \text { E-W } 4 & \text { NW-SE }\end{array}$

Floor Construction Type: MCL

Notes:

Flange Weld Process: SMAW

\section{MRF Connection Inspection/Testing Scope and Damage Summary}

Total No of Conns in Inspected FF's: 2

No of Connections Inspected: $\quad 2$

No of Inspected Floor-Frames: 1

No of Connections Tested:

$\% W_{1}: 0.0 \%$

Damage Score $: 5.00$

Number of Floor-Frames in each Damage Class for each inspected/tested Frame.

\begin{tabular}{|l|l|r|r|r|r|r|r|r|r|r|r|r|r|r|}
\hline Frame & Direction & Bays & Avg Width & Flr-Frms & TG & BG & TC & BC & TW & BW & S & PZ & CW \\
\hline A & EW & 1 & 20 & 1 & 0 & 0 & & & & & 0 & 0 & 1 \\
\hline
\end{tabular}




\begin{tabular}{lclll}
\hline Survey Form : new & Survey Date : 10/3/94 & & \\
Pre Nridge Status : OC & $\begin{array}{c}\text { Status as of } \\
\text { Inspection/Testing: }\end{array}$ & OC & Building ID: & ESI3 \\
& Repair/Retrofit: & IP & Geographic Zone: UC
\end{tabular}

Northridge Tag : N

Non-MRF Structural Damage?

YES "Diagonal braces at Mechanical Penthouse above Main Roof had caused beam web to tear and beam bolts to shear off."

Non-Structural Damage?

Life Safety related: YES "Mechanical equipment at Penthouse had damaged isolators. Exterior stucco tore away from studs @ Penthouse."

Other: $\quad$ YES "Cracked non-structural interior partitions."

\begin{tabular}{lccc}
\hline $\begin{array}{l}\text { Design Code: UBC } \\
\text { Year Designed : } 1984\end{array}$ & 1982 & $\begin{array}{c}\text { MRF Stories Above Ground: } 8 \\
\text { MRF Stories Below Ground: } 2\end{array}$ & $\begin{array}{l}\text { Ground Floor Area [sf]: } \\
\text { Upper Floor Area [sf]: } 8,000\end{array}$ \\
$\begin{array}{l}\text { Year Built: } \\
\text { Plan Irregularities? }\end{array}$ & & Vertical Imregularities? \\
N & & N
\end{tabular}

Column Fy [ksi]:

Girder Fy [ksi]:

Floor Construction Type: $\mathrm{MCL}$

Web Connection Type: B

Flange Weld Process: U
Number of Frames in Each Direction:

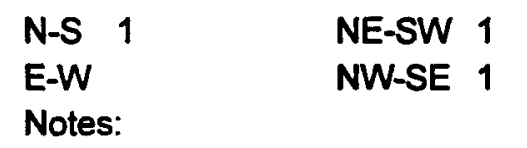

\section{MRF Connection Inspection/Testing Scope and Damage Summary}

Total No of Conns in Inspected FF's: 12

No of Connections Inspected: $\quad 12$

No of Connections Tested: $\quad 3$

No of Inspected Floor-Frames: 1

$\%$ W1 : $100.0 \%$

Damage Score :4.50

Number of Floor-Frames in each Damage Class for each inspected/tested Frame.

\begin{tabular}{|l|l|r|r|r|r|r|r|r|r|r|r|r|r|}
\hline Frame & Direction & Bays & Avg Width & Flr-Frms & TG & BG & TC & BC & TW & BW & S & PZ & CW \\
\hline A & NS & 6 & 20 & 1 & 0 & 0 & 0 & 1 & 0 & 1 & 1 & 0 & 0 \\
\hline
\end{tabular}


Survey Form : old

Survey Date : $8 / 25 / 94$

Pre Nridge Status : LM?

Status as of $6 / 1 / 94$

LM

Building ID: ESI4

Inspection/Testing:

$\mathrm{U}$

Repair/Retrofit:

Northridge Tag : N

Non-MRF Structural Damage?

NO "None reported."

Non-Structural Damage?

Life Safety related: NO "None."

Other:

YES "May have been some drywall separation \&/or cracks."

\begin{tabular}{|c|c|c|c|}
\hline $\begin{array}{l}\text { Design Code : UBC } \\
\text { Year Designed : } 1988\end{array}$ & 1985 & $\begin{array}{l}\text { MRF Stories Above Ground: } 27 \\
\text { MRF Stories Below Ground: } 2\end{array}$ & $\begin{array}{l}\text { Ground Floor Area [sf]: } \\
\text { Upper Floor Area [sf]: } 13,500\end{array}$ \\
\hline
\end{tabular}

Year Built : 1991

Plan Irregularities? $Y$ reent corners

Vertical Irregularities?

$\mathbf{N}$

Column Fy [ksi]: 50

Number of Frames in Each Direction:

Girder Fy [ksi]: 36

N-S 2

NE-SW

Floor Construction Type: MCL

E-W 2

NW-SE

Web Connection Type: WB

Flange Weld Process: $U$

Notes: NOTE: NS frames "bend" in plan, are not in single vertical plane. EW trames differ in orientation by about 40 degrees, but resultant is normal to resultant of NS frames.

\section{MRF Connection Inspection/Testing Scope and Damage Summary \\ Total No of Conns in Inspected FF's: 72 \\ No of Connections Inspected: $\quad 20$ \\ No of Connections Tested: $\quad 14$ \\ No of Inspected Floor-Frames: 10 \\ \%W1 : $10.0 \%$ \\ Damage Score :1.54}

Number of Floor-Frames in each Damage Class for each inspected/tested Frame.

\begin{tabular}{|l|l|r|r|r|r|r|r|r|r|r|r|r|r|}
\hline Frame & Direction & Bays & Avg Width & FIr-Frms & TG & BG & TC & BC & TW & BW & S & PZ & CW \\
\hline A & NWSE & 4 & 20 & 4 & 0 & 0 & 0 & 0 & 2 & 2 & 0 & 0 & 0 \\
B & NWSE & 3 & 26 & 2 & 0 & 0 & 0 & 0 & 2 & 2 & 0 & 0 & 0 \\
NESW & 4 & 19 & 3 & 0 & 0 & 0 & 0 & 0 & 1 & 0 & 0 & 0 \\
\hline
\end{tabular}




\begin{tabular}{lllll}
\hline Survey Form : comb & Survey Date : 10/7/94 & & \\
Pre Nridge Status : OC & $\begin{array}{c}\text { Status as of 9/6/94 } \\
\text { Inspection/Testing: } \\
\text { Repair/Retrofit: }\end{array}$ & $\begin{array}{l}\text { OC } \\
\text { NS }\end{array}$ & Building ID: $\quad$ ESI5 \\
\hline
\end{tabular}

Northridge Tag: $\mathbf{G}$

Non-MRF Structural Damage?

NO "None"

Non-Structural Damage?

Life Safety related: "Unknown"

Other: "Unknown"

\begin{tabular}{|c|c|c|c|c|}
\hline $\begin{array}{l}\text { Design Code : } \\
\text { Year Designed }\end{array}$ & $\begin{array}{l}\text { UBC } \\
: 1989\end{array}$ & 1985 & \multirow[t]{2}{*}{$\begin{array}{l}\text { MRF Stories Above Ground: } 6 \\
\text { MRF Stories Below Ground: } 0\end{array}$} & \multirow[t]{2}{*}{$\begin{array}{l}\text { Ground Floor Area [sf]: } 18,000 \\
\text { Upper Floor Area [sf]: } 15,000\end{array}$} \\
\hline Year Built: & 1990 & & & \\
\hline $\begin{array}{l}\text { Plan Irregula } \\
\text { Y out-of-p }\end{array}$ & ? ${ }_{\text {offse }}$ & 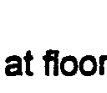 & $\underset{Y}{\text { Vertic }}$ & $\begin{array}{l}\text { ties? } \\
\text { continuity at floor } 5 \text {. }\end{array}$ \\
\hline
\end{tabular}

Column Fy [ksi]: 50

Girder Fy [ksi]: 36

Floor Construction Type: MCLMC

Web Connection Type: B

Flange Weld Process: SMAW

\section{Number of Frames in Each Direction:

$\begin{array}{ll}N-S & \text { NE-SW } 4 \\ \text { E-W } & \text { NW-SE } 2\end{array}$

Notes: At floors 1-4, 22-bay NWSE frames. At firs 5-7, 4 1-bay NWSE frames.

\footnotetext{
MRF Connection Inspection/Testing Scope and Damage Summary

Total No of Conns in Inspected FF's: 112

No of Connections Inspected: $\quad 105$

No of Connections Tested: $\quad 105$

No of Inspected Floor-Frames: 46

$\%$ W1 : $30.0 \%$

Damage Score :2.51
}

Number of Floor-Frames in each Damage Class for each inspected/tested Frame.

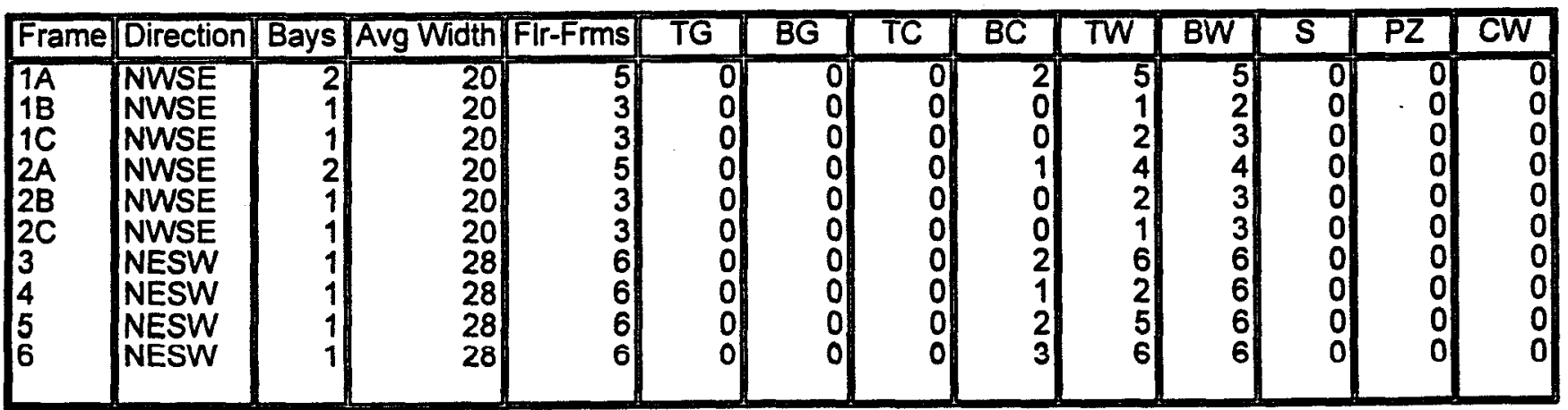


Survey Form : new

Pre Nridge Status : OC

\section{Survey Date : 9/24/91}

Status as of $6 / 21 / 94$

Inspection/Testing:

Repair/Retrofit:
OC

C

C
Building ID: ESI7

Geographic Zone: SO

Northridge Tag: $N$

Non-MRF Structural Damage?

YES "75' CMU block wall on property line \& part of exterior enclosure for building had expansion bolts which tie wall to building shear off. Wall pulled away from building at top (42' above ground floor) approximately $2^{\prime \prime}$."

Non-Structural Damage?

Life Safety related: YES "Exterior plaster soffit above main street entrance considerable cracking (sic). Access to this entrance limited."

Other:

Design Code: LABC 1988

Year Designed :1989

Year Built : 1990

Plan Irregularities?

$Y$ reent comers: L-shaped floors.

Column Fy [ksi]:50

Girder Fy [ksi]: 36

Floor Construction Type: MC

Web Connection Type: B

Flange Weld Process: FCAW
MRF Stories Above Ground: 3

MRF Stories Below Ground: 0
Ground Floor Area [sf]: 15,500

Upper Floor Area [sf]: 15,500
Vertical Irregularities?

N

Number of Frames in Each Direction: .

$\begin{array}{lll}\text { N-S } 3 & \text { NE-SW } \\ \text { E-W } 3 & \text { NW-SE }\end{array}$

Notes:

MRF Connection Inspection/Testing Scope and Damage Summary

Total No of Conns in Inspected FF's: 26

No of Connections Inspected:

No of Connections Tested:

\section{6}

12
No of Inspected Floor-Frames: 13

$\% W_{1}: 0.0 \%$

Damage Score :.65

Number of Floor-Frames in each Damage Class for each inspected/tested Frame.

\begin{tabular}{|l|l|r|r|r|r|r|r|r|r|r|r|r|r|}
\hline Frame & Direction & Bays & Avg Width & Flr-Frms & TG & BG & TC & BC & TW & BW & S & PZ & CW \\
\hline 1 & NS & 1 & 30 & 3 & 0 & 0 & 0 & 0 & 0 & 1 & 1 & 0 & 0 \\
2 & NS & 1 & 30 & 3 & 0 & 0 & 0 & 0 & 0 & 1 & 1 & 0 & 0 \\
3 & NS & 1 & 36 & 2 & 0 & 0 & 0 & 0 & 0 & 0 & 0 & 0 & 0 \\
4 & EW & 1 & 44 & 3 & 0 & 0 & 0 & 0 & 0 & 1 & 0 & 0 & 0 \\
5 & EW & 1 & 30 & 1 & 0 & 0 & 0 & 0 & 0 & 0 & 0 & 0 & 0 \\
6 & EW & 1 & 30 & 1 & 0 & 0 & 0 & 0 & 0 & 0 & 0 & 0 & 0 \\
\hline
\end{tabular}




\begin{tabular}{lllll}
\hline Survey Form : new & Survey Date : 9/24/91 & & \\
Pre Nridge Status : VAC & $\begin{array}{c}\text { Status as of 9/24/94 } \\
\text { Inspection/Testing: } \\
\text { Repair/Retrofit: }\end{array}$ & $\begin{array}{l}\text { VAC } \\
\text { NS }\end{array}$ & Building ID: $\quad$ ESI8 \\
\hline
\end{tabular}

Northridge Tag : N

Non-MRF Structural Damage?

YES "Same location on 4-5 floors, non frame beam connection at a diagonal corner has weld cracks at shear tab to column."

Non-Structural Damage?

Life Safety related:

Other: $\quad$ YES "No damage except one pane of glass broke on 2nd floor. NOTE: Interior spaces not built out."

\begin{tabular}{llcc}
\hline $\begin{array}{l}\text { Design Code : LABC } \\
\text { Year Designed : } 1987\end{array}$ & MRF Stories Above Ground: 25 & Ground Floor Area [sf]: 27,500 \\
Year Built: 1990 & MRF Stories Below Ground: 0 & Upper Floor Area [sf]: 26,500 \\
$\begin{array}{c}\text { Plan Irregularities? } \\
\text { Y reent corners. }\end{array}$ & & Vertical Irregularities? \\
N
\end{tabular}

Column Fy [ksi]: 50

Girder Fy [ksi]: 36

Floor Construction Type: MC

Web Connection Type: B

Flange Weld Process: FCAW
Number of Frames in Each Direction:

$\begin{array}{ll}\text { N-S } 3 & \text { NE-SW } 1 \\ \text { E-W } 3 & \text { NW-SE } 2 \\ \text { Notes: } & \end{array}$

\section{MRF Connection Inspection/Testing Scope and Damage Summary}

Total No of Conns in Inspected FF's: 864

No of Connections Inspected: $\quad 864$

No of Inspected Floor-Frames: 216

No of Connections Tested:

829

$\% W 1: 80.0 \%$

Damage Score :.49

Number of Floor-Frames in each Damage Class for each inspected/tested Frame.

\begin{tabular}{|l|l|r|r|r|r|r|r|r|r|r|r|r|r|}
\hline Frame & Direction & Bays & Avg Width & FIr-Frms & TG & BG & TC & BC & TW & BW & S & PZ & CW \\
\hline 1 & NS & 2 & 23 & 24 & 0 & 0 & 0 & 0 & 14 & 16 & 0 & 0 & 0 \\
2 & NS & 2 & 19 & 24 & 0 & 0 & 0 & 0 & 11 & 13 & 0 & 0 & 0 \\
3 & NS & 2 & 24 & 24 & 0 & 0 & 0 & 0 & 6 & 10 & 0 & 0 & 0 \\
4 & EW & 2 & 24 & 24 & 0 & 0 & 0 & 0 & 7 & 7 & 0 & 0 & 0 \\
5 & EW & 2 & 19 & 24 & 0 & 0 & 0 & 0 & 11 & 5 & 0 & 0 & 0 \\
6 & EW & 2 & 23 & 24 & 0 & 0 & 0 & 0 & 11 & 8 & 0 & 0 & 0 \\
7 & NWSE & 2 & 19 & 24 & 0 & 0 & 0 & 0 & 5 & 4 & 0 & 0 & 0 \\
8 & NWSE & 2 & 19 & 24 & 0 & 0 & 0 & 0 & 5 & 8 & 0 & 0 & 0 \\
9 & NESW & 2 & 24 & 24 & 0 & 0 & 0 & 0 & 4 & 6 & 0 & 0 & 0 \\
\hline
\end{tabular}




\begin{tabular}{lclll}
\hline Survey Form : new & Survey Date : 10/12/94 & & \\
Pre Nridge Status : OC & $\begin{array}{c}\text { Status as of 10/12/94 } \\
\text { Inspection/Testing: }\end{array}$ & OC & Building ID: FE1 \\
& Repair/Retrofit: & na & Geographic Zone: WLA
\end{tabular}

Northridge Tag: N

Non-MRF Structural Damage?

YES "Some minor cracks in shear walls. (Landers EQ [1992] caused more cracks than Northridge EQ.)"

Non-Structural Damage?

Life Safety related:

Other:

YES "Some ceiling tiles fell. other damage unknown by FE [survey engineer firm]."

Design Code: LABC? 1964

Year Designed : 1965

Year Built : 1966

Plan Irregularities?

$Y$ out-of-plane offset at base

Column Fy [ksi]: 36

Girder Fy [ksi]: 36

Floor Construction Type: MC

Web Connection Type: W

Flange Weld Process: FCAW
MRF Stories Above Ground: 17

MRF Stories Below Ground: 0
Ground Floor Area [sf]: 30,000

Upper Floor Area [sf]: 23,000

Vertical Irregularities?

N

Number of Frames in Each Direction:

$\begin{array}{lll}\text { N-S } 0 & \text { NE-SW } \\ \text { E-W } 2 & \text { NW-SE }\end{array}$

Notes: NS direction is Shear Wall System

\section{MRF Connection Inspection/Testing Scope and Damage Summary}

Total No of Conns in Inspected FF's: 88

No of Connections Inspected: $\quad 12$

No of Inspected Floor-Frames: 4

No of Connections Tested:

$\% W 1$ :

Damage Score $: 0.00$

Number of Floor-Frames in each Damage Class for each inspected/tested Frame.

\begin{tabular}{|l|l|r|r|r|r|r|r|r|r|r|r|r|r|}
\hline Frame & Direction & Bays & Avg Width & Flr-Frms & TG & BG & TC & BC & TW & BW & S & PZ & CW \\
\hline \hline P & EW & 11 & 25 & 2 & 0 & 0 & 0 & 0 & 0 & 0 & 0 & 0 & 0 \\
\hline
\end{tabular}


Survey Form : new

Pre Nridge Status : OC

\section{Survey Date : 9/28/94}

Status as of $9 / 28 / 94$

Inspection/Testing:

Repair/Retrofit:
OC

IP

NS
Building ID:

JAM7480

Geographic Zone: WLA

Northridge Tag : N

Non-MRF Structural Damage?

YES Per EQE letter of $2 / 2 / 94$ : "some horizontal cracks at concrete covering of a steel column along the east wall of the DWP vault ... at the steel beam connection to the column."

Non-Structural Damage?

Life Safety related: YES Per EQE letter 2/2/94: "Three elevators were shut down. No additional damage to building support equipment reported. A few supports were lost at some sprinkler lines in the parking garage. Cracks in the drywall ... in various stairway locations as well as glass

Other: damage at the front door ... cracking to non-bearing cmu block walls in stairway \#1."

Design Code : LABC

Year Designed : 1983

Year Built :

1984

Plan Irregularities?

Y possible reent corners
MRF Stories Above Ground: 11

MRF Stories Below Ground: 0
Ground Floor Area [sf]: 32,000

Upper Floor Area [sf]: 23,000

Vertical Irregularities?

$Y$ mass geom irregs due to many setbacks

Column Fy [ksi]:

Girder Fy [ksi]: 36

Floor Construction Type: MC

Web Connection Type: B

Flange Weld Process: U

Number of Frames in Each Direction:

$\begin{array}{lll}\text { N-S } 4 & \text { NE-SW } \\ \text { E-W } 4 & \text { NW-SE }\end{array}$

Notes:

\section{MRF Connection Inspection/Testing Scope and Damage Summary \\ Total No of Conns in Inspected FF's: 116 \\ No of Connections Inspected: \\ 83 \\ No of Inspected Floor-Frames: 14 \\ No of Connections Tested: \\ 83 \\ \%W1 : $33.0 \%$ \\ Damage Score :2.81}

Number of Floor-Frames in each Damage Class for each inspected/tested Frame.

\begin{tabular}{|l|l|r|r|r|r|r|r|r|r|r|r|r|r|}
\hline Frame & Direction & Bays & Avg Width & Flr-Frms & TG & BG & TC & BC & TW & BW & S & PZ & CW \\
\hline 2 & EW & 4 & 29 & 2 & 0 & 0 & 0 & 2 & 0 & 1 & 0 & 0 & 0 \\
6 & EW & 4 & 29 & 2 & 0 & 0 & 0 & 0 & 0 & 2 & 0 & 0 & 0 \\
9 & EW & 7 & 29 & 2 & 0 & 0 & 0 & 1 & 0 & 2 & 0 & 0 & 1 \\
C & NS & 4 & 30 & 2 & 0 & 0 & 0 & 2 & 1 & 2 & 0 & 0 & 0 \\
E & NS & 4 & 29 & 2 & 0 & 0 & 1 & 2 & 1 & 2 & 1 & 0 & 0 \\
H & NS & 4 & 30 & 2 & 0 & 0 & 0 & 1 & 0 & 2 & 0 & 0 & 0 \\
M & NS & 3 & 29 & 2 & 0 & 0 & 0 & 1 & 0 & 1 & 0 & 0 & 0 \\
\hline
\end{tabular}




\begin{tabular}{|c|c|c|c|}
\hline Survey Form: new & Survey Date : 9/27/94 & & \\
\hline Pre Nridge Status: OC & $\begin{array}{l}\text { Status as of } 9 / 27 / 94 \\
\text { Inspection/Testing: } \\
\text { Repair/Retrofit: }\end{array}$ & $\begin{array}{l}C \\
\mathbb{P}\end{array}$ & $\begin{array}{l}\text { Building ID: JAM7482 } \\
\text { Geographic Zone: so }\end{array}$ \\
\hline
\end{tabular}

Northridge Tag: Y

Non-MRF Structural Damage?

YES "Base pl's set fiush into ground floor slab, supported by RC cols below: concrete around inset PL typically spalled."

Non-Structural Damage?

Life Safety related:

Other.

Design Code : LABC 1980 MRF Stories Above Ground: 4

Year Designed : 1983

Year Built : $\quad 1984$

Plan Irregularities?

$Y$ possible reent comers

Column Fy [ksi]: 36

Girder Fy [ksi]: 36

Floor Construction Type: W

Web Connection Type: B

Flange Weld Process:
MRF Stories Below Ground: 0

Ground Floor Area [sf]: 17,000

Upper Floor Area [sf]: $\quad 14,200$
Vertical Irregularities?

N

Number of Frames in Each Direction:
N-S 3
NE-SW
E-W 4
NW-SE

Notes:

\section{MRF Connection Inspection/Testing Scope and Damage Summary \\ Total No of Conns in Inspected FF's: 88 \\ No of Connections Inspected: $\quad 88$ \\ 88
88 \\ No of Inspected Floor-Frames: 28 \\ $\% \mathrm{~W} 1: 50.0 \%$ \\ No of Connections Tested: \\ Damage Score :1.39}

Number of Floor-Frames in each Damage Class for each inspected/tested Frame.

\begin{tabular}{|l|l|r|r|r|r|r|r|r|r|r|r|r|r|}
\hline Frame & Direction & Bays & Avg Width & Fir-Frms & TG & BG & TC & BC & TW & BW & S & PZ & CW \\
\hline 1 & EW & 1 & 24 & 4 & 0 & 0 & 1 & 1 & 2 & 1 & 0 & 0 & 0 \\
3 & EW & 1 & 26 & 4 & 0 & 0 & 0 & 0 & 0 & 2 & 0 & 0 & 0 \\
4 & EW & 2 & 26 & 4 & 0 & 0 & 0 & 0 & 0 & 1 & 0 & 0 & 0 \\
7 & EW & 2 & 28 & 4 & 0 & 0 & 0 & 1 & 1 & 4 & 0 & 0 & 0 \\
A & NS & 1 & 22 & 4 & 0 & 0 & 0 & 0 & 0 & 0 & 0 & 0 & 0 \\
B & NS & 2 & 33 & 4 & 0 & 0 & 1 & 1 & 2 & 4 & 0 & 0 & 0 \\
E & NS & 2 & 33 & 4 & 0 & 0 & 0 & 3 & 3 & 4 & 0 & 0 & 1 \\
\hline
\end{tabular}




\begin{tabular}{lclll}
\hline Survey Form : new & Survey Date : 9/26/94 & & \\
Pre Nridge Status : OC & $\begin{array}{c}\text { Status as of 9/26/94 } \\
\text { Inspection/Testing: } \\
\text { Repair/Retrofit: }\end{array}$ & $\begin{array}{l}\text { VAC } \\
\text { IP }\end{array}$ & Building ID: & JAM7484 \\
& Reographic Zone: so \\
\hline
\end{tabular}

Northridge Tag: $Y$

Non-MRF Structural Damage?

YES "Distortion to beam web \& shear tab in a few nonframe connections. 2-3.5" out-of plumb, northerly, at 4th floor."

Non-Structural Damage?

Life Safety related:

Other:

Design Code :

Year Designed : 1985

Year Built : $\quad 1985$

Plan Irregularities?

N

Column Fy [ksi]: 36

Girder Fy [ksi]: 36

Floor Construction Type: MCL

Web Connection Type: B

Flange Weld Process: U
MRF Stories Above Ground:4

MRF Stories Below Ground: 0
Ground Floor Area [sf]: 15,900

Upper Floor Area [sf]: $\quad 15,900$
Vertical Irregularities?

N
Number of Frames in Each Direction:

$\begin{array}{lll}\text { N-S } 2 & \text { NE-SW } \\ \text { E-W } 2 & \text { NW-SE }\end{array}$

Notes:

\section{MRF Connection Inspection/Testing Scope and Damage Summary}

Total No of Conns in Inspected FF's: 40

No of Connections Inspected: $\quad 40$

No of Inspected Floor-Frames: 20

No of Connections Tested:

40

\%W1 : $50.0 \%$

Damage Score :2.40

Number of Floor-Frames in each Damage Class for each inspected/tested Frame.

\begin{tabular}{|l|l|r|r|r|r|r|r|r|r|r|r|r|r|}
\hline Frame & Direction & Bays & Avg Width & Flr-Frms & TG & BG & TC & BC & TW & BW & S & PZ & CW \\
\hline 1 & NS & 1 & 39 & 5 & 0 & 0 & 1 & 1 & 4 & 5 & 3 & 0 & 1 \\
6 & NS & 1 & 39 & 5 & 0 & 0 & 0 & 0 & 3 & 4 & 1 & 0 & 0 \\
A & EW & 1 & 41 & 5 & 0 & 0 & 0 & 0 & 4 & 3 & 0 & 0 & 0 \\
D & EW & 1 & 46 & 5 & 0 & 0 & 0 & 2 & 4 & 4 & 0 & 0 & 0 \\
\hline
\end{tabular}


Survey Form : new

Pre Nridge Status : OC
Survey Date : 9/26/94

Status as of $9 / 26 / 94$

Inspection/Testing:

Repair/Retrofit:
Building ID: JAM7485

Geographic Zone: WLA

Northridge Tag : NY

Non-MRF Structural Damage?

NO "per EQE, 'no structural damage' as of 1/29/94 walk-through"

Non-Structural Damage?

Life Safety related: YES "Per EQE letter 1/29: 'drywall cracked inside the stainway, and an architectural facade was cracked. Instances of broken glass were also noted."

Other.

Design Code : LABC 1980

Year Designed : 1984

Year Built : 1984

Plan Irregularities? N

MRF Stories Above Ground: 4 MRF Stories Below Ground: 0

$\mathbf{N}$
Ground Floor Area [sf]: 12,200

Upper Floor Area [sf]: 12,200

Vertical Irregularities?

Number of Frames in Each Direction:

Column Fy [ksi]: 36

Girder Fy [ksi]: 36

$\begin{array}{lll}\text { N-S } & 2 & \text { NE-SW } \\ \text { E-W } & 3 & \text { NW-SE }\end{array}$

Notes:

Web Connection Type: B

Flange Weld Process: U

$\begin{array}{lll}\text { MRF Connection Inspection/Testing Scope and Damage Summary } \\ \text { Total No of Conns in Inspected FF's: } & 103 & \text { No of Inspected Floor-Frames: } 25 \\ \text { No of Connections Inspected: } & 103 & \% W 1: 40.0 \% \\ \text { No of Connections Tested: } & 103 & \text { Damage Score :2.03 }\end{array}$

Number of Floor-Frames in each Damage Class for each inspected/tested Frame.

\begin{tabular}{|l|l|r|r|r|r|r|r|r|r|r|r|r|r|}
\hline Frame & Direction & Bays & Avg Width & Fir-Frms & TG & BG & TC & BC & TW & BW & S & PZ & CW \\
\hline 1E & EW & 2 & 16 & 5 & 0 & 0 & 0 & 3 & 3 & 4 & 1 & 0 & 0 \\
IW & EW & 2 & 16 & 5 & 0 & 0 & 0 & 1 & 1 & 2 & 0 & 0 & 0 \\
4 & EW & 2 & 32 & 5 & 0 & 0 & 0 & 1 & 4 & 5 & 0 & 0 & 0 \\
A & NS & 2 & 20 & 5 & 0 & 0 & 0 & 3 & 1 & 3 & 0 & 0 & 0 \\
G & NS & 2 & 20 & 5 & 0 & 0 & 0 & 1 & 2 & 3 & 0 & 0 & 0 \\
\hline
\end{tabular}




\begin{tabular}{lllll} 
Survey Form : new & Survey Date : 10/14/94 & & Building ID: & JAM7486 \\
Pre Nridge Status : OC & $\begin{array}{c}\text { Status as of 10/21/94 } \\
\text { Inspection/Testing: }\end{array}$ & OC & C \\
& Repair/Retrofit: & na & Geographic Zone: WLA \\
\hline
\end{tabular}

Northridge Tag : N

Non-MRF Structural Damage?

NO "none"

Non-Structural Damage?

Life Safety related:

Other: $\quad$ YES "Per EQE letter report, cracking in stairway drywall."

Design Code : LABC

Year Designed : 1983

Year Built : 1984

Plan Irregularities?

$N$

1980

MRF Stories Above Ground: 13

MRF Stories Below Ground: 0
Ground Floor Area [st]: 20,000

Upper Floor Area [sf]: 16,000

Vertical Irregularities?

Y possible mass irreg at floor 6 setback/deck type change

Column Fy [ksi]: 50

Number of Frames in Each Direction:

Girder Fy [ksi]: 36

$\begin{array}{ll}\text { N-S } & \text { NE-SW } 2 \\ \text { E-W } & \text { NW-SE } 2\end{array}$

Notes:

Web Connection Type: B

Flange Weld Process: U

\section{MRF Connection Inspection/Testing Scope and Damage Summary \\ Total No of Conns in Inspected FF's: 294 \\ No of Connections inspected: $\quad 114$ \\ No of Inspected Floor-Frames: 44 \\ No of Connections Tested: \\ 114 \\ $\%$ W1 : $100.0 \%$ \\ Damage Score :.11}

Number of Floor-Frames in each Damage Class for each inspected/tested Frame.

\begin{tabular}{|l|l|r|r|r|r|r|r|r|r|r|r|r|r|}
\hline Frame & Direction & Bays & Avg Width & Flr-Frms & TG & BG & TC & BC & TW & BW & S & PZ & CW \\
\hline 1 & NESW & 3 & 30 & 12 & 0 & 0 & 0 & 0 & 0 & 2 & 0 & 0 & 0 \\
10 & NESW & 4 & 30 & 9 & 0 & 0 & 0 & 0 & 0 & 2 & 0 & 0 & 0 \\
A & NWSE & 3 & 29 & 13 & 0 & 0 & 0 & 0 & 1 & 4 & 0 & 0 & 0 \\
$G$ & NWSE & 3 & 29 & 10 & 0 & 0 & 0 & 0 & 0 & 1 & 0 & 0 & 0 \\
\hline
\end{tabular}




$\begin{array}{lllll}\text { Survey Form : new } & \text { Survey Date : 10/12/94 } & & \\ \text { Pre Nridge Status : OC } & \begin{array}{c}\text { Status as of 10/21/94 } \\ \text { Inspection/Testing: }\end{array} & \text { OC } & \text { Building ID: } & \text { JAM7487 } \\ & \text { Repair/Retrofit: } & \text { na } & \text { Geographic Zone: so }\end{array}$

Northridge Tag : $\mathbf{N}$

Non-MRF Structural Damage?

NO "none" noted by EQE or JAMA, but not out-of-plumb 2" northerly at top, possibly pre-Northridge and not associated with any other damage.

Non-Structural Damage?

Life Safety related:

Other:

YES "Per EQE letter report, minor only, cracking in stairway drywall."

\section{Design Code: LABC 1976 MRF Stories Above Ground: 12 \\ Ground Floor Area [st]: 12,500 \\ Year Designed : 1979 \\ MRF Stories Below Ground: 0 \\ Upper Floor Area [sf]: 15,500}

Year Built :

Plan Irregularities?

Y reent comers \& diaph discont @ partial floors 2 and 3.

Vertical Irregularities?

Y possible soft story at tall columns, floor 2 \& 3

mezzanine/partial floor

Column Fy [ksi]: 36

Number of Frames in Each Direction:

Girder Fy [ksi]: 36

$\begin{array}{ll}\text { N-S } 2 & \text { NE-SW } \\ \text { E-W } 2 & \text { NW-SE } \\ \text { Notes: } & \end{array}$

Floor Construction Type: MCL

Web Connection Type: B

Notes:

Flange Weld Process: $U$

\section{MRF Connection Inspection/Testing Scope and Damage Summary}

Total No of Conns in inspected FF's: 326

No of Connections Inspected: $\quad 94$

No of Inspected Floor-Frames: 41

No of Connections Tested:

94

$\% W 1$ : $100.0 \%$

Damage Score :.18

Number of Floor-Frames in each Damage Class for each inspected/tested Frame.

\begin{tabular}{|l|l|r|r|r|r|r|r|r|r|r|r|r|r|}
\hline Frame & Direction & Bays & Avg Width & Flr-Frms & TG & BG & TC & BC & TW & BW & S & PZ & CW \\
\hline 1 & EW & 5 & 30 & 12 & 0 & 0 & 0 & 0 & 0 & 2 & 0 & 0 & 0 \\
4 & EW & 5 & 30 & 11 & 0 & 0 & 0 & 0 & 0 & 3 & 0 & 0 & 0 \\
B & NS & 3 & 30 & 12 & 0 & 0 & 0 & 1 & 0 & 4 & 0 & 0 & 0 \\
\hline & NS & 3 & 30 & 6 & 0 & 0 & 0 & 0 & 0 & 2 & 0 & 0 & 0 \\
\hline
\end{tabular}




\begin{tabular}{lclll}
\hline Survey Form : new & Survey Date : 10/14/94 & & \\
Pre Nridge Status : OC & $\begin{array}{c}\text { Status as of 10/21/94 } \\
\text { Inspection/Testing: }\end{array}$ & OC & Building ID: & JAM7489 \\
& Repair/Retrofit: & na & Geographic Zone: so \\
\hline
\end{tabular}

Northridge Tag: N

Non-MRF Structural Damage?

NO "none"

Non-Structural Damage?

Life Safety related:

Other. $\quad$ YES "Per EQE letter report, cracking in stainway drywall, planter (on grade?) slightly settled."

$\begin{array}{llll}\text { Design Code : LABC } & 1976 & \text { MRF Stories Above Ground: } 6 & \text { Ground Floor Area [sf]: 21,000 } \\ \text { Year Designed : } 1979 & & \text { MRF Stories Below Ground: } 0 & \text { Upper Floor Area [sf]: 21,000 }\end{array}$

Year Built : $\quad 1979$

Plan Irregularities?

$Y$ reent corners: T-shape floors

Vertical Irregularities?

$\mathbf{N}$

Column Fy [ksi]: 36

Number of Frames in Each Direction:

Girder Fy [ksi]: 36

N-S 4 NE-SW

Floor Construction Type: MCL

E-W 5

NW-SE

Web Connection Type: B

Notes:

Flange Weld Process: $U$

\section{MRF Connection Inspection/Testing Scope and Damage Summary}

Total No of Conns in Inspected FF's: 54

No of Connections Inspected:

8

No of Inspected Floor-Frames: 7

No of Connections Tested:

8 Damage Score $: 0.00$

Number of Floor-Frames in each Damage Class for each inspected/tested Frame.

\begin{tabular}{|l|l|r|r|r|r|r|r|r|r|r|r|r|r|}
\hline Frame & Direction & Bays & Avg Width & Fir-Frms & TG & BG & TC & BC & TW & BW & S & PZ & CW \\
\hline 5 & EW & 5 & 29 & 1 & 0 & 0 & 0 & 0 & 0 & 0 & 0 & 0 & 0 \\
8 & EW & 5 & 20 & 1 & 0 & 0 & 0 & 0 & 0 & 0 & 0 & 0 & 0 \\
A & NS & 3 & 16 & 1 & 0 & 0 & 0 & 0 & 0 & 0 & 0 & 0 & 0 \\
C & NS & 4 & 18 & 2 & 0 & 0 & 0 & 0 & 0 & 0 & 0 & 0 & 0 \\
$J$ & NS & 3 & 16 & 2 & 0 & 0 & 0 & 0 & 0 & 0 & 0 & 0 & 0 \\
\hline
\end{tabular}




\begin{tabular}{|c|c|c|c|}
\hline Survey Form : old & Survey Date : 9/3/94 & & \\
\hline \multirow{3}{*}{ Pre Nridge Status : OC } & Status as of $9 / 3 / 94$ & OC & Building ID: \\
\hline & Inspection/Testing: & C & \\
\hline & Repair/Retrofit: & $\mathbb{P}$ & Geographic Zone: WH \\
\hline
\end{tabular}

\section{Northridge Tag: $\mathbf{N}$}

Non-MRF Structural Damage?

YES "Broken H.S. bolts in tie beam @ roof level."

Non-Structural Damage?

Life Safety related: NO

Other. 도 "Damaged masonry veneer @ corners of bldg on exterior."

Design Code: LABC 1976 MRF Stories Above Ground:4

Year Designed : 1978

Year Built :

Plan Irregularities?

Column Fy [ksi]: 36

Girder Fy [ksi]: 36

Floor Construction Type: MC

Web Connection Type: B

Flange Weld Process: SMAW
Ground Floor Area [sf]:

Upper Floor Area [sf]: 27,600
Vertical Irregularities?

Number of Frames in Each Direction:
N-S
E-W
Notes:

\section{MRF Connection Inspection/Testing Scope and Damage Summary \\ Total No of Conns in Inspected FF's: 102 \\ No of Connections Inspected: $\quad 102$ \\ No of Inspected Floor-Frames: 12 \\ No of Connections Tested: \\ 102 \\ $\%$ W $1: 20.0 \%$ \\ Damage Score :3.32}

Number of Floor-Frames in each Damage Class for each inspected/tested Frame.

\begin{tabular}{|l|l|r|r|r|r|r|r|r|r|r|r|r|r|}
\hline Frame & Direction & Bays & Avg Width & FIr-Frms & TG & BG & TC & BC & TW & BW & S & PZ & CW \\
\hline 2 & EW & 5 & 30 & 3 & 0 & 0 & 0 & 0 & 0 & 1 & 0 & 0 & 0 \\
8 & EW & 4 & 30 & 3 & 0 & 0 & 0 & 1 & 0 & 0 & 0 & 0 & 0 \\
A & NS & 4 & 30 & 3 & 0 & 1 & 0 & 3 & 0 & 2 & 0 & 1 & 3 \\
\hline
\end{tabular}




\begin{tabular}{lll}
\hline $\begin{array}{l}\text { Survey Form : old } \\
\text { Pre Nridge Status : }\end{array}$ & $\begin{array}{l}\text { Survey Date : } 8 / 18 / 94 \\
\text { Status as of } \\
\text { Inspection/Testing: IP } \\
\text { Repair/Retrofit: }\end{array}$ & Building ID: KAR3 \\
& Geographic Zone: SO \\
\hline
\end{tabular}

\section{Northridge Tag:}

Non-MRF Structural Damage?

YES "...measured deflection of 3-1/2" of the top relative to the base [of 18-story N-S frame. All the deformation is within the top six stories.]"

Non-Structural Damage?

Life Safety related:

Other:

\begin{tabular}{lll}
\hline Design Code : & MRF Stories Above Ground: 17 & Ground Floor Area [sf]: \\
Year Designed : & MRF Stories Below Ground: & Upper Floor Area [sf]:
\end{tabular}

Year Built :

Plan Irregularities? N

Vertical Irregularities?

N

Column Fy [ksi]: 36

Girder Fy [ksi]: 36

Floor Construction Type: MC/L?

Web Connection Type:

Flange Weld Process:
Number of Frames in Each Direction:
N-S 2
NE-SW
E-W 2
NW-SE

Notes: Actual compass directions need to be confirmed.

\section{MRF Connection Inspection/Testing Scope and Damage Summary}

Total No of Conns in Inspected FF's:

No of Inspected Floor-Frames: 3

No of Connections Inspected:

$\% W_{1}: 0.0 \%$

No of Connections Tested:

Damage Score :2.00

Number of Floor-Frames in each Damage Class for each inspected/tested Frame.

\begin{tabular}{|c|c|c|c|c|c|c|c|c|c|c|c|c|c|}
\hline Frame & Direction & Bays & Avg Width & Flr-Frms & TG & BG & TC & $\mathrm{BC}$ & TW & BW & $\mathrm{S}$ & $\mathrm{PZ}$ & $\mathrm{CW}$ \\
\hline$\frac{20}{5}$ & $\begin{array}{l}\text { NS } \\
\text { NS }\end{array}$ & \begin{tabular}{l|l}
3 \\
3
\end{tabular} & 28 & $\begin{array}{l}1 \\
2\end{array}$ & $\begin{array}{l}0 \\
0\end{array}$ & $\begin{array}{l}0 \\
0\end{array}$ & $\begin{array}{l}0 \\
0\end{array}$ & $\begin{array}{l}1 \\
2\end{array}$ & $\begin{array}{l}0 \\
0\end{array}$ & $\begin{array}{l}0 \\
0\end{array}$ & $\begin{array}{l}0 \\
0\end{array}$ & $\begin{array}{l}0 \\
0\end{array}$ & $\begin{array}{l}0 \\
0\end{array}$ \\
\hline
\end{tabular}




$\begin{array}{lclll}\text { Survey Form : old } & \text { Survey Date : } 8 / 22 / 94 & & \text { Building ID: } & \text { KPFF1A } \\ \text { Pre Nridge Status : OC } & \begin{array}{c}\text { Status as of } 8 / 22 / 94 \\ \text { Inspection/Testing: }\end{array} & \text { OC } \\ & \text { Repair/Retrofit: } & \text { NS } & \text { Geographic Zone: SC }\end{array}$

Northridge Tag : N

Non-MRF Structural Damage?

Non-Structural Damage?

Life Safety related:

Other: $\quad$ YES "glazing, ceilings"

Design Code: Title 24

Year Designed : 1981

Year Built :

Plan Irregularities?

$\mathrm{N}$

Column Fy [ksi]:

Girder Fy [ksi]:

Floor Construction Type: MCL

Web Connection Type: B

Flange Weld Process: U
MRF Stories Above Ground:2

MRF Stories Below Ground: 0
Ground Floor Area [sf]: 9,700

Upper Floor Area [sf]: 9,700

Vertical Irregularities?

N

Number of Frames in Each Direction:

$\begin{array}{ll}\text { N-S } 2 & \text { NE-SW } \\ \text { E-W 2 } & \text { NW-SE } \\ \text { Notes: } & \end{array}$

N-S 2

Notes:

\section{MRF Connection Inspection/Testing Scope and Damage Summary}

Total No of Conns in Inspected FF's: 20

No of Connections Inspected:

No of Connections Tested:
No of Inspected Floor-Frames: 4

$\% W 1: 60.0 \%$

Damage Score :.68

Number of Floor-Frames in each Damage Class for each inspected/tested Frame.

\begin{tabular}{|l|l|l|l|l|r|r|r|r|r|r|r|r|r|r|}
\hline Frame & Direction & Bays & Avg Width & Frr-Frms & TG & BG & TC & BC & TW & BW & S & PZ & CW \\
\hline A & EW & 4 & 32 & 1 & 1 & 0 & 0 & 0 & 0 & 0 & 1 & 0 & 0 & 0 \\
B & EW & 4 & 32 & 1 & 0 & 0 & 0 & 0 & 0 & 0 & 0 & 0 & 0 \\
C & NS & 2 & 28 & 1 & 0 & 0 & 0 & 0 & 0 & 1 & 0 & 0 & 0 \\
D & NS & 2 & 28 & 1 & 0 & 1 & 0 & 0 & 0 & 1 & 0 & 0 & 0 \\
\hline
\end{tabular}


Survey Form : old

Pre Nridge Status : UC
Survey Date : $8 / 23 / 94$

Status as of $8 / 23 / 94$

Inspection/Testing:

Repair/Retrofit:

$\begin{array}{ll}\text { OC } & \text { Building ID: } \quad \text { LCIB } \\ \text { IP } & \\ \text { IP } & \text { Geographic Zone: NR }\end{array}$

Northridge Tag : $R$

Non-MRF Structural Damage?

YES "sheared bolts in moment-frame seated beam connection."

Non-Structural Damage?

Life Safety related: NO "None observed"

Other. $\quad$ YES "Extensive damage to interior gypsum board finishes and exterior stucco, buckled parapet copings and displaced seismic joints."

$\begin{array}{lll}\text { Design Code : Unknown } 1988 & \text { MRF Stories Above Ground:4 } & \text { Ground Floor Area [sf]: } \\ \text { Year Designed : } 1990 & \text { MRF Stories Below Ground: } 0 & \text { Upper Floor Area [sf]: 31,050 }\end{array}$

Year Built : 1994

Plan Irregularities?

Y apparent diaph discont at atrium, but reported as

Vertical Irregularities?

Unknown Unknown

Column Fy [ksi]: 36

Number of Frames in Each Direction:

Girder Fy [ksi]: 36

N-S NE-SW 6

Floor Construction Type: $M C L$

E-W

NW-SE 8

Web Connection Type: B

Notes:

Flange Weld Process: SMAW

\section{MRF Connection Inspection/Testing Scope and Damage Summary}

Total No of Conns in Inspected FF's: 240

No of Connections Inspected: $\quad 240$

No of Inspected Floor-Frames:

No of Connections Tested: $\quad 240$

$\% \mathrm{~W} 1: 5.0 \%$

Damage Score :

Number of Floor-Frames in each Damage Class for each inspected/tested Frame.

\begin{tabular}{|l|l|r|r|r|r|r|r|r|r|r|r|r|r|}
\hline Frame & Direction & Bays & Avg Width & Flr-Frms & TG & BG & TC & BC & TW & BW & S & PZ & CW \\
\hline A & NESW & 3 & 31 & 1 & 0 & 4 & 0 & 4 & 0 & 4 & 1 & 1 & 1 \\
B & NESW & 1 & 31 & 1 & 0 & 0 & 0 & 0 & 1 & 1 & 0 & 0 & 0 \\
NWSE & 3 & 20 & 1 & 0 & 0 & 0 & 8 & 8 & 8 & 1 & 0 & 3 \\
\hline
\end{tabular}


Survey Form : old

Pre Nridge Status : UC
Survey Date : 9/1/94

Status as of $9 / 1 / 94$

Inspection/Testing:

Repair/Retrofit:
OC

IP

IP
Building ID: LCIE

Geographic Zone: NR

Northridge Tag : $R$

Non-MRF Structural Damage?

NO "None observed."

Non-Structural Damage?

Life Safety related: NO "None observed."

Other:

YES "Extensive damage to interior gypsum board finishes and exterior stucco. Brick tile finishes adjacent to west stair support damaged due to movement."

Design Code : Unknown 1988

Year Designed : 1990

Year Built : 1994

Plan Irregularities?

$Y$ apparent reent comers, but reported as Unknown

MRF Stories Above Ground: 3

MRF Stories Below Ground: 0
Ground Floor Area [sf]: 26,640

Upper Floor Area [sf]: 15,300
Vertical Irregularities?

Unknown
Column Fy [ksi]: 36

Girder Fy [ksi]: 36

Floor Construction Type: $\mathrm{MCL}$

Web Connection Type: B

Flange Weld Process: SMAW
Number of Frames in Each Direction:
N-S 8
NE-SW
E-W 11
NW-SE
Notes:

\section{MRF Connection Inspection/Testing Scope and Damage Summary \\ Total No of Conns in Inspected FF's: 164 \\ No of Connections Inspected: $\quad 164$ \\ No of Connections Tested: $\quad 164$ \\ No of Inspected Floor-Frames: 2 \\ \%W1 : $0.0 \%$ \\ Damage Score :}

Number of Floor-Frames in each Damage Class for each inspected/tested Frame.

\begin{tabular}{|l|l|r|r|r|r|r|r|r|r|r|r|r|r|}
\hline Frame & Direction & Bays & Avg Width & Flr-Frms & TG & BG & TC & BC & TW & BW & S & PZ & CW \\
\hline A & NS & 2 & 31 & 1 & 0 & 0 & 0 & 1 & 0 & 3 & 0 & 0 & 0 \\
B & NS & 2 & 31 & 1 & 0 & 0 & 0 & 4 & 2 & 4 & 0 & 1 & 3 \\
C & EW & 3 & 20 & 1 & 0 & 0 & 0 & 0 & 0 & 0 & 0 & 0 & 0 \\
D & EW & 3 & 20 & 1 & 0 & 0 & 0 & 0 & 0 & 0 & 0 & 0 & 0 \\
E & EW & 3 & 20 & 1 & 0 & 0 & 0 & 0 & 0 & 2 & 0 & 0 & 0 \\
F & EW & 3 & 20 & 1 & 0 & 0 & 0 & 0 & 0 & 0 & 0 & 0 & 0 \\
G & EW & 3 & 20 & 1 & 0 & 0 & 0 & 0 & 0 & 1 & 0 & 0 & 0 \\
H & EW & 3 & 20 & 1 & 0 & 0 & 0 & 0 & 0 & 2 & 0 & 0 & 0 \\
J & EW & 1 & 20 & 1 & 0 & 0 & 0 & 1 & 0 & 1 & 0 & 0 & 0 \\
\hline
\end{tabular}


Survey Form : old

Pre Nridge Status : OC
Survey Date : 8/18/94

Status as of $8 / 17 / 94$

Inspection/Testing:

Repair/Retrofit:
OC

IP

NS
Building ID: $\quad$ MNH02

Geographic Zone: WH

Northridge Tag : G

Non-MRF Structural Damage?

NO "As of yet, no other structural damage has been observed."

Non-Structural Damage?

Life Safety related: NO

Other:

YES Loss of glazing at first and second floors, stucco cracking around windows and corners (slight to moderate), dropped ceiling tiles, overtumed furniture \& bookcases.

Design Code : LABC
Year Designed : 1984
Year Built: 1985
Plan Irregularities?
Y reent corners

Column Fy [ksi]:36

Girder Fy [ksi]: 36

Floor Construction Type: MC

Web Connection Type: B

Flange Weld Process: FCAW
MRF Stories Above Ground: 3

MRF Stories Below Ground: 0
Ground Floor Area [sf]:

Upper Floor Area [sf]: 30,900
Vertical Irregularities?

N
Number of Frames in Each Direction:

$\begin{array}{ll}\text { N-S } 4 & \text { NE-SW } \\ \text { E-W } 2 & \text { NW-SE }\end{array}$

Notes:

\section{MRF Connection Inspection/Testing Scope and Damage Summary}

Total No of Conns in Inspected FF's: 88

No of Connections Inspected:

No of Connections Tested:
56

56
No of Inspected Floor-Frames: 16

\%W1 : $75.0 \%$

Damage Score :1.67

Number of Floor-Frames in each Damage Class for each inspected/tested Frame.

\begin{tabular}{|l|l|r|r|r|r|r|r|r|r|r|r|r|r|}
\hline Frame & Direction & Bays & Avg Width & Frr-Frms & TG & BG & TC & BC & TW & BW & S & PZ & CW \\
\hline A & NS & 2 & 28 & 3 & 0 & 0 & 0 & 1 & 0 & 3 & 0 & 1 & 1 \\
B & EW & 5 & 28 & 2 & 0 & 0 & 0 & 0 & 0 & 0 & 0 & 0 & 0 \\
C & NS & 2 & 28 & 3 & 0 & 0 & 0 & 1 & 0 & 2 & 0 & 1 & 1 \\
D & NS & 2 & 28 & 3 & 0 & 0 & 0 & 1 & 0 & 2 & 0 & 1 & 1 \\
E & EW & 5 & 28 & 2 & 0 & 0 & 0 & 0 & 0 & 0 & 0 & 0 & 0 \\
F & NS & 2 & 28 & 3 & 0 & 0 & 0 & 1 & 0 & 2 & 0 & 1 & 1 \\
\hline
\end{tabular}


Survey Form : comb

Pre Nridge Status : OC
Survey Date : $10 / 4 / 94$

Status as of $8 / 1 / 94$

Inspection/Testing:

Repair/Retrofit:
OC

C

C
Building ID: $\quad$ MNH03AB

Geographic Zone: WLA

Northridge Tag : N

Non-MRF Structural Damage?

YES "Minor spalling of concrete @ expansion joints for subterranean parking. Corbel at joint provides vertical support for 14' trib 2-way slab. Concrete spalled from corbel causing partial loss of support."

Non-Structural Damage?

Life Safety related: YES "All common exits remained open and unobstructed; however, ... overtumed filing cabinets, bookcases, cubicle partitions, etc. blocked hallways and corridors in tenant

Other: SPąeS"."inwall/steel stud walls out of plumb, numerous falling T-bar track and tiles, minor window cracking, HVAC cooling towers spring isolators broke." ALSO: see LS-related damage regarding overturned furnishings.

Design Code : LABC 1976

Year Designed :1978

Year Built : 1979

Plan Irregularities? $\mathbf{N}$

Column Fy [ksi]: 36

Girder Fy [ksi]: 36

Floor Construction Type: W

Web Connection Type: B

Flange Weld Process:
MRF Stories Above Ground: 3 MRF Stories Below Ground: 0
Ground Floor Area [sf]: 11,200

Upper Floor Area [sf]: 11,200
Vertical Irregularities?

N
Number of Frames in Each Direction:

$\begin{array}{ll}\text { N-S } & \text { NE-SW } 6 \\ \text { E-W } & \text { NW-SE } 8\end{array}$

Notes:

\section{MRF Connection Inspection/Testing Scope and Damage Summary}

Total No of Conns in Inspected FF's: 148

No of Connections Inspected: $\quad 76$

No of Connections Tested:
No of Inspected Floor-Frames: 38

$\%$ W1 : $0.0 \%$

Damage Score :.28

Number of Floor-Frames in each Damage Class for each inspected/tested Frame.

\begin{tabular}{|l|l|r|r|r|r|r|r|r|r|r|r|r|r|}
\hline Frame & Direction & Bays & Avg Width & FIr-Frms & TG & BG & TC & BC & TW & BW & S & PZ & CW \\
\hline 1 & NWSE & 3 & 18 & 3 & 0 & 0 & 0 & 0 & 0 & 0 & 0 & 0 & 0 \\
2 & NWSE & 3 & 18 & 3 & 0 & 0 & 0 & 0 & 0 & 0 & 0 & 0 & 0 \\
3 & NWSE & 3 & 18 & 3 & 0 & 0 & 0 & 0 & 0 & 0 & 0 & 0 & 0 \\
4 & NWSE & 2 & 12 & 1 & 0 & 0 & 0 & 0 & 0 & 0 & 0 & 0 & 0 \\
5 & NWSE & 3 & 18 & 3 & 0 & 0 & 0 & 0 & 0 & 0 & 0 & 0 & 0 \\
6 & NWSE & 3 & 18 & 3 & 0 & 0 & 0 & 0 & 0 & 0 & 0 & 0 & 0 \\
7 & NWSE & 3 & 18 & 3 & 0 & 0 & 0 & 0 & 0 & 0 & 0 & 0 & 0 \\
8 & NWSE & 2 & 12 & 1 & 0 & 0 & 0 & 0 & 0 & 0 & 0 & 0 & 0 \\
A & NESW & 2 & 11 & 3 & 0 & 0 & 0 & 0 & 0 & 1 & 0 & 0 & 0 \\
B & NESW & 2 & 11 & 3 & 0 & 0 & 0 & 0 & 1 & 1 & 0 & 0 & 0 \\
C & NESW & 2 & 11 & 3 & 0 & 0 & 0 & 0 & 1 & 1 & 0 & 0 & 0 \\
$D$ & NESW & 2 & 11 & 3 & 0 & 0 & 0 & 0 & 0 & 1 & 0 & 0 & 0 \\
E & NESW & 2 & 11 & 3 & 0 & 0 & 0 & 0 & 0 & 1 & 0 & 0 & 0 \\
F & NESW & 2 & 11 & 3 & 0 & 0 & 0 & 0 & 0 & 0 & 0 & 0 & 0 \\
\hline
\end{tabular}




\begin{tabular}{lllll}
\hline Sunvey Form : comb & Survey Date : 10/4/94 & & Building 1D: MNHO3CDE \\
Pre Nridge Status : OC & $\begin{array}{c}\text { Status as of 8/1/94 } \\
\text { Inspectiontesting: } \\
\text { Repair/Retrofit }\end{array}$ & OC & C & Geographic Zone: WA \\
\hline
\end{tabular}

Northridge Tag: $\mathbf{N}$

Non-MRF Structural Damage?

YES "Minor spalling of concrete @ expansion joints for subterranean parking. Corbel at joint provides vertical support for 14' trib 2-way slab. Concrete spalled from corbel causing partial loss of support"

Non-Structural Damage?

Life Safety related: YES "All common exits remained open and unobstructed; however, ... overturned filing cabinets, bookcases, cubicle partitions, etc. blocked hallways and comidors in tenant

Other: SRgeess." "inwall/steel stud walls out of plumb, numerous falling T-bar track and tiles, minor window cracking, HVAC cooling towers spring isolators broke." ALSO: see LS-related damage regarding overtumed furnishings.

\begin{tabular}{llll}
\hline Design Code : LABC & 1976 & MRF Stories Above Ground:3 & Ground Floor Area [sf]: 17,000 \\
Year Designed : 1978 & & MRF Stories Below Ground: 0 & Upper Floor Area [sf]: 17,000
\end{tabular}

Year Built: 1979

Plan Irregularities?

Y reent comers

Column Fy [ksi]: 36

Girder Fy [ksi]: 36

Floor Construction Type: $\mathbf{W}$

Web Connection Type: B

Flange Weld Process: U
Vertical Imegularities?

$\mathbf{N}$

Number of Frames in Each Direction:
$\begin{array}{ll}\text { N-S } & \text { NE-SW 14 } \\ \text { E-W } & \text { NW-SE 13 } \\ \text { Notes: } & \end{array}$

\footnotetext{
MRF Connection Inspection/Testing Scope and Damage Summary

Total No of Conns in Inspected FF's: 304

No of Connections Inspected: $\quad 154$

No of inspected Floor-Frames: 77

No of Connections Tested:

0

\%W1 : $0.0 \%$

Damage Score :.22
}

Number of Floor-Frames in each Damage Class for each inspectedtested Frame.

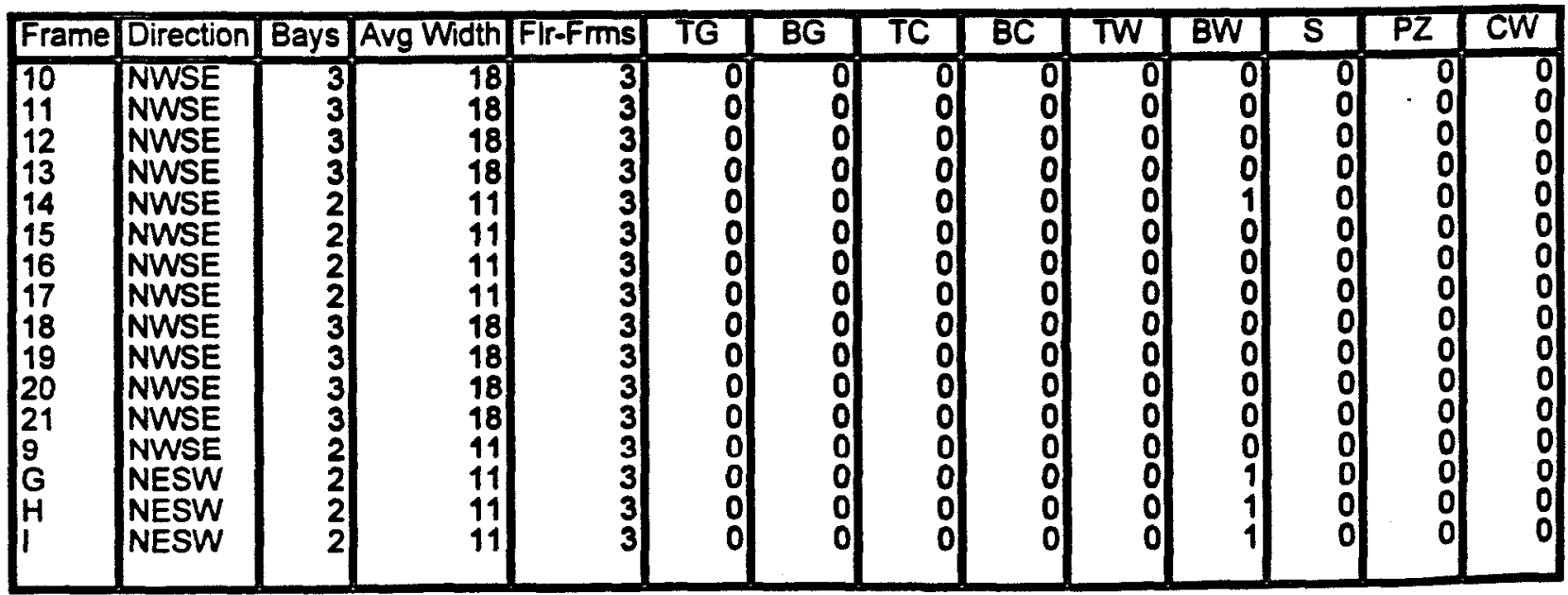


Friday, January 13, 1995

NIST Survey of Steel MRF Buildings

Affected by the Northridge Earthquake

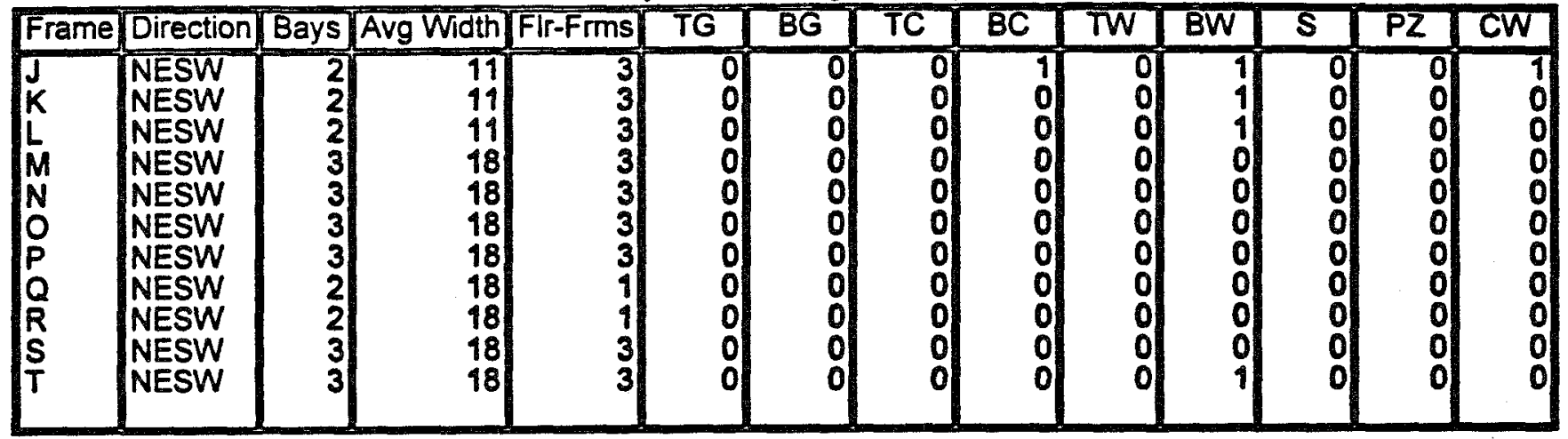


Survey Form : comb

Pre Nridge Status : OC
Survey Date : $10 / 4 / 94$

$\begin{array}{cc}\text { Status as of } 8 / 1 / 94 & \text { OC } \\ \text { Inspection/Testing: } & \text { C } \\ \text { Repair/Retrofit: } & \text { C }\end{array}$

Building ID: MNH03F

Geographic Zone: WLA

Northridge Tag: $\mathbf{N}$

Non-MRF Structural Damage?

YES "Minor spalling of concrete @ expansion joints for subterranean parking. Corbel at joint provides vertical support for 14' trib 2-way slab. Concrete spalled from corbel causing partial loss of support."

Non-Structural Damage?

Life Safety related: YES "All common exits remained open and unobstructed; however, ... overturned filing cabinets, bookcases, cubicle partitions, etc. blocked hallways and corridors in tenant

Other: Spaces."
window cracking, HVAC cooling towers spring isolators broke." ALSO: see LS-related damage regarding overturned furnishings.

$\begin{array}{llcc}\text { Design Code : LABC } & 1976 & \text { MRF Stories Above Ground:3 } & \text { Ground Floor Area [sf]: 5,600 } \\ \text { Year Designed : } 1978 & & \text { MRF Stories Below Ground: } 0 & \text { Upper Floor Area [sf]: 5,600 } \\ \text { Year Built: } 1979 & & \text { Vertical Irregularities? } \\ \begin{array}{l}\text { Plan Irregularities? } \\ \text { N }\end{array} & & \text { N }\end{array}$

Column Fy [ksi]:36

Girder Fy [ksi]: 36

Floor Construction Type: W

Web Connection Type: B

Flange Weld Process: $U$
Number of Frames in Each Direction:

$\begin{array}{ll}\text { N-S } & \text { NE-SW } 3 \\ \text { E-W } & \text { NW-SE } 4\end{array}$

Notes:

\section{MRF Connection Inspection/Testing Scope and Damage Summary}

Total No of Conns in Inspected FF's: 86

No of Connections Inspected: $\quad 44$

No of Connections Tested:

$44 \quad \% W_{1}: 0.0 \%$

No of Inspected Floor-Frames: 17

0

Damage Score :.26

Number of Floor-Frames in each Damage Class for each inspected/tested Frame.

\begin{tabular}{|l|l|r|r|r|r|r|r|r|r|r|r|r|r|}
\hline Frame & Direction & Bays & Avg Width & Flr-Frms & TG & BG & TC & BC & TW & BW & S & PZ & CW \\
\hline 22 & NWSE & 3 & 15 & 2 & 0 & 0 & 0 & 0 & 0 & 0 & 0 & 0 & 0 \\
23 & NWSE & 3 & 15 & 2 & 0 & 0 & 0 & 0 & 0 & 0 & 0 & 0 & 0 \\
24 & NWSE & 3 & 15 & 2 & 0 & 0 & 0 & 0 & 0 & 0 & 0 & 0 & 0 \\
25 & NWSE & 3 & 15 & 2 & 0 & 0 & 0 & 0 & 0 & 0 & 0 & 0 & 0 \\
N & NESW & 3 & 23 & 3 & 0 & 0 & 0 & 0 & 0 & 1 & 0 & 0 & 0 \\
V & NESW & 3 & 23 & 3 & 0 & 0 & 0 & 0 & 0 & 1 & 0 & 0 & 0 \\
W & NESW & 3 & 23 & 3 & 0 & 0 & 0 & 0 & 0 & 1 & 0 & 0 & 0 \\
\hline
\end{tabular}




\begin{tabular}{|c|c|c|c|}
\hline Survey Form : comb & Survey Date : 10/4/94 & & \\
\hline Pre Nridge Status : OC & $\begin{array}{l}\text { Status as of } 8 / 1 / 94 \\
\text { Inspection } / \text { Testing: } \\
\text { Repair/Retrofit: }\end{array}$ & $\begin{array}{l}\text { OC } \\
\mathrm{C} \\
\mathrm{C}\end{array}$ & $\begin{array}{l}\text { Building ID: MNH03G } \\
\text { Geographic Zone: WLA }\end{array}$ \\
\hline
\end{tabular}

Northridge Tag: $N$

Non-MRF Structural Damage?

YES "Minor spalling of concrete @ expansion joints for subterranean parking. Corbel at joint provides vertical support for 14' trib 2-way slab. Concrete spalled from corbel causing partial loss of support."

Non-Structural Damage?

Life Safety related: YES "All common exits remained open and unobstructed; however, ... overturned filing cabinets, bookcases, cubicle partitions, etc. blocked hallways and corridors in tenant

Other: Spaces." "irywall/steel stud walls out of plumb, numerous falling T-bar track and tiles, minor window cracking, HVAC cooling towers spring isolators broke." ALSO: see LS-related damage regarding overturned furnishings.

\begin{tabular}{llll}
\hline Design Code : LABC & 1976 & MRF Stories Above Ground: 3 & Ground Floor Area [sf]: 4,500 \\
Year Designed : 1978 & & MRF Stories Below Ground: 0 & Upper Floor Area [s]]: 4,500 \\
Year Built: 1979 & & Vertical Irregularities? \\
$\begin{array}{l}\text { Plan Irregularities? } \\
\text { N }\end{array}$ & & $N$
\end{tabular}

Column Fy [ksi]: 36

Girder Fy [ksi]: 36

Floor Construction Type: W

Web Connection Type: B

Flange Weld Process: $U$
Number of Frames in Each Direction:

$\begin{array}{ll}\text { N-S } & \text { NE-SW } 2 \\ \text { E-W } & \text { NW-SE } 2 \\ \text { Notes: } & \end{array}$

\section{MRF Connection Inspection/Testing Scope and Damage Summary \\ Total No of Conns in Inspected FF's: 72 \\ No of Connections Inspected: $\quad 32$ \\ No of Inspected Floor-Frames: 12 \\ No of Connections Tested: \\ 0 \\ $\% W_{1}: 0.0 \%$ \\ Damage Score :.13}

Number of Floor-Frames in each Damage Class for each inspected/tested Frame.

\begin{tabular}{|l|l|r|r|r|r|r|r|r|r|r|r|r|r|}
\hline Frame & Direction & Bays & Avg Width & Fir-Frms & TG & BG & TC & BC & TW & BW & S & PZ & CW \\
\hline 26 & NWSE & 4 & 17 & 3 & 0 & 0 & 0 & 0 & 0 & 0 & 0 & 0 & 0 \\
27 & NWSE & 4 & 17 & 3 & 0 & 0 & 0 & 0 & 0 & 0 & 0 & 0 & 0 \\
$X$ & NESW & 3 & 23 & 3 & 0 & 0 & 0 & 0 & 0 & 1 & 0 & 0 & 0 \\
$Y$ & NESW & 3 & 23 & 3 & 0 & 0 & 0 & 0 & 0 & 0 & 0 & 0 & 0 \\
\hline
\end{tabular}




\begin{tabular}{lllll}
\hline Survey Form : comb & Survey Date : 10/4/94 & & Building ID: & MNH03H \\
Pre Nridge Status : OC & $\begin{array}{c}\text { Status as of 8/1/94 } \\
\text { Inspection/Testing: } \\
\text { Repair/Retrofit: }\end{array}$ & $\begin{array}{l}\text { OC } \\
\text { C }\end{array}$ & Geographic Zone: WLA \\
\hline
\end{tabular}

Northridge Tag: $\mathbf{N}$

Non-MRF Structural Damage?

YES "Minor spalling of concrete @ expansion joints for subterranean parking. Corbel at joint provides vertical support for 14' trib 2-way slab. Concrete spalled from corbel causing partial loss of support."

Non-Structural Damage?

Life Safety related: YES "All common exits remained open and unobstructed; however, ... overturned filing cabinets, bookcases, cubicle partitions, etc. blocked hallways and corridors in tenant

Other: Spaces." window cracking, HVAC cooling towers spring isolators broke." ALSO: see LS-related damage regarding overturned furnishings.

\begin{tabular}{lccc}
\hline $\begin{array}{l}\text { Design Code : } \\
\text { Year Designed : } 1978\end{array}$ & 1976 & MRF Stories Above Ground: 3 & Ground Floor Area [sf]: 7,000 \\
Year Built: 1979 & & MRF Stories Below Ground: 0 & Upper Floor Area [sf]: 7,000 \\
$\begin{array}{l}\text { Plan Irregularities? } \\
\text { N }\end{array}$ & & Vertical Irregularities?
\end{tabular}

Column Fy [ksi]: 36

Girder Fy [ksi]: 36

Floor Construction Type: $W$

Web Connection Type: B

Flange Weld Process: U
Number of Frames in Each Direction:

$\begin{array}{ll}\text { N-S } & \text { NE-SW } 2 \\ \text { E-W } & \text { NW-SE } 3\end{array}$

Notes:

\section{MRF Connection Inspection/Testing Scope and Damage Summary}

Total No of Conns in Inspected FF's: 52

No of Connections Inspected: $\quad 32$

No of Inspected Floor-Frames: 9

No of Connections Tested:

0

$\% W_{1}: 0.0 \%$

Damage Score : 0.00

Number of Floor-Frames in each Damage Class for each inspected/tested Frame.

\begin{tabular}{|l|l|r|r|r|r|r|r|r|r|r|r|r|r|}
\hline Frame & Direction & Bays & Avg Width & FIr-Frms & TG & BG & TC & BC & TW & BW & S & PZ & CW \\
\hline 28 & NWSE & 3 & 28 & 1 & 0 & 0 & 0 & 0 & 0 & 0 & 0 & 0 & 0 \\
29 & NWSE & 3 & 28 & 1 & 0 & 0 & 0 & 0 & 0 & 0 & 0 & 0 & 0 \\
30 & NWSE & 3 & 31 & 1 & 0 & 0 & 0 & 0 & 0 & 0 & 0 & 0 & 0 \\
AA & NESW & 4 & 15 & 3 & 0 & 0 & 0 & 0 & 0 & 0 & 0 & 0 & 0 \\
$Z$ & NESW & 4 & 15 & 3 & 0 & 0 & 0 & 0 & 0 & 0 & 0 & 0 & 0 \\
\hline
\end{tabular}


Survey Form : new

Pre Nridge Status : OC
Survey Date : 9/29/94

Status as of $9 / 29 / 94$

Inspection/Testing:

Repair/Retrofit:
OC

C

na
Building ID: $\quad$ MNHO4

Geographic Zone: SO

Northridge Tag : U

Non-MRF Structural Damage?

NO "None"

Non-Structural Damage?

Life Safety related:

Other:

YES "Minor ceiling tile displacement. Minor cracking of interior partitions."

$\begin{array}{lccc}\text { Design Code : UBC } & 1979 & \text { MRF Stories Above Ground:6 } & \text { Ground Floor Area [sf]: 32,000 } \\ \text { Year Designed : } 1981 & & \text { MRF Stories Below Ground: } 0 & \text { Upper Floor Area [sf]: } 32,000 \\ \begin{array}{l}\text { Year Built: } 1981 \\ \text { Plan Irregularities? }\end{array} & & \text { Vertical Irregularities? }\end{array}$

Column Fy [ksi]: 36

Girder Fy [ksi]: 36

Floor Construction Type: $\mathrm{MCL}$

Web Connection Type: B

Flange Weld Process: SMAW
Number of Frames in Each Direction:

$\begin{array}{lll}\text { N-S } 4 & \text { NE-SW } \\ \text { E-W } 4 & \text { NW-SE }\end{array}$

Notes:

MRF Connection Inspection/Testing Scope and Damage Summary

Total No of Conns in Inspected FF's: 54

No of Connections Inspected:

No of Connections Tested:
31

31
No of Inspected Floor-Frames: 12

\%W1:

Damage Score : $\mathbf{0 . 0 0}$

Number of Floor-Frames in each Damage Class for each inspected/tested Frame.

\begin{tabular}{|l|l|r|r|r|r|r|r|r|r|r|r|r|r|r|}
\hline Frame & Direction & Bays & Avg Width & Flr-Frms & TG & BG & TC & BC & TW & BW & S & PZ & CW \\
\hline 2 & EW & 2 & 34 & 3 & 0 & 0 & 0 & 0 & 0 & 0 & 0 & 0 & 0 \\
6 & EW & 2 & 34 & 3 & 0 & 0 & 0 & 0 & 0 & 0 & 0 & 0 & 0 \\
A2 & NS & 2 & 30 & 1 & 0 & 0 & 0 & 0 & 0 & 0 & 0 & 0 & 0 \\
C & NS & 2 & 30 & 2 & 0 & 0 & 0 & 0 & 0 & 0 & 0 & 0 & 0 \\
E & NS & 3 & 30 & 3 & 0 & 0 & 0 & 0 & 0 & 0 & 0 & 0 & 0 \\
\hline
\end{tabular}


Survey Form : old

Survey Date : $8 / 21 / 94$

Pre Nridge Status : $O C$

Status as of $8 / 21 / 94$

OC

Building ID:

NYA539

Inspection/Testing:

Repair/Retrofit:

NS

Geographic Zone: WH

Northridge Tag : $U$

Non-MRF Structural Damage?

Non-Structural Damage?

Life Safety related:

Other:

Design Code: LABC 1980

Year Designed : 1984

Year Built :

1985

Plan Irregularities?

Y reentrant corner (L-shaped diaphragm)

Column Fy [ksi]: 36

Girder Fy [ksi]: 36

Floor Construction Type: MC

Web Connection Type: B

Flange Weld Process: U
MRF Stories Above Ground: 3

MRF Stories Below Ground: 0
Ground Floor Area [sf]:

Upper Floor Area [sf]: 28,000

Vertical Irregularities?

$\mathrm{N}$

Number of Frames in Each Direction:

$\begin{array}{ll}\text { N-S } 6 & \text { NE-SW } \\ \text { E-W } 6 & \text { NW-SE }\end{array}$

Notes:

MRF Connection Inspection/Testing Scope and Damage Summary

Total No of Conns in Inspected FF's: 54

No of Connections Inspected: $\quad 33$

$33 \quad \% W 1: 100.0 \%$

No of Connections Tested:

33

Damage Score :.68

Number of Floor-Frames in each Damage Class for each inspected/tested Frame.

\begin{tabular}{|c|c|c|c|c|c|c|c|c|c|c|c|c|c|}
\hline Frame & Direction & Bays & Avg Width & Flr-Frms & TG & BG & TC & $B C$ & TW & $\mathrm{BW}$ & $s$ & $\mathrm{PZ}$ & $\mathrm{CW}$ \\
\hline $\begin{array}{l}3 \\
5 \\
7 \\
9 \\
D \\
G \\
\text { X10 } \\
X 12 \\
X 5 \\
X 8 \\
Y 1 \\
Y 5\end{array}$ & $\begin{array}{l}\text { EW } \\
\text { EW } \\
\text { EW } \\
\text { EW } \\
\text { NS } \\
\text { NS } \\
\text { NS } \\
\text { NS } \\
\text { NS } \\
\text { NS } \\
\text { EW } \\
\text { EW }\end{array}$ & \begin{tabular}{l|}
1 \\
1 \\
1 \\
1 \\
3 \\
4 \\
1 \\
1 \\
1 \\
1 \\
3 \\
4
\end{tabular} & $\begin{array}{l}34 \\
34 \\
34 \\
34 \\
20 \\
20 \\
34 \\
34 \\
34 \\
34 \\
20 \\
20\end{array}$ & $\begin{array}{l}1 \\
1 \\
1 \\
1 \\
1 \\
1 \\
1 \\
1 \\
2 \\
1 \\
1 \\
2\end{array}$ & $\begin{array}{l}0 \\
0 \\
0 \\
0 \\
0 \\
\\
0 \\
0 \\
0 \\
0 \\
0\end{array}$ & $\begin{array}{l}0 \\
0 \\
0 \\
0 \\
0 \\
0 \\
0 \\
0 \\
0 \\
0 \\
0 \\
0\end{array}$ & $\begin{array}{l}0 \\
0 \\
0 \\
0 \\
0 \\
0\end{array}$ & $\begin{array}{l}0 \\
0 \\
0 \\
0 \\
0 \\
0 \\
0 \\
0 \\
0 \\
0 \\
0 \\
0\end{array}$ & $\begin{array}{l}0 \\
0 \\
1 \\
1\end{array}$ & $\begin{array}{l}1 \\
1 \\
1 \\
1 \\
1 \\
1 \\
1 \\
1 \\
2 \\
1\end{array}$ & $\begin{array}{l}0 \\
0 \\
0 \\
0 \\
0 \\
0 \\
0 \\
0 \\
0 \\
0 \\
0 \\
0\end{array}$ & $\begin{array}{l}0 \\
0 \\
0 \\
0 \\
0 \\
0 \\
0 \\
0 \\
0 \\
0 \\
0 \\
0\end{array}$ & $\begin{array}{l}0 \\
0 \\
0 \\
0 \\
0 \\
0 \\
0 \\
0 \\
0 \\
0 \\
0 \\
0\end{array}$ \\
\hline
\end{tabular}




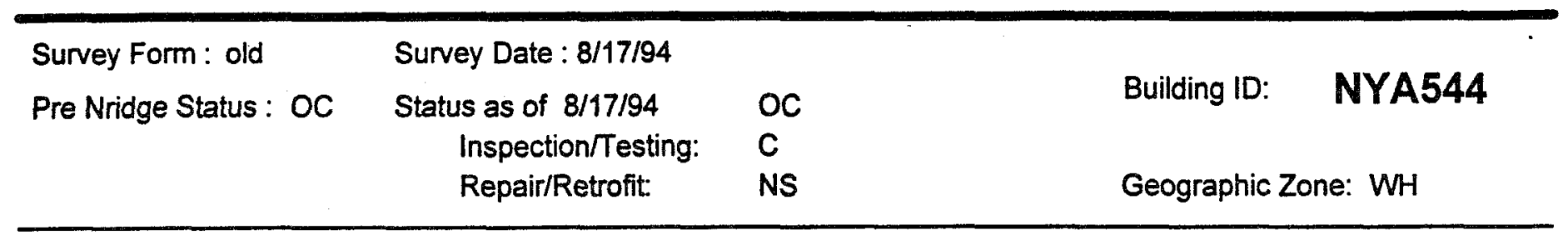

Northridge Tag : U

Non-MRF Structural Damage?

Non-Structural Damage?

Life Safety related:

Other:

Design Code: LABC

Year Designed : 1975

Year Built :

1976

Plan Irregularities?

N

Column Fy [ksi]: 36

Girder Fy [ksi]: 36

Floor Construction Type: MC

Web Connection Type: B

Flange Weld Process:
MRF Stories Above Ground: 13

MRF Stories Below Ground: 1
Ground Floor Area [sf]: 25,600

Upper Floor Area [sf]: $\quad 25,600$
Vertical Irregularities?

$\mathrm{N}$

Number of Frames in Each Direction:

$\begin{array}{lll}\text { N-S } & 2 & \text { NE-SW } \\ \text { E-W } 2 & \text { NW-SE }\end{array}$

Notes:

\section{MRF Connection Inspection/Testing Scope and Damage Summary}

Total No of Conns in inspected FF's: $\mathbf{5 6 0}$

No of Connections Inspected:

No of Connections Tested:
545

545
No of Inspected Floor-Frames: 56

$\%$ W1 : $50.0 \%$

Damage Score :1.09

Number of Floor-Frames in each Damage Class for each inspected/tested Frame.

\begin{tabular}{|l|l|r|r|r|r|r|r|r|r|r|r|r|r|r|}
\hline Frame & Direction & Bays & Avg Width & Fir-Frms & TG & BG & TC & BC & TW & BW & S & PZ & CW \\
\hline 4 & NS & 5 & 32 & 14 & 1 & 5 & 0 & 5 & 0 & 9 & 4 & 0 & 0 \\
9 & NS & 5 & 32 & 14 & 2 & 1 & 0 & 2 & 0 & 5 & 2 & 0 & 0 & 0 \\
B & EW & 5 & 32 & 14 & 0 & 3 & 0 & 1 & 0 & 6 & 2 & 0 & 0 \\
\hline & EW & 5 & 32 & 14 & 2 & 0 & 0 & 1 & 0 & 5 & 1 & 0 & 0 \\
\hline
\end{tabular}




\begin{tabular}{|c|c|c|c|}
\hline Survey Form : old & Survey Date : $8 / 22 / 94$ & & \\
\hline Pre Nridge Status : $O C$ & $\begin{array}{l}\text { Status as of } 8 / 22 / 94 \\
\text { Inspection/Testing: } \\
\text { Repair/Retrofit: }\end{array}$ & $\begin{array}{l}\text { OC } \\
\text { C } \\
\text { NS }\end{array}$ & $\begin{array}{l}\text { Building ID: NYA550 } \\
\text { Geographic Zone: So }\end{array}$ \\
\hline
\end{tabular}

Northridge Tag : U

Non-MRF Structural Damage?

Non-Structural Damage?

Life Safety related:

Other.

Design Code :

Year Designed : 1985

Year Built : 1985

Plan Irregularities? $Y$ reentrant corner
MRF Stories Above Ground: 6

MRF Stories Below Ground: 0
Ground Floor Area [sf]: 53,400

Upper Floor Area [sf]: 21,000

Vertical Irregularities?

$Y$ mass \& geom irreg at floor 4 setback.

Number of Frames in Each Direction:

Column Fy [ksi]: 36

Girder Fy [ksi]: 36

$\begin{array}{ll}\text { N-S } 5 & \text { NE-SW } \\ \text { E-W } 5 & \text { NW-SE }\end{array}$

Floor Construction Type: MCL

Notes: At floors 5-7(rf), 2 NS, 2 EW.

Flange Weld Process:

MRF Connection Inspection/Testing Scope and Damage Summary

Total No of Conns in Inspected FF's: 90

No of Connections Inspected: $\quad 31$

No of Inspected Floor-Frames: 15

No of Connections Tested:

$\% W 1$ : $100.0 \%$

Damage Score :.13

Number of Floor-Frames in each Damage Class for each inspected/tested Frame.

\begin{tabular}{|l|l|r|r|r|r|r|r|r|r|r|r|r|r|}
\hline Frame & Direction & Bays & Avg Width & Flr-Frms & TG & BG & TC & BC & TW & BW & S & PZ & CW \\
\hline $2 \mathrm{C}$ & $\mathrm{EW}$ & 3 & 32 & 2 & 0 & 0 & 0 & 0 & 0 & 1 & 0 & 0 & 0 \\
$2 \mathrm{~K}$ & $\mathrm{EW}$ & 3 & 32 & 1 & 0 & 0 & 0 & 0 & 0 & 0 & 0 & 0 & 0 \\
$5 \mathrm{C}$ & $\mathrm{EW}$ & 3 & 32 & 2 & 0 & 0 & 0 & 0 & 0 & 0 & 0 & 0 & 0 \\
$5 \mathrm{~K}$ & $\mathrm{EW}$ & 3 & 32 & 1 & 0 & 0 & & 0 & 0 & 0 & 0 & 0 & 0 \\
7 & $\mathrm{EW}$ & 3 & 32 & 2 & 0 & 0 & 0 & 0 & 0 & 1 & 0 & 0 & 0 \\
$\mathrm{~B}$ & $\mathrm{NS}$ & 3 & 32 & 2 & 0 & 0 & 0 & 0 & 0 & 1 & 0 & 0 & 0 \\
$\mathrm{~J}$ & $\mathrm{NS}$ & 3 & 32 & 1 & 0 & 0 & 0 & 0 & 0 & 0 & 0 & 0 & 0 \\
0 & $\mathrm{NS}$ & 3 & 32 & 2 & 0 & 0 & 0 & 0 & 0 & 0 & 0 & 0 & 0 \\
$\mathrm{R}$ & $\mathrm{NS}$ & 3 & 32 & 2 & 0 & 0 & 0 & 0 & 0 & 1 & 0 & 0 & 0 \\
\hline
\end{tabular}




\begin{tabular}{|c|c|c|c|}
\hline Survey Form : old & Survey Date : 8/28/94 & & \\
\hline Pre Nridge Status : OC & $\begin{array}{l}\text { Status as of } 8 / 28 / 94 \\
\text { Inspection/Testing: }\end{array}$ & $\begin{array}{l}O C \\
C\end{array}$ & Building ID: \\
\hline & Repair/Retrofit: & NS & Geographic Zone: WLA \\
\hline
\end{tabular}

Northridge Tag : U

Non-MRF Structural Damage?

Non-Structural Damage?

Life Safety related:

Other:

Design Code :

Year Designed : 1980

Year Built : $\quad 1981$

Plan Irregularities?

$N$

Column Fy [ksi]: 50

Girder Fy [ksi]: 36

Floor Construction Type: $\mathrm{MCL}$

Web Connection Type: B

Flange Weld Process: $U$
MRF Stories Above Ground: 14

MRF Stories Below Ground: 0
Ground Floor Area [sf]: 32,000

Upper Floor Area [sf]: 17,700
Vertical Irregularities?

$Y$ mass \& geom irreg at floor 2 \& 3 low roof setbacks.

Number of Frames in Each Direction:

$\begin{array}{lll}\text { N-S } 6 & \text { NE-SW } \\ \text { E-W } 2 & \text { NW-SE }\end{array}$

Notes: At ground, including small frames under low roofs: 8 NS, 4 EW, 2 NWSE.

\section{MRF Connection Inspection/Testing Scope and Damage Summary}

Total No of Conns in Inspected FF's: 94

No of Connections Inspected: $\quad 29$

No of Connections Tested: $\quad 29$

No of Inspected Floor-Frames: 20

$\% W_{1}: 100.0 \%$

Damage Score :.53

Number of Floor-Frames in each Damage Class for each inspected/tested Frame.

\begin{tabular}{|c|c|c|c|c|c|c|c|c|c|c|c|c|c|}
\hline Frame & Direction & Bays & Avg Width & Flr-Frms & TG & BG & TC & $B C$ & TW & BW & 5 & $\overline{P Z}$ & $\mathrm{CW}$ \\
\hline $\begin{array}{l}A \\
B \\
C \\
D \\
E \\
H\end{array}$ & $\begin{array}{l}\text { EW } \\
\text { EW } \\
\text { NS } \\
\text { NS } \\
\text { NS } \\
\text { NS }\end{array}$ & $\begin{array}{l}4 \\
4 \\
1 \\
1 \\
1 \\
1\end{array}$ & $\begin{array}{l}30 \\
30 \\
31 \\
31 \\
27 \\
27\end{array}$ & $\begin{array}{l}5 \\
4 \\
4 \\
5 \\
1 \\
1\end{array}$ & $\begin{array}{l}0 \\
0 \\
0 \\
0 \\
0 \\
0\end{array}$ & $\begin{array}{l}0 \\
0 \\
0 \\
0 \\
0 \\
0\end{array}$ & $\begin{array}{l}0 \\
0 \\
0 \\
0 \\
0 \\
0\end{array}$ & $\begin{array}{l}0 \\
0 \\
0 \\
0 \\
0 \\
0\end{array}$ & $\begin{array}{l}0 \\
1 \\
1 \\
0 \\
0 \\
0\end{array}$ & $\begin{array}{l}5 \\
4 \\
4 \\
5 \\
0 \\
1\end{array}$ & $\begin{array}{l}0 \\
0 \\
0 \\
0 \\
0 \\
0\end{array}$ & $\begin{array}{l}0 \\
0 \\
0 \\
0 \\
0 \\
0\end{array}$ & $\begin{array}{l}0 \\
0 \\
0 \\
0 \\
0 \\
0\end{array}$ \\
\hline
\end{tabular}




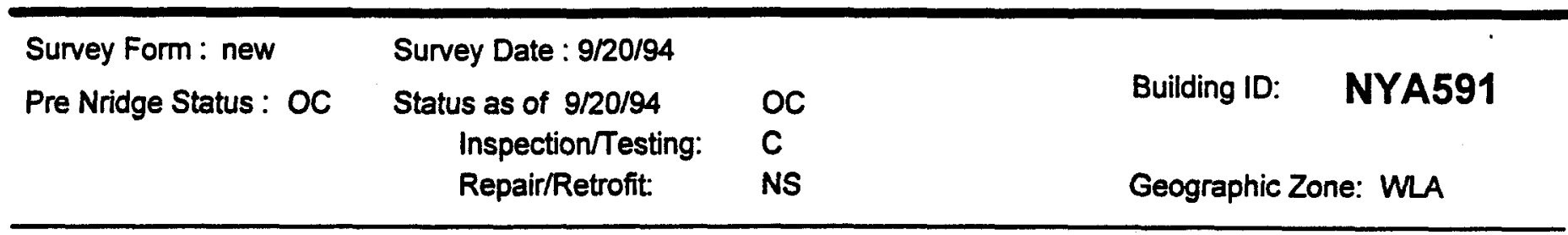

Northridge Tag : U

Non-MRF Structural Damage? NO "N"

Non-Structural Damage?

Life Safety related: U

Other:

U

Design Code: LABC

Year Designed : 1970

Year Built : $\quad 1970$

Plan Irregularities?

$\mathbf{N}$

Column Fy [ksi]: 36

Girder Fy [ksi]: 36

Floor Construction Type: MCL

Web Connection Type: W

Flange Weld Process: U
MRF Stories Above Ground:28

MRF Stories Below Ground: 4
Ground Floor Area [sf]: 24,000

Upper Floor Area [sf]: 24,000
Vertical Irregularities?

N

Number of Frames in Each Direction:
$\mathrm{N}-\mathrm{S} 0$
NE-SW
E-W 2
NW-SE

Notes: NS direction is Braced Frame Dual System

\section{MRF Connection Inspection/Testing Scope and Damage Summary}

Total No of Conns in Inspected FF's: 208

No of Connections Inspected: $\quad 18$

No of Inspected Floor-Frames: 16

No of Connections Tested:

$\% W_{1}: 100.0 \%$

Damage Score :.09

Number of Floor-Frames in each Damage Class for each inspected/tested Frame.

\begin{tabular}{|l|l|r|r|r|r|r|r|r|r|r|r|r|r|}
\hline Frame & Direction & Bays & Avg Width & Flr-Frms & TG & BG & TC & BC & TW & BW & $S$ & PZ & CW \\
\hline 3 & EW & 11 & 20 & 5 & 0 & 0 & 0 & 0 & 1 & 2 & 0 & 0 & 0 \\
9 & EW & 11 & 20 & 2 & 0 & 0 & 0 & 0 & 0 & 0 & 0 & 0 & 0 \\
F & NS & 3 & 40 & 4 & 0 & 0 & 0 & 0 & 0 & 0 & 0 & 0 & 0 \\
G & NS & 3 & 40 & 2 & 0 & 0 & 0 & 0 & 0 & 0 & 0 & 0 & 0 \\
R & NS & 3 & 40 & 3 & 0 & 0 & 0 & 0 & 0 & 0 & 0 & 0 & 0 \\
\hline
\end{tabular}




\begin{tabular}{llll}
\hline Survey Form : new & Survey Date : 9/19/94 & & Building ID: \\
Pre Nridge Status : OC & $\begin{array}{c}\text { Status as of 9/19/94 } \\
\text { Inspection/Testing: }\end{array}$ & OC & NY592 \\
& Repair/Retrofit: & NS & Geographic Zone: WLA \\
\hline
\end{tabular}

Northridge Tag : $U$

Non-MRF Structural Damage?

NO "N"

Non-Structural Damage?

Life Safety related: $U$

Other:

Design Code: LABC

Year Designed : 1969

Year Built : 1969

Plan Irregularities?

$\mathrm{N}$

Column Fy [ksi]: 36

Girder Fy [ksi]: 36

Floor Construction Type: LC

Web Connection Type: W

Flange Weld Process: U
MRF Stories Above Ground:20

MRF Stories Below Ground: 1
Ground Floor Area [sf]: 24,300

Upper Floor Area [sf]: 24,300

Vertical Irregularities?

$\mathbf{N}$

Number of Frames in Each Direction:

$\begin{array}{ll}\text { N-S 2 } & \text { NE-SW } \\ \text { E-W 2 } & \text { NW-SE } \\ \text { Notes: } & \end{array}$

$\mathrm{N}-\mathrm{S} \quad 2$

Notes:

\section{MRF Connection Inspection/Testing Scope and Damage Summary}

Total No of Conns in Inspected FF's: 124

No of Connections Inspected:

No of Connections Tested:
10

10
No of Inspected Floor-Frames: 10

\%W1 :

Damage Score :0.00

Number of Floor-Frames in each Damage Class for each inspeeted/tested Frame.

\begin{tabular}{|l|l|l|r|r|r|r|r|r|r|r|r|r|r|}
\hline Frame & Direction & Bays & Avg Width & Flr-Frms & TG & BG & TC & BC & TW & BW & $S$ & PZ & CW \\
\hline 1 & EW & 5 & 22 & 5 & 0 & 0 & 0 & 0 & 0 & 0 & 0 & 0 & 0 \\
\hline FW & NS & 5 & 22 & 1 & 0 & 0 & 0 & 0 & 0 & 0 & 0 & 0 & 0 \\
& & 9 & 25 & 4 & 0 & 0 & 0 & 0 & 0 & 0 & 0 & 0 & 0 \\
\hline
\end{tabular}




$\begin{array}{llll}\text { Survey Form: old } & \text { Survey Date : } 8 / 17 / 94 & & \\ \text { Pre Nridge Status : OC } & \begin{array}{c}\text { Status as of } 8 / 12 / 94 \\ \text { Inspection/Testing: }\end{array} & \text { OC } \\ & \text { Repair/Retrofit: } & \text { C } & \text { Building ID: } \\ & \begin{array}{ll}\text { ROA } \\ \end{array} & \text { Geographic Zone: SO }\end{array}$

Northridge Tag: $Y$

Non-MRF Structural Damage?

YES "Base plate anchors broke free from base plates. Large areas of spalled concrete around many column bases. One base shifted 3/4" north, another 3/8"."

Non-Structural Damage?

Life Safety related: YES Facade of Brick veneer cracked \& broke away from anchorage,...falling hazard....

Other: $\quad$ YES Lots of broken glazing panels, cracked facade, stucco cracks @ elev core, racked doors, ...ceiling panels...interior walls...settlement of exterior slabs and walkways.

$\begin{array}{llll}\text { Design Code : LABC } & 1980 & \text { MRF Stories Above Ground:4 } & \text { Ground Floor Area [sf]: 29,800 } \\ \text { Year Designed : } 1984 & & \text { MRF Stories Below Ground: } 0 & \text { Upper Floor Area [sf]: 25,015 }\end{array}$

Year Built : 1985

Plan Irregularities?

$Y$ reent corners

Vertical Irregularities?

N

Column Fy [ksi]: 36

Number of Frames in Each Direction:

Girder Fy [ksi]: 36

N-S 4 NE-SW

Floor Construction Type: MC

Web Connection Type: B

E-W $6 \quad$ NW-SE

Flange Weld Process: U

Notes:

MRF Connection Inspection/Testing Scope and Damage Summary

Total No of Conns in Inspected FF's: 184

No of Connections Inspected: $\quad 160$

No of Connections Tested: $\quad 160$

No of Inspected Floor-Frames: 22

$\% W 1: 0.0 \%$

Damage Score :1.95

Number of Floor-Frames in each Damage Class for each inspected/tested Frame.

\begin{tabular}{|l|l|r|r|r|r|r|r|r|r|r|r|r|r|}
\hline Frame & Direction & Bays & Avg Width & Flr-Frms & TG & BG & TC & BC & TW & BW & S & PZ & CW \\
\hline A & NS & 5 & 13 & 4 & 0 & 0 & 0 & 2 & 0 & 3 & 1 & 0 & 0 \\
B & NS & 5 & 13 & 4 & 0 & 1 & 0 & 2 & 0 & 2 & 1 & 0 & 0 \\
C & NS & 5 & 13 & 4 & 0 & 1 & 0 & 2 & 0 & 2 & 2 & 0 & 0 \\
D & NS & 5 & 13 & 4 & 0 & 1 & 0 & 2 & 1 & 2 & 2 & 0 & 0 \\
E & EW & 5 & 13 & 1 & 0 & 0 & 0 & 0 & 0 & 0 & 0 & 0 & 0 \\
F & EW & 2 & 13 & 1 & & 0 & 0 & 0 & 0 & 0 & 0 & 0 & 0 \\
G & EW & 4 & 13 & 1 & & 0 & 0 & 0 & 0 & 0 & 0 & 0 & 0 \\
H & EW & 2 & 13 & 1 & & 0 & 0 & 0 & 0 & 0 & 0 & 0 & 0 \\
EW & EW & 5 & 13 & 1 & & 0 & 0 & 0 & 0 & 0 & 0 & 0 & 0 \\
J & EW & 5 & 13 & 1 & & 0 & 0 & 0 & 0 & 0 & 0 & 0 & 0 \\
\hline
\end{tabular}




\section{Survey Form : old \\ Survey Date : 8/25/94 \\ Pre Nridge Status : OC \\ Status as of $5 / 27 / 94$ \\ OC \\ Building ID: $\quad$ SOM1 \\ Inspection/Testing: \\ C \\ Repair/Retrofit: \\ NS \\ Geographic Zone: MW}

Northridge Tag: $\mathbf{N}$

Non-MRF Structural Damage?

YES "Noticable separation of mid-floor stair landing from adjacent stair drywall."

Non-Structural Damage?

Life Safety related: NO "None"

Other: $\quad$ YES "Some ceiling panels."

Design Code: $\angle A B C$

Year Designed : 1986

Year Built :

Plan Irregularities?

$N$

Column Fy [ksi]: 36

Girder Fy [ksi]: 36

Floor Construction Type: W

Web Connection Type: B

Flange Weld Process: U
1985

MRF Stories Above Ground: 4

MRF Stories Below Ground: 0
Ground Floor Area [sf]: 18,400

Upper Floor Area [sf]: 18,400
Vertical Irregularities?

$\mathbf{N}$

Number of Frames in Each Direction:

$\begin{array}{lll}\text { N-S } & 3 & \text { NE-SW } \\ \text { E-W } & 3 & \text { NW-SE }\end{array}$

Notes:

\section{MRF Connection Inspection/Testing Scope and Damage Summary}

Total No of Conns in Inspected FF's: 38

No of Connections Inspected:

No of Connections Tested:

\section{7}

17
No of Inspected Floor-Frames: 9

$\%$ W : $100.0 \%$

Damage Score :.33

Number of Floor-Frames in each Damage Class for each inspected/tested Frame.

\begin{tabular}{|l|l|l|r|r|r|r|r|r|r|r|r|r|r|}
\hline Frame & Direction & Bays & Avg Width & FIr-Frms & TG & BG & TC & BC & TW & BW & S & PZ & CW \\
\hline A & EW & 2 & 24 & 2 & & 0 & & 0 & & 2 & 0 & 0 & 0 \\
EW & 2 & 17 & 1 & & 0 & & 0 & & 0 & 0 & 0 & 0 \\
C & EW & 2 & 22 & 2 & & 0 & & 0 & & 0 & 0 & 0 & 0 \\
D & NS & 3 & 30 & 2 & & 0 & & 0 & & 2 & 0 & 0 & 0 \\
E & NS & 2 & 30 & 1 & & 0 & & 0 & & 1 & 0 & 0 & 0 \\
FS & 2 & 30 & 1 & & 0 & & 0 & & 1 & 0 & 0 & 0 \\
\hline
\end{tabular}




\begin{tabular}{|c|c|c|c|}
\hline \multirow{3}{*}{$\begin{array}{l}\text { Survey Form : new } \\
\text { Pre Nridge Status : } O C\end{array}$} & \multicolumn{3}{|l|}{ Survey Date : 9/23/94 } \\
\hline & $\begin{array}{l}\text { Status as of } 9 / 23 / 94 \\
\text { Inspection/Testing: }\end{array}$ & $\begin{array}{l}O C \\
C\end{array}$ & Building ID: \\
\hline & Repair/Retrofit: & NS & Geographic Zone: UC \\
\hline
\end{tabular}

Northridge Tag : N

Non-MRF Structural Damage?

YES "CMU block @ elev shaft cracked \& fell; steel bms pulled from wall; wood bms @ stainwell damaged."

Non-Structural Damage?

Life Safety related: YES "Elev unusable; stair well exit inhibited"

Other:

YES "isolated ceil'g tiles fell; tall cabinets (file) fell."

$\begin{array}{lccc}\text { Design Code : UBC } & 1976 & \text { MRF Stories Above Ground:4 } & \text { Ground Floor Area [sf]: 7,000 } \\ \text { Year Designed : } 1979 & & \text { MRF Stories Below Ground: } 0 & \text { Upper Floor Area [sf]: 18,000 } \\ \text { Year Built: } 1981 & & \text { Vertical Irregularities? } \\ \text { Plan Irregularities? } & \text { Y mass irreg }\end{array}$

Column Fy [ksi]: 36

Girder Fy [ksi]: 36

Floor Construction Type: W

Web Connection Type: B

Flange Weld Process:
Number of Frames in Each Direction:

$\begin{array}{lll}\text { N-S } 2 & \text { NE-SW } \\ \text { E-W } 4 & \text { NW-SE }\end{array}$

Notes:

\section{MRF Connection Inspection/Testing Scope and Damage Summary}

Total No of Conns in Inspected FF's: 48

No of Connections Inspected:

No of Connections Tested:
No of Inspected Floor-Frames: 24

$\% \mathrm{~W} 1: 0.0 \%$

Damage Score :1.54

Number of Floor-Frames in each Damage Class for each inspected/tested Frame.

\begin{tabular}{|l|l|r|r|r|r|r|r|r|r|r|r|r|r|}
\hline Frame & Direction & Bays & Avg Width & FIr-Frms & TG & BG & TC & BC & TW & BW & S & PZ & CW \\
\hline 10 & EW & 1 & 24 & 4 & 0 & 0 & 0 & 1 & 0 & 1 & 0 & 0 & 1 \\
2 & EW & 1 & 24 & 4 & 0 & 0 & 0 & 0 & 0 & 0 & 0 & 0 & 0 \\
5 & EW & 1 & 24 & 4 & 0 & 0 & 0 & 2 & 0 & 2 & 0 & 0 & 2 \\
7 & EW & 1 & 24 & 4 & 0 & 0 & 0 & 1 & 0 & 1 & 0 & 0 & 1 \\
B & NS & 1 & 30 & 4 & 0 & 0 & 0 & 1 & 2 & 2 & 0 & 0 & 1 \\
F & NS & 1 & 30 & 4 & 0 & 0 & 0 & 0 & 0 & 0 & 0 & 0 & 0 \\
\hline
\end{tabular}




\begin{tabular}{|c|c|c|c|}
\hline Survey Form : old & Survey Date : 9/6/94 & & \\
\hline Pre Nridge Status: OC & $\begin{array}{l}\text { Status as of } 6 / 1 / 94 \\
\text { Inspection/Testing: }\end{array}$ & OC & Building ID: \\
\hline
\end{tabular}

Northridge Tag: $\mathrm{N}$

Non-MRF Structural Damage?

YES " 6 inch permanent lateral displacement in height of 18 story building. Steel stair connections broken. Mechanical room block walls broken at connections to steel floor framing. Marble panel anchorages in lobby damaged."

Non-Structural Damage?

Life Safety related: YES "Elevators not operational. Fire and electrical systems temporarily out."

Other: YES "Ceiling tiles displaced, drywall partitions cracked, overturned shelves, etc."

\begin{tabular}{llcc}
\hline $\begin{array}{l}\text { Design Code : UBC } \\
\text { Year Designed: }\end{array}$ & 1985 & $\begin{array}{l}\text { MRF Stories Above Ground: } 18 \\
\text { MRF Stories Below Ground: } 1\end{array}$ & $\begin{array}{l}\text { Ground Floor Area [sf]: 19,200 } \\
\text { Upper Floor Area [sf]: 19,200 }\end{array}$ \\
$\begin{array}{l}\text { Year Built: } 1986 \\
\begin{array}{l}\text { Plan Irregularities? } \\
\text { N }\end{array}\end{array}$ & & $\begin{array}{c}\text { Vertical Irregularities? } \\
\text { N }\end{array}$
\end{tabular}

Column Fy [ksi]: 50

Girder Fy [ksi]: 36

Floor Construction Type: MC

Web Connection Type: B

Flange Weld Process: FCAW
Number of Frames in Each Direction:

$\begin{array}{ll}\text { N-S } 2 & \text { NE-SW } \\ \text { E-W } 2 & \text { NW-SE }\end{array}$

Notes:

\section{MRF Connection Inspection/Testing Scope and Damage Summary}
Total No of Conns in Inspected FF's:
272
No of Connections inspected:
272
No of Inspected Floor-Frames: 68
No of Connections Tested:
41
$\% \mathrm{~W} 1: 0.0 \%$
Damage Score :.46

Number of Floor-Frames in each Damage Class for each inspected/tested Frame.

\begin{tabular}{|l|l|r|r|r|r|r|r|r|r|r|r|r|r|}
\hline Frame & Direction & Bays & Avg Width & Flr-Frms & TG & BG & TC & BC & TW & BW & S & PZ & CW \\
\hline A & NS & 2 & 28 & 17 & 0 & 0 & 0 & 4 & 0 & 9 & 0 & 0 & 0 \\
B & NS & 2 & 28 & 17 & 0 & 0 & 0 & 2 & 0 & 4 & 0 & 0 & 0 \\
D & $\mathrm{EW}$ & 2 & 31 & 17 & & 0 & & 0 & & 0 & 0 & 0 & 0 \\
D & $\mathrm{EW}$ & 2 & 31 & 17 & & 0 & & 0 & & 0 & 0 & 0 & 0 \\
\hline
\end{tabular}




\section{Appendix B: Survey Forms}

B-1 


\section{SURVEY OF \\ STEEL MRF BUILDINGS \\ AFFECTED BY THE JANUARY 1994 \\ NORTHRIDGE EARTHQUAKE}

Building NamanD:

Survey Engr: Firm:

Orig Date:

Revn Date:

Page:

\section{INSTRUCTIONS TO SURVEY ENGINEERS}

1. Complete survey form for each structurally distinct MRF building.

2. Report all inspected and/or tested conditions, whether damaged or undamaged.

3. Do not leave blanks. Use "U", "NA", or dashes "-." where necessary. See abbreviations.

4. Please give the street address in Section I. If confidential, this information will not be released to database users. If address or building name is to be kept confidential, use an appropriate unique code for "Building Name/10" at the top of each page.

\section{ABBREVIATIONS}

General

$\begin{array}{llllll}\text { N } & \text { No, None } & U & \text { Unknown } & \text { PD } & \text { Principal Direction } \\ \text { NA } & \text { Not Applicable } & Y & \text { Yes } & \text { MRF Moment-Resisting Frame } \\ \text { O } & \text { Other } & & & \text { HAZ Heat-Affected Zone } \\ & & & & \text { UT } & \text { Ultrasonic Testing } \\ & & & \text { VI } \text { Visual Inspection }\end{array}$

Building Use

$\begin{array}{llll}\text { A } & \text { Apartment House } & \text { OF } & \text { Office } \\ \text { C } & \text { Condominiums } & \text { P } & \text { Parking } \\ \text { D } & \text { Data/Computing Center } & \text { R } & \text { Retail } \\ \text { E } & \text { Emergency (fire, ambulance, otc) } & \text { S } & \text { School } \\ \text { H } & \text { Hospital/Clinic } & \text { SD } & \text { School w/ DSA approval } \\ \text { HO } & \text { Hospital w/ OSHPD approval } & T & \text { Theatre/Church/Assembly } \\ \text { HL } & \text { Hotel/Motel } & \text { U } & \text { Utility } \\ \text { L } & \text { Laboratory/Research } & \text { W } & \text { Warehouse }\end{array}$

M Manufacturing/Industry

Lateral Load Resisting Systems

OMRF Ordinary MRF

SMRF Special MRF

DMRF Ductile MRF (pre-1988 UBC)

CBF Concentrically Braced Frame

EBF Eccentrically Braced Frame

DSW Dual System: MRF + shear walls

DCBF Dual System: MRF + CBF

DEBF Dual System: MRF + EBF

\section{Floor Construction Types}

W. Wood diaphragm w/ wood or metal joists

$M \quad$ Bare metal deck $w /$ steel beams or joists

MC Metal deck w/ normal wt concrete fill

MCL Metal deck w/ lightweight concrete fill

$P$ Precast concrete planks $w /$ topping slab

$\begin{array}{ll}\text { Weld Processes } \\ \text { FCAW } & \text { Flux Cored Arc Weld } \\ \text { SMAW } & \text { Shielded Metal Arc Weld } \\ \text { SAW } & \text { Submerged Arc Weld } \\ \text { GMAW } & \text { Gas Metal Arc Weld }\end{array}$

DEFINITIONS

Building

MRF

Connection

Floor-Frame
Set of diaphragms laterally supported by the same set of frames or structurally separated from other diaphragms by seismic joints.

Moment-resisting frame. System of moment-connected beams and columns generally in a single vertical plane. One frame has the same name/designation at each floor. Intersection of one frame beam with one frame column, generally comprising a top flange connection, a bottom flange connection, and a web connection. A typical joint with a continuous column and beams on both sides constitutes two connections. The set of connections in one MRF at one floor level. 


\section{SURVEY OF}

STEEL MRF BUILDINGS

AFFECTED BY THE JANUARY 1994

NORTHRIDGE EARTHQUAKE
Building Name/ID:

Survey Engr: Firm:

Orig Date:

Revn Date: Page:

\section{SECTION I: PROCEDURAL}

Person(s) Completing Survey (Survey Engineer)

Agency/Firm

Firm Address

Telephone

Building Location

Confidential? $(Y / N)$

Street Number

Street Name

City

\section{Zip Code}

Cross Street(s)

Neighborhood/District

Note: for major renovations or additions at the same address, please distinguish original frames from added or strengthened frames and complete the applicable sections of a separate form.

Indicate items available to the survey engineer or used as the basis of survey responses:

Architectural drawings

Structural design drawings

Structural as-built drawings

Original structural calcs

Geotech/soil report

Site specific design spectrum

Steel/Welding specifications

Fabrication/Erection drawings

Post-Northridge visual insp'n data

Post-Northridge testing data

Post-Northridge calcs/analysis results

\section{Available \\ Used}

Photographs of inspected conditions

Weld or steel samples removed

Other

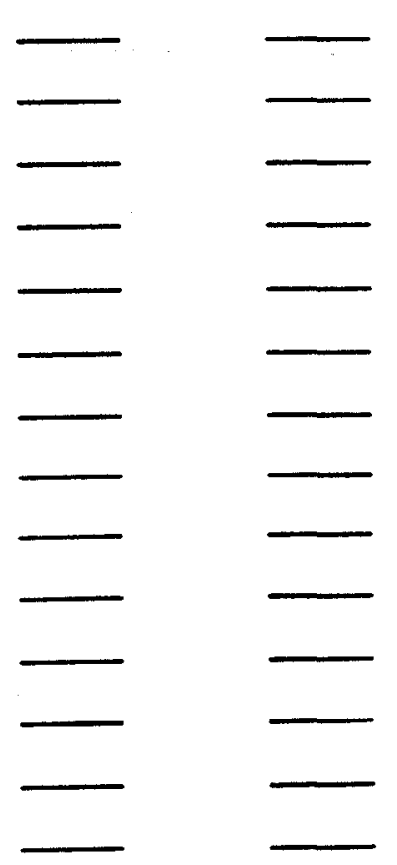




\section{SURVEY OF}

\section{STEEL MRF BUILDINGS}

AFFECTED BY THE JANUARY 1994 NORTHRIDGE EARTHQUAKE
Building Name/1D:

Survey Engr: Firm:

Orig Date:

Revn Date: Page:

\section{SECTION II: BUILDING HISTORY}

Year Designed

Year Constructed

Building Use (see Abbrev.):

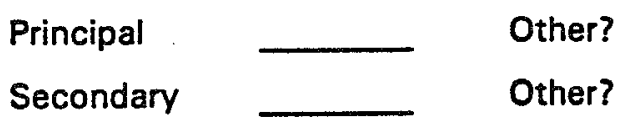

Is the building owner a government or non-profit agency?

Pre-Northridge building status (Occupied, Under Construction, Vacant, etc.)

Post-Northridge Team

Visual Insp Engr/Firm

Testing Lab

Repair/Retrofit Engr

Current building status (Occupied, Under Construction, Vacant, etc.)

Visual inspection Complete, in Progress, or Not Started (C, IP, NS)

Testing Complete, In Progress, or Not Started

Repair/Rehabilitation Design Complete, In Progress, or Not Started

Repair/Rehab Construction Complete, In Progress, or Not Started

Additional description of current building status

Date of above status information 
SURVEY OF

STEEL MRF BUILDINGS

AFFECTED'BY THE JANUARY 1994

NORTHRIDGE EARTHQUAKE
Building Name/ID:

Survey Engr: Firm:

Orig Date:

Revn Date:

Page:

\section{SECTION III: NORTHRIDGE EARTHQUAKE PERFORMANCE}

Was the building tagged after Northridge (Unknown, None, Red, Yellow, Green)?

If building was retagged or had its tag status changed in any way, please explain:

Describe structural damage other than in MRF connections (consider permanent lateral set, if any):

Describe non-structural damage (consider especially falling hazards and loss of egress):

Describe the impact of damage on users (e.g., known injuries? voluntary evacuation? business downtime?): .

Classify the distribution of structural damage (including MRF connection damage) as None, Isolated, or Widespread:

Classify the impact of structural damage (including MRF connection damage) on the building's overall life safety as None, Minimal, or Substantial:

Classify potential required repairs of all damage as None, Cosmetic (non-structural only), Moderate (repairable without substantial demolition), or Heavy: 
SURVEY OF

STEEL MRF BUILDINGS

AFFECTED BY THE JANUARY 1994 NORTHRIDGE EARTHQUAKE
Building Name/1D:

Survey Engr: Firm:

Orig Date:

Revn Date: Page:

\section{SECTION IV: BUILDING DESCRIPTION}

Total \# of stories above ground:

Total \# of stories below ground:

Maximum roof height above ground:

Approximate footprint area:
\# of steel MRF stories above ground:

\# of steel MRF stories below ground:

Typical floor construction (see Abbreviations):

Describe the lateral load-resisting system in each Principal Direction (see Abbreviations):

Note: If building's frames are in two directions only, ignore PD3 and PD4.

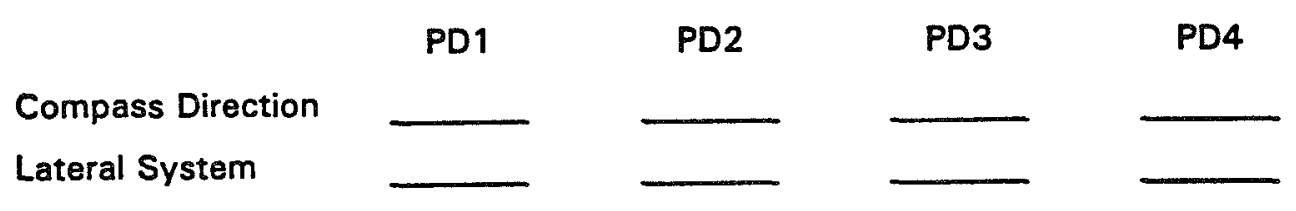

Which (if any) vertical irregularities per 1991 UBC Table 23-M appear to be present in the building?

Which (if any) plan irregularities per 1991 UBC Table 23-N appear to be present in the building?

\section{Design Code \& year}

Typical column $F_{y}$ (ksi)

Typical girder $F_{y}(k s i)$

Typical girders expected to act composite with deck?

Typical girder web connections welded only (W), bolted only (B), or welded \& bolted (WB)?

Girder flange weld process (see Abbreviations): Field or Shop?

Describe each MRF in Section $V$ table. Add sheets as necessary. Only inspected or tested conditions need be reported, but descriptions of member sizes, number of bays, etc. in uninspected frames are also appreciated. 
SURVEY OF

STEEL MRF BUILDINGS

AFFECTED BY THE JANUARY 1994 NORTHRIDGE EARTHQUAKE
Building Name/1D:

Survey Engr: Firm:

Orig Date:

Rovn Date: Page:

\section{SECTION V: DAMAGE DESCRIPTION}

1. Respond to the questions on this and the next page.

2. Assign a name to each MRF. A given frame should have the same name at each floor.

3. Complete one copy of the table below for each inspected MRF, whether damaged or not.

4. Show the MRF locations and names on a plan sketch in Section VII below.

Note: Generally, each line of each Section V table will describe one inspected floor-frame. However, one line can be used for several identical floors. Frames with more than seven non-identical inspected floor levels will require more than one page. As an alternate to completing the tables, provide Section Vill frame elevations for each frame, showing member sizes, extent of inspection/testing, and damage type according to the reference schedule of damage types below.

Describe the type and extent of typical visual inspection and typical testing $(y / n / u)$ :

\section{Visual Inspection:}

fireproofing removed from beam

fireproofing removed from col flange

fireproofing removed from panel zone

steel cleaned

backup bars removed for weld VI/UT

slab removed for top flange access

window wall removed for far side access at perimeter frames

Testing:

ultrasonic

magnetic particle

dye penetrant

weld sample taken

$\mathrm{bm} / \mathrm{col}$ sample taken

plumbness survey

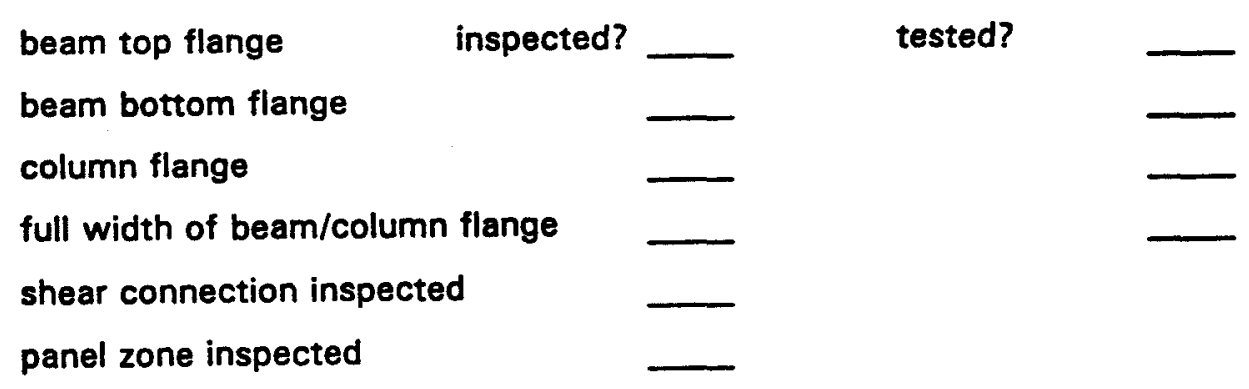

Basis for selecting locations to VI/UT (e.g. cost, access, analysis, random):

Describe inspection or testing criteria/procedures (e.g. AWS D1.1):

Describe any constraints on typical VI/testing (e.g. at top flanges and perimeter frames): 
SURVEY OF

STEEL MRF BUILDINGS

AFFECTED BY THE JANUARY 1994 NORTHRIDGE EARTHQUAKE
Building Name/D:

Survey Engr: Firm:

Orig Date:

Revn Date: Page:

SECTION V continued

Describe any observed evidence of poor workmanship (e.g. use of end dams, small cope holes):

Describe any observed deviations from approved drawings or specifications.

Is there reason to think that poor workmanship or deviations contributed to damage? Explain:

Of all the weld damage indicated in the floor-frame tables below, estimate the percentage that is UT-detected incipient root cracks only (type W.1) or minor discontinuities that may have existed preearthquake:

If Column Web damage (class $\mathrm{CW}$ ) is indicated for any of the floor-frames in the tables below, describe more completely the nature and location of such damage (or illustrate in Section VI below): 


\section{SURVEY OF}

STEEL MRF BUILDINGS

AFFECTED BY THE JANUARY 1994 NORTHRIDGE EARTHQUAKE
Buiding Nema/D:

Survey Enor: Fim:

Orig Dato:

Rovn Date:

Page:

SECTION V continued Describe each inspected floor-frame. See Section V instructions above.

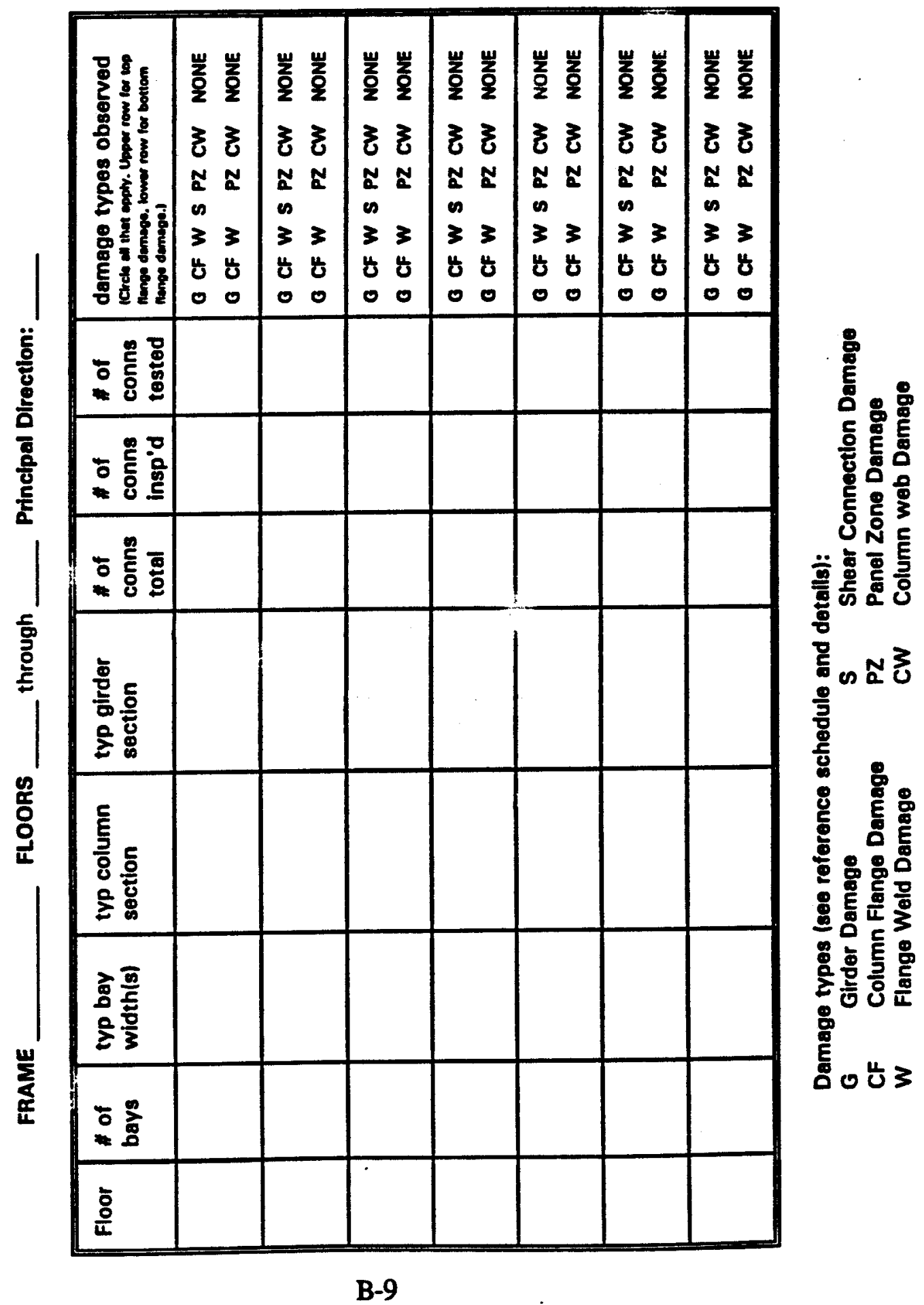




\section{SURVEY OF}

STEEL MRF BUILDINGS

AFFECTED BY THE JANUARY 1994 NORTHRIDGE EARTHQUAKE
Building NamenD:

Survey Engr: Firm:

Orig Date:

Revn Date:

Page:

\section{SECTION V continued}

REFERENCE SCHEDU!E OF DAMAGE TYPES (See Reference Details below for pictorial description.)

G

GIRDER DAM EE
G1 buckleo flange
G2 yielded flange
G3 flange tearout near weld
G4 flange crack outside HAZ

CF COLUMN FLANGE DAMAGE

C1 incipient flange crack (detected by UT)

C2 complete flange tearout or divot

C3 full or partial cross-flange crack in HAZ

C4 full or partial cross-flange crack outside HAZ

C5 lamellar flange tearing

W FLANGE WELD DAMAGE

W1 incipient crack, especially at weld root (detected by UT)

W2 crack through weld metal, full or partial width of flange

W3 fracture at girder interface

W4 fracture at column interface

S SHEAR CONNECTION DAMAGE

S1 column to web or column to shear tab weld crack

S2 web to shear tab supplemental weld crack

S3 web or shear tab crack, especially through bolt holes

S4 web or shear tab deformation, especially at holes.

S5 loose, damaged, or missing bolts; faying surfaces out of contact

PZ PANEL ZONE DAMAGE

P1 fracture, buckle, or yield of continuity plate

P2 crack in continuity plate welds

P3 buckle, yield, or ductile deformation of doubler plate or column web

P4 crack in doubler plate welds

CW COLUMN WEB DAMAGE

P5 partial depth crack in column web or doubler plate (extension of C3 or C4)

P6 full or near full depth crack in column web or doubler plate 


\section{SURVEY OF}

STEEL MRF BUILDINGS

AFFECTED BY THE JANUARY 1994 NORTHRIDGE EARTHQUAKE
Building Name/nD:

Survey Engr: Firm:

Orig Date:

Rovn Date: Page:

\section{SECTION $V$ continued}

REFERENCE DETAIL (See Reference Schedule above for damage type descriptions.)

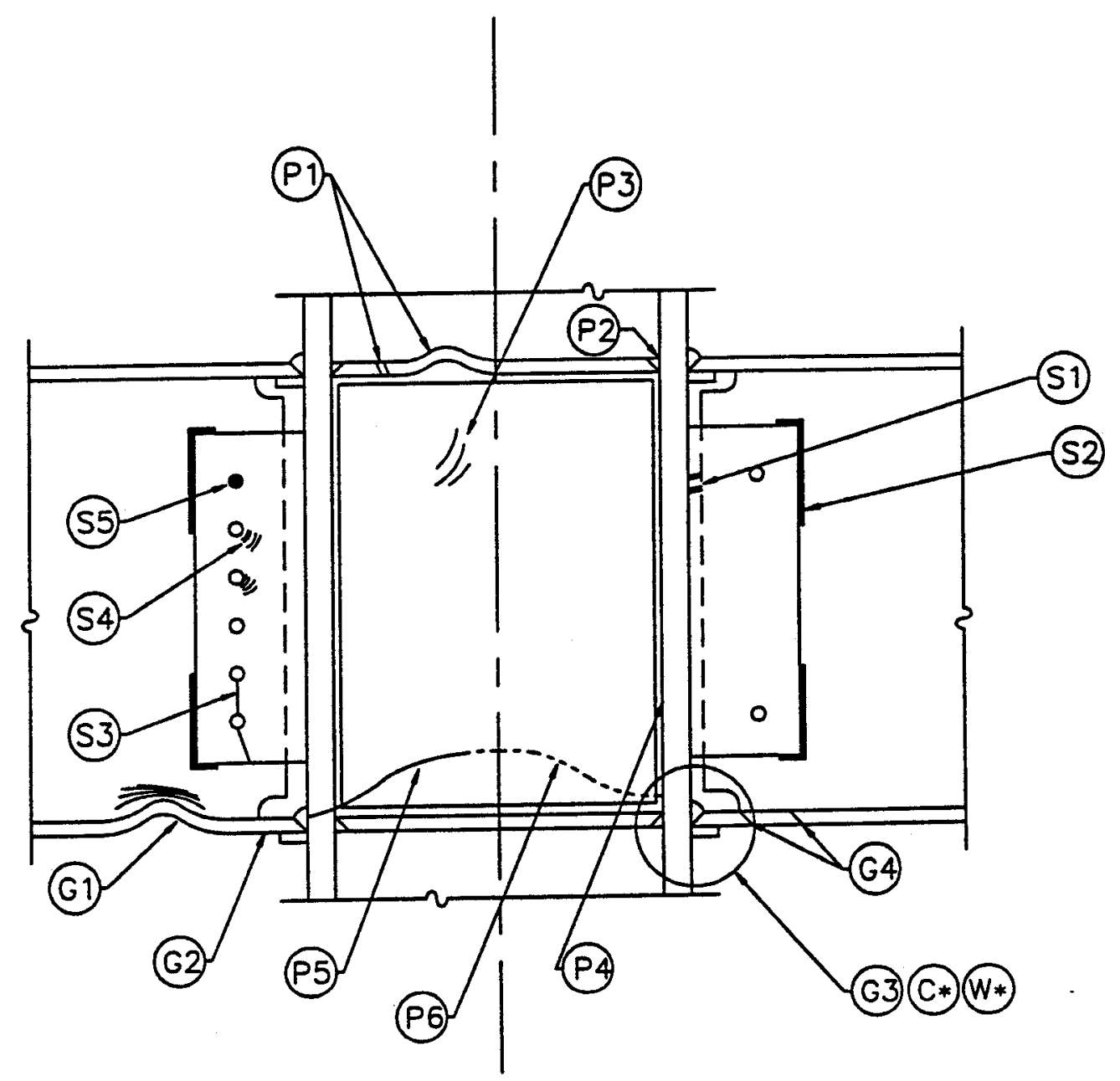

REFERENCE DETAIL: MRF JOINT DAMAGE TYPES
NOTE: SEE REFERENCE SCHEDULE FOR DESCRIPTION 


\section{SURVEY OF}

STEEL MRF BUILDINGS

AFFECTED BY THE JANUARY 1994 NORTHRIDGE EARTHQUAKE
Building Name/ID:

Survey Engr: Firm:

Orig Date:

Revn Date: Page:

\section{SECTION V continued}

REFERENCE DETAIL (See Reference Schedule above for damage type descriptions.)

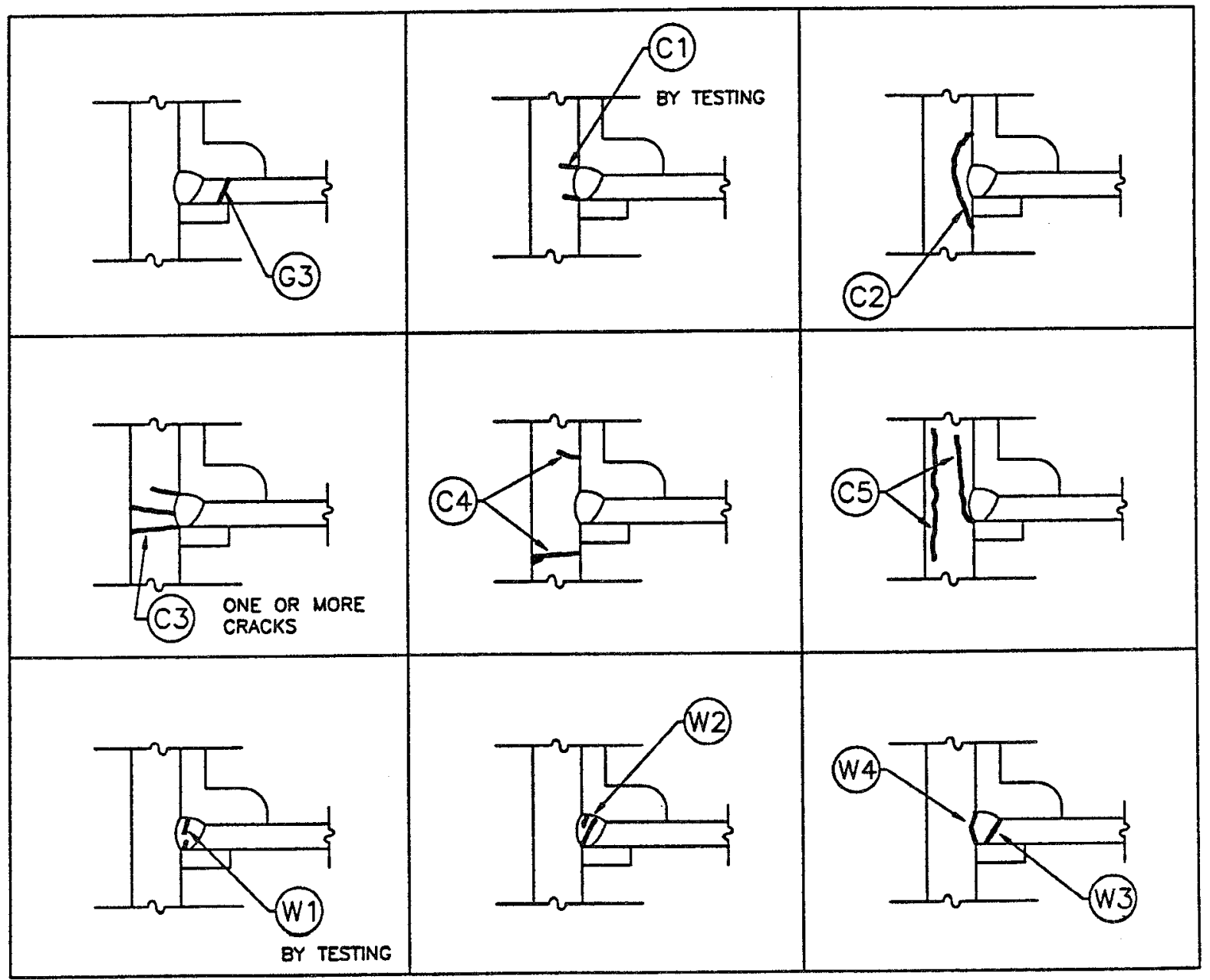

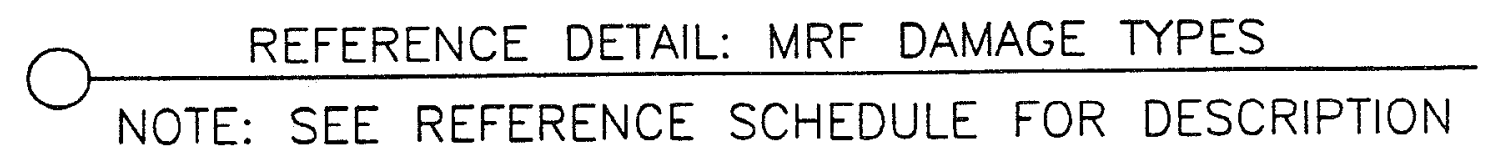


SURVEY OF

STEEL MRF BUILDINGS

AFFECTED BY THE JANUARY 1994

NORTHRIDGE EARTHQUAKE
Building Name/10:

Survey Engr: Firm:

Orig Date:

Revn Date: Page:

\section{SECTION VI: SPECIFIC DAMAGE DETAILS}

Instructions to Survey Engineer: Complete details shown for one or two specific conditions per building. Show damage and identify by type according to Reference Schedule above.

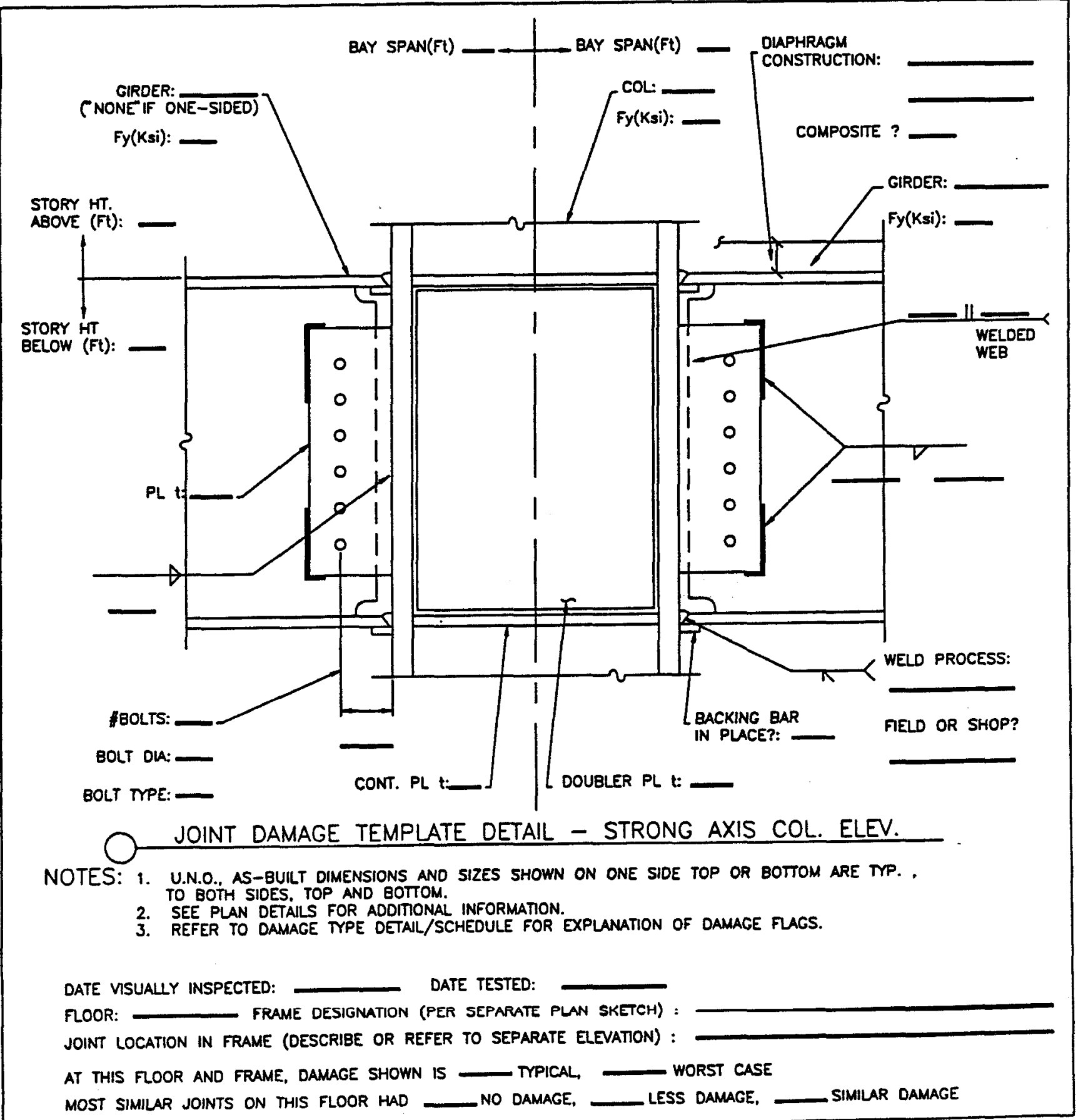




\section{SURVEY OF}

STEEL MRF BUILDINGS

AFFECTED BY THE JANUARY 1994

NORTHRIDGE EARTHQUAKE

Building Name/ID:

Survay Engr: Firm:

Orig Date:

Revn Date: Page:

\section{SECTION VI: SPECIFIC DAMAGE DETAILS}

Instructions to Survey Engineer: Complete details shown for one or two specific conditions per building. Show damage and identify by type according to Reference Schedule above.
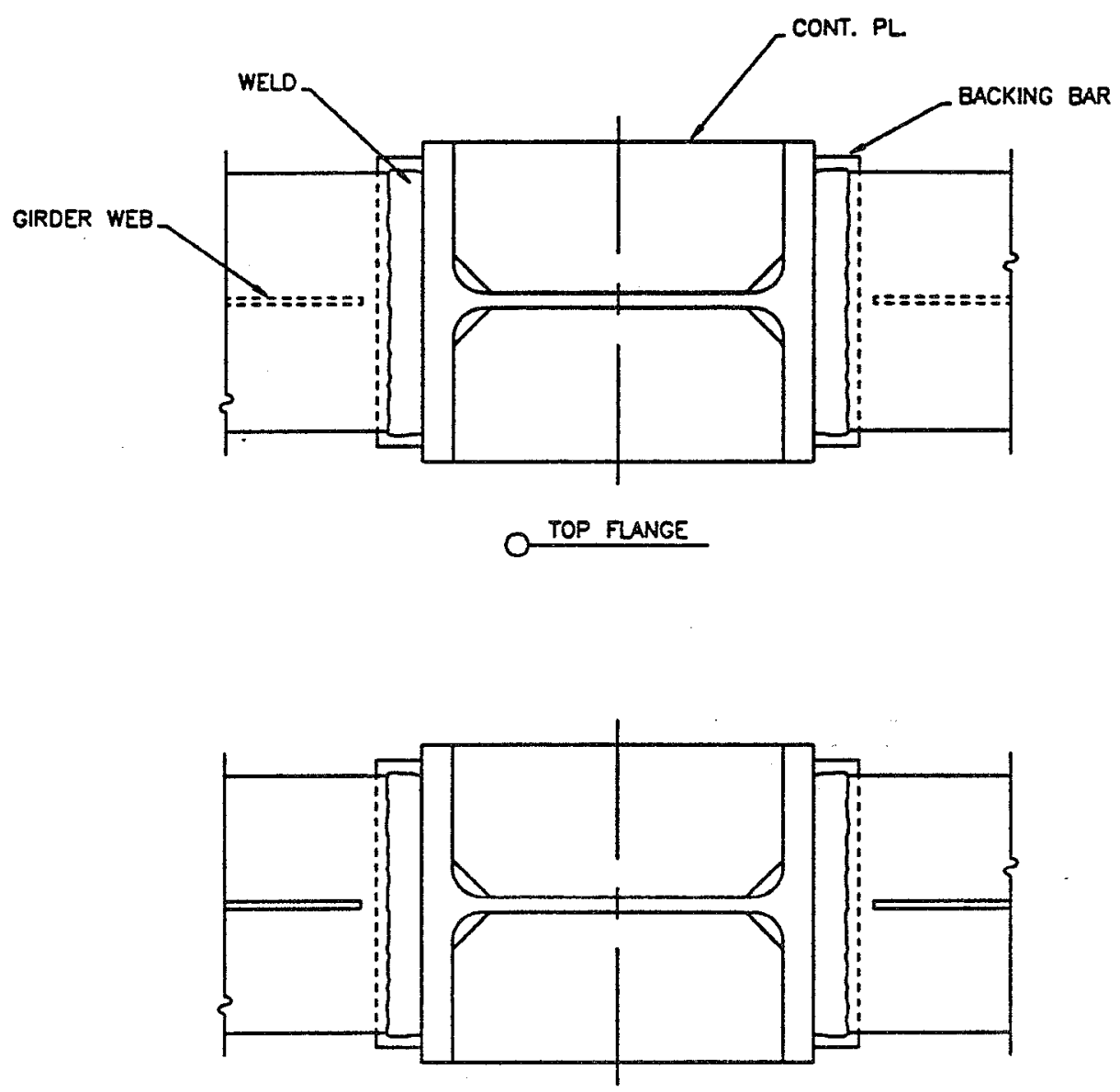

BOTTOM FLANGE

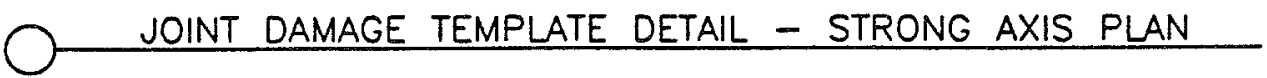

NOTES:

1. SEE COLUMN ELEVATION FOR MEMBER SIZES, DIMENSIONS, AND AODITIONAL INFORMATION.

2. REFER TO DAMAGE TTPE DETAIL/SCHEDULE FOR EXPLANATION OF DAMAGE FLAGS. 


\section{SURVEY OF}

STEEL MRF BUILDINGS

AFFECTED BY THE JANUARY 1994

NORTHRIDGE EARTHQUAKE
Building Name/ID:

Survey Engr: Firm:

Orig Date:

Revn Date:

Page:

SECTION VI: SPECIFIC DAMAGE DETAILS

Instructions to Survey Engineer: Complete details shown for one or two specific conditions per building. Show damage and identify by type according to Reference Schedule above.

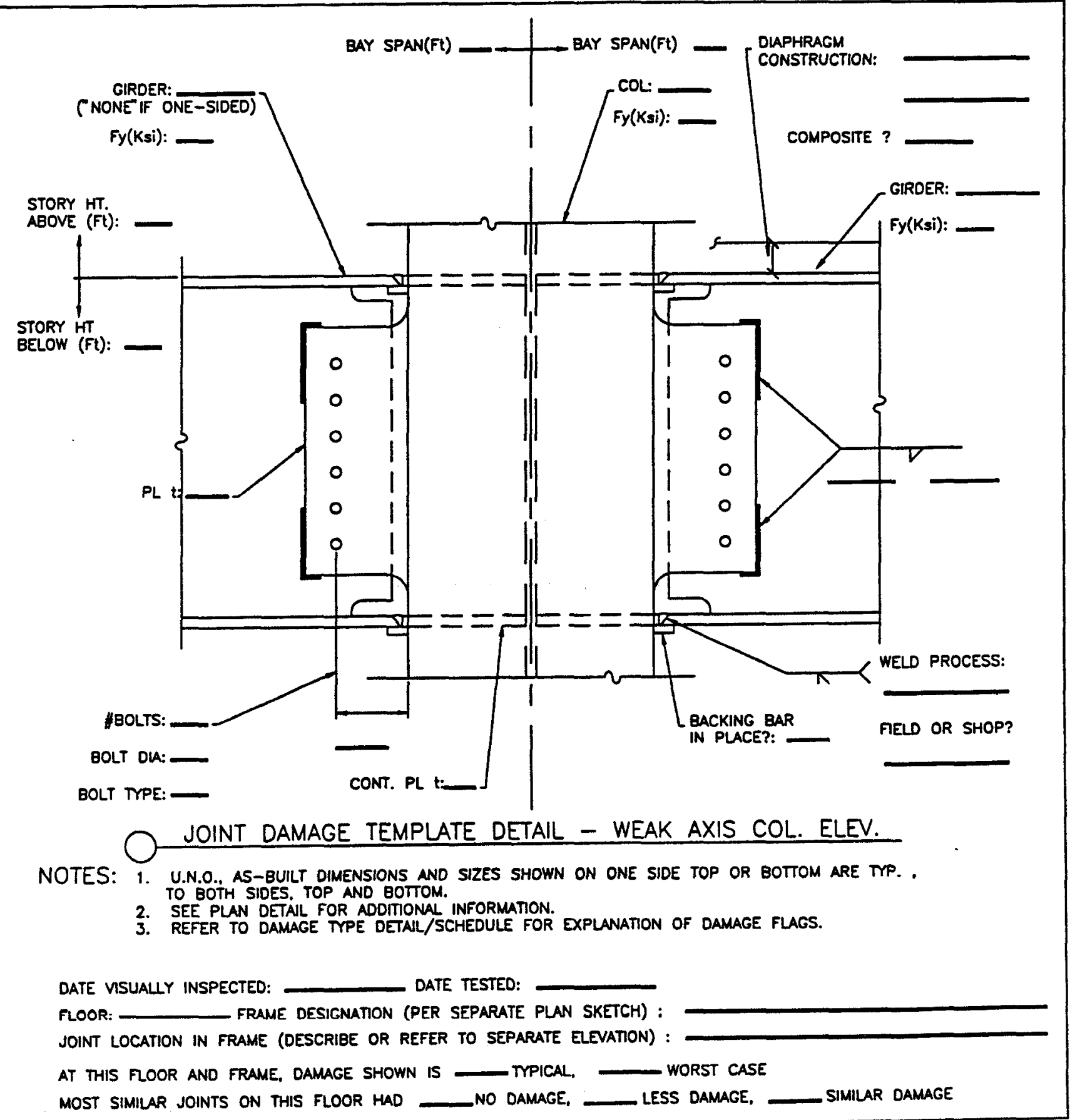


SURVEY OF

\section{STEEL MRF BUILDINGS}

AFFECTED BY THE JANUARY 1994 NORTHRIDGE EARTHQUAKE
Building Name/ID:

Survey Engr: Firm:

Orig Date:

Revn Date: Page:

SECTION VI: SPECIFIC DAMAGE DETAILS

Instructions to Survey Engineer: Complete details shown for one or two specific conditions per building. Show damage and identify by type according to Reference Schedule above.
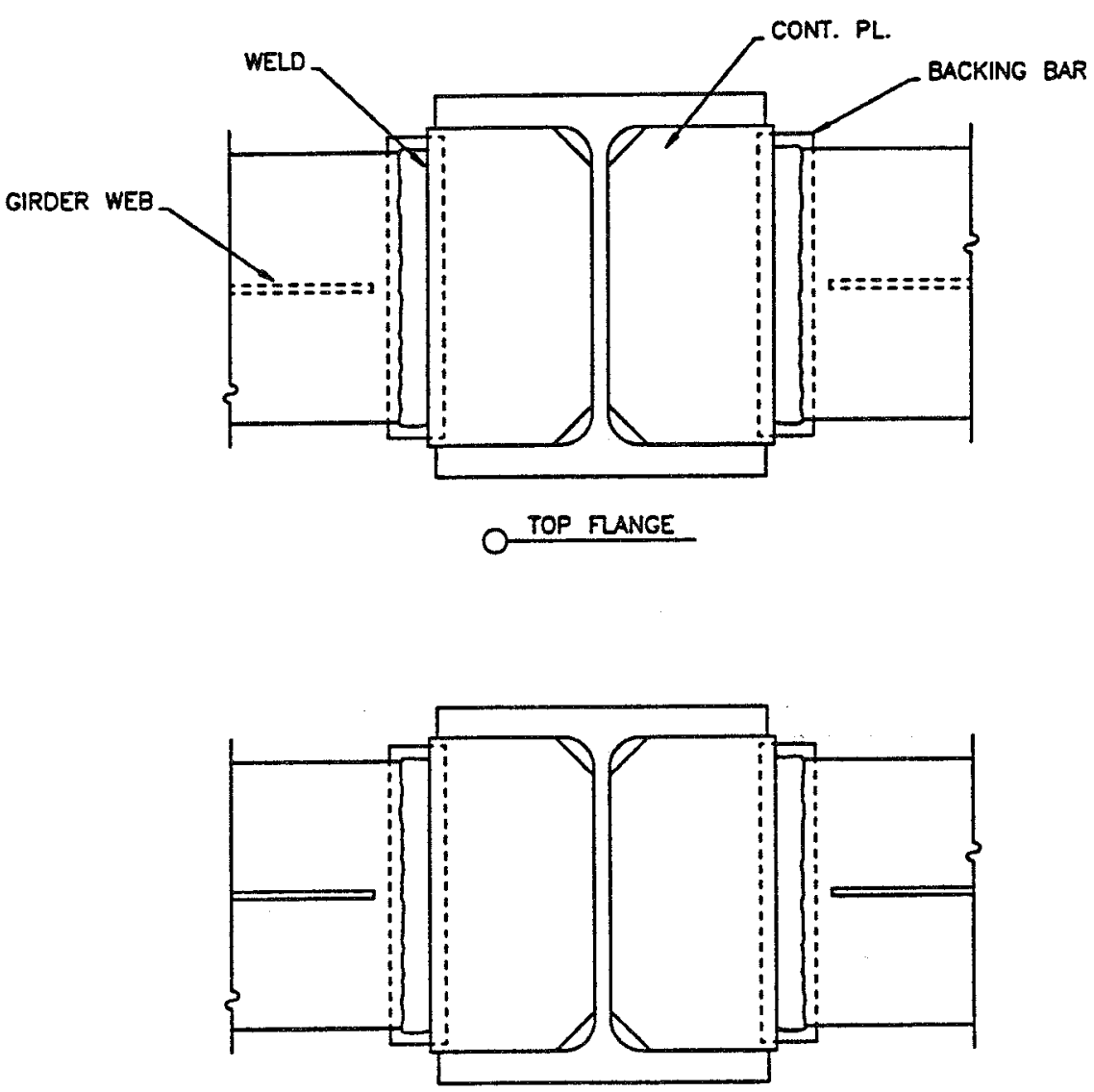

OOTTOM FLANGE

\section{JOINT DAMAGE TEMPLATE DETAIL - WEAK AXIS PLAN}

NOTES:

1. SEE COLUMN ELEVATION FOR MEMBER SIZES, DIMENSIONS, AND ADDITIONAL INFORMATION.

2. REFER TO DAMAGE TTPE DETALL/SCHEDULE FOR EXPLANATION OF DAMAGE FLAGS. 
SURVEY OF

STEEL MRF BUILDINGS

AFFECTED BY THE JANUARY 1994

NORTHRIDGE EARTHQUAKE
Building Name/1D:

Survey Engr: Firm:

Orig Date:

Revn Date:

Page:

\section{SECTION VII: PLAN SKETCH}

Instructions to Survey Engineer: Provide a plan sketch of the building showing compass direction,

Principal Directions, basic floor plate dimensions, relative locations of frames, and frame names/designations as tabulated above in Section $\mathrm{V}$. 
SURVEY OF

STEEL MRF BUILDINGS

AFFECTED BY THE JANUARY 1994 NORTHRIDGE EARTHQUAKE
Building Name/ID:

Survey Engr: Firm:

Orig Date:

Revn Date: Page:

SECTION VIII: FRAME ELEVATIONS (Optional)

Instructions to Survey Engineer: Provide frame elevations showing frame name/designation, Principal Direction, basic bay and story dimensions, and indications of inspected and damaged connections. 


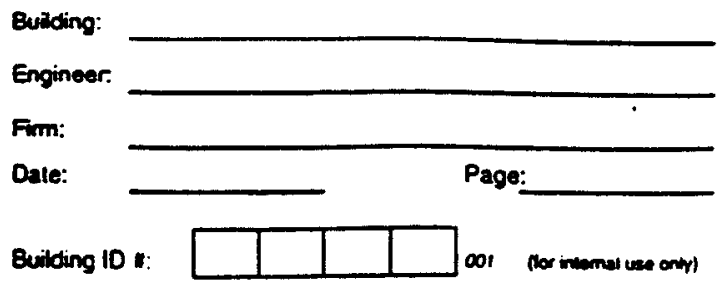

\section{GLOSSARY OF TERMS}

\section{Bullding Use}
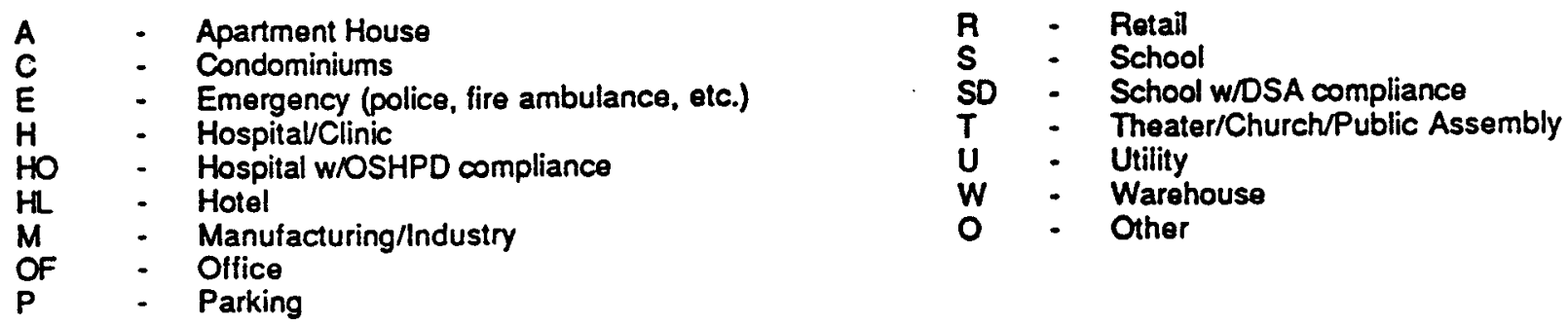

\section{Plan Shapes}

R - Rectangular Shaped

S - Square Shaped

L - L-Shaped

U - U-or W-Shaped

D - Doughnut (center courtyard)

\section{Lateral Load Reslsting Systems}

$\begin{array}{lll}\text { EBF } & \text { - } & \text { Eccentrically Braced Frame } \\ \text { CBF } & - & \text { Concentrically Braced Frame } \\ \text { SMRF } & - & \text { Special MRF } \\ \text { OMRF } & - & \text { Ordinary MRF } \\ \text { DSW } & - & \text { Dual System SMRF with shear walls } \\ \text { DEBF } & - & \text { Dual System SMRF with EBF } \\ \text { DCBF } & - & \text { Dual System SMRF with CBF }\end{array}$

\section{Column Fixlty}

P - Pinned base

F - Fixed base or continuous into stiff wall element

C - Continuous into basement frame columns

\section{Foundation Types}

SF - Individual spread footings

of - Continuous or combined footings

M - Mat

P - Piles or caissons with individual pile caps

PC - Piles or caissons with combined or continuous pile cap

\section{Floor Construction Types}

W - Wood diaphragm with wood or metal floor joists

M - Bare metal deck with steel beams or floor joists

MC - Metal deck with nomal weight concrete fill

$\mathrm{MCL}$ - Motal deck with lightweight concrete fill

P - Precast concrete planks with topping slab

\section{Other - Describe}

\section{Weld Process Used}

$\begin{array}{ll}\text { FCAW : } & \text { Flux-Cored Arc Weld } \\ \text { SMAW : } & \text { Shielded Metal-Arc Weld } \\ \text { SAW : } & \text { Submerged-Arc Weld } \\ \text { GMAW : } & \text { Gas metal-Arc Weld } \\ \text { O } & \text { Other }\end{array}$




\section{SURVEY OF STEEL MRF BUILDINGS}

DAMAGED BY THE NORTHRIDGE EARTHQUAKE,

JANUARY, 1994

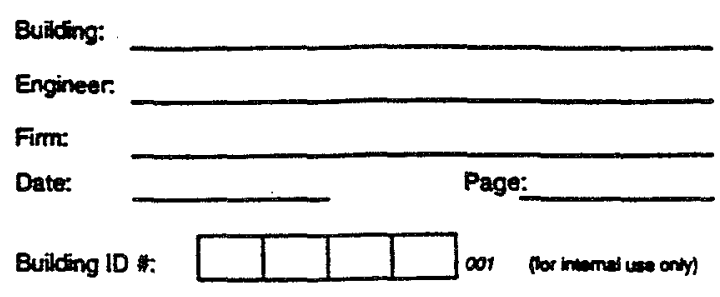

\section{INSTRUCTIONS:}

1) Complete entire survey form for original building.

2) For major renovations or additions, complete the applicable portions of a separate survey form.

3) Please respond to all items. Where necessary, use "U" (for unknown) or dashes "- " to show that information is not available.

Do not leave blanks without explanation.

4) Where not specified, the following abbreviated responses may be used: $Y=$ yes, $N=$ no, $U=U n k n o w n$, or $N / A=$ not applicable.

\section{SECTION I: Procedural}

1) Date of original survey:

2) Date of this revision to survey:

3) Person Completing Survey

4) Agency/Firm

5) Phone Number

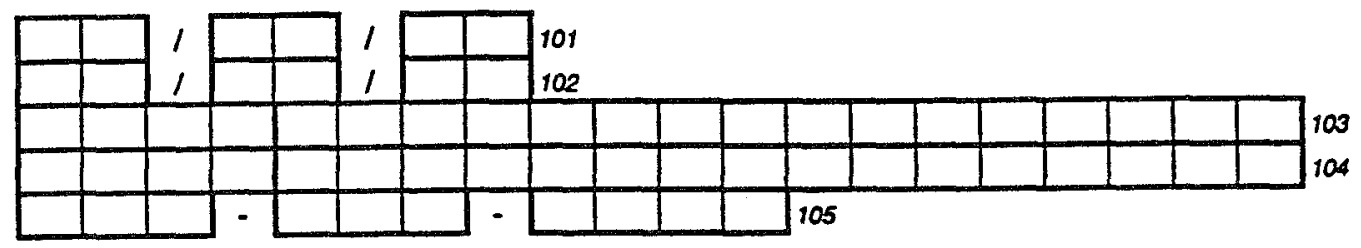

6) Building Location

Number

Street

City

Zip Code

Cross Street

Vicinity/Neighborhood

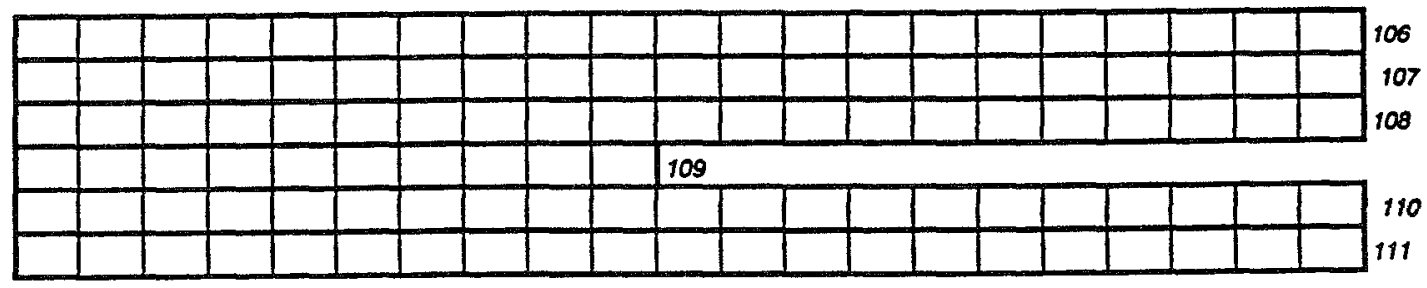

$7)$ is this survey for the original building $(O)$, for a pre-Northridge renovation $(R)$, or an addition $(A)$ ? Enter $O, R$, or $A$.

(Note: For each major renovation/addition, complete the applicable portions of a separate survey form)

8) Basis of survey responses (enter $Y, N$ or N/A to each):

Structural Drawings

Fabrication/Erection Drawings

Firsthand post-Northrige visual inspection

Post-Northridge visual inspection report by other engineer

Post-Northridge test report

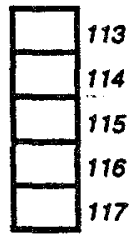




\section{SURVEY OF STEEL MRF BUILDINGS \\ DAMAGED BY THE NORTHRIDGE EARTHQUAKE, JANUARY, 1994}

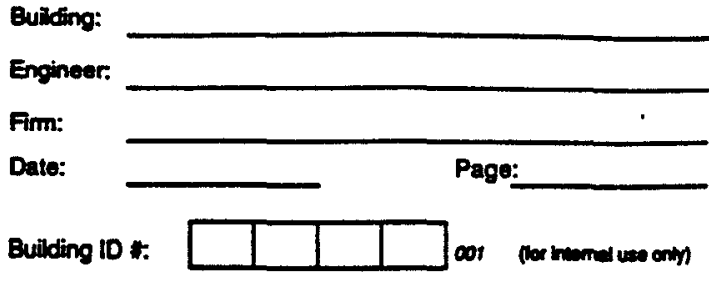

\section{ECTION II: Building History}

1) Year Designed:

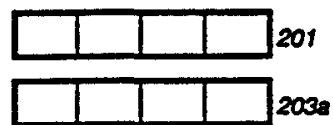

2) Year Constructed:

3) Years of Major Renovations/Additions:

(Note: For each major renovation/addition, complete the applicable portions of a separate survey form)

4) Building Use: (Enter the appropriate choice for each from the glossary of terms, building use section)

Principal Use

Secondary Use

Tertiary Use

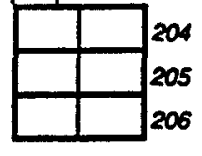

206
If other, please describe
If other, please describe
If other, please describe

5) is this primarily a government building? (Enter $Y$ or $N$ )

207

6) Pre-Nerthridge Team:

Engineer of Record:

Architect:

Source of Steel (i.e. US, Japan, etc.)

Steel Fabricator.

Steel Erector:

Permit Granting Authority:

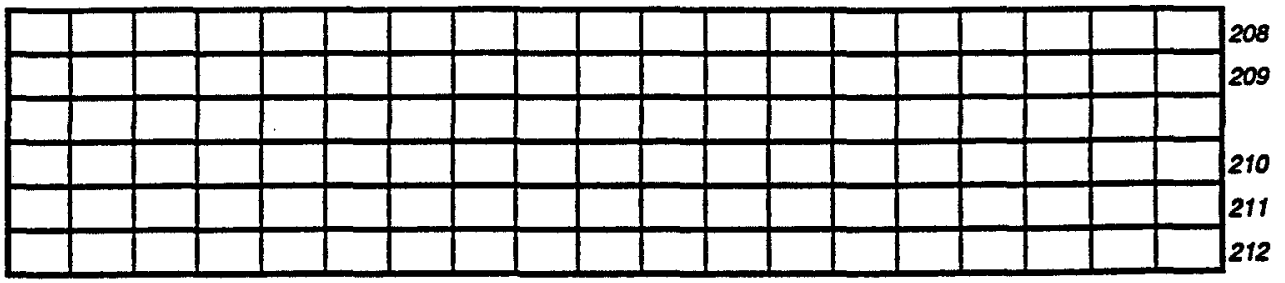

7) Post-Northridge Team: Inspecting Engineer: Inspection/Testing Lab: Repair/Retrofit Engineer: Repair/Retrofit General Contractor. Permit Granting Authority:

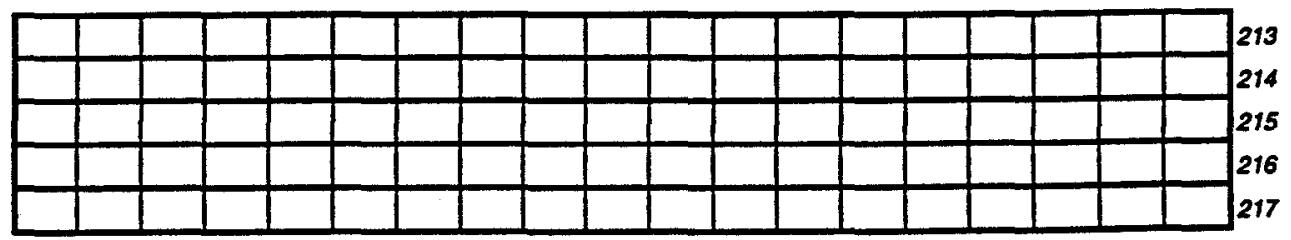

B) Building status before Northridge earthquake:

$O C=$ occupied, $L M=$ limited occupancy, $V=$ vacated, $U C=$ under construction, $O=$ other

9) Current Building Status:

Enter OC for occupied, LM for limited occupancy, or $V$ for vacated:

Is an investigation or testing in progress (IP), completed (C), or not yet started (NS)?

Is the repair or rehabilitation design in progress (IP), completed (C), or not yet started (NS)?

Is the repair or rehabilitation construction in progress (IP), completed (C), or not yet started (NS)?

Additional description of building status:

0) Date of above status report:
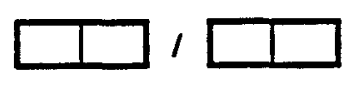

$1 \square \square_{224}$ 


\section{SURVEY OF STEEL MRF BUILDINGS DAMAGED BY THE NORTHRIDGE EARTHQUAKE, JANUARY, 1994}

\section{SECTION III: Earthquake Performance}

1) Did the building sustain non-structural damage in previous earthquakes? $(Y$ or $N$ ) 1971 San Femando Earthquake 1987 Whittier Narrows Earthquake 1992 Big Bear Earthquake

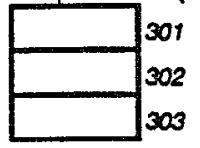

2) Did the building sustain structural damage in previous earthquakes? ( $\mathrm{O}$ or $\mathrm{N}$ )

1971 San Femando Earthquake

1987 Whittier Narrows Earthquake

1992 Big Bear Earthquake

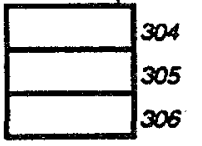

3) Was any previous damage repaired prior to the Northrigde Earthquake? $(\mathrm{Y}, \mathrm{N}$, or $N / A)$

4) Was the building tagged after the Northridge Earthquake? ( $R=\mathrm{red}, Y=y e l l o w, G=g r e e n, N=$ none)

5) Was the building voluntarily evacuated? ( $\mathrm{Y}$ or $\mathrm{N}$ )

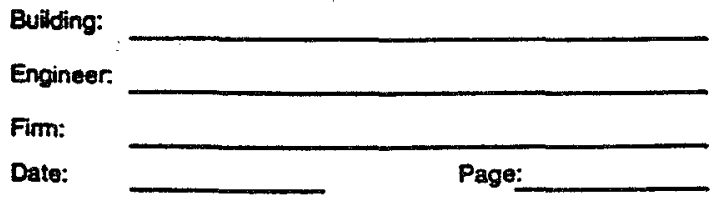

Building ID :

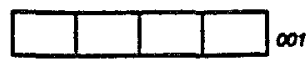

(for interned ues onity

6) Describe any Northridge structural damage observed (other than steel MRF joints discussed below). Consider base plates, anchor bolts, diagonal braces, non-MRF members, shear walls, disphragms, etc.

7 Classify structural damage (including MRF joints) in terms of its distribution as None (N), Isolated (l) or Widespread (W).

8) Classify structural damage (including MRF joints) in terms of its impact on the building's overall life-safety as None (N), Minimal (M), or Substantial (S).

9) Classify overall damage (including MRF joints) in terms of repairability as None (N), Cosmetic (non-structural only) (C), Moderate (repairable without substantial demolition) (M), or Heavy (H).

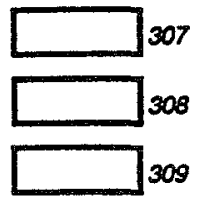

If Yes, please describe:

11) Was there apparent pounding? ( $Y$ or $N)$

12) Was there apparent foundation failure? ( $Y$ or $N$ ) Was there apparent liquefaction? ( $Y$ or $N$ ) Was there apparent differential ground movement? ( $Y$ or $N$ ) Was there apparent settlement? ( $Y$ or $N)$

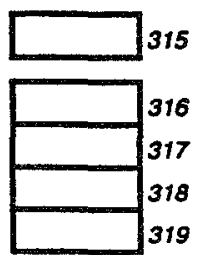

13) List/describe any Northridge life-safety related non-structural damage. Consider blocked exits (including stairs and elevators), falling hazards over exits and sidewalks, hazardous material spils, loss of fire protection systems, etc.:

14) List/describe any other Northridge non-structural damage. Consider exterior cladding, parapets, glazing, partitions, ceilings, lights, equipment failures (including HVAC/Electrical/Plumbing), overturned shelving, etc: 


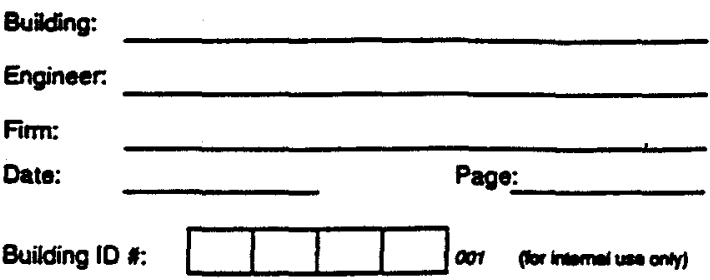

\section{ECTION IV: Building Description and Design}

1) Total \# of stories above ground:

Total \# of stories below ground:

3) Maximum roof height above ground:
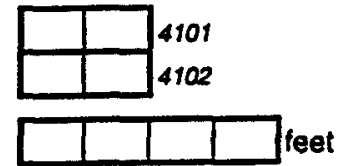

2) \# of Steel MRF stories above ground: \# of Steel MRF stories below ground:

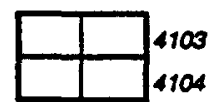

4105

Approximate Ground Floor Dimensions:

4) Total Length:

5) Total Width:

5) Total ground floor enclosed area:

n) Total building floor area (not including roof area): feet

3) Plan shape of building at ground floor: (See glossary of terms, for choices)

Э) Plan shape of building at typical MRF floor. (See glossary of terms, for choices)

\section{7}

4106

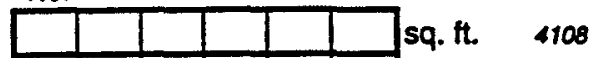
sq. ft. 4109

$\square_{4111}^{4110}$

If other, describe:

If other, describe:

0) Design Code Used: ( $U=U B C, T=$ Title 24, $O=$ Other 4201

1) Year of Design Code:

4203

2) UBC Construction Type (I, II, III, IV, or V):

3) ASD or LRFD for steel MRF?

4) Was a dynamic analysis used for the design of the building? ( $\mathrm{O}$ or $\mathrm{N}$ )

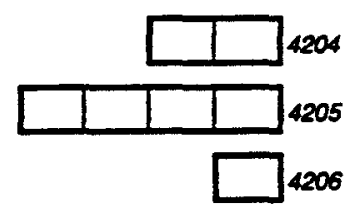

5) Describe additional design criteria (MPE, drift limits, etc.), if any. 4301

6) Code Static Design Importance Factor, I, used:

Soil Factor, S, used:

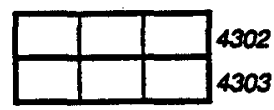

7) Principal Direction 1 (PD1):

Compass direction for Principal Direction 1 (N-S, NE-SW, etc.):

Steel Lateral Load Resisting System (See glossary of terms for choices):

Coefficient K (pre-1988):

Coefficient Rw:

Fundamental Period $T$ used for design, in seconds:

Base Shear Coefficient VW (if available):

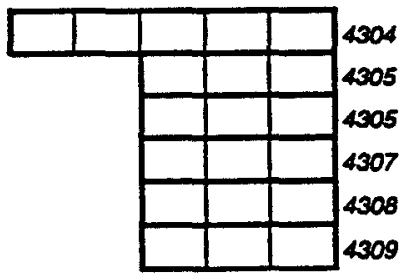

8) Principal Direction 2 (PD2):

Compass direction for Principal Direction 2 (N-S, NE-SW, etc.):

Steol Lateral Load Resisting System (See glossary of terms for choices):

Coefficient K (pre-1988):

Coefficient Rw:

Fundamental Period T used for design, in seconds:

Base Shear Coefficient VN (if available):

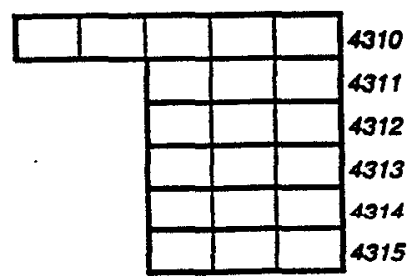




\section{(Section IV Continued)}

19) Potential Structural Irregularities (indicate $Y, N$, or N/A):

Discontinuous Columns/Weak Story

Soft Story

Plan setbacks/out-of-plane offsets

Diaphragm Discontinuity

Torsional Irregularity

Reentrant Comers

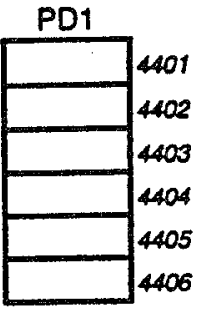

\begin{tabular}{|l|l}
\hline & \\
\hline & 407 \\
408 \\
\hline & 4409 \\
410 \\
411 \\
\hline \\
\hline
\end{tabular} 412

20) Grade of Steel Specified: $(36,50$, or sim)

Frame Columns

Frame Girders

Diagonal Braces

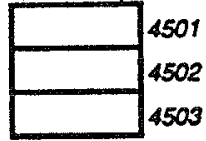

21) Ground level column fixity, P, F or $C$ (See glossary of terms for description):

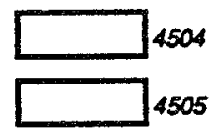

22) Foundation Types (See glossary of terms for choices):

Describe the following non-structural components.

Consider materials, vertical support, lateral support, ability to accommodate interstory drifts, etc.

23) Exterior Cladding/Glazing/Curtain Walls/Parapets:

24) Interior Partitions, including stair and shaft enclosures:

25) Ceilings: 


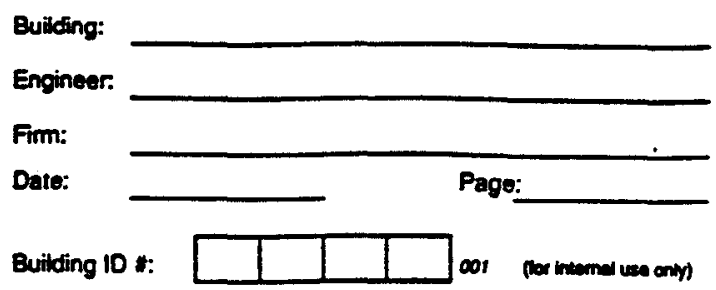

\section{ECTION V: Detailed MRF Data}

iomplete 1 set of Section $V$ data for each floor with inspected connections, i.e. provide sets 1, 2, 3, etc., where the floor number becomes the last digit of the database entry number below)

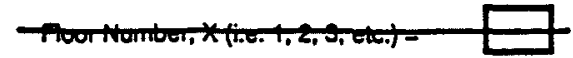

1) Floor Number.

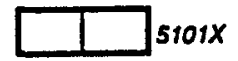

!) Story height above:

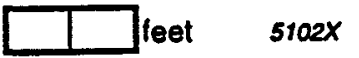

1) Story height below:

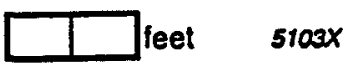

1) Floor Area:

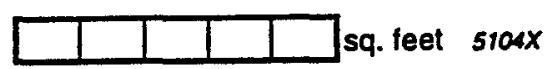

i) Approximate Floor Dimensions:

Length

\begin{tabular}{|l|l|lll}
\hline & & & feet & $5105 x$ \\
\hline & & & feet & $5105 x$
\end{tabular}

Width

$5106 x$

i) Does floor have discontinuities or reentrant comers as noted above? ( $Y$ or $N$ )

) Floor Construction (See glossary of terms for choices):

$5108 x$

If other, describe:

1) Total number of MRFs intersecting this floor in Principal Direction 1:

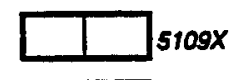

1) Total number of MRF's intersecting this floor in Principal Direction 2: $5110 x$ 
SURVEY OF STEEL MRF BUILDINGS

DAMAGED BY THE NORTHRIDGE EARTHQUAKE.

JANUARY, 1994

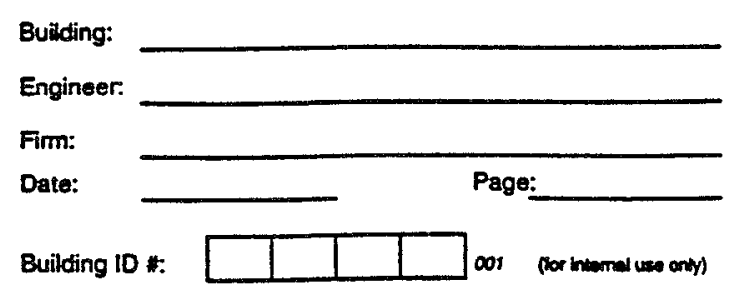

\section{SECTION V: Continued}

Complete the following information for each inspected frame at this floor, i.e. provide data sets a, b, etc. for floors 1, 2, etc.

Foor Number, X (i.e. 1. 2,3, etc.) $=$

10) Principal Direction:

11) Total Frame Length

12) Length of diaphragm openings adjacent to trame:

13) Column Strong or Weak Axis (S or W):

14) Box Columns $(Y$ or $N)$ :

15) Number of Bays:

16) Total number of beam-column connections:

17) Total number of connections visually inspected:

18) Total number of connections tested:

19) Minimum bay width:

20) Typical bay width:

21) Maximum bay width:

22) Typical end column section:

23) Typical interior column section:

24) Typical girder section:

25) Is the girder expected to act composite with the deck? ( $Y$ or N)

Complete the following for a typical inspected connection at this frame and floor:

26) Top flange Complete (C) or Partial (P) penetration weld?

27) Was the top flange backing bar left in place? ( $Y$ or $N$ )

28) Bottom flange Complete $(C)$ or Partial $(P)$ penetration weld?

29) Was the bottom flange backing bar left in place? ( $Y$ or $N$ )

30) Were run-off dams used? ( $Y$ or $N$ )

31) What weld process was used? (See glossary of terms for choices)

32) Was the connection of the girder web to the shear tab welded only $(W)$, bolted only (B), or welded \& bolted (WB)?

S9) What type of damage do the WfF commections at one or bothend cotums have?

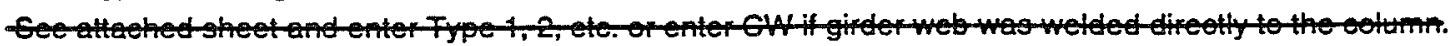

$5401 \times x$

$5402 \times x$

$5403 \times x$

$5404 x x$

$5405 x x$

$5406 \times x$ If other, describe: 


\section{SURVEY OF STEEL MRF BUILDINGS DAMAGED BY THE NORTHRIDGE EARTHQUAKE, JANUARY, 1994}

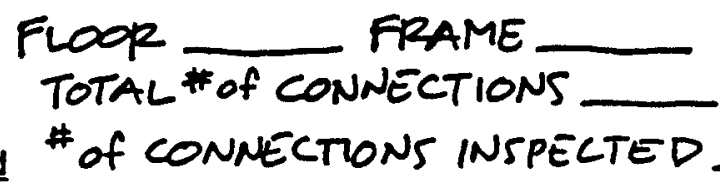

\section{¿ECTION V: Continued}

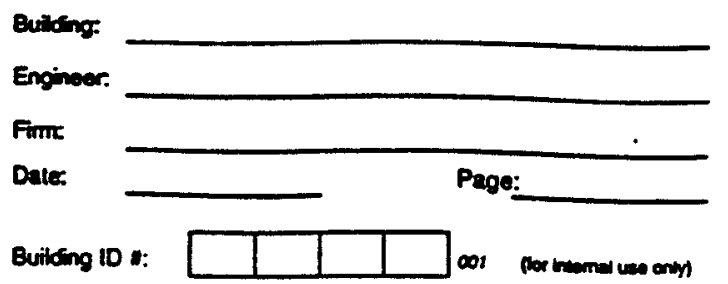

Jamage Description: For this floor and frame, indicate the total \# of connections showing each damage type. Indicate II for conditions not inspected. Indicate NA where appropriate.

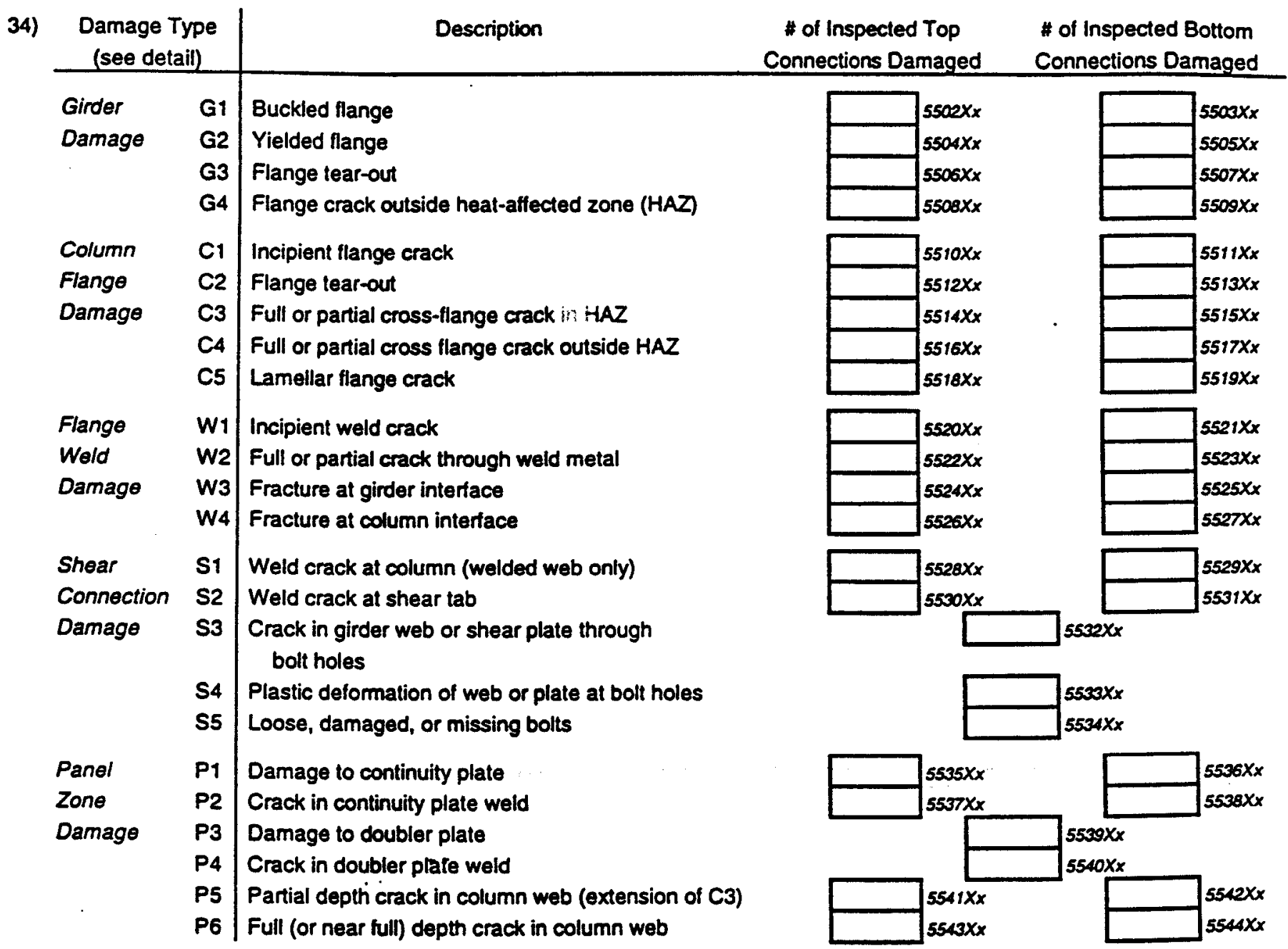

ovide additional descriptions of MAF joint damage as appropriate: 
SURVEY OF STEEL MRF BUILDINGS DAMAGED BY THE NORTHRIDGE EARTHQUAKE. JANUARY, 1994

\section{SECTION V: Continued}
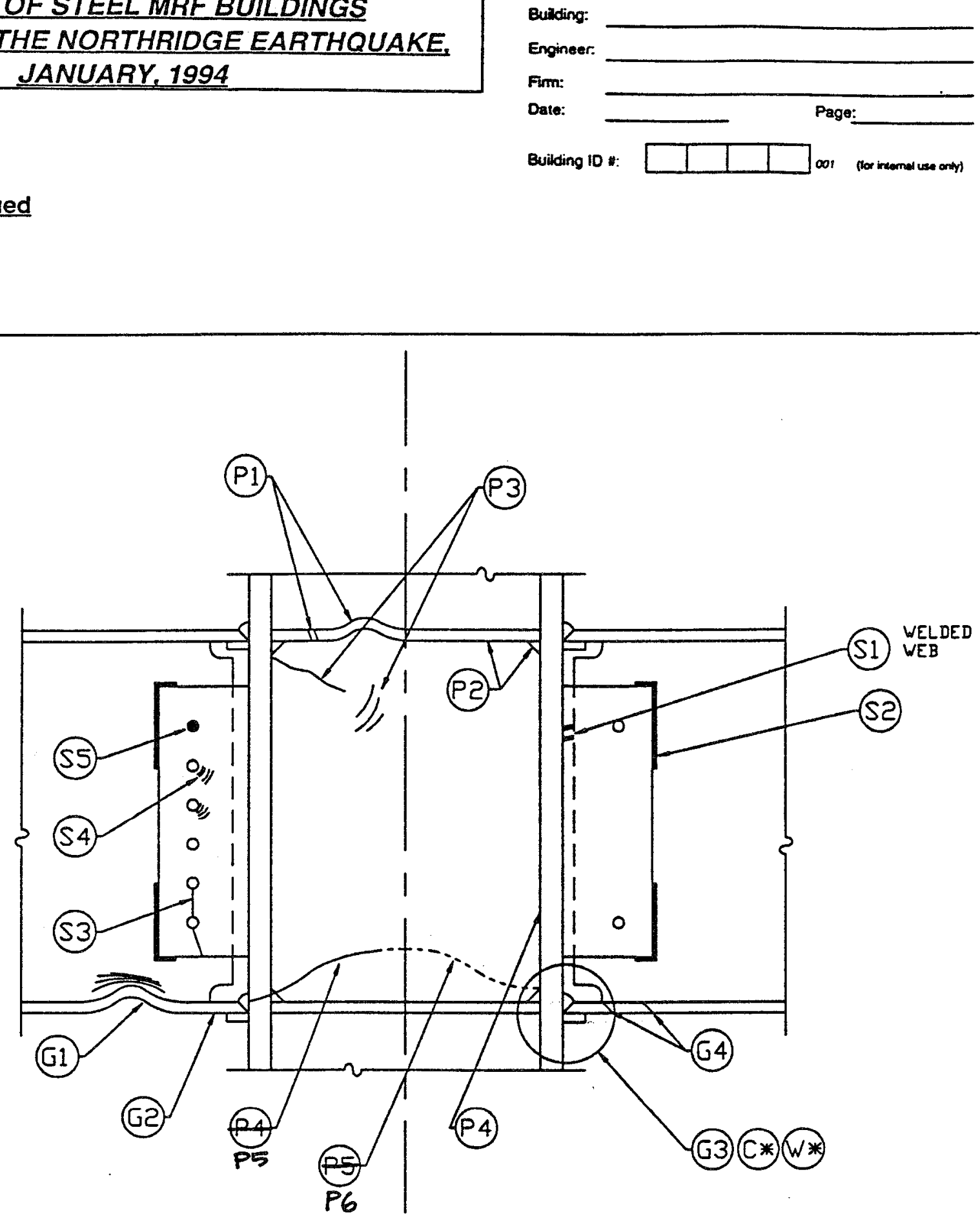

REFERENCE DETAIL: MRF JUINT DAMAGE TYPES

NOTE: SEE SURVEY FORM SECTION $\vee$ FOR DESCRIPTION 
SURVEY OF STEEL MRF BUILDINGS DAMAGED BY THE NORTHRIDGE EARTHQUAKE, JANUARY, 1994

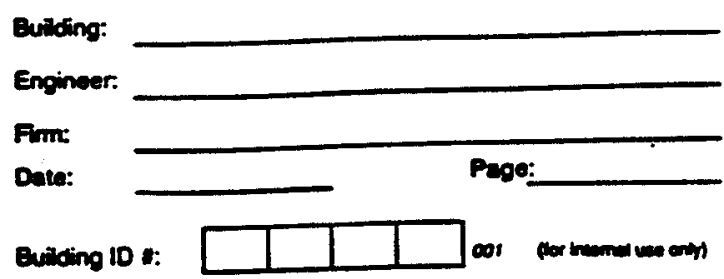

\section{ECTION V: Continued}

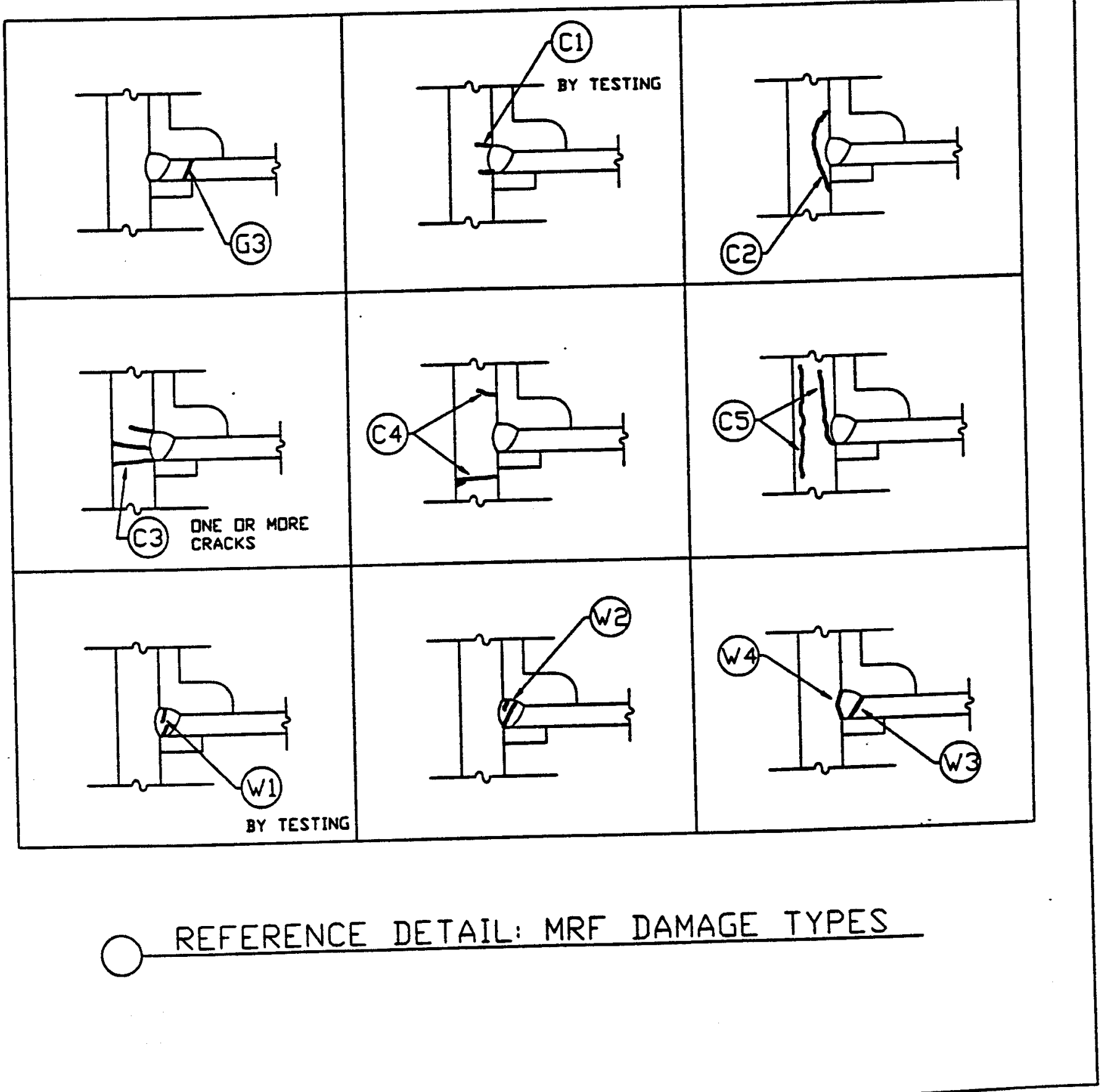




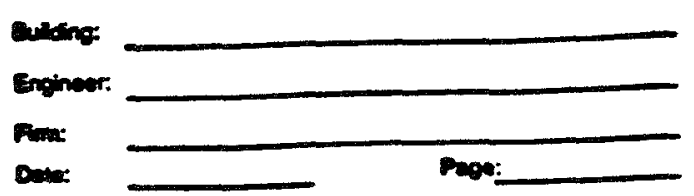

Ding to: $\int$ SECTION VI: Details of Specific Damaged Joints (ONE OR TWO PETAILS PER BUILDING ONLT.)

\section{INSTRUCTIONS TO REPORTING ENGINEER :}

1. COMPLETE DETAIL FOR SPECIFIC (NOT GENERIC) JOINT BY FRLDHG IN ALL RANKS

2. SKETCH DAMAGE OBSERVED AT SPECIFIC (NDT GENERIC) OINT ON DETAIL AND ADD FLAES. E.G. CI TO INDICATE DAMACE TYPE CL TO REFERENCE SEPARATE DAMACE TYPE SCHEDULE

3. COMPLETE INFDRMATION BELOW.

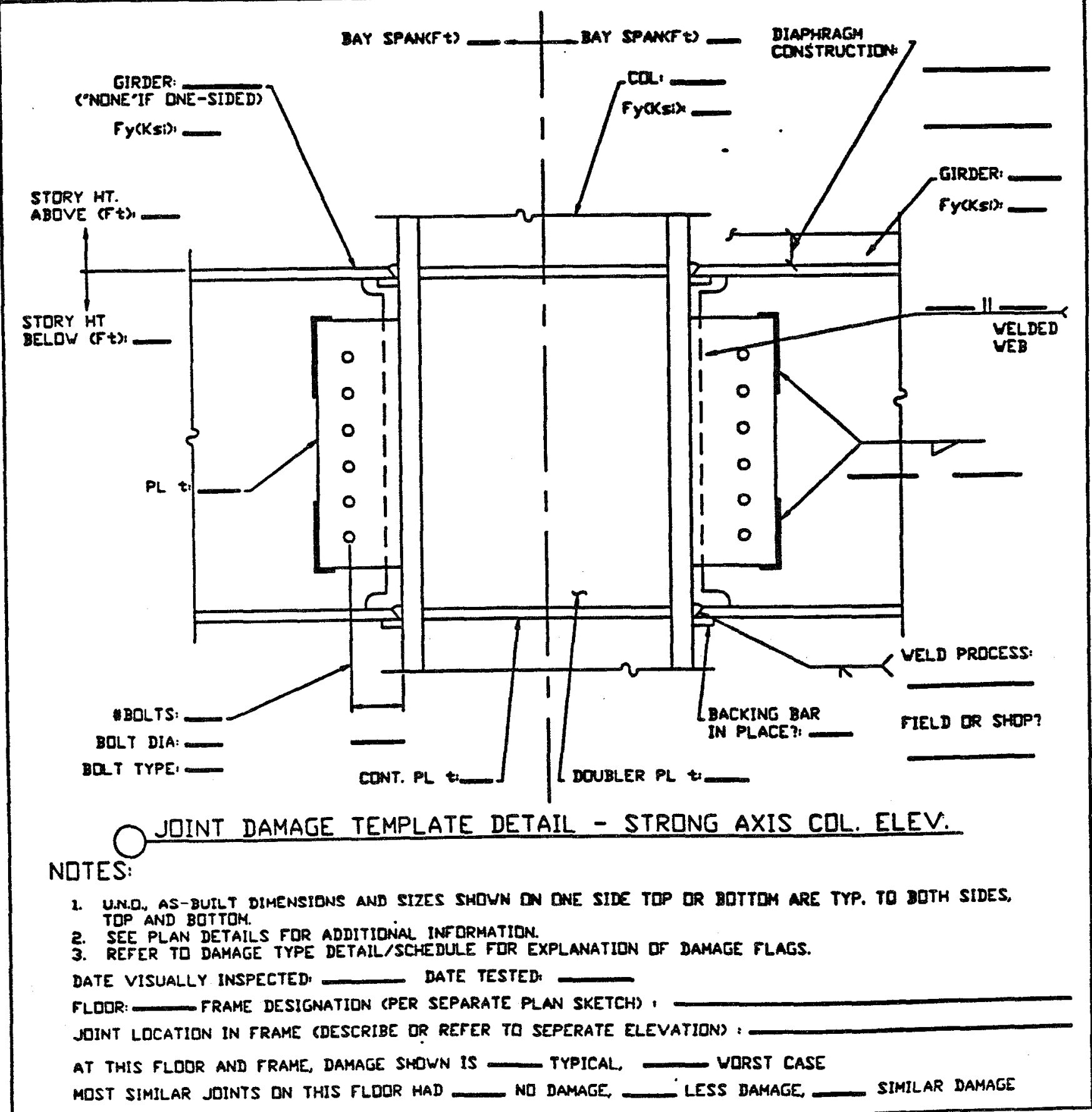




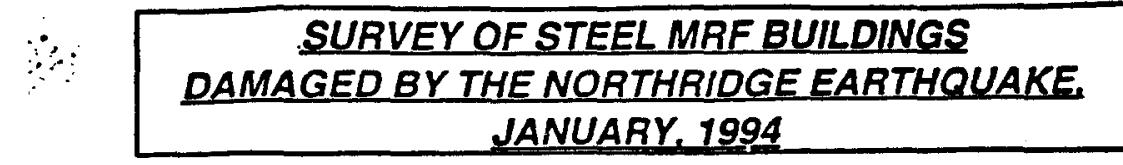

JANUARY, 1994

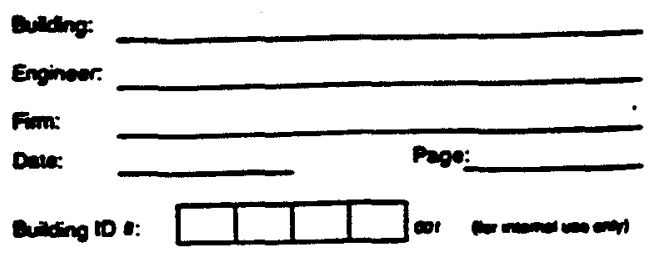

\section{SECTION VI: Details of Specific Damaged Joints}

\section{INSTRUCTIONS TD REPORTING ENGINEER :}

1. COMPLETE DETAIL FOR SPECIFIC (NOT GENERIC) JOINT BY FMLING IN ALL OLANKS.

2. SKETCH DAMAEE DBSERVED AT SPECIFIC (NDT GENERIC) JOINT ON DETAIL AND ADD FLAGS, E.G. CI TO INDICATE DAMAEE TYPE CL TO REFERENCE SEPARATE DAMAGE TYPE SCHEDULE.

3. COMPLETE INFDRMATION BELDW.

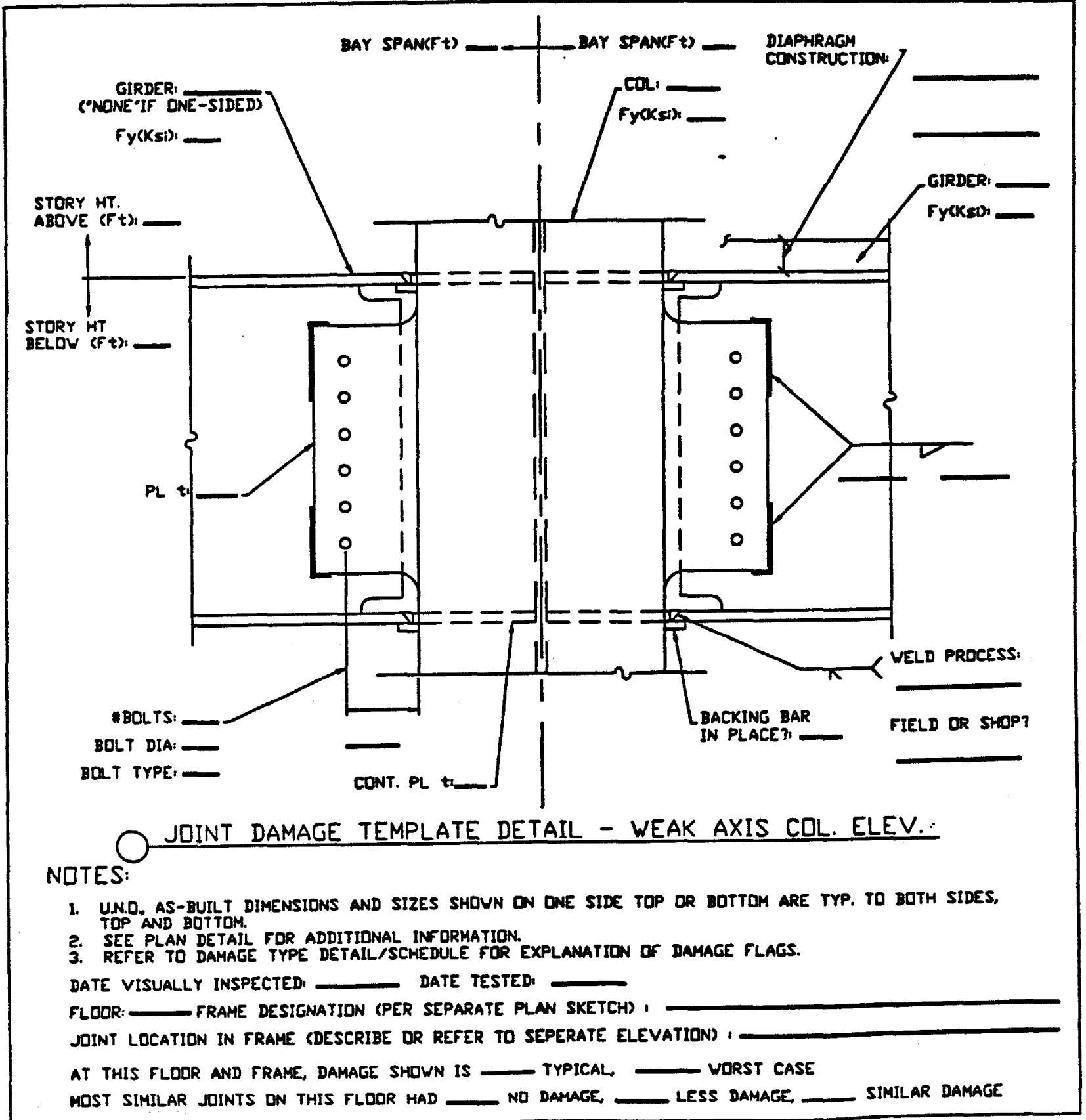



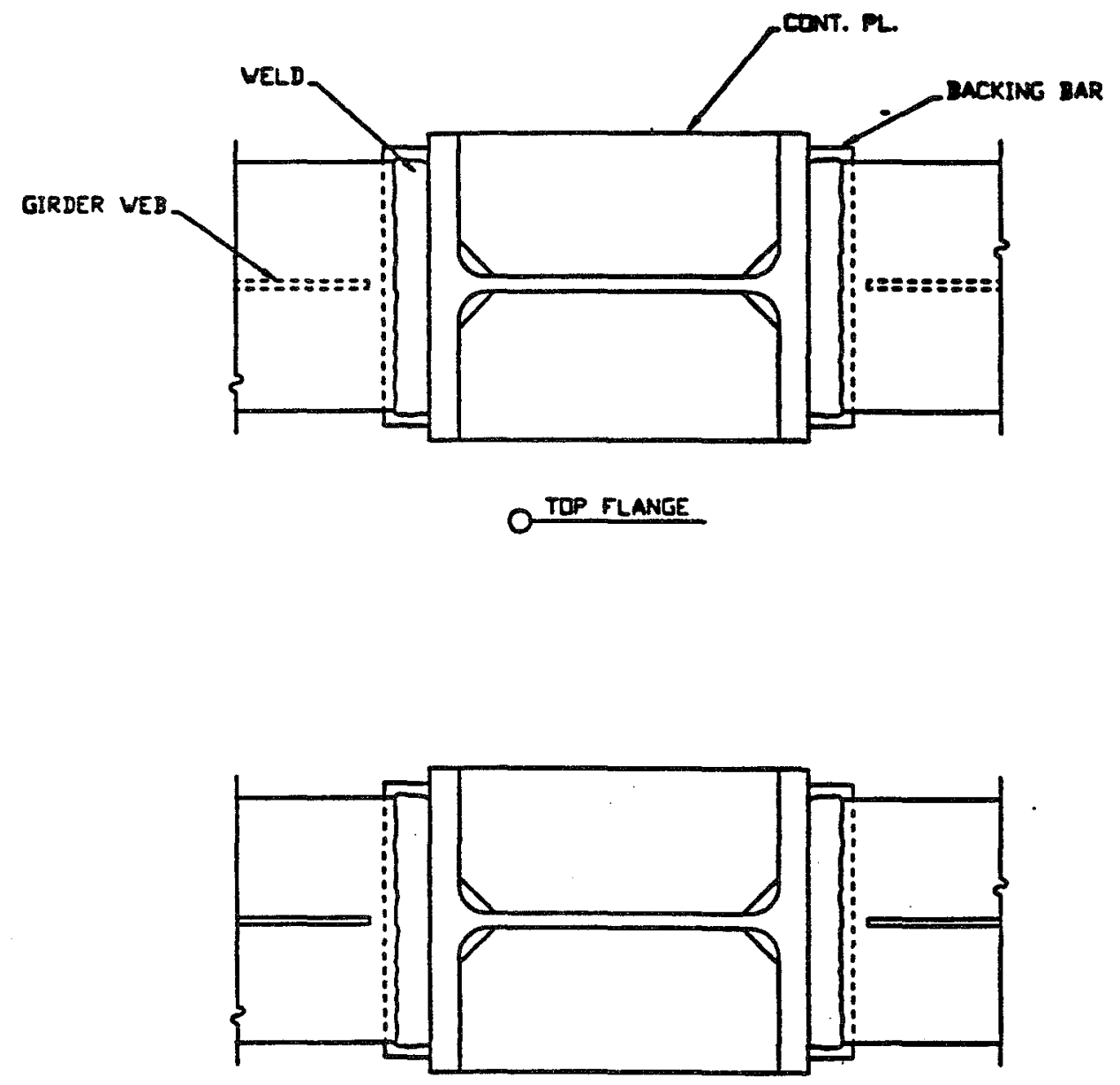

ODTTOM FLANGE

\section{SECTION VI: Details of Specific Damaged Joints}

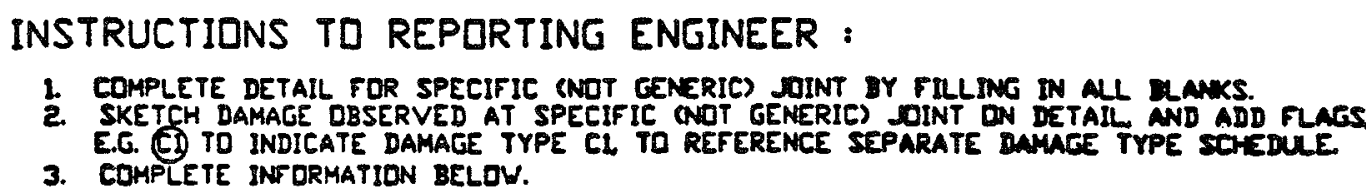

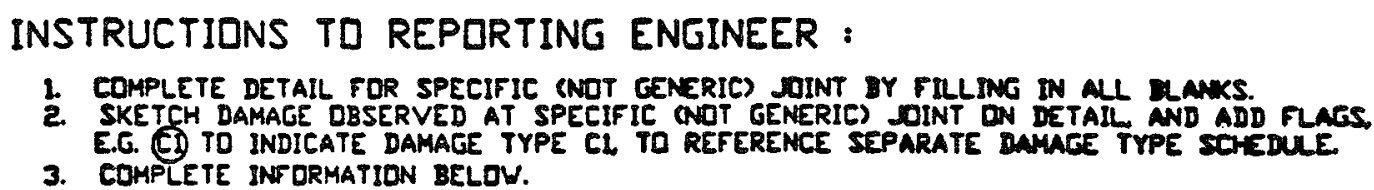

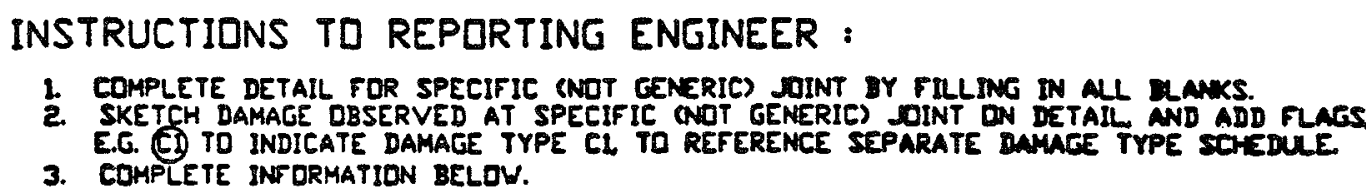

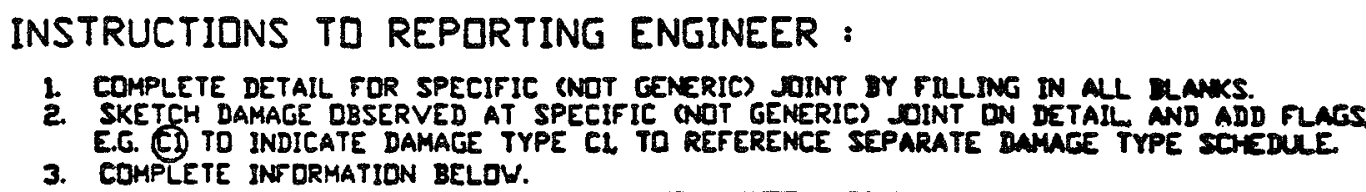

OTH PLANGE

\section{NDTES:}

\section{O JOINT DAMAGE TEMPLATE DETAIL - STRDNG AXIS PLAN}

1. SEE COLUMN ELEVATION FDR MEMBER SIZES, DIMENSIONS, AND ADDITIONAL INFORMATION.

2. REFER TD DAMAGE TYPE DETAIL/SCHEDLLE FOR EXPLANATION DF DAMAGE FLAGS.

FLOCR: - FRAME DESIGNATION (PER SEPARATE PLAN SKETCH): 
SURVEY OF STEEL MRF BUILDINGS

DAMAGEDBYT ENORTHRIDGE EARTHQUAKE JANUARY, 1994

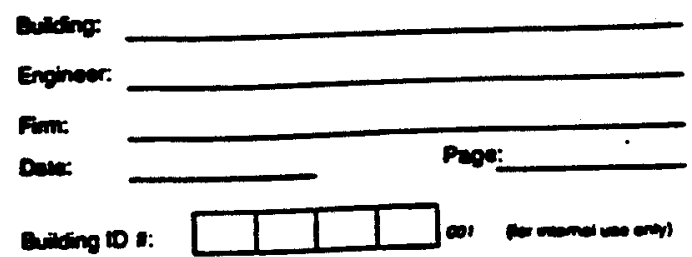

SECTION VI: Details of S5:- ific Damaged Joints

INSTRUCTIONS TO REPORTING ENGINEER :

1. COMPLETE DETAIL FOR SPECIFIC (NDT TENERIC) JOINT BY FILLING IN ALL BLANKS.

2 SKETCH DAMACE OBSERVED AT SPECIFIC ONDT GENERIC) JOINT ON DETAIL AND ADD FLAGS.

EE

3. COMPLETE INFDRMATION BELDW.
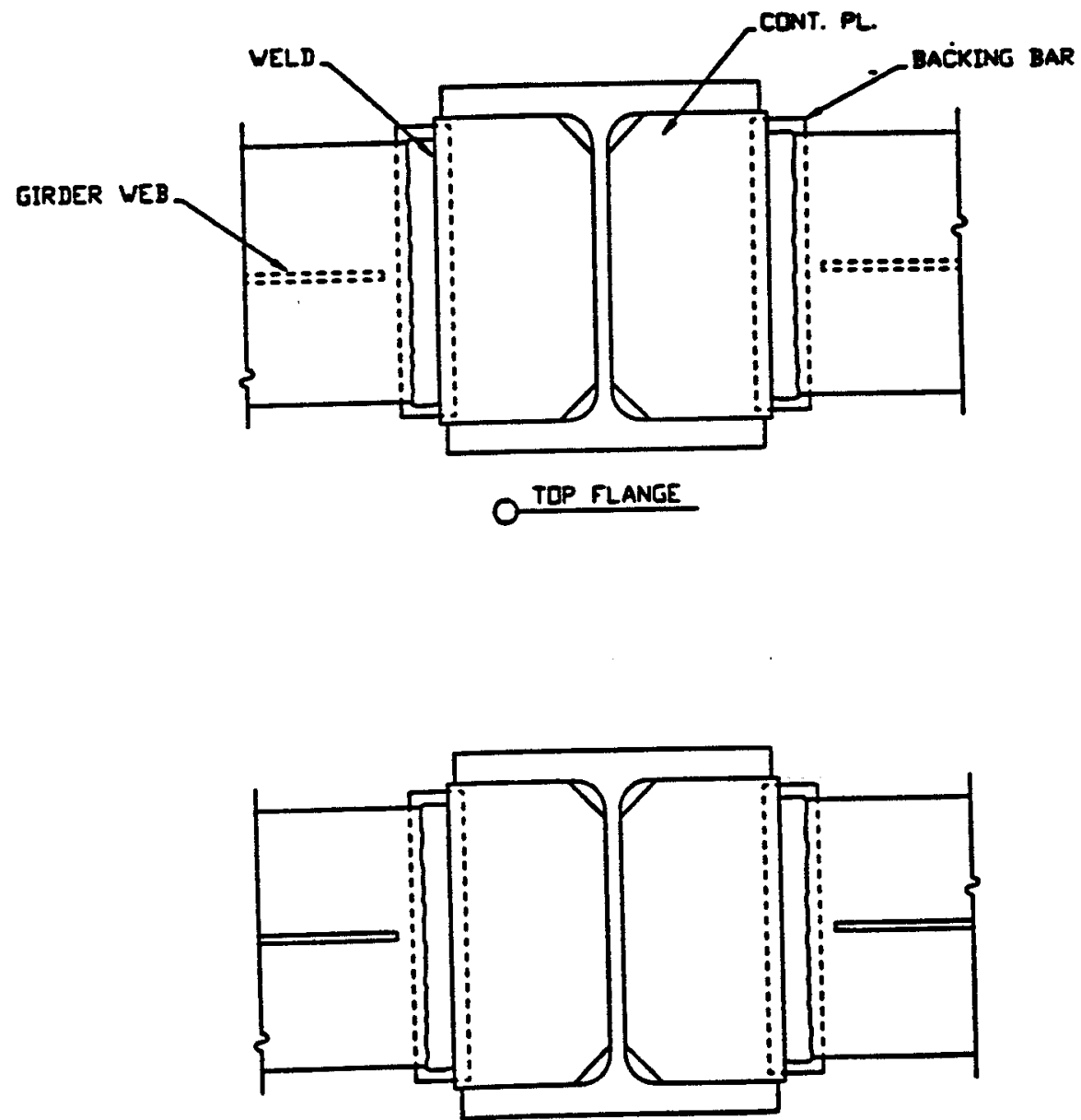

BOTTOM FLANGE

JUINT DAMAGE TEMPLATE DETAIL - WEAK AXIS PLAN

NDTES:

1. SEE COLUMN ELEVATIDN FDR MEMBER SIZES, DIMENSIONS, AND ADDITIDNAL INFDRMATIUN.

2. REFER TO DAMAGE TYPE DETAIL/SCHEDULE FQR EXPLANATIDN OF DAMAGE FLAGS.

FLDOR:

FRAME DESIGNATION (PER SEPARATE PLAN SKETCH) : 


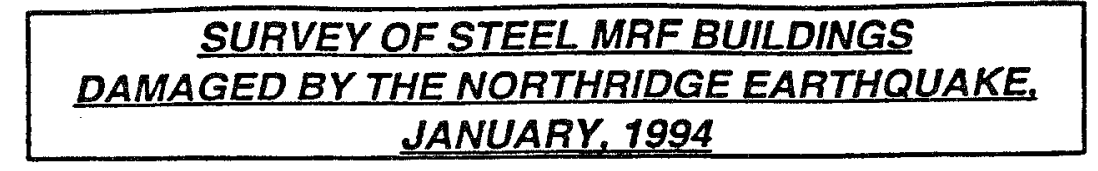
JANUARY, 1994

\section{SECTION VIl: Plan Sketch of Building}

Provide a sketch of the building plan showing the compass orientation, street orientation, overall bullding dimensions, frame locations and spacings, and frame designations.

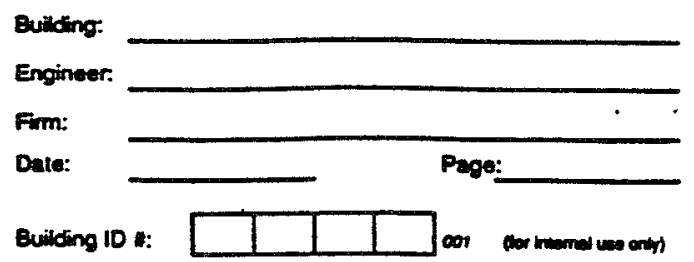




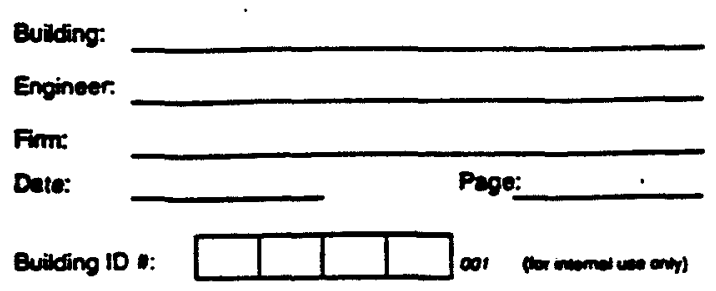

\section{ECTION VIll: Frame Elevations of Building}

rovide one sketch per frame of the frame elevation showing the frame designation, floor numbering, approximate story height and bay width dimensions, and damage locations with reference to damage type listed on the attached sheet. 
Appendix C: Inspection \& Testing Criteria and Report Formats

C-1 
Fax (253) 746.7228 OLIRASONIC TEST PROCEDURE FOR SEISMIC EVALUATION

1. SCOPE

A. THIS PROCEDURE COVERS THE METHODS AND ACCEPTANCE AND REJECTION CRITERIA FOR PULSE-RERLECTION ULTRASONIC EXAMINATION OF POSSIBLE CRACKS IN COLUMN FLANGES. WEID METAL OR BASE METAL OF WIDE FLANGE BEAM MOMENT CONNECTIONS.

B. TIIS PROCEDURE COVERS SHEAR WAVE (ANGLE BEAM) TESTING METHODS AND LONGITUDINAL (STRAJGHT-BEAM) IESTING METHODS USING CONTACT TECHNIQUES WITH HAND OPERATED PROBES.

C. PROCEDURE REQUIREMENTS TO THIS EXAMINATION SHLLLL CONFORM TO THE FOLLOWING SPECIFICATIONS.

\section{C.1 ASTM E-114-90 PRACTICE FOR ULTRASONIC PULSE-ECHO STRAIGHT-BEAM TESTING BY THE CONTACT METHOD. \\ C.2 ASTM E-164-88 STANDARD PRACTICE FOR ULTRASONIC CONTACT EXAMINATION OF WEIDMENTS.}

C.3 AWS D1.1-94 STRUCTURAL WELDING CODE SECTION \#6 AND \#8.

C.4 ASNT RECOMMENDED PRACTICE SNT-TC-1A

2. EQUIPMENT

A INSTRUMENTS

\section{A1 KRAUTKRAMER ULTRASONIC DETECTOR (TYPE USK-6 AND USK-7)}

B. TRANSDUCERS

B.1 TRANSDUCERS FOR STRAIGHT BEAM EXAMINATION SHALL HAVE AN ACTIVE AREA OF NOT LESS THAN $1 / 2$ INCH NOR MORE THAN 1 NCH. TRANSDUCERS SHALL BE CAPABLE OF RESOLVING THE THREE REILECTIONS AS DESCRIBED IN AWS DI.I SECTION \#6 PAR: 6.21.1 WITH NOMINAL FREQUENCIES OF 2.25 MAZZ.

B.1.A IN ADDITION A TWIN CRYSTAL 5 MHZ, WITH AN OVERAIL DLAMETER OF 1/2 DNCH $(10 \mathrm{~mm}-12 \mathrm{~mm})$ MAY BE UTILIZED AS AN AID FOR DISCONTINUITY SIZING AND RECOGNITION.

B.2 TRANSDUCER CRYSTAIS FOR ANGLE BEAM EXAMINATION SHALL BE SQUARE OR RECTANGULAR IN SHAPE AND MAY VARY FROM 5/8 INCH TO $13 / 16$ INCH IN HEIGHT AND S/8 INCH TO I NCH IN WIDTH THE MAXIMUM RATIO OF WDTH TO HEIGHT SHAII BE 1.2 TO 1.0 AND THE MINIMUM 1.0 TO 1.0 WIIH NOMINAL FREQUENCIES OF $2.25 \mathrm{MHZ}$. A $45^{\circ}, 60^{\circ}$ AND $70^{\circ}$ WEDGE SHALL BE USED FOR ALL WEID EXAMINATION.

\section{B.2.A WHERE ACCESSIBIITY IS LIMITED A 1/2" DIAMETER, 2.25 MHZ TRANSDUCERS} MAY BE EMPLOYED UTIIIZING ANGLES OF $45^{\circ} 60^{\circ}$ AND $70^{\circ}$.

Copyrigat o 1994. Smith-Emery Company

Al righes reserved inctuding righes of reprotuction and wee in any form or by any means. inctuding the muking of copies by any phoco proceser or by any elearonic or mechanial devioes printed or writen or oral, or recording for sound or visual reproducion or for use in any knowledge or revival syszen or Anaheim

device, unless permission in writing is obcined from the copyright propriesors.

San Francisco 


\section{SMIth-EMERy Compayy}

B.3 BOTH TYPES OF TRANSDUCERS SHALL MEET THE MINIMUM REQUIREMENTS AS SPECIFIED IN AWS D1.1.

C. BASIC CALIBRATION REFLECTORS (BLOCK).

C.1 IIW-BLOCK

C.2 BASIC CALIBRATION BLOCKS AS SPECIFIED IN AWS DI.1

D. COUPLANT

D.1 COUPLANTS USED TO ASSURE TRANSMISSION OF SIGNAL BETWEEN TRANSDUCERS AND THE TEST SURFACE WII BE CEI LULOSE GUM, GL YCERDNE OR OTHER APPROVED MATERIALS.

3. PERSONNEL

A SHALL BE THOSE QUALIFIED TO THE REQUTREMENTS OF ASNT SNT-TC-1A AS REQUIRED BY THE QUALITY CONTROL SECTION OF THE SMITH-EMERY COMPANY QUALITY ASSURANCE PROGRAM AND THE REFERENCING SECTION OF THE AWS CODE. PERSONNEL WHO CONFORM ARE PERMITTED TO PERFORM THIS EXAMINATION AND INTERPRET THE RESULTS.

4. JOINT CONFIGURATION

A THE WEID JOINT ASSEMBLAGE WILL CONFORM TO SKETCH NO. 1.

5. SURFACE

A ALI SURFACES MUST BE THOROUGHI Y CLEANED OF FIREPROOFING, RUST, HEAVY MILL SCALE AND OTHER FOREIGN MATIER THAT WOULD PREVENT POSITIVE COUPLING OF THE TRANSDUCER TO THE SCANNING SURFACE. SEE EXTIBIT \#4

6. PRETEST VISUAL INSPECTION

A A DETAIIED INSPECTION SHALL BE MADE PRIOR TO ANY COUPLING MEDIUM BEING APPLIED. OBSER VATIONS WHICH MAY BE INDICATTVE AS INTERNAI FAIIURE SUCH AS BACKING DISTORTION, CRACKED TACK WEIDS, BACKING BAR SEPARATION, OR MIIL SCALE DETACHMENT AND COLUMN BLISTERING WILL BE NOTED ON THE REPORT.

7. CALIBRATION

A CALIBRATION

A.1 CALIBRATION FOR SHEAR WAVE (TRANSVERSE) SHALL BE DONE IN ACCORDANCE WITH AWS DI.1 SECTION NO. 6 PAR: 6.21.2.

B. STRAIGHT BEAM

B.1 CALIBRATION FOR LONGTUDRAL MODE SHALL BE DONE IN ACCORDANCE WTTH AWS D1.1 SECTION NO 6 PAR: 6.21.1.

Copyright e 1994. Smich-Emery Company

All rigats reserved including rights of reprochuction and use in any form or by any means including the making of oopies by any phos process. or by any electronic or mechanical devices primted or wricen or oral, or recording for sound or visual reproduction or for use in any knowledge or retrival system or device. un less perrussion in writing is obrained form the copyright proprietors. 


\section{SMITE·EMERY COMPANY}

8. RE-CALIBRATION

A THE PROPER FUNCTIONING OF THE EXAMINATION EQUIPMENT SHALL BE CHECKED AND THE EQUTPMENT CALIBRATED TO THIE REFERENCE BLOCKS AS FOLLOWS:

Al WHEN THERE IS A CHANGE OF OPERATORS.

A.2 AT 30 MINUTE MAXIMUM TIME RNTERVAL.

A3 AT ANY TIME THE OPERATOR THINKS THERE MAY BE A MALFUNCTION.

A + WHEN THE EIECIRICAL CIRCUITY IS DISTURBED IN ANYWAY, CHANGE OF IRANSDUCER, BATIERIES, COAXIAL CABLES ETC.

A.5 IF DURDNG A CHECK $T$ IS DETERMINED THAT THE EQUTPMENT IS NOT FUNCTIONDNG PROPERLY, ALL WEIDS IESTED SINCE THE LAST VALD CALIBRATION CHECKS SHALL BE RE-EXAMINED.

9. EXAMINATION COVERAGE

A ALL WELDS AND BASE MATERIALS ASSOCIATED WITH THE MOMENT FRAME ASSEMBLAGE AS SHOWN DN SKETCH \#1 SHALI HAVE 100\% COVERAGE.

10. SCANNING

A. STRAIGHT BEAM

Al SCANNING SHALL BE CONDUCTED SO AS TO REVEAL ALL LAMEILAR DEFECTS CONTAINED DN ALL BASE MATERIALS AND AIL INDICATIONS INCLUDED IN THE WELD METAL.

A.2 COLUMN FLANGES WIII BE SCANNED 8 INCHES BEIOW TOP BEAM FLANGE AND 8 INCHES ABOVE AND BEIOW BOTTOM BEAM FLANGE. COLUMN FLANGES WLLL BE SCANNED FROM BOTH SIDES OF COLUMN IF POSSBBLE AS SHOWN IN SKETCH \#1 SCAN "D".

A3 SCANNING do LEVEIS SHALL BE AS FOLLOWS:

2. CONDUCT THE EXAMINATION WITH A TEST FREQUENCY AND INSTRUMENT ADIUSTMENT THAT WIIL PRODUCE A MINIMUM 30 TO A MAXIMUM $75 \%$ OF FULL SCALE REFERENCE BACK REFLECTION FROM THE OPPOSITE SDE OF A SOUND AREA OF THE COLUMN FLANGE. AN ADDITIONAL 15 dbs WILL BE ADDED TO THIS REFERENCE LEVEI FOR SCANNING PURPOSES. INDICATIONS DETECIED AT THE BEAM FLANGE WEID TO COLUMN FLANGE NTERFACE AND PROPAGATING INTO COLUMN FLANGE WILI BE FURTHER EVALUATED UTIIIZMNG $70^{\circ},+5^{\circ}$ OR $60^{\circ}$ ANGLE BEAM TRANSDUCERS AS SHOWN IN SKETCH "I SCAN "C".

B. SHEAR WAVE

B.1 THE SCANNING PROCEDURE FOR ANGLE BEAM TESTING OF THE TOP AND BOTTOM BEAM FLANGE WEIDS SHALL BE AS FOLLOWS: 
a. TOP BEAM FIANGE WELD WILL BE SCANNED FROM FACE "B" AND BOTTOM BEAM FLANGES WIIL BE SCANNED FROM BOTH FACE "A" AND " $B$ " UTILIZING A $45^{\circ}, 70^{\circ}$ OR $60^{\circ}$ TRANSDUCER DEPENDNNG ON MATERLAL THLCKNESS. SEE SKETCH \#1 SCAN "A" AND "B".

b. SCANNING LEVEIS FOR SHEAR WAVE WILL BE IN ACCORDANCE WTTH AWS SECTION 6 AND 8 EXCEPT AN ADDIMIONAL 6 dOS WILL BE ADDED FOR SCANNING PURPOSES. THE INTENT IS TO BE SURE THE DETECTION OF THE BACKSDE OF THE COLUMN WHILE WATCHING FOR ANY CRACK LIKE SIGNALS IN EITHER THE WEIDMENT OR PARENT MATERIAL.

\section{ACCEPTANCE AND REJECTION CRITERLA}

\section{A. LONGITUDINAL WAVE SCAN}

B.1 $45^{\circ}, 70^{\circ}$ OR $60^{\circ}$ ANGLE BEAM TRANSDUCERS WIL BE EMPLOYED TO EVALUATE INDICATIONS AT BEAM FLANGE WELD COLUMN INTERFACE AND INTO COLUMN FLANGE BASE MATERIAL. SEE SKETCH \#1 SCAN "A" AND "B". DISCONTINUITIES DETECTED WIL BE CLASSIFIED IN ACCORDANCE WITH ACCEPTANCEREJECTION CRITERIA SEE ATTACHED EXHIIIT MARKED 2.

\section{REPORTING}

A ALL WEIDS SHALL BE REPORTED ON SMITH EMERY COMPANY INSPECTION REPORT FOR SEISMIC EVALUATION AND AS MODIFIED. SEE ATTACHMENT EXXIIBT \#3. COPIES ARE TO BE DISTRIBUTED TO THE STRUCTURAL ENGINEER AND OWNER ONLY. NO REPORTS WIIL BE DISTRIBUTED TO OTHER INDIVIDUALS OR AGENCIES WITHOUT THE EXPRESSED APPROVAL OF THE OWNER OR HIS AGENT.

13. REPAIR OF WELDS

A ALL WELDS WILL BE REPAIRED IN ACCORDANCE WTTH THE STRUCTURAL ENGLNEERS APPROVAL AND AWS D1.1-94.

14. REINSPECTION
A ANY REINSPECTION OF REPAIRS TO WELDS SHALL BE SUBJECT TO THE SAME REQUTREMENTS OF TIIS ULTRASONIC PROCEDURE UNLESS SPECIFICALLY STIPULATED BY THE STRUCTURAL ENGINEER

\footnotetext{
Copyrigat o 1994. Smith-Emery Company

All rights reserved including rigtis of reprocuction and use in any form or by any means. including the making of ocpies by any photo process, or by any elecronic or mechinical devices, prined or writien or oral. or recording for sound or visual reproducion or for use in any knowledge or retrival system or device, unless perrission in writing is obtained from the copyright proprietors.
} 


\section{Smite-EMERy Company}

15. PREPARED BY:

A NIGEI FALIS-HAND - SMIIH-EMERY COMPANY - ASNT LEVEI II

B. STEVE GROVE - SMITIERMERY COMPANY - ASNT LEVEL I

16. REVIEWED BY:

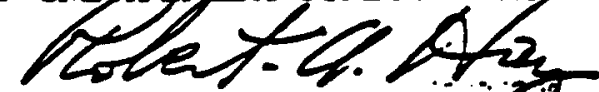

SMITH-EMERY COMPANY

ROBERT OOFESSTO LEVEL/KM-1230

17. APPROVED BY:
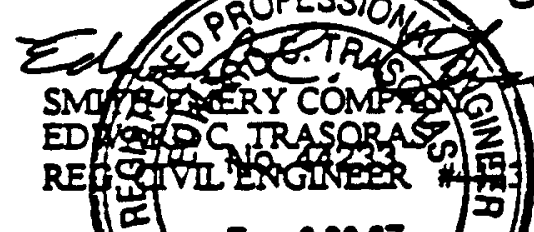

Exp. 6-30-97

Copyritat O 1994, Smith-Emery Cocopeny

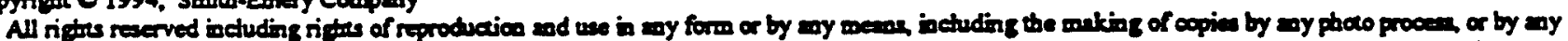

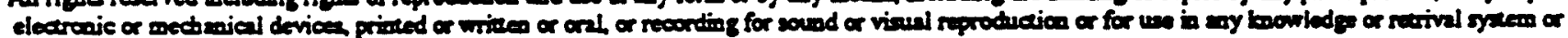

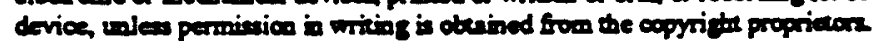




\section{EXIIBIT I}

SCANNING PROCEDURE FOR

\section{ULTRASONIC IESTING}

1/2" TRANSDUCERS MAY BE REQUIRED DUE TO BOLT CLEARANCE

( GO TO BACXSDE OF COLUMN FLANGE IF

USE $70^{\circ}, 60^{\circ}$ OR $45^{\circ}$

WHERE APPLICABLE

RECOMOMEND USING AT LEAST \& FROM TOP AND BOTIOM OF WEID ON MATIRIAL 3/4" AND THICTER.

POSSIBLE, DEPENDLNG ON OBSTRUCTHONS)

FROM BOTTOM FLANGE OR REI Y ON SCAN"B" USNG 1" IRANSDUCER

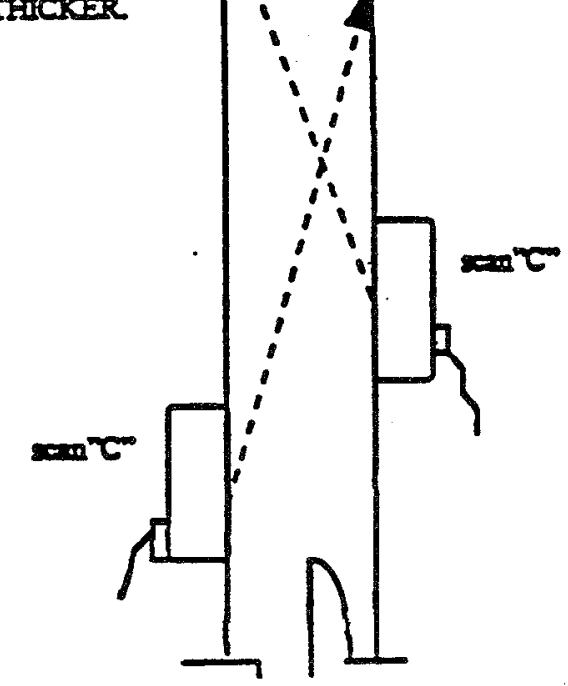

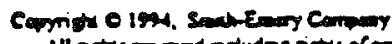

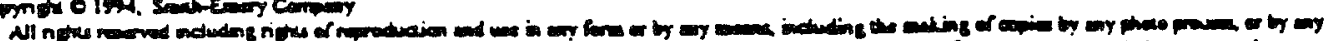

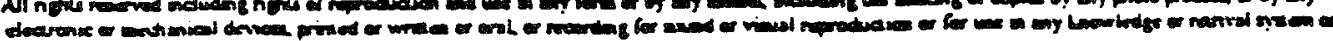

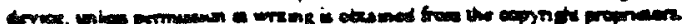




\section{SMITH-EMERY COMPANY \\ SEISMIC EVALUATION}

\section{EXIIBIT 2}

\section{ULTRASONIC CLASSIFICATION Accepranco-Rejection Criteria}

CLASS I

Severe couct in Ange or crack propagating into the colwom Exhibiting Plaser Finw Chrreteristiese or reject bevels amocined with defeets believed to be meses induced

CLASS 2

Reject bevel indications posisibly from the oripinal constriecion Mry be a prior "Acceptable Lever" discoatinuiny which hes been developed by stess. Location is a good indientor, ie. bevel or mid-weld discostinnity is probably original Rool or exp are discontinutites my be opened up 20 a seject kevel by boilding motion.

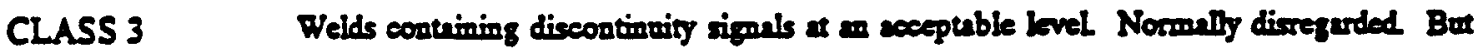
the to sigal type pattern mry be sonall root tears which would be beneficial to invescigate and remove.

-CAUTION: FLAW CHARACTERISTICS ARE SUCH THAT AN AWS TABLE 83 REJECT CLASSIFICATIONS AMPLTUDE MAY NOT BE ACFIIEVED. EVALUATION OF SIGNAI TYPE IS OF UTMOST IMPORTANCE. See Notes 5 or Table 8.2.
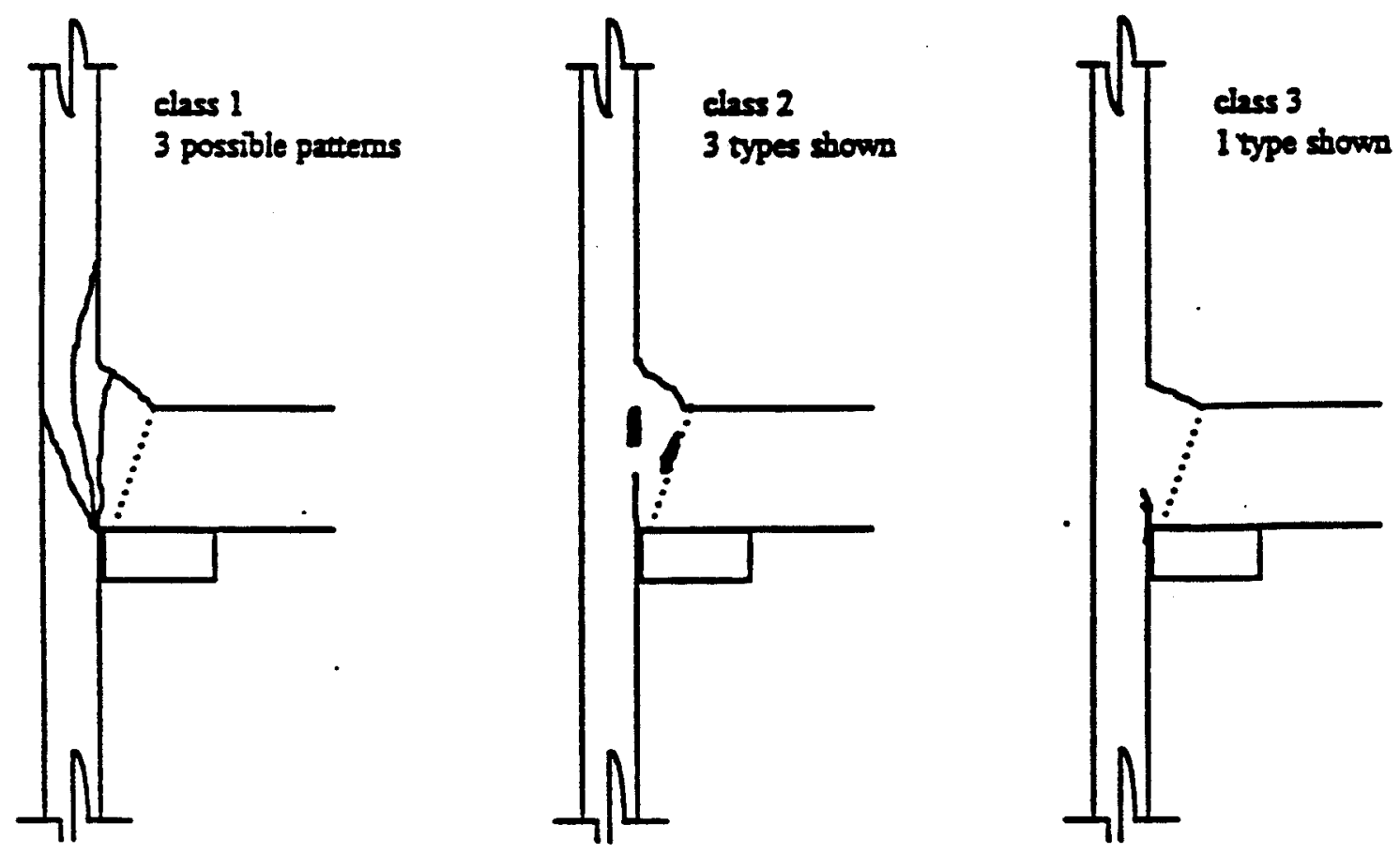

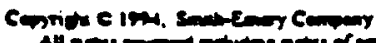

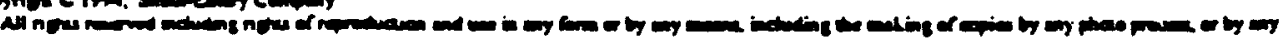

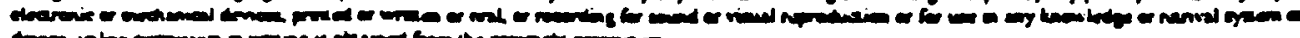

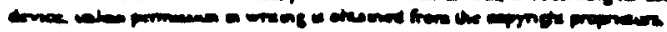




\section{SMITH-EMERY COMPANY}

\section{SEISMIC EVALUATION RECORD}

EXIIBT 3

\section{PROJECT NAME}

PROJECT ADDRESS

CITY

JOB NUMBER

WO NUMBER

DATE
FLOOR LEVEL

GRID LOCATION

BEAM LOCATION

UPPER FLANGE

LOWER FLANGE

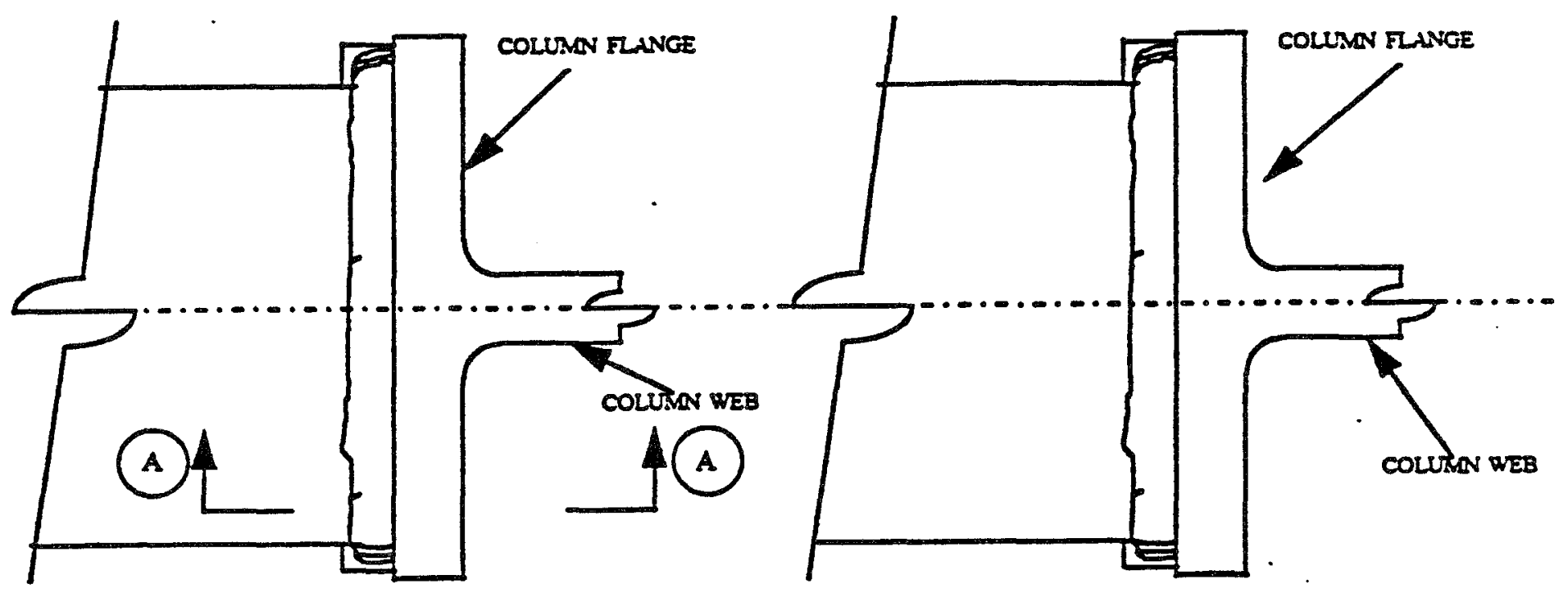

LOWER FLANGE

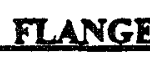

TIPER IIANGE

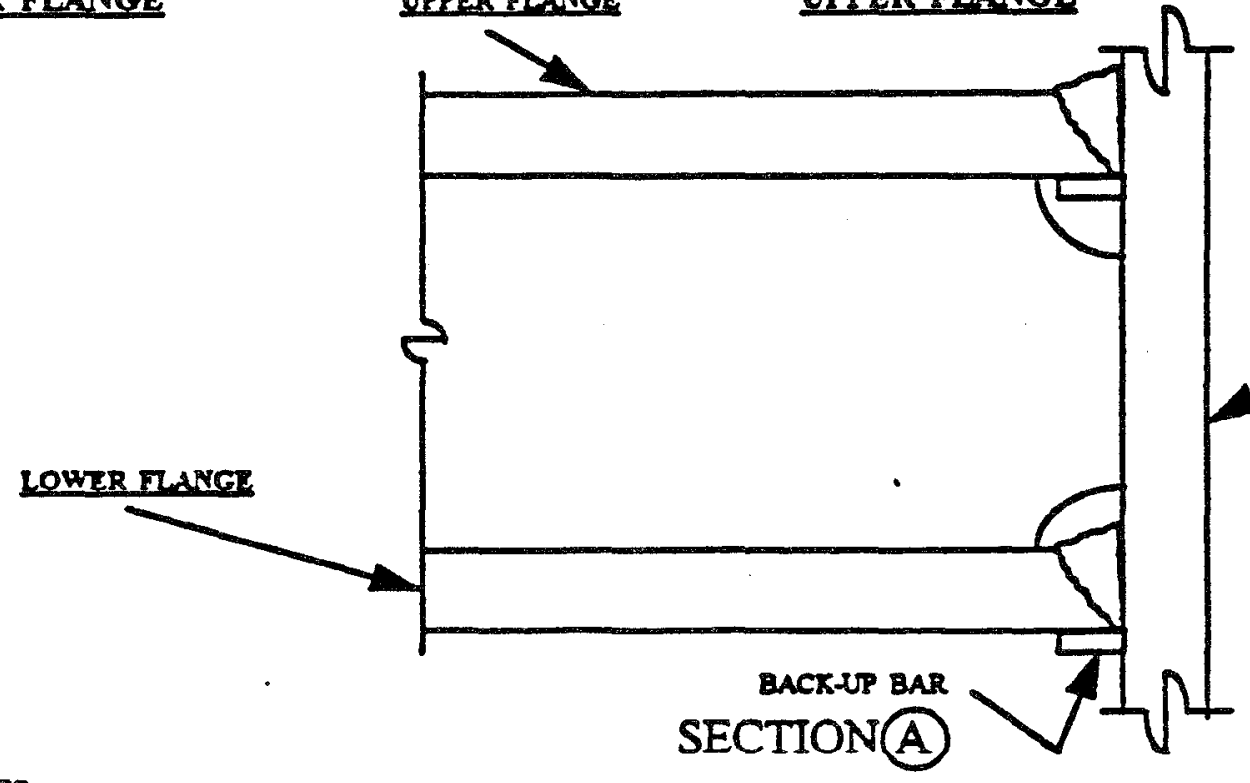

COMMENTS: 


\section{EXTIBIT 4}
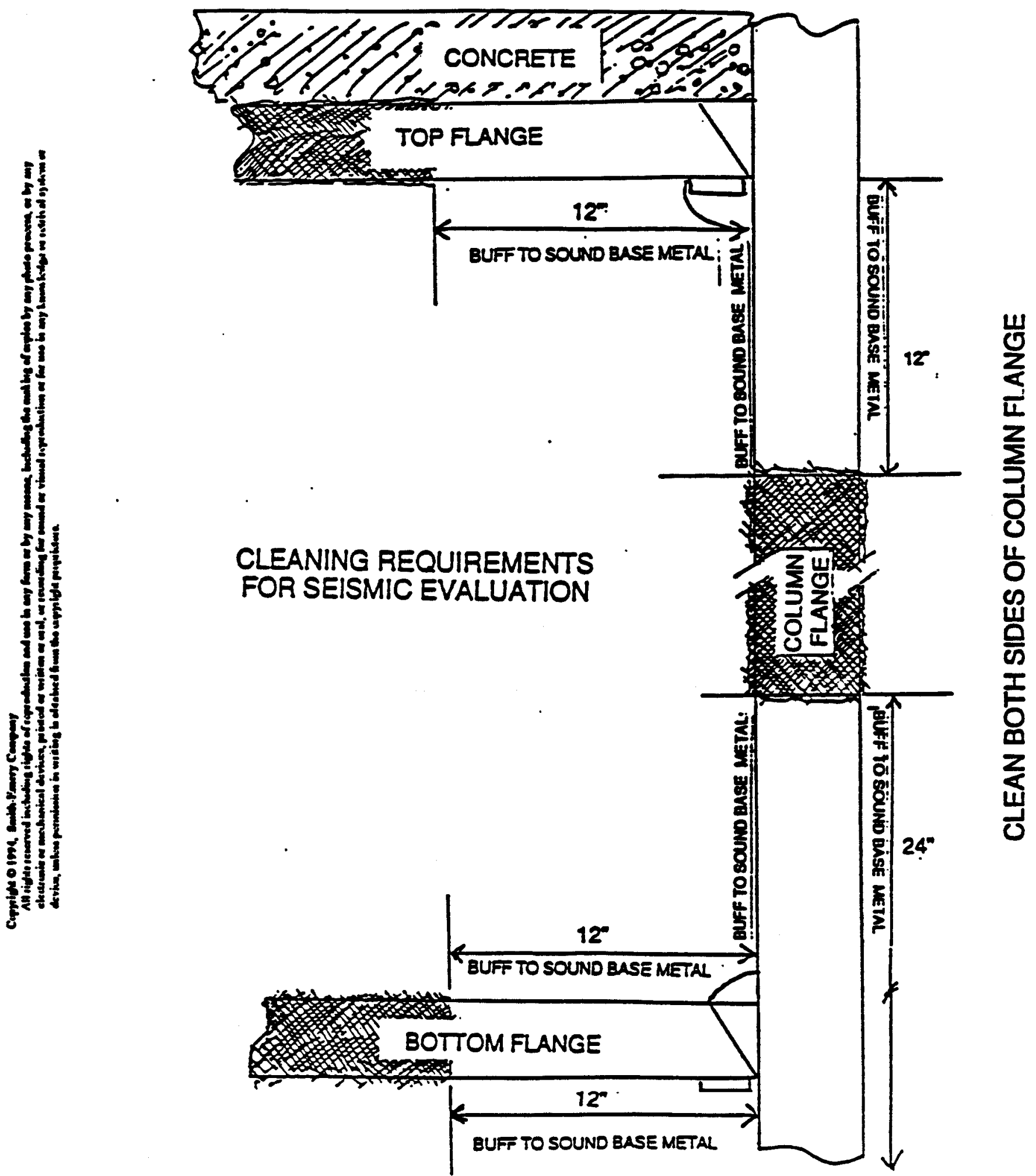


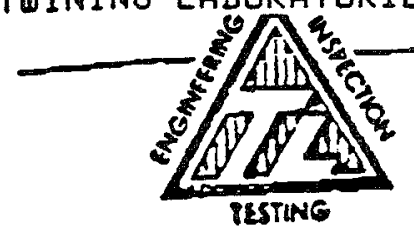

\section{NoTES:}

F\& FuLL LENGES NCinot CLEAN NA. NOACCESS NM: Res Macent
3910 Aiport Wry

Long Beseh. Ca 90806

Mut: P.O. Box 47. 00801
(Bio) 226-3255

(714) $825-6192$

FAX (310) $486-6124$

\section{POST-EARTMQUAKE INSPECTION REPORT STEE FRANE MOMENT CONNECTIONS}

PROEECT ADORESS:

MSPECTION OATE.

MISPECTOR.

FOOR FRAMNA LIVE: GRIO LCCATION:

prover vous wegcion of $\mathrm{AL}$

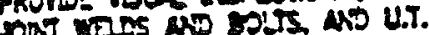
Nractor of NI CS. vinos

creax mi eusstincinon

O - NO DANATE FOUND

1 - WITHW VED MTERL

2 - LONG HEAT AFTECTED ZONE

3 - ETENOS MTO COLUMN

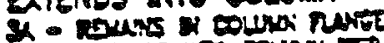
3. - expos no couvi ias

4 - OMret

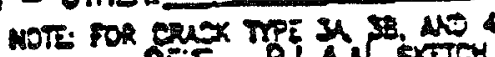
SEE TPLAN SETCN
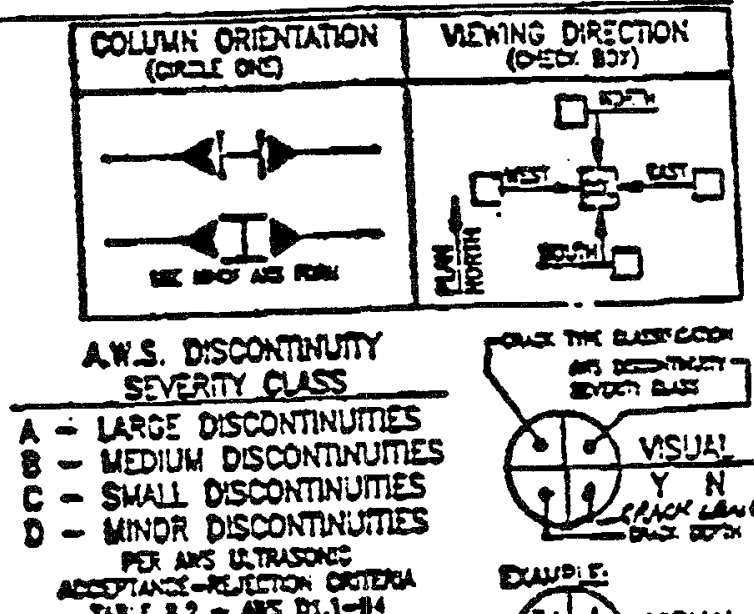

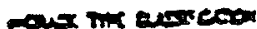
$\rightarrow$

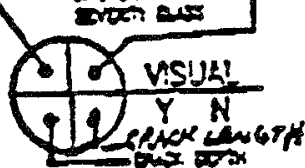

Despeis.

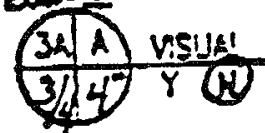

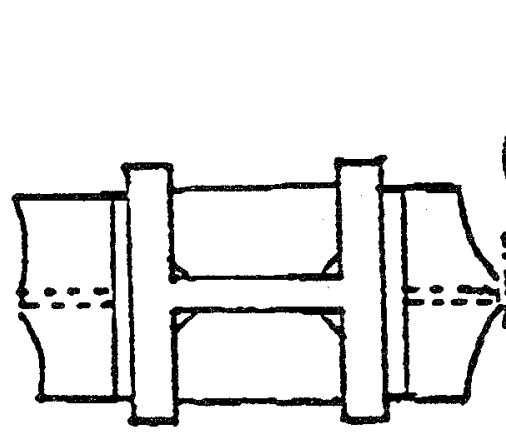

TOF FLANGE (PLAN)

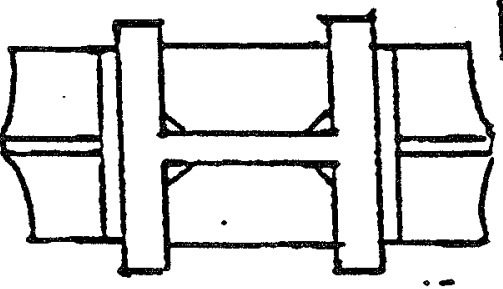

BOTOY FLANGE (PLAN)

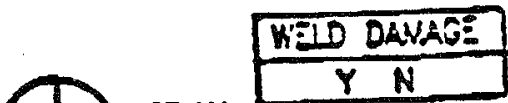
SHEAR $Y$ PLATE N WELEOE \begin{tabular}{|c|c|}
\hline$Y$ N \\
\hline
\end{tabular} . GIRD?

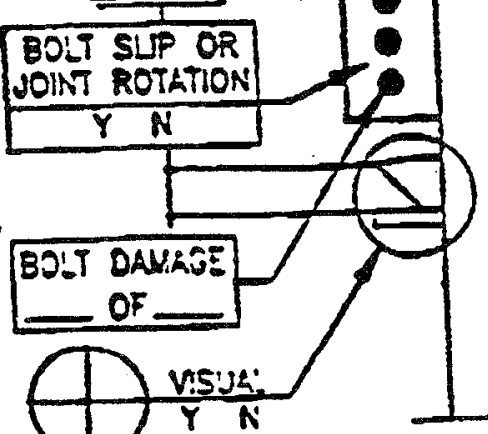

Co:us: $\frac{Y}{N}$ STIF. PLATES

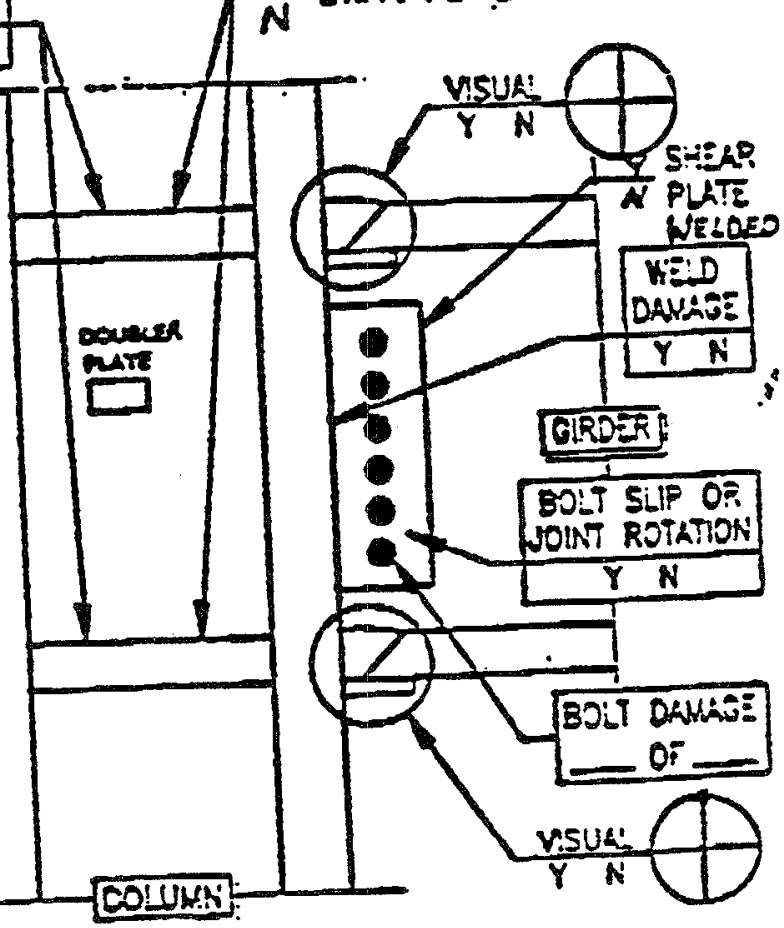

Comments: 
POST-EARTHQUAKE WSPECTION REPORT STEET FRAKE MOMENT CONHECTIONS

\section{NOTES:}

E:EuLLLENGTH NC:NoT CLEAN NA. NOACEESS NM: Nex-Mamest

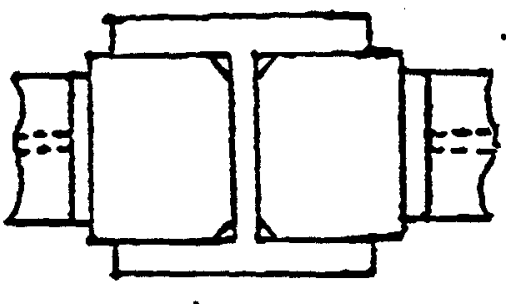

TOF FLANGE (PLAN)

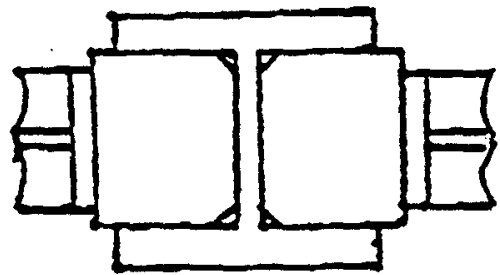

BCTTON FLANGE (PLAN)
PROLET ADDRESS:

WSPECTON DUTE:

WSPECTOR:

nOOR FRUANE LVII: GRID LOCAJON:

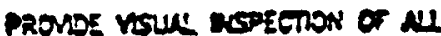

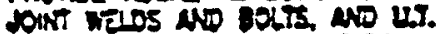
RLSPiction of AU C. WhOS

CeAC MPE GLSSITCLNON

o - No Davase founto

1 - MTHIN WEID MIENWL

2 - $L O N G$ HEAI AFECTED ZONE

3 - DTENDS NTO COLUMN in - buns neolan fux D - Enves stro callar tro

4 - OTMER.

not: Fon cuex MPg $u$ mo 4 SEE PLAN STEA

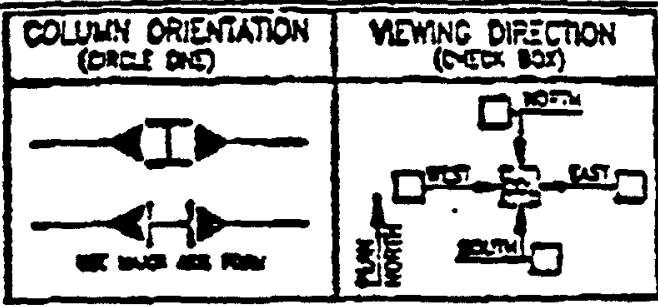
SYVERT CUSS

A - UREE DLSCONTnUmes

8 - MEDIUM DISCONTNUIIES

c - sukl DLscontunumes

D - yinOR Discontavines ax as unusond

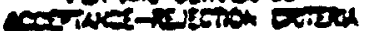

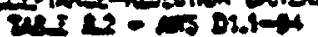

Aits Dosconturim

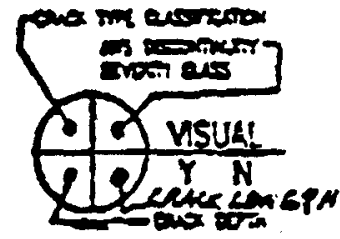

saven.

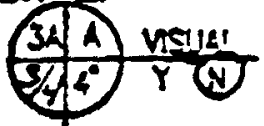

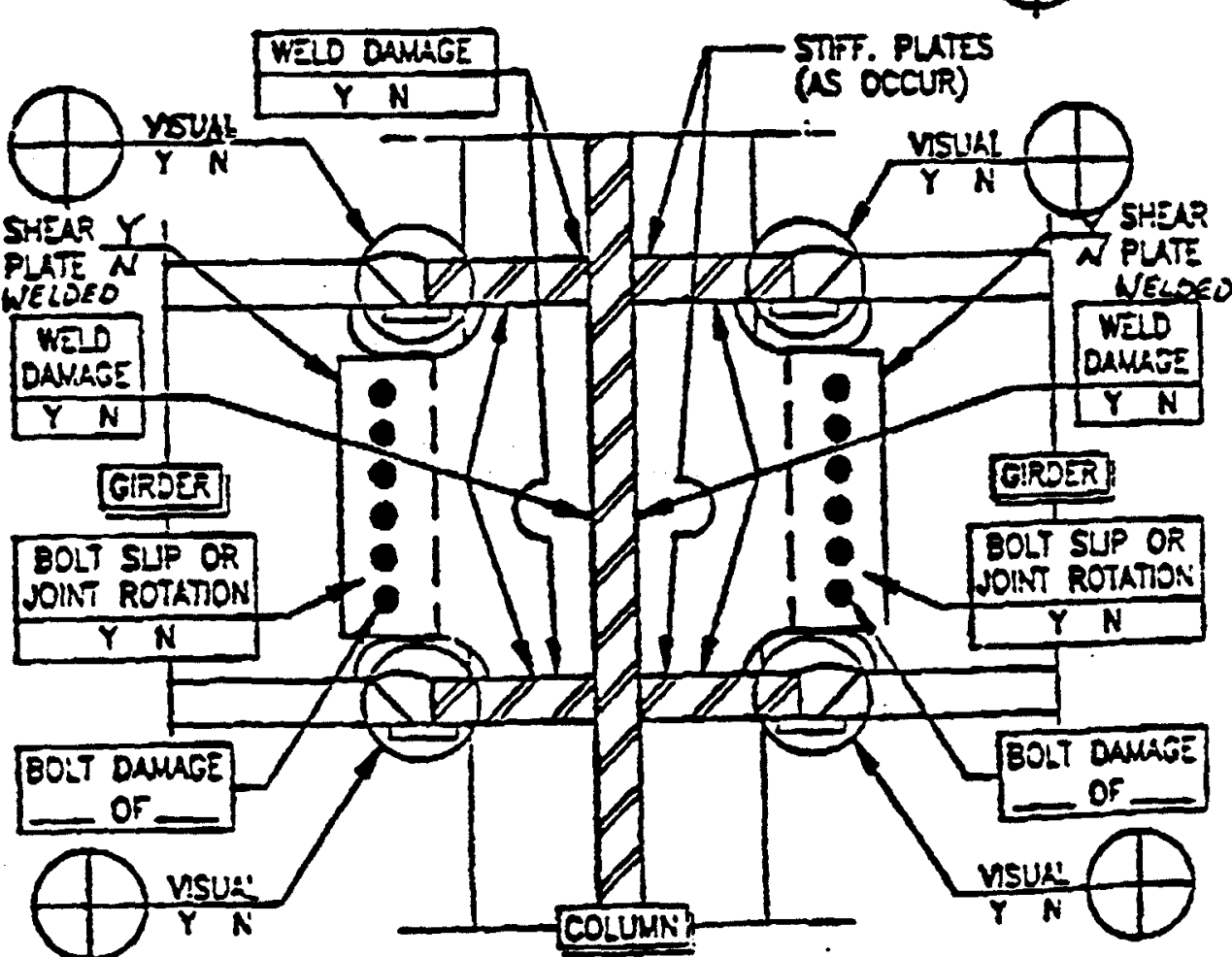

conarirs: 